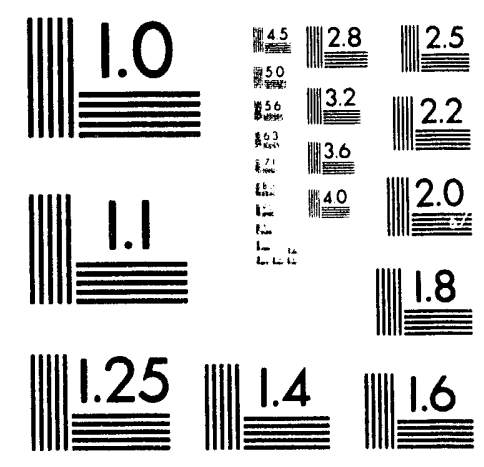



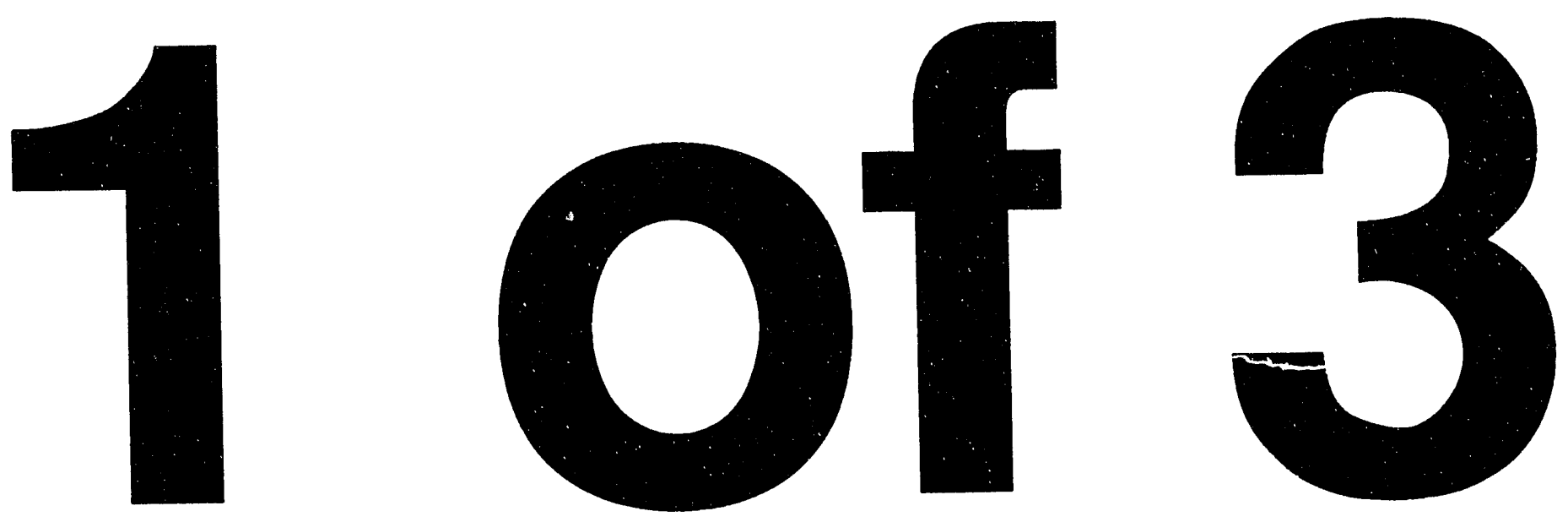
SAND92-2863

Distribution

Unlimited Release

Category UC-G10

Printed June 1993

\title{
MELCOR 1.8.1 Calculations of ISP31: The CORA-13 Experiment
}

\author{
Robert J. Gross, Samuel L. Thompson, and Gale M. Martinez \\ Thermal/Hydraulic Analysis Department \\ Sandia National Laboratories \\ Albuquerque, New Mexico 87185
}

\begin{abstract}
The MELCOR code was used to simulate one of GRS's (a reactor research group in Germany) core degradation experiments conducted in the CORA out-of-pile test facility. This test, designated CORA-13, was selected as one of the International Standard Problems, Number ISP31, by the Organization for Economic Cooperation and Development. In this blind calculation, only initial and boundary conditions were provided. The experiment consisted of a small core bundle of twenty-five PWR fuel elements that was electrically heated to temperatures greater than $2800 \mathrm{~K}$. The experiment comprised three phases: a 3000 second gas preheat phase, an 1870 second transient phase, and a 180 second water quench phase. MELCOR predictions are compared both to the experimental data and to eight other ISP31 submittals. Temperatures of various components, energy balance, zircaloy oxidation, and core blockage are examined. Up to the point where oxidation was significant, MELCOR temperatures agreed very well with the experiment -- usually to within $50 \mathrm{~K}$. MELCOR predicted oxidation to occur about 100 seconds earlier and at a faster rate than experimental data. The large oxidation spike that occurred during quench was not predicted. However, the experiment produced 210 grams of hydrogen, while MELCOR predicted 184 grams, which was one of the closest integral predictions of the nine submittals. Core blockage was of the right magnitude; however, material collected on the lower grid spacer in the experiment at an axial location of $450 \mathrm{~mm}$, while in MELCOR the material collected at the 50 to $150 \mathrm{~mm}$ location. In general, compared to the other submittals, the MELCOR calculation was superior.
\end{abstract}

\section{MASTER}




\section{Table of Contents}

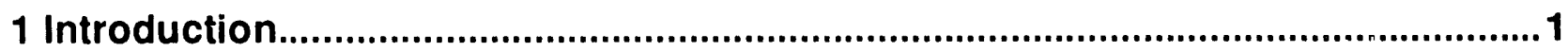

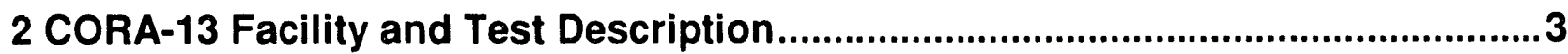

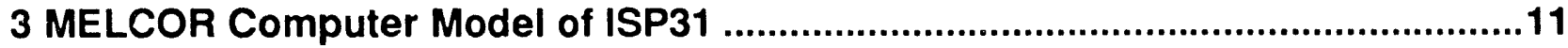

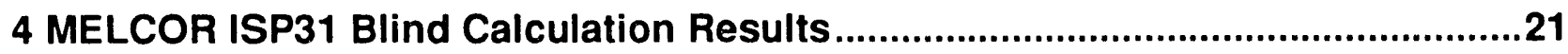

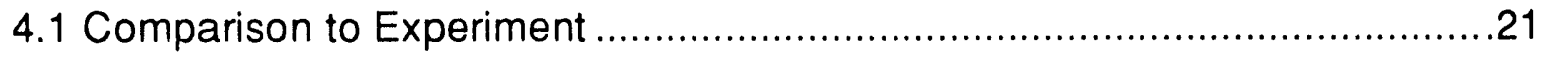

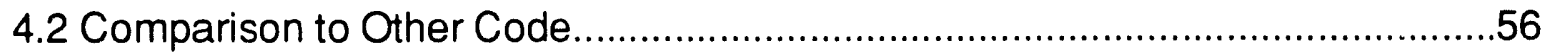

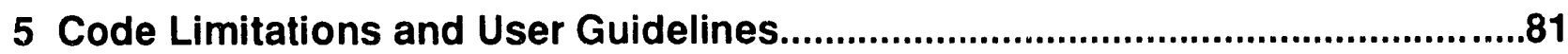

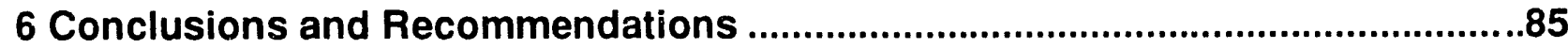

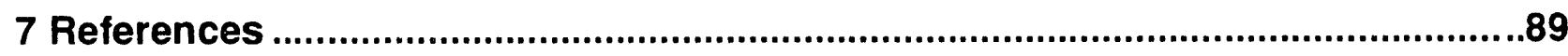

Appendix A:Blind Calculation MELCOR Input Deck.....................................................91

Appendix B: Auxiliary Routines for Electrical Input to Rods........................................203 


\section{List of Figures}

Figure

Page

2.1 Schematic of the CORA Test Facility

2.2 Schematic of the CORA-13 Bundle Arrangement showing the Location of the

Test Bundle, Spacers, Shroud, and Insulation. .5

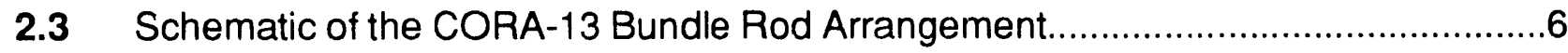

3.1 MELCOR Hydrodynamic Nodalization of the CORA-13 Experiment......................13

3.2 MELCOR Heat Structures used for Simulation of the CORA-13 Experiment......16

3.3 MELCOR Nodalization of the CORA-13 Core. .18

4.1.1 MELCOR Rod Resistance Rescale Factor for Both Rings................................22

4.1.2 MELCOR Calculated Power to the Core

4.1.3 MELCOR and Experimental Hydrogen Generation Rate................................25

4.1.4 Electrical and Oxidation Energy Produced in the MELCOR Calculation of ISP31..... 26

4.1.5 MELCOR Prediction of Energy Stored in the Core and Energy Leaving the System Radially Through the Shroud.

4.1.6 MELCOR Prediction of Energy Stored in the Working Fluid, and Energy Lost Through the Core Top and Bottom.

4.1.7 MELCOR Prediction of Energy Sources and Sinks for the CORA-13

Experiment.

4.1.8 Experimental Temperature of the Second Ring (First Heated Ring) at $+50 \mathrm{~mm}$ Compared to the Blind MELCOR Fuel and Cladding Temperatures of the Second and Fourth Rings

4.1.9 Experimental Temperature of the Second Ring (First Heated Ring) at $+350 \mathrm{~mm}$ Compared to the Blind MELCOR Fuel and Cladding Temperatures of the Second and Fourth Rings 


\section{List of Figures (continued)}

Figure

Page

4.1.10 Experimental Temperature of the Second Ring (First Heated Ring) at $+550 \mathrm{~mm}$ Compared to the Blind MELCOR Fuel and Cladding Temperatures of the Second and Fourth Rings

4.1.11 Experimental Temperature of the Second Ring (First Heated Ring) at $+750 \mathrm{~mm}$ Compared to the Blind MELCOR Fuel and Cladding Temperatures of the Secon $d$ and Fourth Rings

4.1.12 Experimental Temperature of the Second Ring (First Heated Ring) at $+950 \mathrm{~mm}$ Compared to the Blind MELCOR Fuel and Cladding Temperatures of the Second and Fourth Rings 35

4.1.13 Experimental Temperature of the Second Ring (First Heated Ring) at $+1150 \mathrm{~mm}$ Compared to the Blind MELCOR Fuel and Cladding Temperatures of the Second and Fourth Rings 36

4.1.14 Experimental Temperature of the Second Ring (First Heated Ring) at $+1350 \mathrm{~mm}$ Compared to the Blind MELCOR Fuel and Cladding Temperatures of the Second and Fourth Rings 37

4.1.15 Experimental Temperature of the Third Ring at $+150 \mathrm{~mm}$ Compared to the Blind MELCOR Fuel and Cladding Temperatures of the Third Ring

4.1.16 Experimental Temperature of the Third Ring at $+350 \mathrm{~mm}$ Compared to the Blind MELCOR Fuel and Cladding Temperatures of the Third Ring

4.1.17 Experimental Temperature of the Third Ring at $+750 \mathrm{~mm}$ Compared to the Blind MELCOR Fuel and Cladding Temperatures of the Third Ring

4.1.18 Experimental Temperature of the Third Ring at $+1050 \mathrm{~mm}$ Compared to the Blind MELCOR Fuel and Cladding Temperatures of the Third Ring

4.1.19 Experimental Temperature of the Third Ring at $+1350 \mathrm{~mm}$ Compared to the Blind MELCOR Fuel and Cladding Temperatures of the Third Ring. .43

4.1.20 Experimental Temperature of the Shroud Compared to the Blind MELCOR Temperature of the Shroud at $+50 \mathrm{~mm}$. 


\section{List of Figures (continued)}

Fiqure

Page

4.1.21 Experimental Temperature of the Shroud Compared to the Blind MELCOR Temperature of the Shroud at $+350 \mathrm{~mm}$.

4.1.22 Experimental Temperature of the Shroud Compared to the Blind MELCOR Temperature of the Shroud at $+550 \mathrm{~mm}$ 46

4.1.23 Experimental Temperature of the Shroud Compared to the Blind MELCOR Temperature of the Shroud at $+750 \mathrm{~mm}$

4.1.24 Experimental Temperature of the Shroud Insulation at its Outer Diameter Compared to the Blind MELCOR Temperature at $+50 \mathrm{~mm}$

4.1.25 Experimental Temperature of the Shroud Insulation at its Outer Diameter Compared to the Blind MELCOR Temperature at $+350 \mathrm{~mm}$

4.1.26 Experimental Temperature of the Shroud Insulation at its Outer Diameter Compared to the Blind MELCOR Temperature at $+550 \mathrm{~mm}$

4.1.27 Experimental Temperature of the Shroud Insulation at its Outer Diameter Compared to the Blind MELCOR Temperature at $+750 \mathrm{~mm}$ 51

4.1.28 Experimental Temperatures of the Inner Surface of the High Temperature Insulation at Various Axial Locations at a Circumference of $345^{\circ}$ .54

4.1.29 MELCOR Single Curve Prediction of the Temperature of the High Temperature Insulation (Labeled HiTemp In -200 to $1000 \mathrm{~mm}$ ) .55

4.2.1 Experimental Bundle Power Compared to the Results of the Nine Submittals.....57

4.2.2 Experimental Steam Inlet Flow Compared to the Results of the Nine Submittals.

4.2.3 Experimental Fuel Temperature of Inner Heated Rod at $+750 \mathrm{~mm}$ Compared to the Results of the Nine Submitted. .60

4.2.4 Experimental Fuel Temperature of Inner Heated Rod at $+50 \mathrm{~mm}$ Compared to the Results of the Nine Submittals. .61 


\section{List of Figures (continued)}

Figure

Page

4.2.5 Experimental Fuel Temperature of Inner Heated Rod at $+350 \mathrm{~mm}$ Compared to the Results of the Nine Submittals.

4.2.6 Experimental Fuel Temperature of Inner Heated Rod at $+550 \mathrm{~mm}$ Compared to the Results of the Nine Submittals.

4.2.7 Experimental Fuel Temperature of an Unheated Rod (MELCOR Ring 3) at $+750 \mathrm{~mm}$ Compared to the Results of the Nine Submittals

4.2.8 Experimental Temperature of the Cladding from the Inner Heated Ring at $+750 \mathrm{~mm}$ Compared to the Results of the Nine Submittals.

4.2.9 Experimental Temperature of the Cladding from the Inner Heated Ring at $+50 \mathrm{~mm}$ Compared to the Results of the Nine Submitta.

4.2.10 Experimental Temperature of the Cladding from the Inner Heated Ring at $+350 \mathrm{~mm}$ Compared to the Results of the Nine Submittals

4.2.11 Experimental Temperature of the Cladding from the Inner Heated Ring at $+550 \mathrm{~mm}$ Compared to the Results of the Nine Submittals.

4.2.12 Experimental Temperature of the Cladding from the Third MELCOR Ring at $+750 \mathrm{~mm}$ Compared to the Results of Eight Submittals.

4.2.13 Experimental Temperature of the High Temperature Insulation at $+550 \mathrm{~mm}$ Compared to the Results of the Six Submittals. 71

4.2.14 Fluid Temperature of the Nine Submittals at $+750 \mathrm{~mm}$ .72

4.2.15 Zircaloy Oxidized in the Inner Heated Ring at 4250 Seconds. Results of the Nine Submittals.

4.2.16 Zircaloy Oxidized in the Inner Heated Ring at 4750 Seconds. Results of the Nine Submittals. .74

4.2.17 Molten Zircaloy in the Inner Heated Ring at 4750 Seconds. Results of the Six Submittals. 


\section{List of Figures (continued)}

Fiqure

Page

4.2.18 Total $\mathrm{UO}_{2}$ Mass at 4750 Seconds. Results of Seven Submittals.....................76

4.2.19 Zircaloy Total Mass at 4750 Seconds. Results of Seven Submittals.................77

4.2.20 $\mathrm{ZrO}_{2}$ Total Mass at 4750 Seconds. Results of Seven Submittals...................78

4.2.21 Accumulated Hydrogen Generation in Both the Bundle and Shroud.

Results of Eight Submittals and the Experiment...........................................79 


\section{List of Tables}

Table

Page

2.1 Design Characteristics of CORA-13 Test Bundle.............................................

3.1 Time Dependent Sources for the CORA-13 Experiment used by MELCOR $\ldots . . .14$

4.1.1 Experimental and MELCOR Calculated Core Blockage .................................52

4.2.1 Organizations and Computer Codes Used for ISP31 .....................................59 


\section{Acknowledgments}

First, we would like to thank the NRC/RES/Accident Evaulation Branch for funding and supporting this effort. We would also like to thank several individuals who contributed to this work. Randy Summers modified the COR Package to accommodate an additional core material and and also accept energy input from separate electrical heater routines. Randy Cole diagnosed early problems caused by debris falling into the quench control volume, splashing water into upper regions of the core, and causing the problem to become very stiff in a numerical sense. This difficulty was readily corrected. Ed Boucheron and Fred Davis conducted the final, formal review of this document 


\section{Introduction}

MELCOR [1] is a fully-integrated, engineering-level computer code being developed at Sandia National Laboratories for the US Nuclear Regulatory Commission (USNRC). The term "fully-integrated" refers to the high level of uniformity and integration of the database that ties the various packages together, as well as the input and output structure. The term "engineering level" means that MELCOR was designed to model the progression of severe accidents in light water reactor nuclear power plants, but its flexibility allows it to be used in a wide range of physical problems, as evinced in this report. The entire spectrum of severe accident phenomena -- reactor coolant systems; containment thermal and hydraulic response; core heatup, degradation and relocation; and fission product release and transport -- is treated in MELCOR for several types of nuclear reactors. MELCOR has been successfully applied in severe accident analyses [2, 3].

As part of an ongoing quality and technical assessment program, MELCOR is being used in the International Standard Problem (ISP) Program. The ISP Program is structured such that the analyses are conducted in a blind or semi-blind manner, i.e. most or all of the experimental results were not released until after all calculational results are submitted to the governing agency. MELCOR has previously been used to simulate ISP28 [4], which consisted of the SFD Phebus B9+ Experiment. This was a semi-blind problem in that some internal temperature data was made available. Application of MELCOR to ISP31 represents the second endeavor in this area. ISP31 was a totally blind calculation -- only initial and boundary conditions were made available to the analysts.

ISP31 consisted of the CORA-13 experiment, which was conducted in Germany on November 15, 1990 [5]. The core assembly was electrically heated. Its purpose was to examine core meltdown behavior such as might occur during an unmitigated severe LWR accident. Beside thermal data, there was also interest in such phenomena as chemical interactions of the different rod materials, melting, material relocations, blockage formation, and hydrogen generation. This application of MELCOR to one of the many CORA experiments performed was the first such effort, and as such, required the creation of an input deck for MELCOR from scratch. This was in direct contrast to some of the other submittal to ISP31. Input decks geared towards CORA experiments for codes such as SCDAP/RELAP, for instance, had the advantage of years of effort and refinement.

At the time of this computational effort, MELCOR lacked the capability to include electrically heated rods in its core software. As part of this effort, a special MELCOR COR Package was created. Beside the special COR Package, further coding was necessary to properly enter the CORA-13 electrical energy in both a temporal and spatial sense. The special COR Package and additional heater routines were compiled with the remaining mainstream MELCOR software to create a special version of MELCOR. This special MELCOR version was applied to the ISP31 Problem. After the completion of the ISP31 MELCOR calculations, the COR Package capability to model electrically heated rods has become part of mainstream MELCOR. MELCOR version 1.8LF should be 
considered the earliest version in which to perform calculations which incorporate electrically heated cores.

Reported are the comparison of the blind MELCOR results to the experimental data and to eight other submittals to ISP31. MELCOR code limitations discovered in the course of completing this project are discussed, as well as providing user guidelines for MELCOR calculations for this type of problem. Finally, conclusions are discussed and recommendations for further work in this area are made. 


\section{Facility and Test Description}

The experimental geometry of the ISP31 (CORA-13) test, excerpted with permission from [5], is shown in Figures 2.1 and 2.2. Water was injected into a steam generator/superheater and mixed with argon to serve as the coolant gas. This gas mixture then entered the test bundle via the steam distribution tube near the bottom of the bundle. The gas then flowed upward through the twenty-five rod bundle test section to the top bundle flange, and from thence to the condenser.

The test bundle itself consisted of twenty-five PWR rods, shown in Figure 2.3. Sixteen of the rods had fuel pellets in the middle annular region replaced with a tungsten heater rod and were termed heat $j \mathrm{~J}$ rods. Seven of the rods were typical fuel elements common to PWR's and were unheated rods. Two of the rods were absorber $(\mathrm{Ag} 80 \%, \ln 15 \%$, Cd $5 \%)$ rods which had stainless steel cladding and were contained in zircaloy guide tubes. The rod arrangement was organized in four "rings" (See Figure 2.3). The first ring was the center unheated rod. The second ring consisted of four heated rods. The third ring contained six unheated rods plus the two absorber rods. The fourth ring comprised of twelve heated rods. The bundle was enclosed in a zircaloy shroud backed by $\mathrm{ZrO}_{2}$ fiber insulation. After the insulation there was an annular space followed by a high temperature radiation shield (See Figure 2.2). Below the bundle was a quench unit composed of a water-filled quench cylinder, which was raised around the bundle to terminate the experiment.

The $1000 \mathrm{~mm}$ tall tungsten part of the heated rods was screwed into molybdenum electrodes at both the top and bottom. The molybdenum electrodes were in turn connected to copper electrodes to give a total heated rod length of $1960 \mathrm{~mm}$. The design characteristics of the CORA-13 test bundle are given in Table 2.1 [5].

The reference "zero" height was the location of the steam inlet pipe (See Figure 2.2). Important dimensions were the location of the upper bundle flange at $+1471 \mathrm{~mm}$, the bottom of the water level at $-220 \mathrm{~mm}$, the cottom of an unheated rod at $-200 \mathrm{~mm}$, and the bottom of a heated rod at $-489 \mathrm{~mm}$. The rods were held in place by three grid spacers located at $-5 \mathrm{~mm},+4: 96 \mathrm{~mm}$, and $+880 \mathrm{~mm}$. The top and bottom spacers were composed of zircaloy, while the middle spacer was made of Inconel.

The high temperature radiation shield consisted of an inner layer of plates made of $2 \mathrm{r} \mathrm{rO}_{2}$ and an outer layer of $\mathrm{Al}_{2} \mathrm{O}_{3}$. The shield itself was pierced by three $30 \mathrm{~mm}$ high by $40 \mathrm{~mm}$ wide viewing holes, or windows, for observation purposes. These holes were not physically obstructed (with glass, for instance) so that there was flow leakage from the test bundle to the annular space between the bundle and high temperature shield and energy leakage from the test bundle to the environment. The radiation heat loss also caused local refreezing of melt that contributed to additional core blockage, and altered the experimental results more than was desirable. Thus, these openings were a source of major perturbations in an otherwise well-designed experiment. 


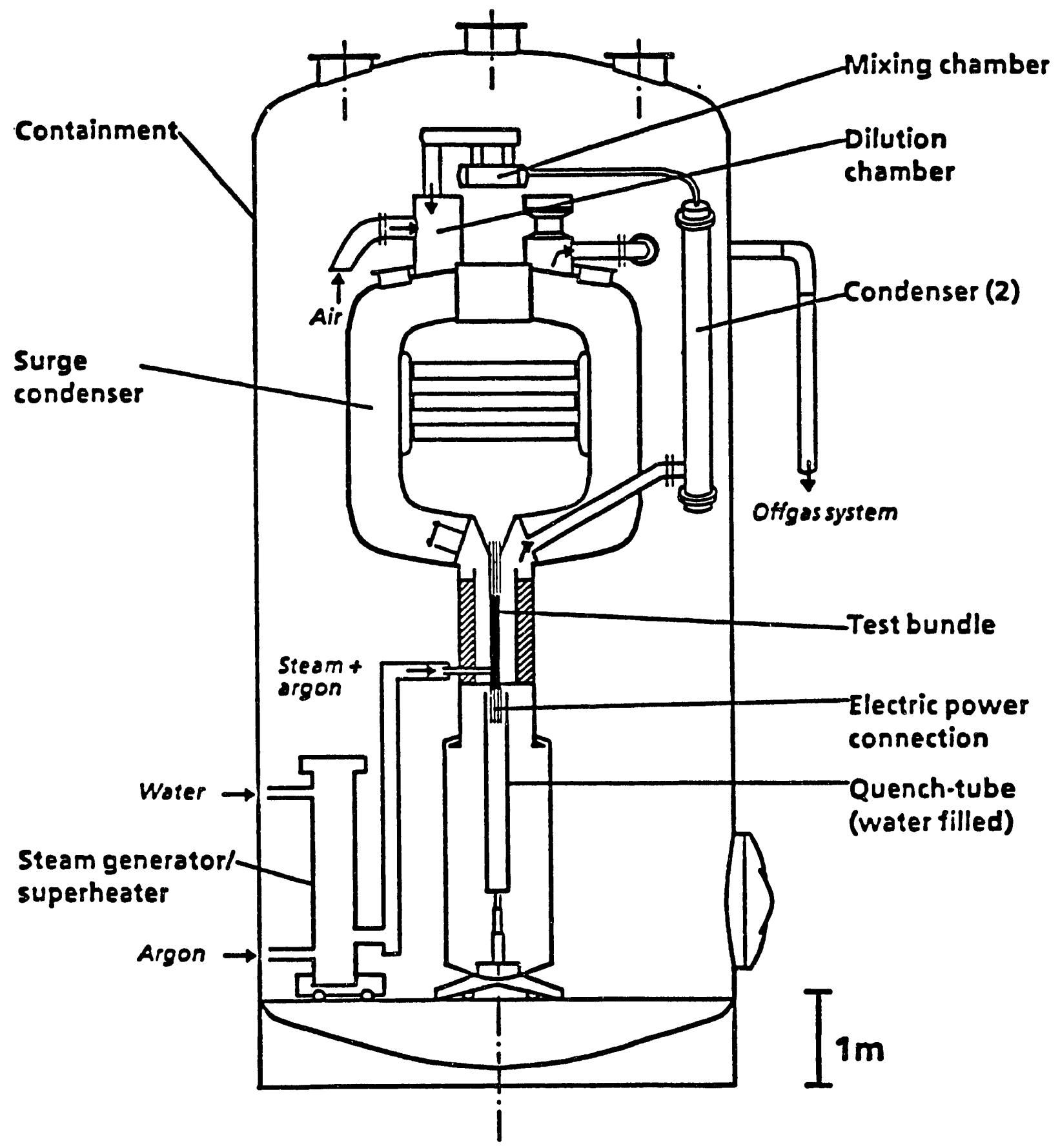

Figure 2.1 Schematic of the CORA Test Facility 


\section{CORA Bundle Arrangement}

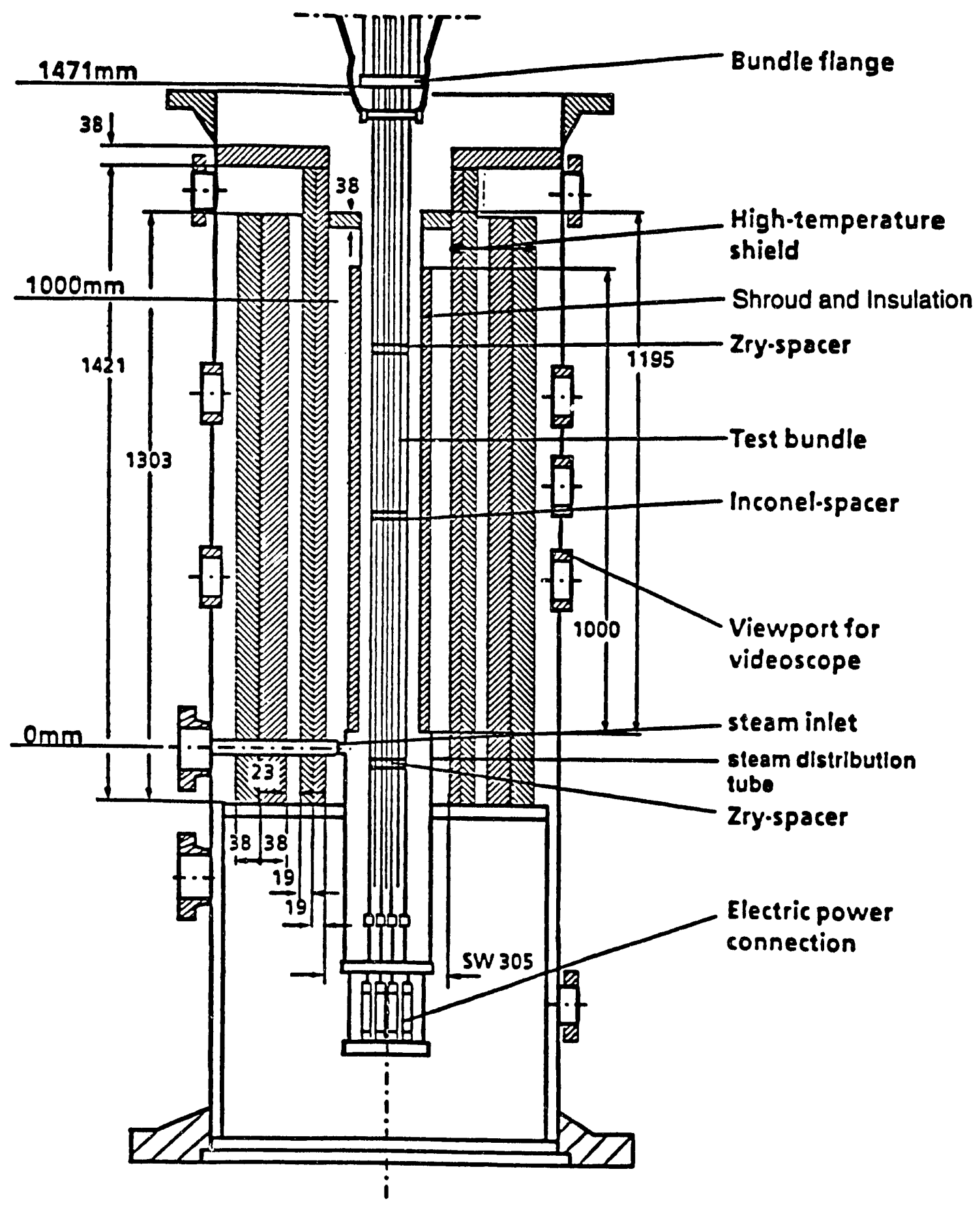

Figure 2.2 Schematic of the CORA-13 Bundle Arrangement showing the Location of the Test Bundle, Spacers, Shroud, and Insulation. 

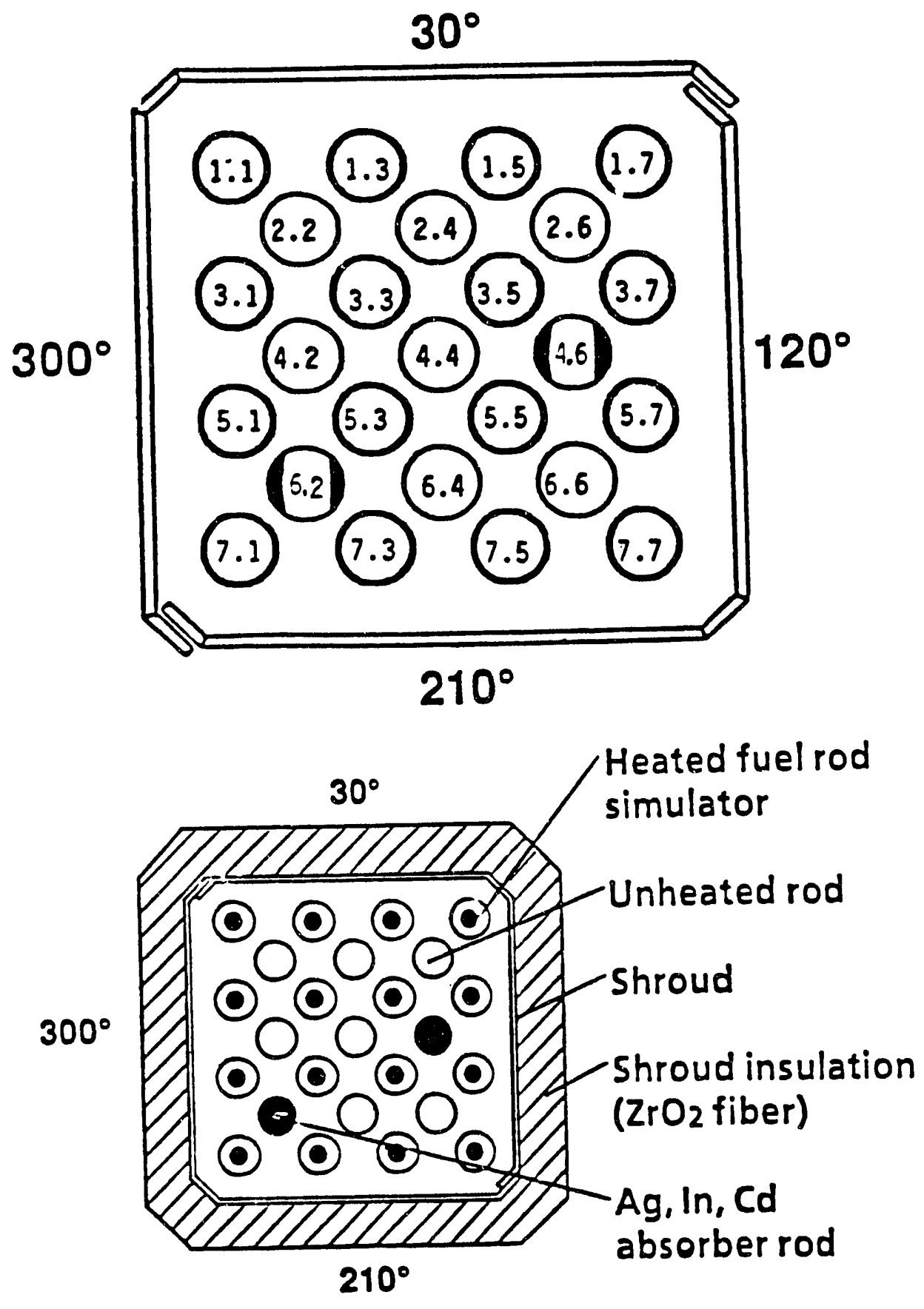

Figure 2.3 Schematic of the CORA-13 Bundle Rod Arrangement 
Table 2.1 Design Characteristics of CORA-13 Test Bundle

Bundle Type:

PWR

Bundle Size:

25 Rods

Number of Heated Rods:

16

Number of Unheated Rods:

7

Pitch:

$14.3 \mathrm{~mm}$

Rod Outside Diameter:

$10.75 \mathrm{~mm}$

Cladding Material:

Zircaloy-4

Cladding Thickness:

$0.725 \mathrm{~mm}$

\begin{tabular}{llr}
\hline Rod Length & Heated Rods: & $1960 \mathrm{~mm}$ \\
& Elevation: & -489 to +1 \\
& Unheated Rods: & $1672 \mathrm{~mm}$ \\
& Elevation: & -201 to +147 \\
& & \\
\hline Heater & Material: & Tungsten \\
& Length: & $1024 \mathrm{~mm}$ \\
& Diameter: & $6 \mathrm{~mm}$
\end{tabular}

Fuel Pellets

Pellet Stack

U-235 Enrichment:

Pellet Outer Diameter:
Heated Rods:

Unheated Rods:

Heated Rods:

Unheated Rods:
$\mathrm{UO}_{2}$ annular pellets

$\mathrm{UO}_{2}$ full pellets

0 to $1000 \mathrm{~mm}$

-199 to $+1295 \mathrm{~mm}$

$0.2 \%$

$9.1 \mathrm{~mm}$

Zircaloy-4, Inconel 718

$\mathrm{Zr} 42 \mathrm{~mm}$

In $38 \mathrm{~mm}$

Locations:

Center (In) +496 mm

Upper $(\mathrm{Zr})+880 \mathrm{~mm}$

Shroud

Material:

Wall Thickness:

Outside Dimensions:

Elevation:
Zircaloy-4

$1.2 \mathrm{~mm}$

$89.4 \times 90.4 \mathrm{~mm}$

+36 to $+1231 \mathrm{~mm}$ 
Table 2.1 (con't)

\begin{tabular}{|c|c|c|c|}
\hline Shroud Insulation & \multicolumn{2}{|c|}{$\begin{array}{l}\text { Material: } \\
\text { Thickness: } \\
\text { Elevation: }\end{array}$} & $\begin{array}{l}\mathrm{ZrO}_{2} \text { Fiber } \\
19 \mathrm{~mm} \\
+36 \text { to }+1036 \mathrm{~mm}\end{array}$ \\
\hline Electrodes & \multicolumn{2}{|c|}{$\begin{array}{l}\text { Material: } \\
\text { Length: } \\
\text { Diameter: } \\
\text { Material: } \\
\text { Length: }\end{array}$} & $\begin{array}{l}\text { Molybdenum } \\
300 \mathrm{~mm} \\
8.6 \mathrm{~mm} \\
\text { Copper } \\
189 \text { (Lower), } 669 \text { (Upper) }\end{array}$ \\
\hline mm & \multicolumn{2}{|c|}{ Diameter: } & $8.6 \mathrm{~mm}$ \\
\hline $\begin{array}{l}\text { Absorber Rod } \\
\text { (wt.) }\end{array}$ & $\begin{array}{l}\text { Number } \\
\text { Materia } \\
\text { Claddin } \\
\text { Claddin } \\
\text { Claddin } \\
\text { Length: } \\
\text { Elevatic }\end{array}$ & position: & $\begin{array}{l}2 \\
80 \% \mathrm{Ag}, 15 \% \mathrm{ln}, 5 \% \mathrm{Cd} \\
\text { Stainless Steel } \\
11.2 \mathrm{~mm} \\
10.2 \mathrm{~mm} \\
1660 \mathrm{~mm} \\
-189 \text { to }+1300 \mathrm{~mm}\end{array}$ \\
\hline Absorber Rod Guide & le Tube: & $\begin{array}{l}\text { Material: } \\
\text { Outer Diameter: } \\
\text { Tube Wall Thickness: }\end{array}$ & $\begin{array}{l}\text { Zircaloy-4 } \\
13.8 \mathrm{~mm} \\
0.8 \mathrm{~mm}\end{array}$ \\
\hline Plenum Volume & \multicolumn{2}{|c|}{$\begin{array}{l}\text { Heated Rods: } \\
\text { Unheated Rods: } \\
\text { Absorber Rods: }\end{array}$} & $\begin{array}{l}12.0 \times 10^{-6} \mathrm{~m}^{3} \\
87.0 \times 10^{-6} \mathrm{~m}^{3} \\
71.0 \times 10^{-6} \mathrm{~m}^{3}\end{array}$ \\
\hline
\end{tabular}

The CORA-13 experiment was divided into three phases: (1) a gas preheat phase from 0 to 3000 seconds and a low constant electric power input of $0.65 \mathrm{~kW}$; (2) a transient heatup phase from 3000 to 4870 seconds in which the electrical power was increased from 6 to $27 \mathrm{~kW}$; and (3) a cooling phase from 4870 to 5050 seconds initiated by the rise of the quench cylinder. For the entire time the argon flowrate was about $8 \mathrm{~g} / \mathrm{s}$. From 3300 to 4900 seconds, steam in addition to the argon was flowed into the bundle at a rate of 6 $\mathrm{g} / \mathrm{s}$. Total power, and the corresponding voltage and current to the heater rods were also provided, as well as the rate of water rise during the quench sequence. 
The experiment was terminated by the quench phase, which operationally involved raising a long tube filled with water (Figure 2.1). During the raising of this tube, the gas inlet pipe was cut. In a desire to prevent cutting of instrumentation as well, all thermocouples for collecting temperature data were introduced at the top of the bundle. Unfortunately, this resulted in a strong chemical attack on the compensation cable located in the upper part of the bundle at the beginning of oxidation. Thus, the data exhibited irregular temperature readings after 4200 seconds, and much of the temperature data after this time must be considered unreliable. This determination was made in [7]. 


\section{MELCOR Computer Model}

Because the CORA-13 experiment was essentially a rod bundle experiment, the most important aspect of the MELCOR model was the input to the MELCOR COR Package. One constraint placed on the COR model was that the delivery of results to Gesellschaft für Anlagen- und Reaktorsicherheit (GRS) in Germany had very exact specifications. One specification was that the temperature of a number of bundle components be specified every $100 \mathrm{~mm}$ from $-50 \mathrm{~mm}$ to at least $1250 \mathrm{~mm}$, using the previously discussed axial "zero" reference location. If these temperatures were to represent the center of a COR node, then the COR model needed nodes at least every $100 \mathrm{~mm}$ between $-100 \mathrm{~mm}$ and $+1300 \mathrm{~mm}$ elevations. A second specification was that the temperatures at each axial location be provided in each of the four "rings" of the bundle. Thus, the ISP specification required a minimum of fifteen axial times four radial, or sixty total, COR Package nodes. (Fewer nodes could have been used if one was willing to take the MELCOR output and interpolate on it.)

In MELCOR, each COR node must be assigned to a Control Volume Hydrodynamics (CVH) Package control volume. It would be possible to create sixty control volumes, one to each COR node, but not very practical. For one thing, the flow network, especially in the radial direction, would be very large. For another, the Courant limit which is constrained by control volume size, would make the timestep so small that the entire ISP31 modeling effort would be constrained by the computer processing time required to run the problem. The modeling philosophy of MELCOR is to use a minimum number of control volumes. The previous section discussed the three windows that allowed flow radially out of the bundle assembly at three different axial locations. Thus, in the core region itself, three axial control volumes were created, each covering the entire radial extent of the bundle. MELCOR, of course, allows multiple flow paths in and out of a control volume, so one control volume could have been placed in the core region instead of the three. However, since the fluid temperature from the CVH Package effected the core temperatures and there was a significant thermal gradient in the axial direction, three control volumes were chosen for additional temperature resolution.

The MELCOR hydrodynamic nodalization is shown in Figure 3.1. There were a total of twelve control volumes. Control Volume 100 provided an input volume for the argon and steam, as did Control Volume 300 for the videoscope cooling source flow for the windows at the pressure tube wall. The three control volumes in the bundle were CV210, CV220, and CV230 which ran from $-200 \mathrm{~mm}$ to $+400 \mathrm{~mm},+400 \mathrm{~mm}$ to $+800 \mathrm{~mm}$, and $+800 \mathrm{~mm}$ to $+1400 \mathrm{~mm}$, respectively. In the experiment, the quench source was a moving tank of water that moved up into the bypass region and completely immersed the bundle, shroud, and part of the bypass region in water. MELCOR does not provide moving control volumes. Rather, the water source was modeled by two quench sources -- one beneath the lowest bundle control volume and one beneath the bypass control volume, CV 310 . 
These quench sources were located in CV110 and CV111 (See Figure 3.1), and introduced water at the proper rate and energy to model the rising water level. The pressure tube was modeled by CV320. Finally, gas from the bundle flowed to the outlet region, CV240, and thence to an artificially large collector, CV250. Flow from the pressure tube was routed to a large environment control volume, CV330. The latter two control volumes were made arbitrarily large to avoid a pressure build-up, which would effect upstream flow conditions.

Control Volume Hydrodynamic $(\mathrm{CVH})$ mass and energy sources were used to simulate the injection of argon and steam into Control Volume 100 and the videoscope cooling source in Control Volume 300. These sources, which were time dependent, are summarized in Table 3.1. The modeling of the quench source differed from the actual physical event in one important point. In the experiment, the rising cylinder of water rose in the bypass region between the outer shroud insulation and the high temperature insulation. In the MELCOR model, water was injected to fill the entire bypass region. The quench flow was adjusted to properly match the rate as in the experiment. As a result, after quench initiation the temperatures in the high temperature insulation, especially on the inner wall, were not representative of those of the experiment. In the experiment, that inner wall was still only exposed to a gaseous mixture, while in MELCOR it was exposed to cold water. Since the quench sequence occurred at the end of the experiment and its major purpose was to examine what the flooding did to the core, we believe this approximation was justified.

The bundle water quench energy was tied to a control function which uses the timedependent temperature of the water in Control Volume 110.

Refer to Appendix A for initial temperatures of control volumes, heat structures and COR nodes.

As can be seen from Figure 3.1, generally, axial flow paths connected each successive control volume in series. For the radial flow paths, FL100 represented the steam inlet pipe and connected the mass sources to the lower bundle control volume. FL221 and FL311 represented the lower window openings from bundle to bypass and bypass to pressure tube, respectively. FL222 and FL312 represented the middle window openings, and FL223 and FL313 represented the upper window openings. In the geometry data given in [5], it was also clear that there were small leaks from the bundle to the bypass region both at the top and bottom of the bundle. These two flow paths were represented by FL231 and FL211, respectively. 


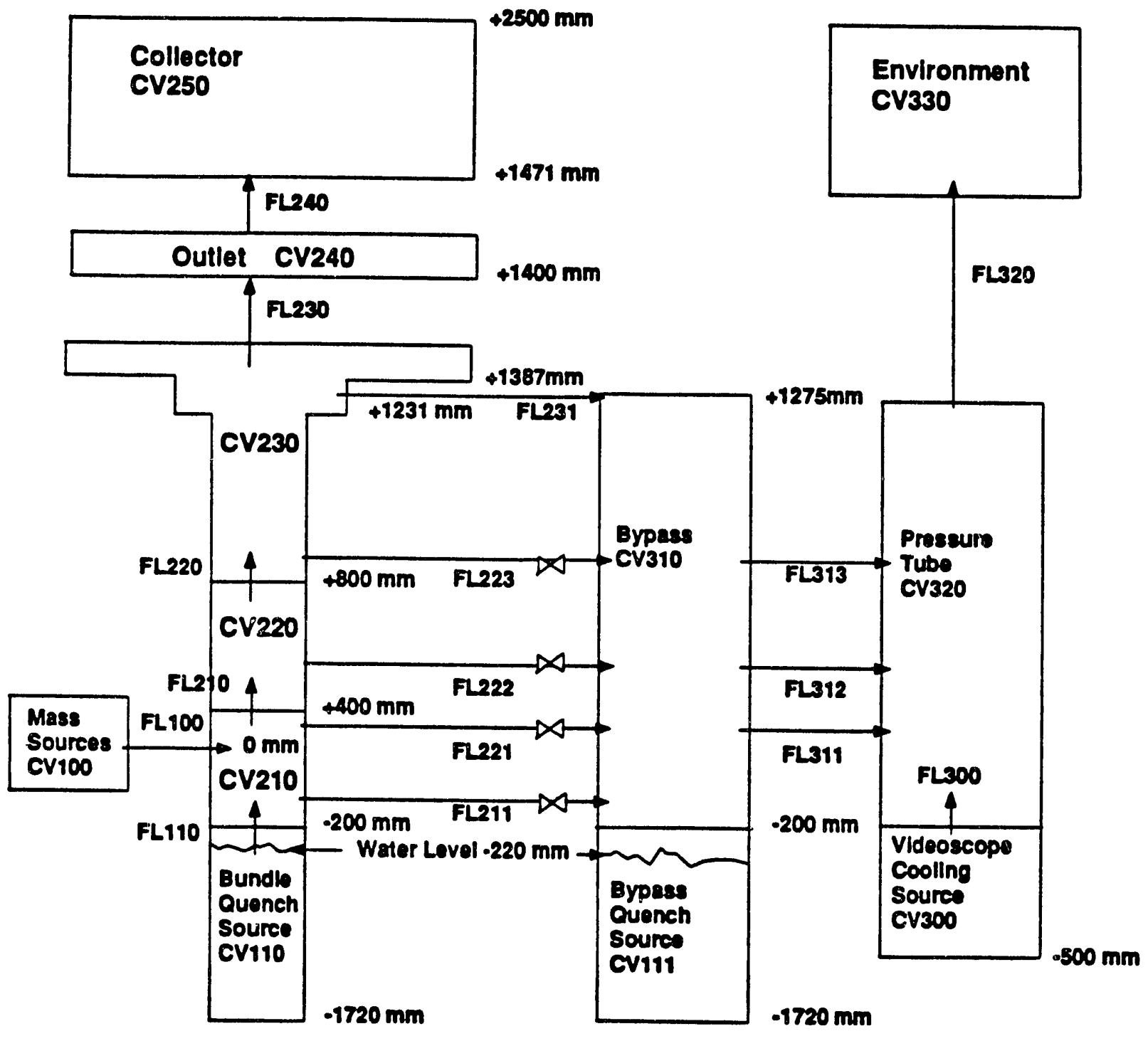

Figure 3.1 MELCOR Hydrodynamic Nodalization of the CORA-13 Experiment 
Table 3.1. Time Dependent Sources for the CORA-13 Experiment used by MELCOR

\begin{tabular}{rl}
$\frac{\text { Time }}{0.0}$ & Argon Flow Rate $(\mathrm{kg} / \mathrm{s})$ \\
4870.0 & 0.008 \\
4880.0 & 0.008 \\
5050.0 & 0.0 \\
& 0.0 \\
Time & Argon Temperature $(\mathrm{K})$ \\
\hline 0.0 & 803.0 \\
3440.0 & 803.0 \\
3600.0 & 837.0 \\
3800.0 & 873.0 \\
4000.0 & 896.0 \\
4200.0 & 913.0 \\
4315.0 & 923.0 \\
4885.0 & 923.0 \\
4900.0 & 393.0 \\
5050.0 & 393.0 \\
& \\
Time & Steam Flow Rate $(\mathrm{kg} / \mathrm{s})$ \\
\hline 0.0 & 0.0 \\
3300.0 & 0.0 \\
3350.0 & 0.006 \\
4870.0 & 0.006 \\
4880.0 & 0.0 \\
5050.0 & 0.0
\end{tabular}


Table 3.1. (con't)

\begin{tabular}{rl}
$\frac{\text { Time }}{0.0}$ & $\frac{\text { Steam Enthalpy }(\mathrm{J} / \mathrm{s})}{0.0}$ \\
3300.0 & 0.0 \\
3350.0 & 21305.5 \\
3600.0 & 21747.7 \\
3800.0 & 22220.9 \\
4000.0 & 22526.0 \\
4200.0 & 22753.0 \\
4315.0 & 22887.0 \\
4870.0 & 22887.0 \\
4880.0 & 0.0 \\
5050.0 & 0.0 \\
& \\
Time & Bundle Water Quench Flow Rate $(\mathrm{kg} / \mathrm{s})$ \\
\hline 0.0 & 0.0 \\
4870.0 & 0.0 \\
4880.0 & 0.060 \\
4993.0 & 0.060 \\
4993.5 & 0.0 \\
5050.0 & 0.0
\end{tabular}

From [6], an estimation of the flow rates versus time in the bypass regions and the top and bottom leak paths was obtained. The flow rates in these flow paths were small, usually much less than $0.5 \mathrm{~g} / \mathrm{s}$. An exception was that the lower window and upper leak did slightly exceed $1 \mathrm{~g} / \mathrm{s}$. However, MELCOR, being a control volume code, does not have any knowledge concerning the spatial nature of flow patterns. In this geometry, primarily axial flow is bleeding off small portions of its flow in a radial direction. MELCOR uses pressures, velocities, areas, and flow resistances to divide flow to and from control volumes with multiply connected flow paths. Using standard loss coefficients [8] resulted in flows through the windows and leak paths that were much too high. The flow through these paths was adjusted to more realistic levels by increasing the loss coefficients assigned these flow paths significantly (See Appendix A). The results of [6] were used as a guide to achieve more realistic flows.

The heat structures used in the MELCOR model are shown in Figure 3.2. The heat structure numbering convention was that the first three numbers were the control volume to which the heat structure was assigned, and the last two numbers were the axial level as given in Figure 3.3. HS11001, HS11002, HS21003, and HS21004 represented the 


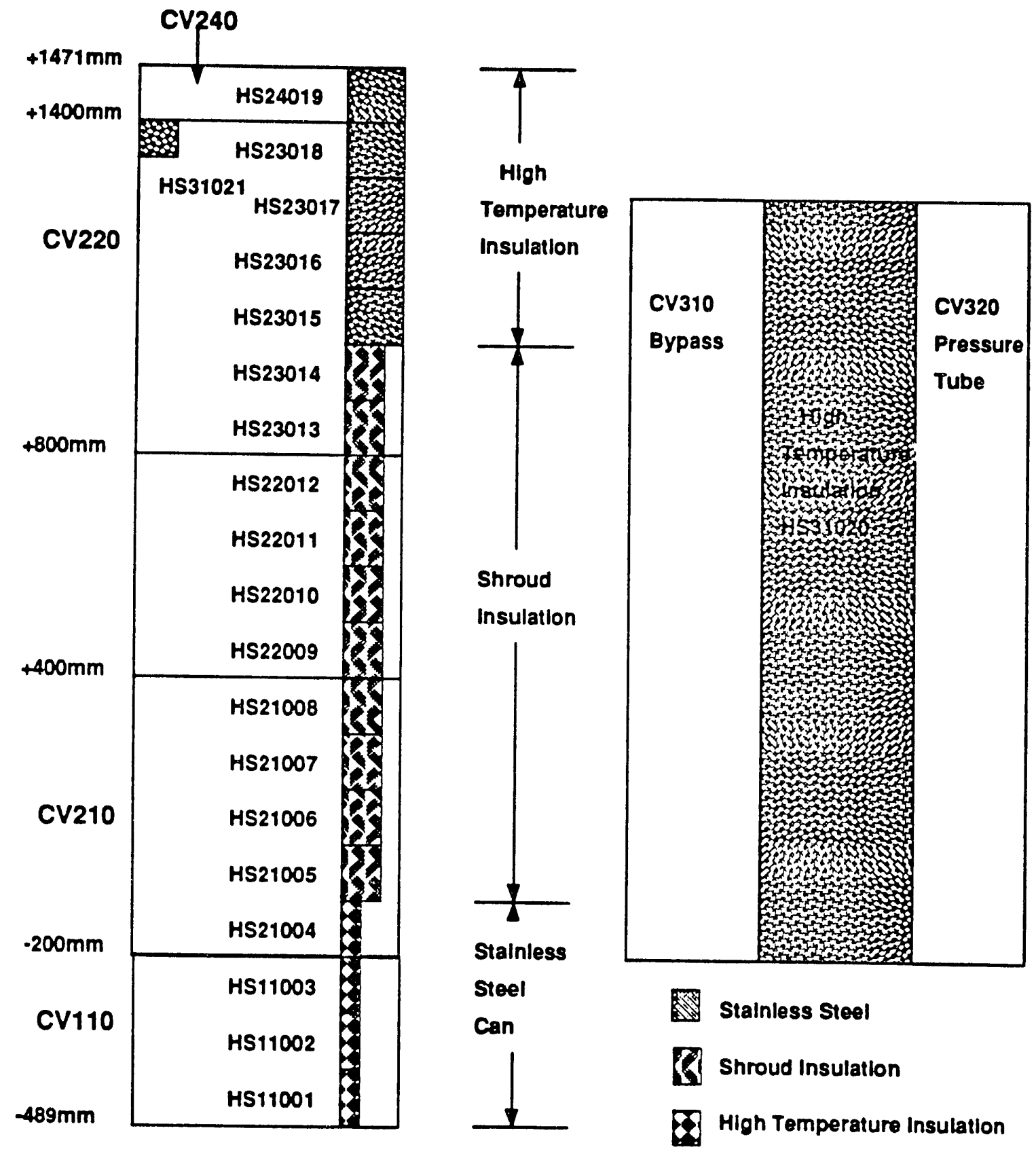

Figure 3.2 MELCOR Heat Structures used for Simulation of the CORA - 13 Experiment 
stainless steel cannister below the $0 \mathrm{~mm}$ mark. Above this, the stainless steel can was connected to the zircaloy shroud. HS21005 through HS23014 represented the shroud insulation. Material properties for the porous $\mathrm{ZrO}_{2}$ shroud insulation were obtained from [5]. HS31020 represented the ceramic high temperature insulation located in-between the bypass region and the pressure tube up to the $1000 \mathrm{~mm}$ mark. Again, material properties were obtained from [6]. HS23015 to HS24019 represented the high temperature insulation up to the $1447 \mathrm{~mm}$ mark, which was the axial extent of the outlet control volume, CV240. From the figures provided in [6], it was apparent that an insulated section covered the radial area between the shroud and high temperature insulation at the 1200$1231 \mathrm{~mm}$ axial location. This insulation was represented by HS31021, which was the only heat structure which diverged from the established numbering convention. Each heat structure representing the shroud insulation contained six nodes, which gave each cell in the heat structure a width of about $2.5 \mathrm{~mm}$. For the high temperature insulation there were a total of nineteen nodes, which gave each cell a width of about $7.0 \mathrm{~mm}$. The finer resolution in the shroud insulation was deemed necessary to resolve the higher temperature gradients that were expected to be encountered in regions so close to the core.

The MELCOR model of the core, or bundle, was the most challenging and complex of the various packages to create. A total of nineteen axial sections from $-489 \mathrm{~mm}$ to $+1447 \mathrm{~mm}$ and four radial sections were created, for a total of seventy six COR Package nodes. The $24 \mathrm{~mm}$ thermal expansion gap for the rods that existed in the experiment was ignored in the MELCOR model, so the $+1447 \mathrm{~mm}$ height in the MELCOR model was really the $+1471 \mathrm{~mm}$ height of the experiment, where the top bundle flange was located. Figure 3.3 shows the axial extent of each of the nineteen nodes and, if heated rods existed, the material actually present in the experiment in that axial location for the heater. In MELCOR, only one electrical heating material is presently allowed. As a compromise in thermal properties for tungsten, molybdenum, and copper, the properties of uranium metal from the MELCOR Material Properties Package was used. For radial rings which contained more than one rod, the masses of all rods in that ring were lumped together in the input. Hydraulic diameters of various materials such as the $\mathrm{UO}_{2}$ fuel and the zircaloy cladding were also properly adjusted. It should be clear from this discussion, then, that the MELCOR COR Package does not model individual fuel rods. The maximum $\mathrm{ZrO}_{2}$ temperature permitted to hold up melt was $2750 \mathrm{~K}$ instead of the default value of $2500 \mathrm{~K}$. It was recognized that this value was artificially high, but, as shall be seen in Section 4.1, was necessary to offset early oxidation which caused premature melting and relocation. Only the lower spacer was modeled, and it was crudely modeled by adding its mass at the 0 to $100 \mathrm{~mm}$ axial level as "other structure" material, which MELCOR modeled as stainless steel in the ISP31 Problem. Parameters such as flow areas between the rods in a ring and surface areas were carefully computed based on the bundle geometry. The reason that the shroud insulation was broken into so many heat structures was that each COR axial level required its own unique heat structure assigned to it. A necessary change was also made to two of the COR sensitivity coefficients. The COR Package was originally intended to model large cores. The CORA-13 experiment represents a small core with very small masses. For proper computation of masses and energies, the 
COR Number $(R=1,2,3,4)$

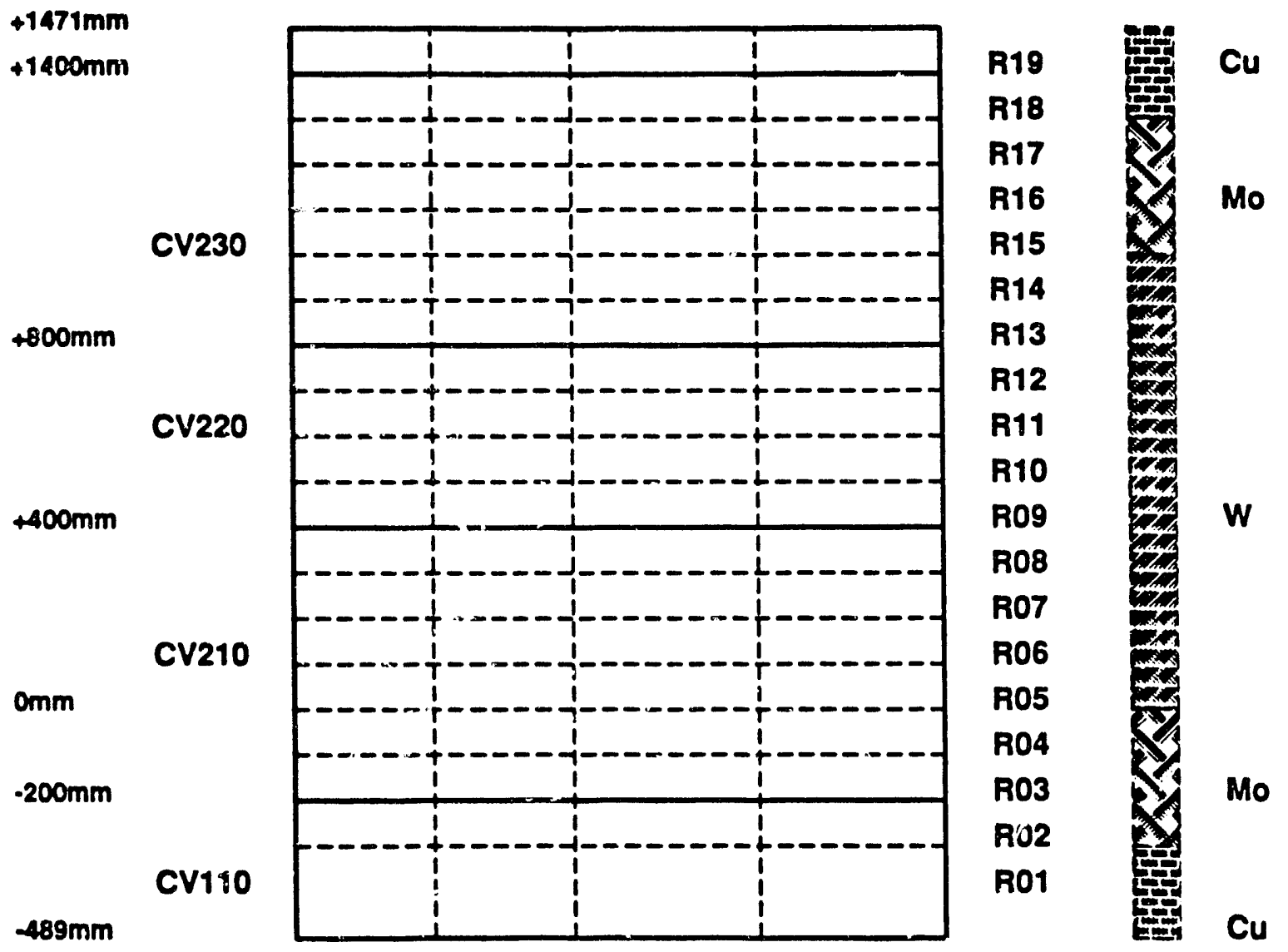

Figures 3.3 MELCOR Nodalization of the CORA-13 Core 
minimum total mass of a component was changed from the default value of 0.001 to $1.0 \mathrm{E}-6 \mathrm{~kg}$, and the minimum mass subject to timestep control was changed from 10.0 to $0.001 \mathrm{~kg}$.

At the time that this blind calculation was being performed, MELCOR did not have the capability to model electrical resistance heating. Four routines, listed in Appendix B, were written to simulate the heaters in the experiment and input the correct energy, in both space and time, to the MELCOR core nodes. The COR Package was modified to include the tungsten heaters in the sixteen heated rods, and to interface with the four routines that passed energy to the COR Package. The methodology used to calculate the energy in each of the seventy six nodes at an instant in time is as follows. MELCOR temperatures were used to calculate the resistance in a representative rod in eacr of the two heated rings. Thus, each rod in a ring was treated identically, and only two calculations were performed -- one for each of the two heated radial rings. The inner rod result was multiplied by four and the outer rod result was multiplied by twelve to obtain the proper total energy input to each radial ring. Total rod resistance could directly be extracted from nodal temperatures. Experimental rod resistances were also available as a boundary condition. MELCOR computed resistances at an instant in time were not likely to match the experimental resistances unless rod temperatures for computation and experiment were identical. The ratio of these two resistances was used to create a scale factor. This scale factor was then used to correct the computational power to match that of the experimental power for that timestep. Thus, experimental power, and the corresponding current and rod resistances, in a global sense, was matched exactly. Since the coupling between the electrical energy routines and the COR Package was explicit, temperatures from the previous timestep were used. However, from timestep to timestep, rod temperature, were slowly varying. Also, note that the total rod resistance was obtained by summing over nineteen nodes, which allowed for local spatial variation in rod resistance and thus temperature between model and experiment.

The information from the model to be provided for ISP31 was required to be presented in two tables [5]. Table 1 had 230 entries, while Table 2 was specified to have 480 entries. The data for these two tables varied in time, but was roughly every 2.5 seconds for the duration of the experiment. Thus, the amount of information required to be submitted was substantial. To automate the creation of so much data as much as possible, extensive control function and external data function input was created. Many of the parameters required for the ISP31 tables was not available directly from MELCOR as either a control function or plotable output. Much of it, however, could be inferred from the available MELCOR information and be created by using a number of control functions. Once that data was available either from the control function or from the normal MELCOR database, it was outputted to two files in the required print format using the MELCOR External Data File (EDF) Package. Thus, every time MELCOR was run, the two required tables were provided. Even so, manipulation and addition to these tables was required after a calculation for several reasons. For example, the electrical heating information (for this early MELCOR version) was not availa'ole in MELCOR, and auxiliary software was required that took this information from a separate output file, and entered it into the ISP31 tables. 
MELCOR was allowed to select its own timestep during the entire time of the calculation. Most of the time, a Courant limit on Control Volume 220, which was the smallest volume, was the constraining factor. The timestep began at 0.2 seconds, made a sudden step decrease to 0.06 seconds at 3400 seconds, and then linearly decreased to about 0.025 seconds at 4870 seconds. The timestep oscillated frequently during quench between about 0.01 and 0.10 seconds. The MELCOR simulation required about 6.2 hours of $\mathrm{cpu}$ time on an IBM RISC 6000 Model 550 workstation.

A copy of the MELGEN and MELCOR input used for the ISP31 blind calculation is given in Appendix $A$. The EDF input that was at the end of the MELGEN input has not been included in order to keep the length of the document reasonable. The four auxiliary routines specially written to compute the electrical energy input to the core for the ISP31 experiment are listed in Appendix B. 


\section{MELCOR ISP31 Blind Calculation Results}

The MELCOR ISP31 calculation was a blind calculation. Only the experimental information necessary for geometry specification and initial and boundary conditions were available. The results discussed in this section represent the MELCOR calculation that were the most accurate that could obtained from MELCOR using the available information. The blind calculation was performed on an IBM RISC 6000 Model 550 workstation using the IBM AIX 3.1.5 operating system and AIX XL FORTRAN 2.2.

\subsection{Comparison to Experiment}

The previous discussion illuminated the fact that experimental power, current, and global resistance were accurately matched by MELCOR through the use of the four auxiliary routines added. An important indicator of the overall global temperature accuracy of MELCOR within the core was the correction factor, which was the ratio of the total experimental resistance to the total MELCOR resistance of the rods. Since resistance was directly related to temperature, the value of this correction factor imparted knowledge concerning the global temperature accuracy of MELCOR within the core as compared to the experiment. Figure 4.1.1 shows the plot of the correction factor with time. When the correction factor was greater than one, the MELCOR core had a lower resistance than the experimental core and the MELCOR resistance for the next timestep needed to be increased. Conversely, when the correction factor was less than one, MELCOR core resistances were too high, and the MELCOR resistances for the next timestep were decreased by the correction factor. Initially, when the experimental power was ramped up (See Figure 4.1.2), the correction factor rose to its largest value of about 1.25, but then quickly dropped to a fairly steady value of about 1.1 from 3200 to 4200 seconds in time. The initial large correction at early time was probably due to: (1) thermocouples which provided initial conditions in [5] were cooler exterior rod temperatures, and not an average rod temperature, so MELCOR initial conditions were slightly too high; and (2) the MELCOR core model did not appear to respond to sudden power changes as quickly as the experiment. From 3200 to 4200 seconds, the MELCOR model was predicting global resistances in the core to within $10 \%$ accuracy. After 4200 seconds, when oxidation energy became more important, the MELCOR model overpredicted the resistances compared to experiment. The correction factor, as a result, dropped to a value of about 0.95 . Due to the manner of implementing the quench sequence in MELCOR, there is an inverse spike in the correction factor near 4900 seconds, but its effect on the overall calculation was negligible. Thus, in a global sense, considering that the relation between temperature and resistance was almost linear, MELCOR appeared to match throughout most of the experiment inferred core temperatures to within $10 \%$ or less.

Oxidation of core materials was another important parameter that graded the accuracy of the MELCOR calculation with experiment. Oxidation created $\mathrm{ZrO}_{2}$ from the cladding and grid spacers, and also was capable of oxidizing the steel from the cladding from the two control rods, although the latter was a small effect. The oxidation energy created was 


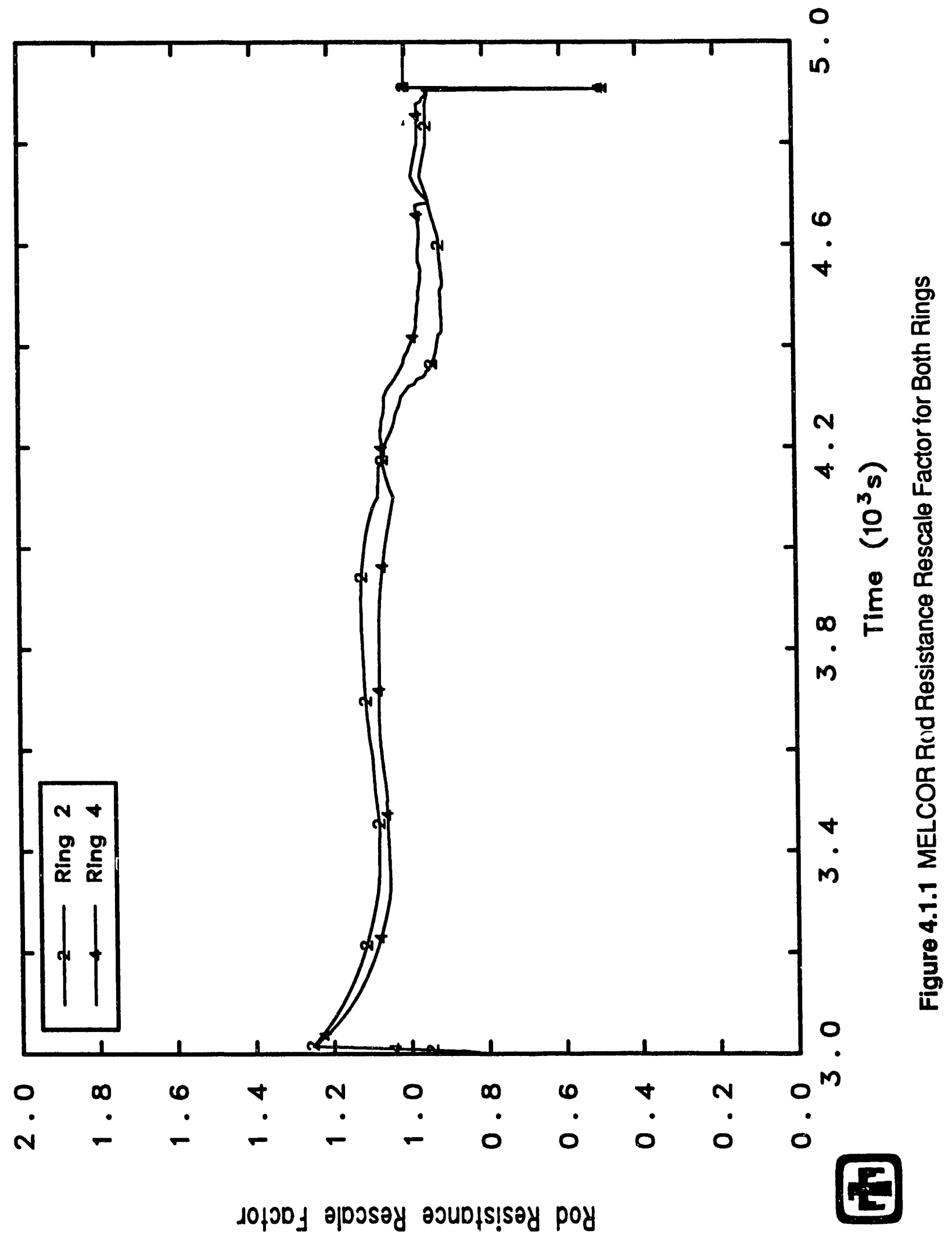




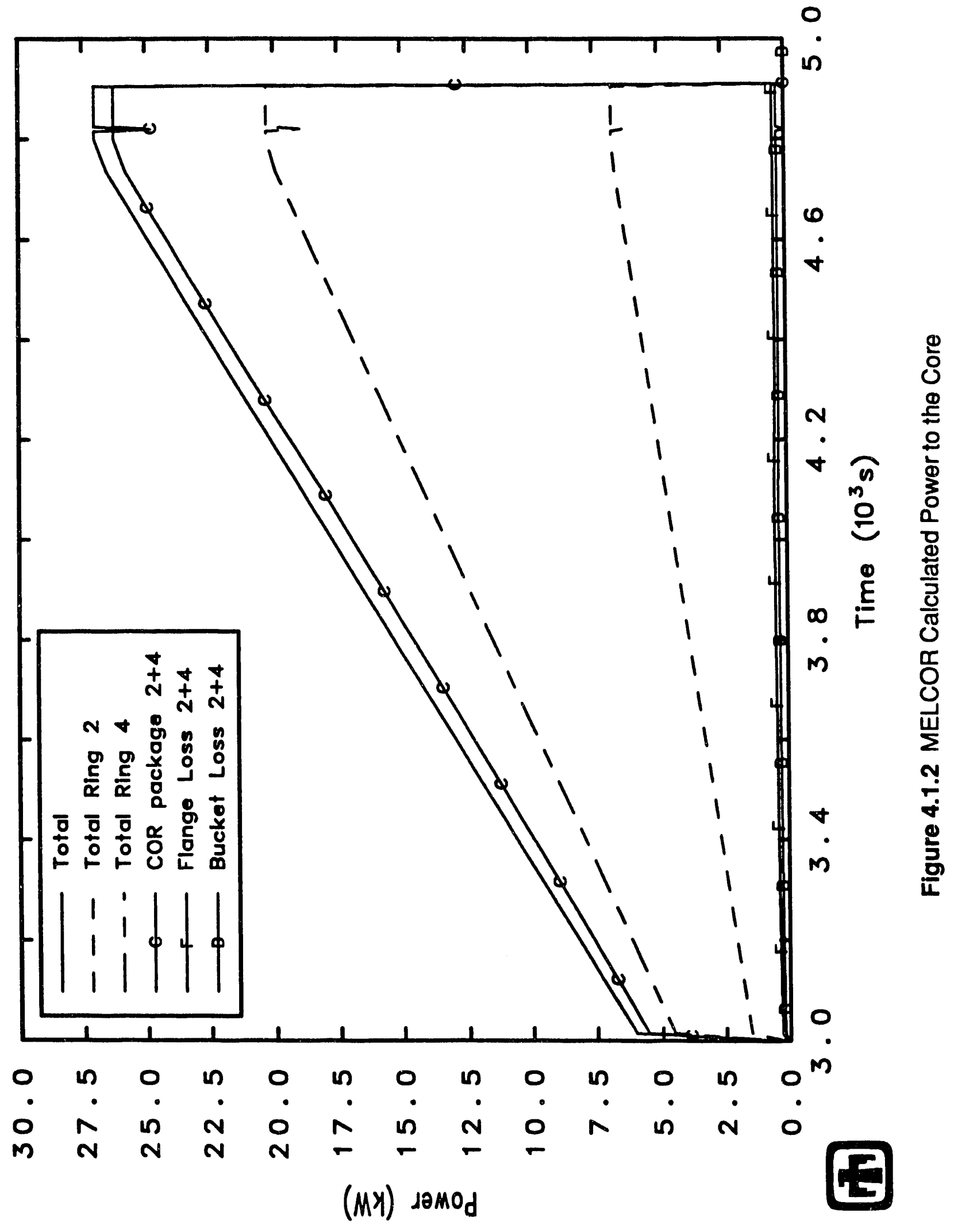


$49 \%$ [7] of the total energy input during the experiment. Figure 4.1 .3 compares the experimental hydrogen production rate with that of the MELCOR result. MELCOR predicted hydrogen production to begin about 500 seconds earlier than experiment (however, MELCOR prediction of rapid oxidation was only 100 seconds early), and the initial oxidation rate (the slope in Figure 4.1.3) was higher than the experiment. The intense oxidation that occurred during the quench sequence was also severely underpredicted. Note, however, that the areas under each curve, if the experimental quench spike was ignored, were about equal. This is confirmed by the fact that in the experiment about 210 giams total of hydrogen was produced while MELCOR predicted about 184 grams of total hydrogen production. The experimental value includes the quench hydrogen spike; if this was subtracted, the two quantities would be in even closer agreement. During quench, MELCOR did predict a spike in hydrogen production, but it was only about 250 $\mathrm{mg} / \mathrm{sec}$, not the nearly $700 \mathrm{mg} / \mathrm{sec}$ in the experiment, and the duration of the spike for the MELCOR result was very small compared to experiment. MELCOR lacks a stress fracture/spalling model which removes the oxidation layer and exposes fresh zircaloy to steam for oxidation. This explains the lack of an oxidation spike in the MELCOR results during quench.

Energy was inputted to the experimental core in the form of electrical energy and oxidation energy. Figure 4.1.4 shows the MELCOR predictions of the contributions of these two energies. The MELCOR oxidation model is divided into two parts -- one for low temperatures and one for high temperatures. On a global average, Figures 4.1.4 shows that the transition from the low temperature model to the high temperature model occurred at about 4100 seconds in MELCOR. From that point in time, oxidation energy was as important as the electrical energy. This energy input to the system found its way to one of five places as expressed by the following thermodynamic first law equation:

$$
E_{\text {electrical }}+E_{\text {oxidation }}=E_{\text {bundle storage }}+E_{\text {fluid }}+E_{\text {shroud }}+E_{\text {bottom }}+E_{\text {top }}
$$

which merely states that the energy produced by the electrical heaters and chemical reactions is manifested as energy stored in the bundle, energy in the coolant fluid, or energy leaving the system radially through the shroud or through the top or bottom of the core. Figures 4.1.5 and 4.1.6 show how the two energy sources in Equation 1 became distributed to the five sinks on the right-hand side of Equation 1. Energy stored in the core at first followed the electrical energy curve of Figure 4.1.4 (because oxidation was insignificant), but then followed the oxidation energy curve at 4100 seconds when oxidation became the dominant energy source. Energy leaving the core radially through the shroud was small, increasing to a peak value of about $7 \mathrm{~kW}$ at 4300 seconds. Energy in the fluid was small until about 4250 seconds, increased to $16 \mathrm{~kW}$ at 4700 seconds, and then remained fairly steady until quench. The handful of "peaks" for the fluid curve occurred when core debris fell into the quench pool and splashed water up into the core region which then flashed into steam and added momentarily to the fluid energy until it flowed out of the core. Energy lost through the top of the core was very small until 4200 seconds, when it became as significant as energy in the fluid. Energy lost through the bottom was insignificant. Figure 4.1.7 shows the totals of each side of Equation (1) (the left-hand side 


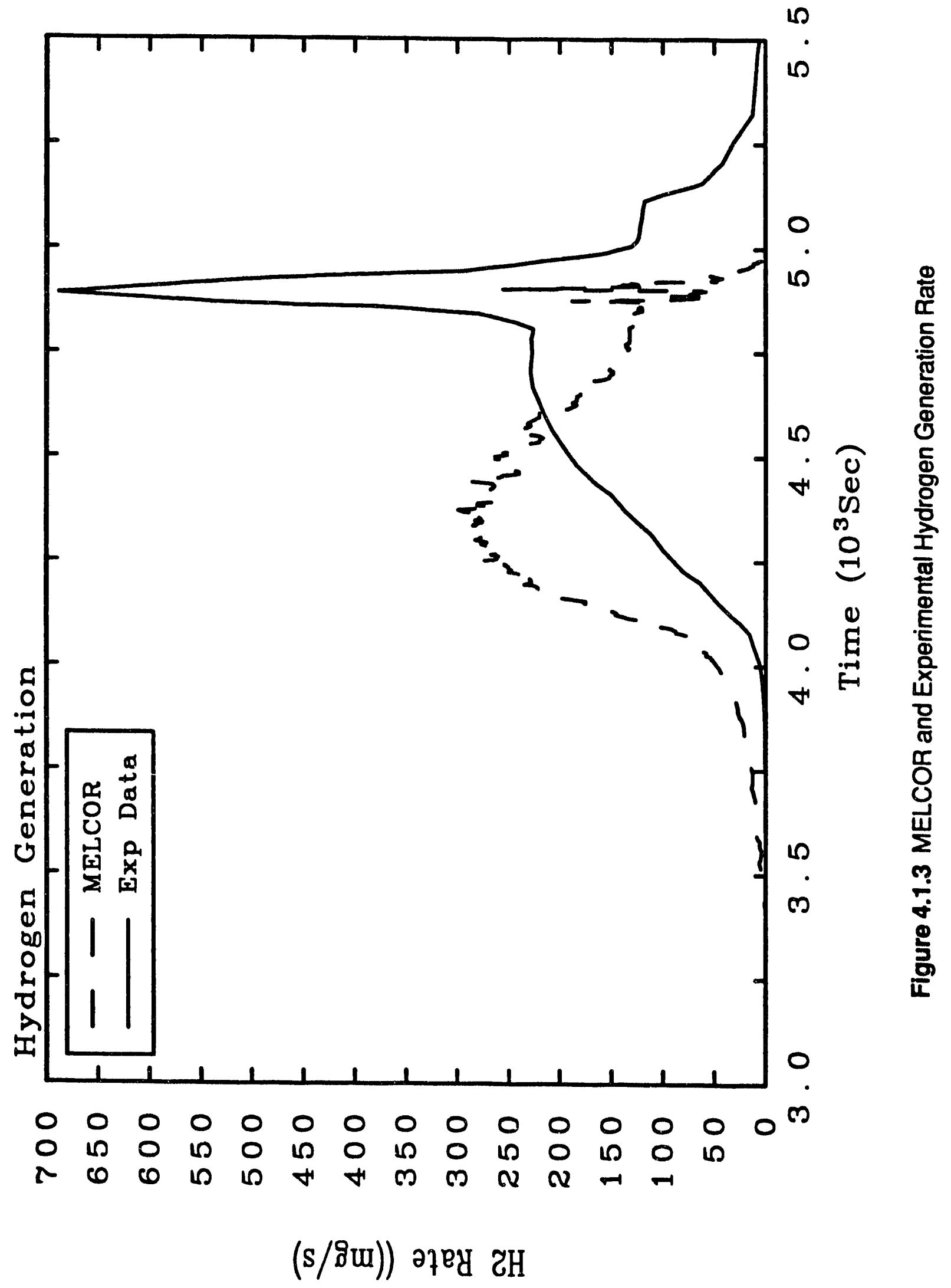




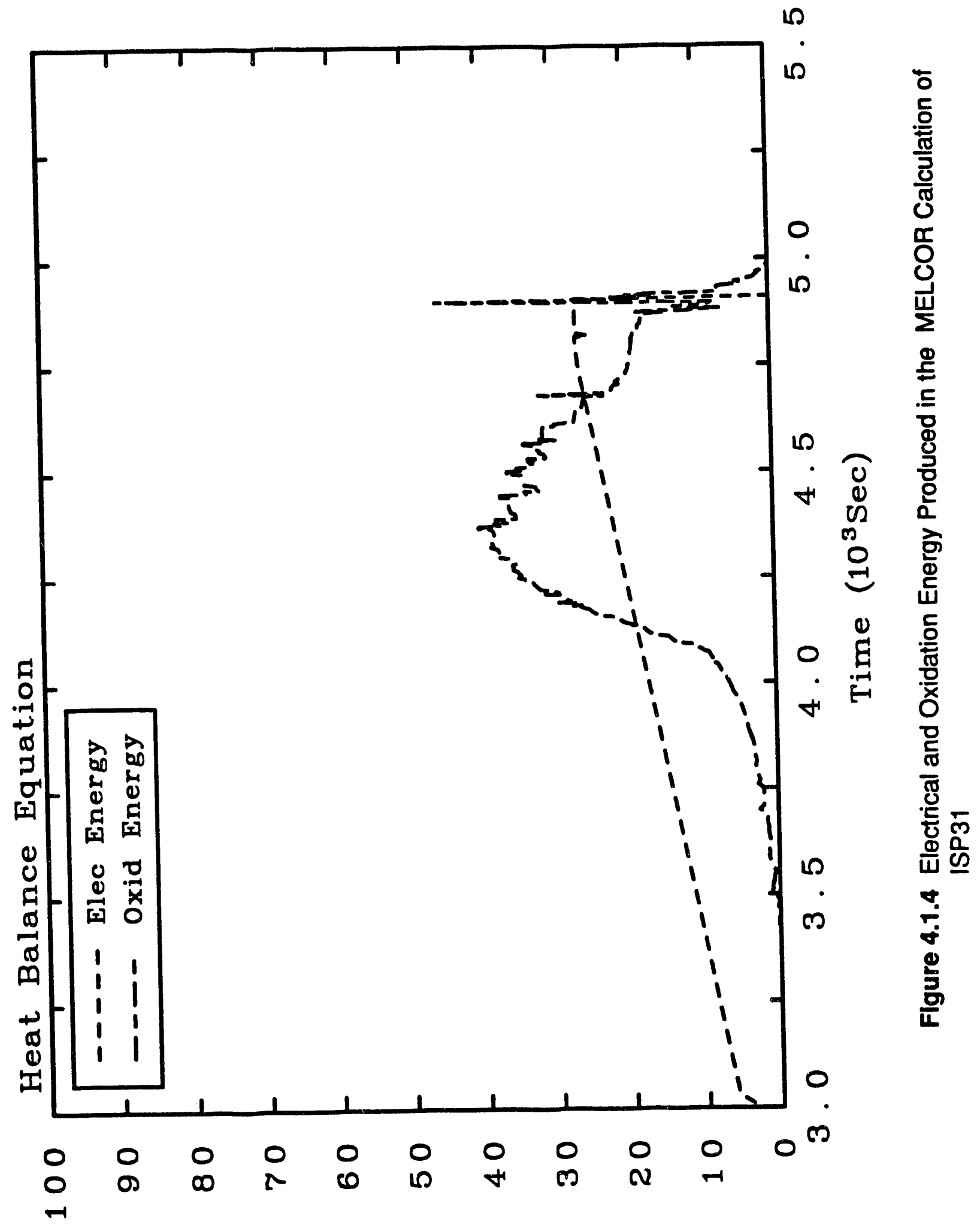

(싸) səMOd 


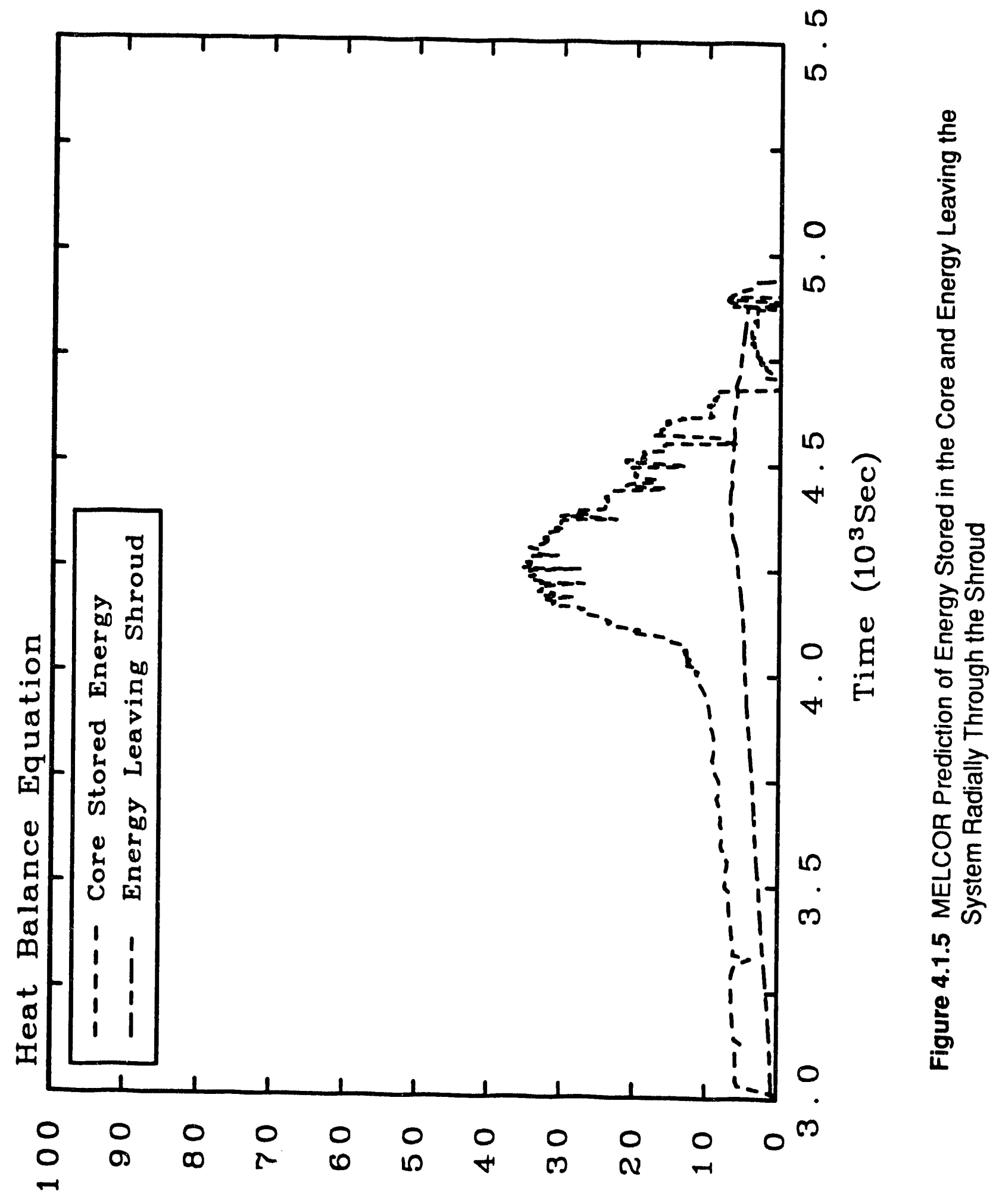

(싸) $\mathrm{IəMO}_{\mathrm{d}}$ 


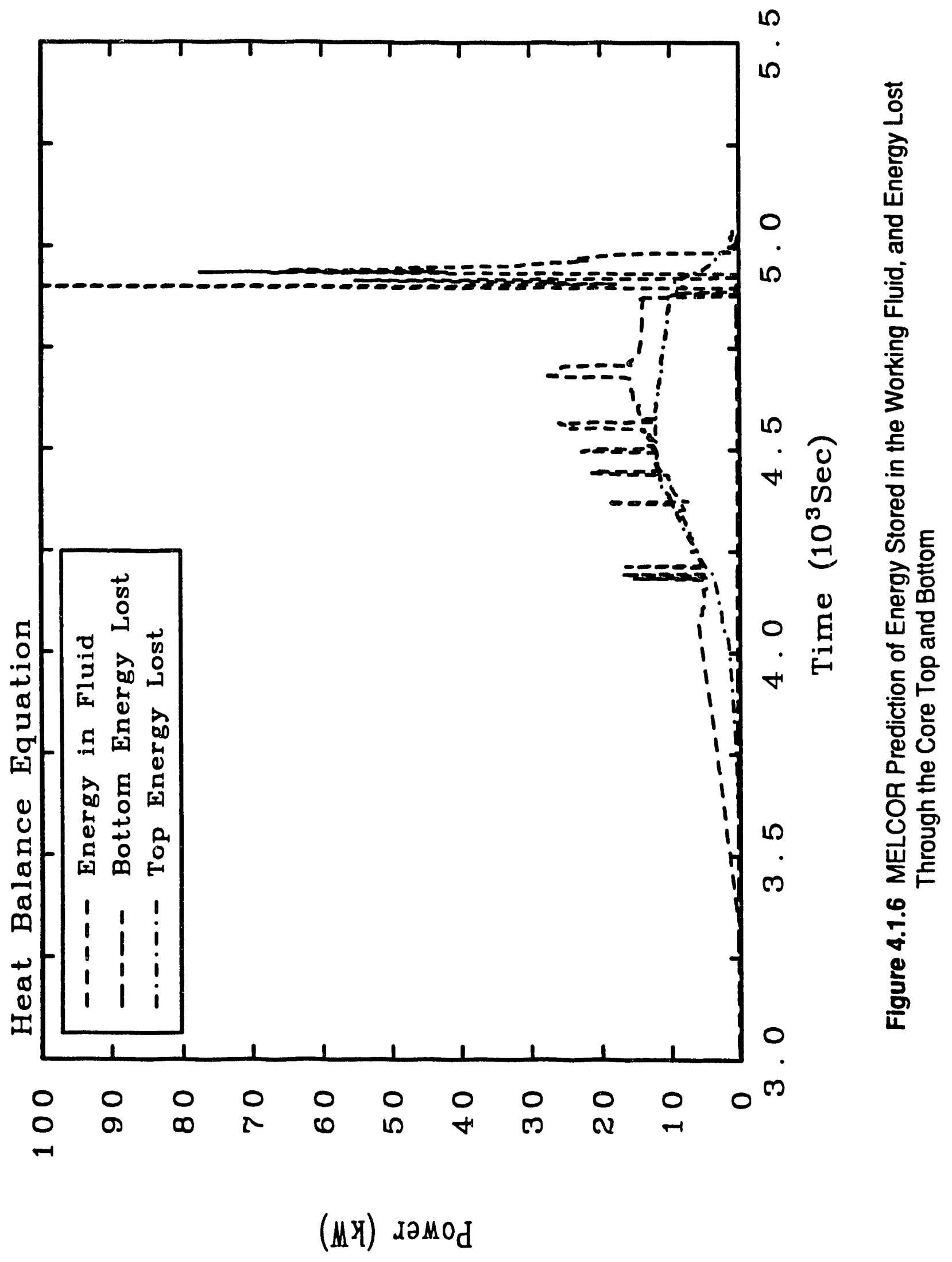




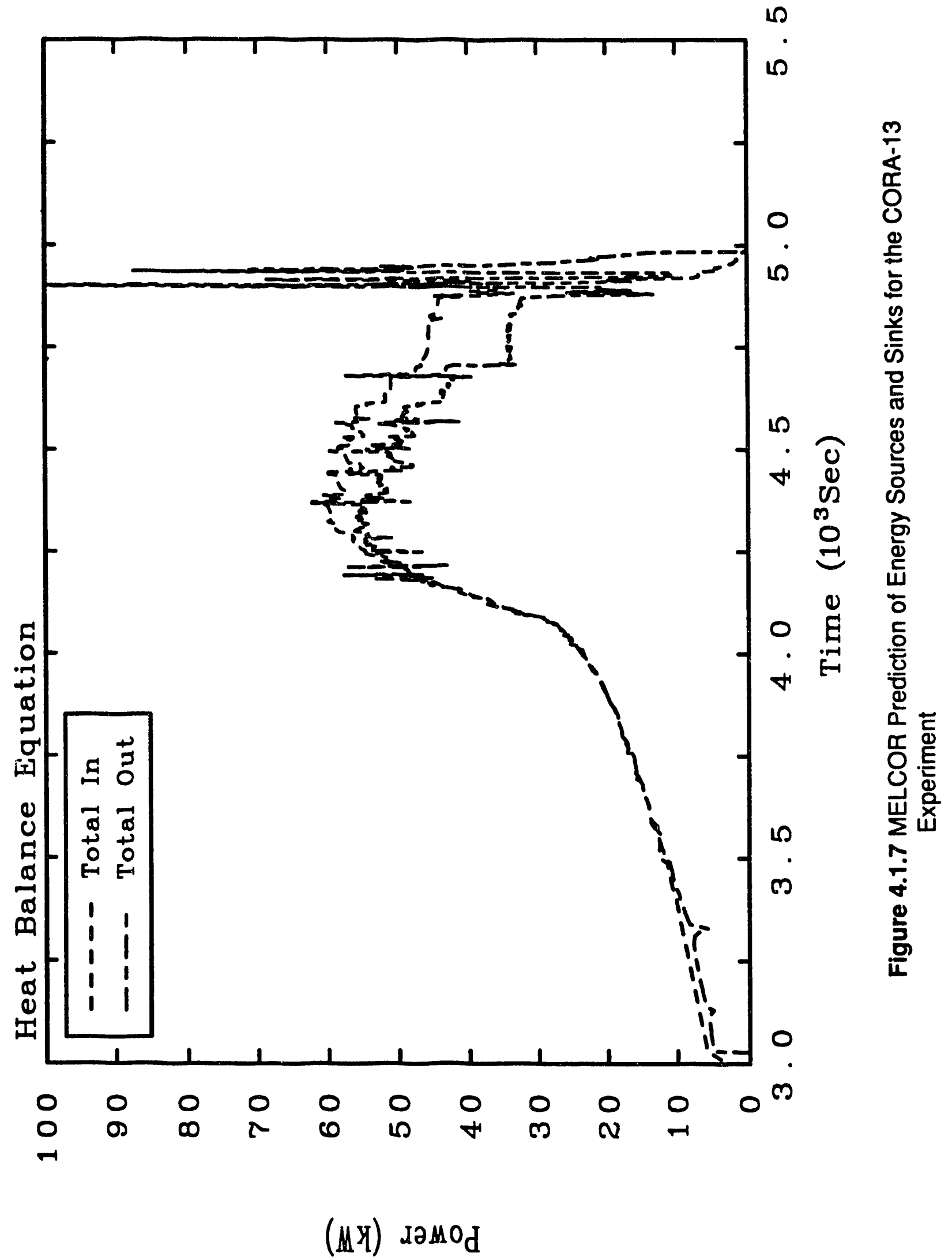


represents "Total In"). The two curves do not match for a number of reasons. First, MELCOR only provided an integrated total both of $E_{\text {oxidation }}$ and $E_{\text {bundle storage }}$, so taking a derivative was necessary to obtain these quantities. Second, the heat flux to or from the shroud was not available, so a computation using available temperatures and average thermophysical properties was necessary. Similar approximations were made to obtain $E_{\text {bottom }}$ and $E_{\text {top. }}$. However, for the first 4250 seconds, the energies balanced very well. Even during the height of oxidation from 4250 to about 4700 seconds the balance was acceptable, although the Total Out begins to fall beneath the Total In. From $4700 \mathrm{sec}-$ onds to the time of quench at 4870 seconds, the two curves disagree by a significant margin. Since at this time the core stored energy curve went to zero, the extreme inaccuracy after 4700 was due to this curve. After examining the data, $E_{\text {bundle storage }}$ after 4500 seconds was determined to be erratic, taking a derivative was extremely difficult, and the curve of $E_{\text {bundle storage }}$ after this time is unreliable.

Figures 4.1.8 to 4.1.14 show the temperatures in both the MELCOR second ring (the first heated ring containing four rods) and the fourth ring compared to experiment at different axial levels. The experimental temperatures were located on the outside of the rod, so both the MELCOR fuel and cladding temperatures are displayed. Although the MELCOR cladding temperature is more appropriate for comparison, the fuel temperatures were included to convey information concerning the radial gradient through the rods. Experimental results were given for both the second and fourth rings, but, at least on the outside of the rods, the experimental temperature gradient across rings was negligible, so only one curve was sufficient to display the data. Again, the temperatures at both MELCOR rings were displayed to provide information concerning the radial temperature gradient across rings in MELCOR. All of the experimental results displayed were digitized from curves provided in [7]. Finally, the maximum holdup temperature of $2750 \mathrm{~K}$ for the cladding is evident in all the figures. As soon as the cladding reached this temperature, the cladding at this level turned to debris and fell to lower core levels.

Figure 4.1.8 compares experiment to MELCOR predictions at the $+50 \mathrm{~mm}$ level. The MELCOR prediction was 100 to $150 \mathrm{~K}$ higher than the experiment until a time of about 4700 seconds, at which point the MELCOR data matched the experimental result. Shortly thereafter, the thermocouple at this level failed. At $+350 \mathrm{~mm}$, shown in Figure 4.1.9, the MELCOR prediction was in excellent agreement with the experimental data right up to the point of thermocouple failure. Oxidation in the MELCOR model began earlier in the second ring than the fourth ring, so there was a larger thermal gradient in the MELCOR results after about 4600 seconds than in the experiment. At the $+550 \mathrm{~mm}$ and $+750 \mathrm{~mm}$ axial levels, agreement between MELCOR and experiment was again excellent up to the point of thermocouple failure (Figures 4.1 .10 and 4.1.11). Figure 4.1.12 displays MELCOR and experimental temperatures for the rods at $+950 \mathrm{~mm}$. Again, the MELCOR prediction was 100 to $150 \mathrm{~K}$ higher than experiment. The experimental data leveled out at a time of about 4400 seconds and failed shortly thereafter. Since a rapid temperature run-up due to oxidation was occurring in the core during this time period, the experimental data after 4400 seconds for Figure 4.1.11 is suspect. Figure 4.1 .13 compares experiment to MELCOR predictions at $+1150 \mathrm{~mm}$. Two observations concerning Figure 4.1 .13 are 


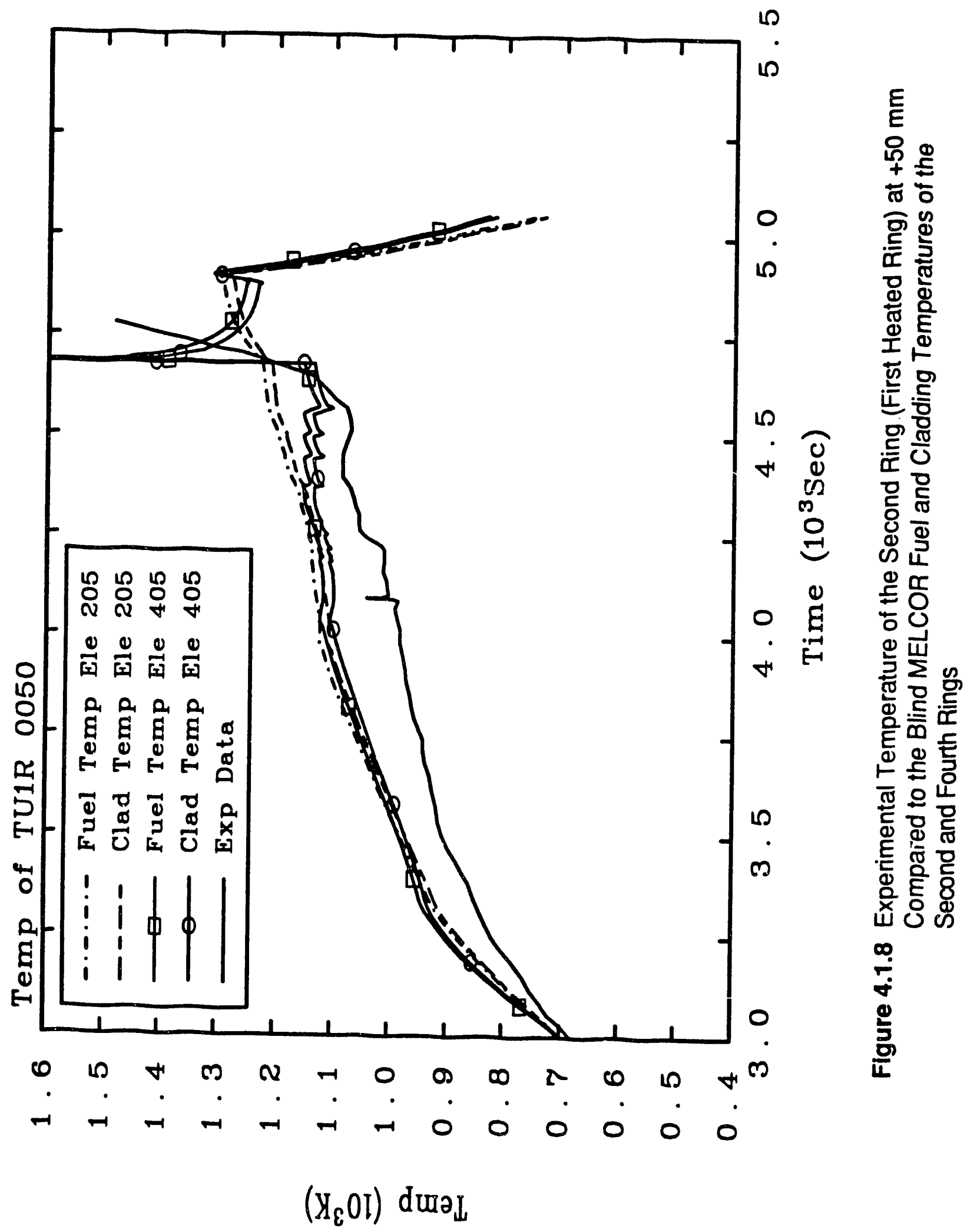




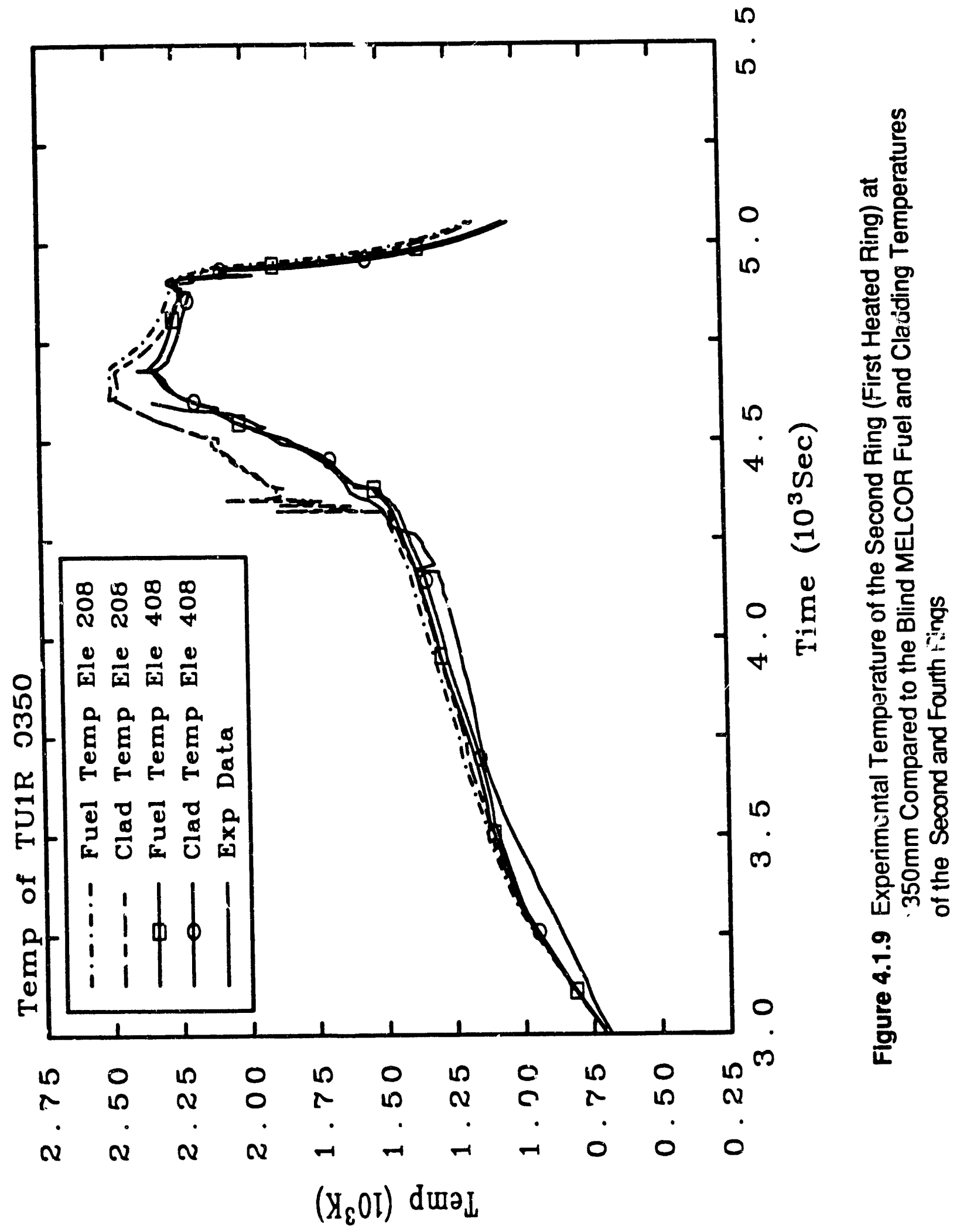




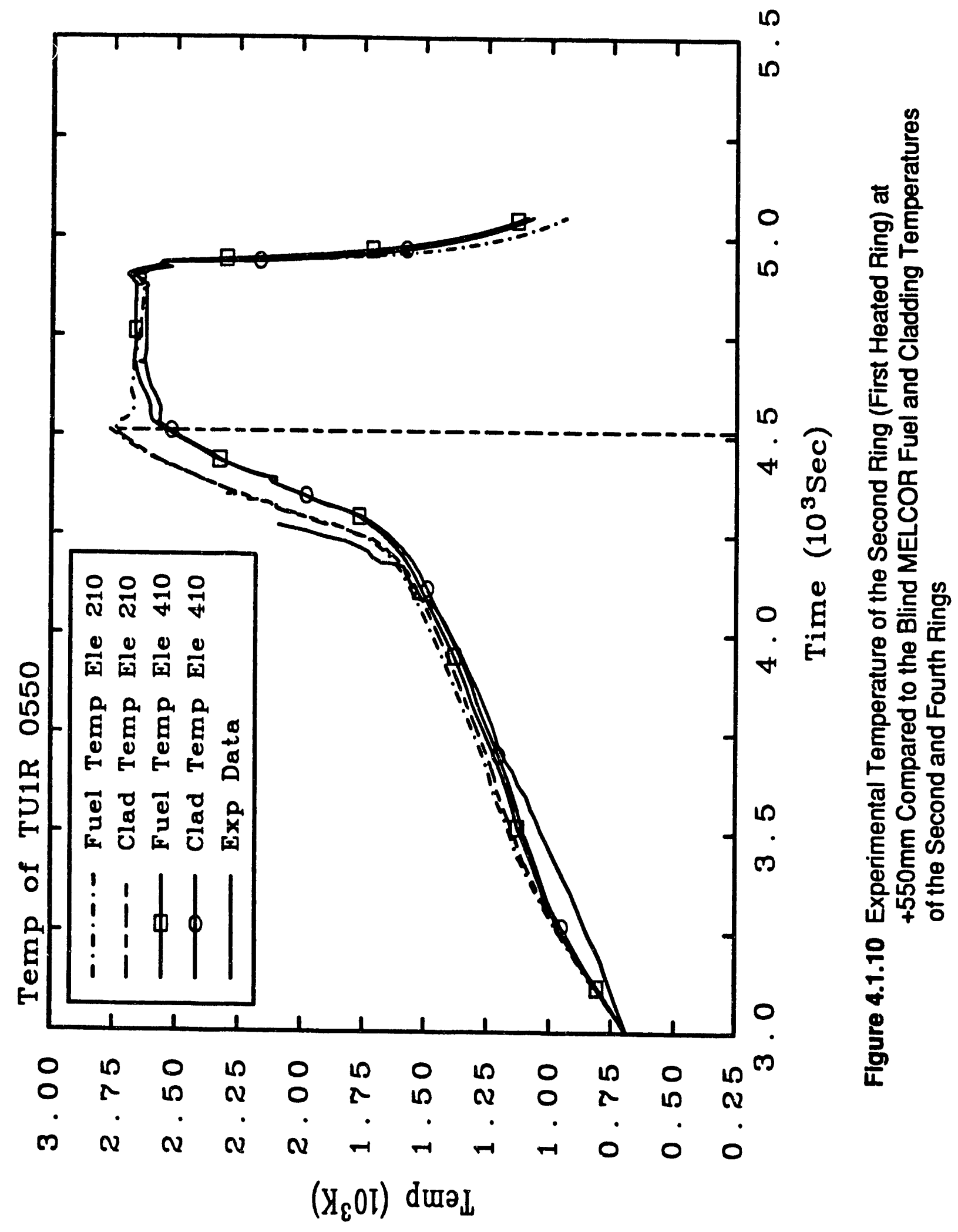




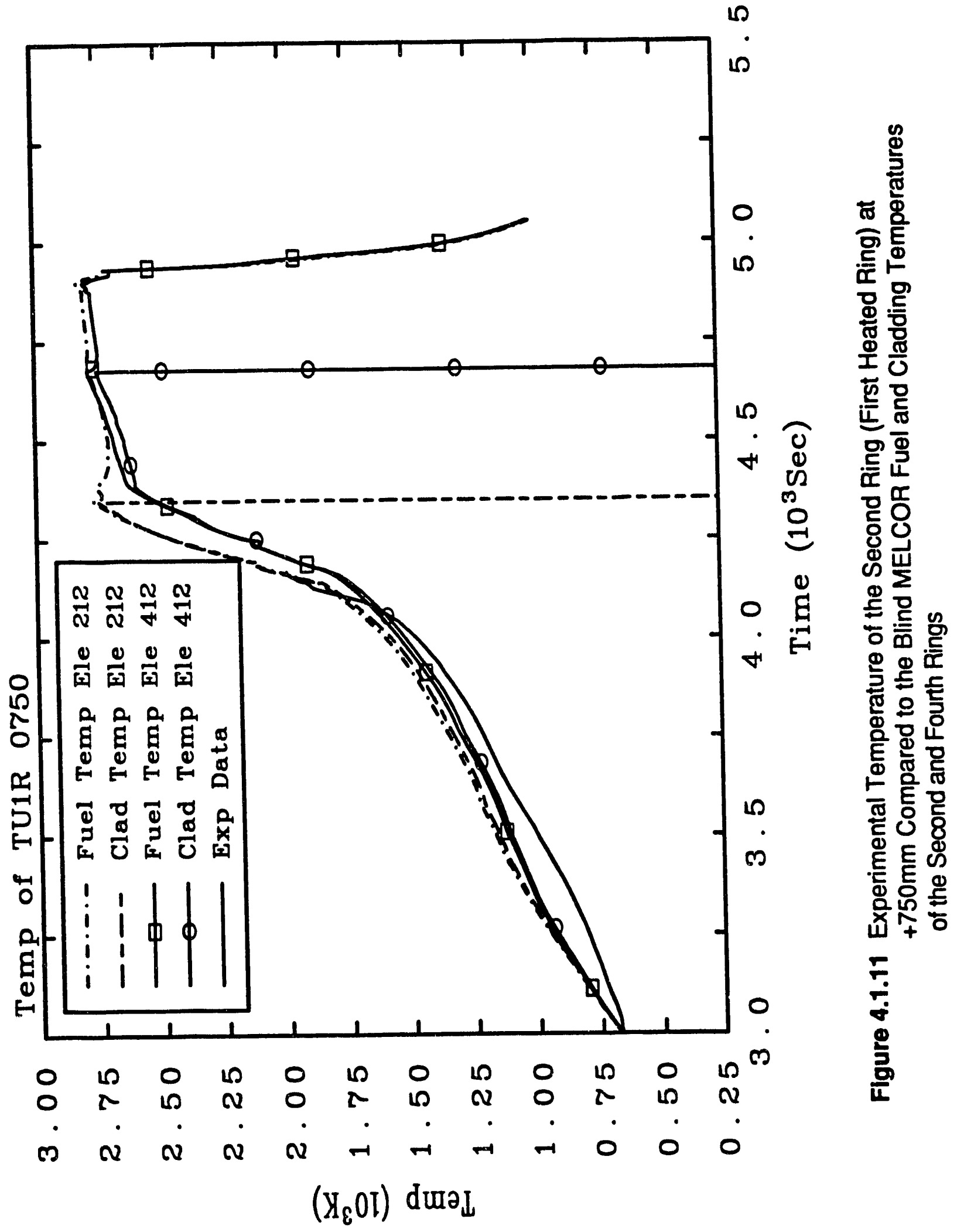




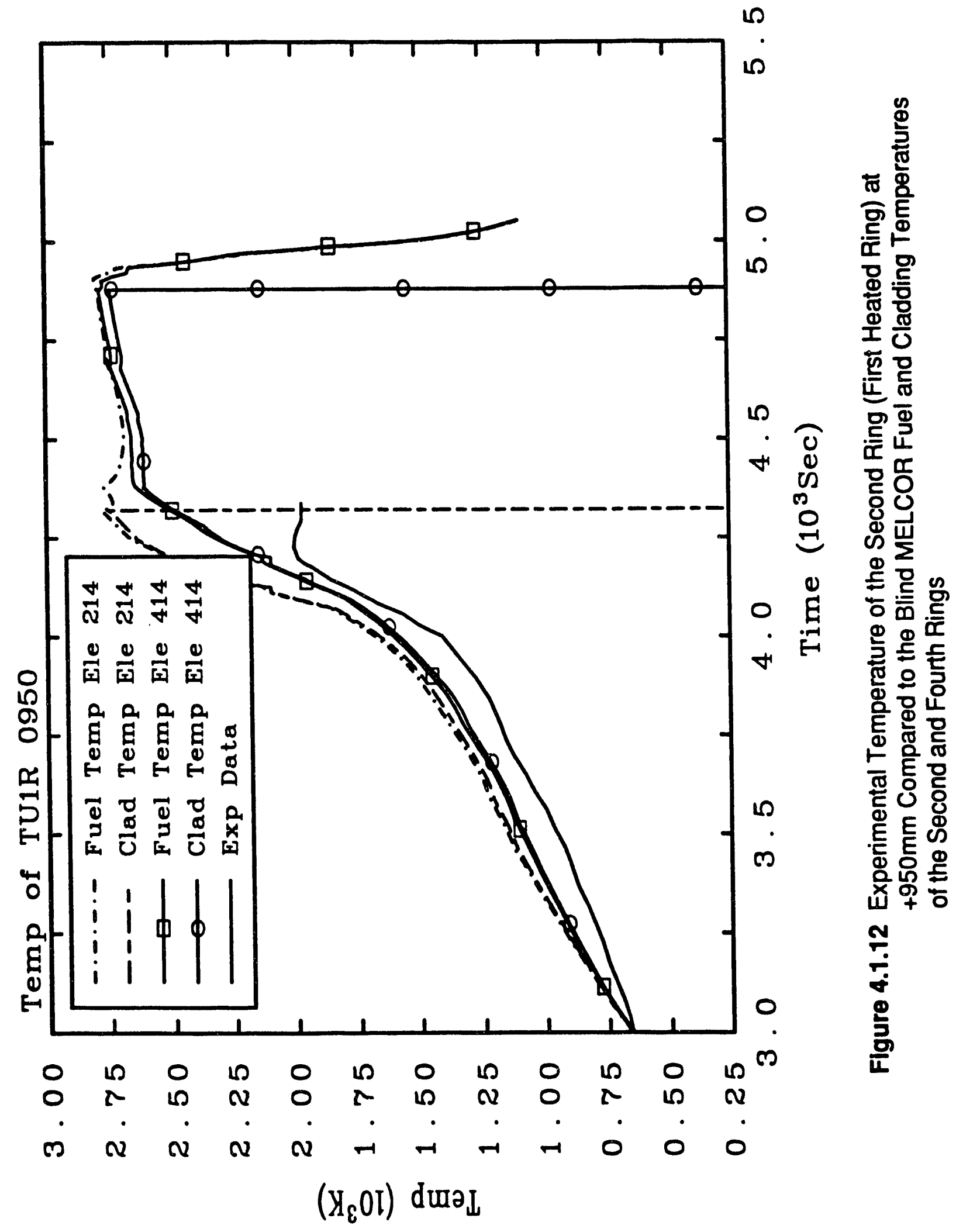




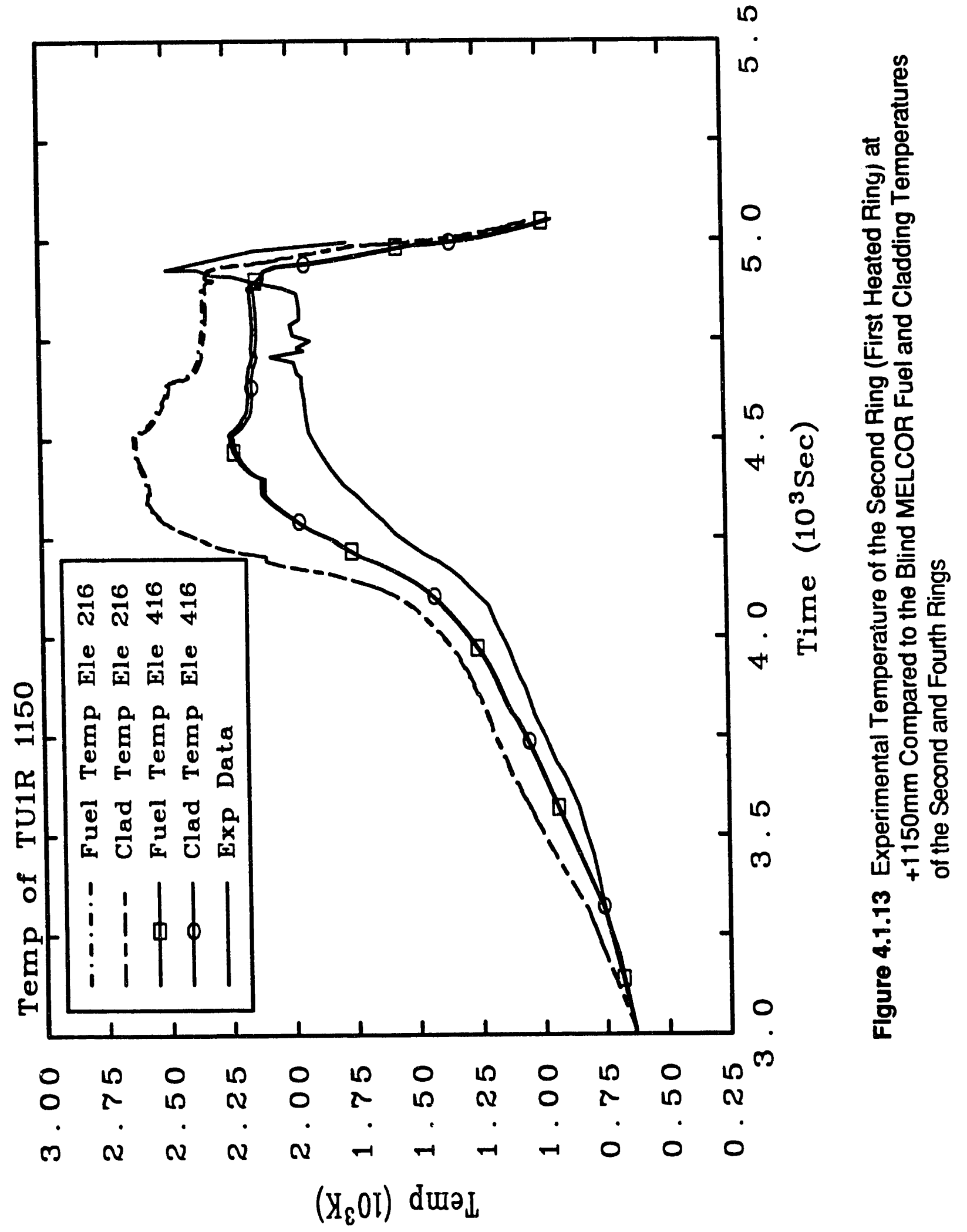




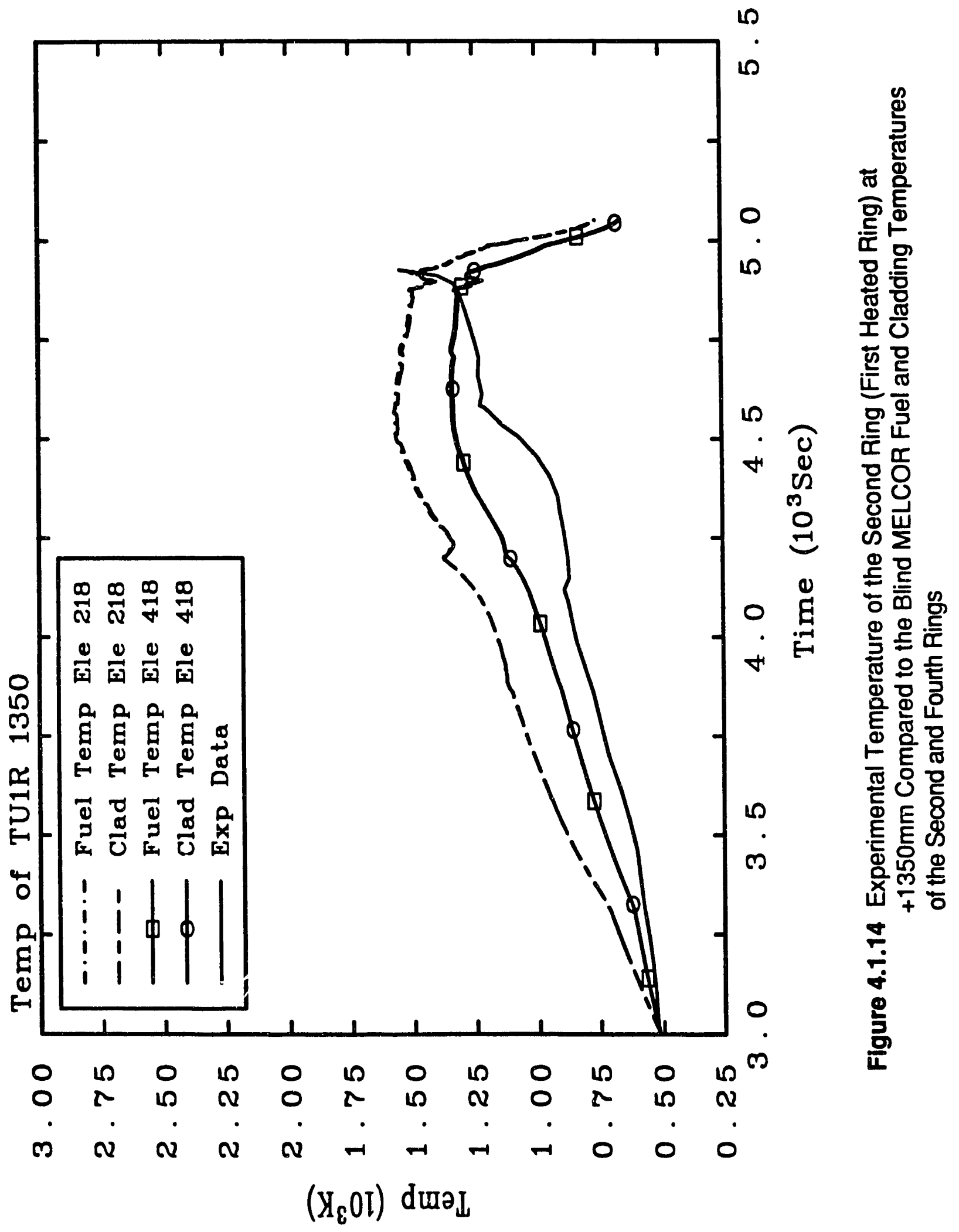


that the radial gradient between rings in MELCOR at this level was greater than experiment (which was negligible) and that MELCOR predicts temperatures 200 to $300 \mathrm{~K}$ higher than experiment after oxidation became important at this level, which was at about 4200 seconds. Since the temperatures at the $+950 \mathrm{~mm}$ level agreed better with the experimental data, either significant cooling occurred in the +950 to $+1150 \mathrm{~mm}$ region that was not predicted by MELCOR and/or the MELCOR predicted energy production from electrical and oxidation sources was higher than experiment at this level. At $+1350 \mathrm{~mm}$, this trend continued, as shown in Figure 4.1.14. Again, MELCOR predicted a significant radial thermal gradient across the rings that was not obsenved in the experiment, and the temperature prediction worsened when oxidation began in the core.

The third MELCOR ring contained nine unheated rods, including two poison control rods. Figures 4.1.15 to 4.1.19 show the temperatures in this ring at the different axial positions. Figure 4.1.15 compares experiment to the MELCOR prediction at $+150 \mathrm{~mm}$. Overall, agreement is very good, especially for a blind calculation. At $+350 \mathrm{~mm}$, shown in Figure 4.1.16, the MELCOR calculation again compared very well with experiment. This agreement lasted right up to the time of thermocouple failure. At $+750 \mathrm{~mm}$ (Figure 4.1.17) the MELCOR prediction again ran just slightly high until the time of oxidation. MELCOR took slightly more time for oxidation to become important (by perhaps 50 seconds), so the two curves crossed. However, overall, until thermocouple failure, agreement was again very good. Figure 4.1.18 compares the results for the unheated rods at $+1050 \mathrm{~mm}$. Again, the results compared very well up to the oxidation time with the MELCOR results just slightly high. As with the heated rods in the upper part of the core, after oxidation MELCOR significantly overpredicted the temperature. This trend continued at the $+1350 \mathrm{~mm}$ level, shown in Figure 4.1.19.

Figures 4.1.20 to 4.1.23 compare predicted and experimental shroud temperatures at various axial levels. Again, at $+50 \mathrm{~mm}$, the MELCOR results ran consistently high, but not by a large margin -- about 50 to $100 \mathrm{~K}$. At $+350 \mathrm{~mm}$, agreement between MELCOR and experiment was excellent. Time of significant oxidation was predicted fairly well. At +550 $\mathrm{mm}$, the MELCOR prediction was actually somewhat lower, but the overall agreement until oxidation began must still be considered excellent. MELCOR slightly overestimated the time of significant oxidation at this level. At $+750 \mathrm{~mm}$, agreement was again excellent and the time of oxidation was again within about 50 seconds.

Comparison between MELCOR and experiment in the outer insulation of the shroud is shown in Figures 4.1.24 to 4.1.27. At $+50 \mathrm{~mm}$, MELCOR slightly overpredicted the insulation temperature. At late time at this spatial location there was obviously a large temperature excursion that caused thermocouple failure not predicted by the MELCOR code. At $+350 \mathrm{~mm}$, MELCOR again slightly overpredicted the experiment, but the experimental temperature excursion at late time due to oxidation has been somewhat damped. The results at $+550 \mathrm{~mm}$ and $+750 \mathrm{~mm}$ were similar to those at $+50 \mathrm{~mm}$. 


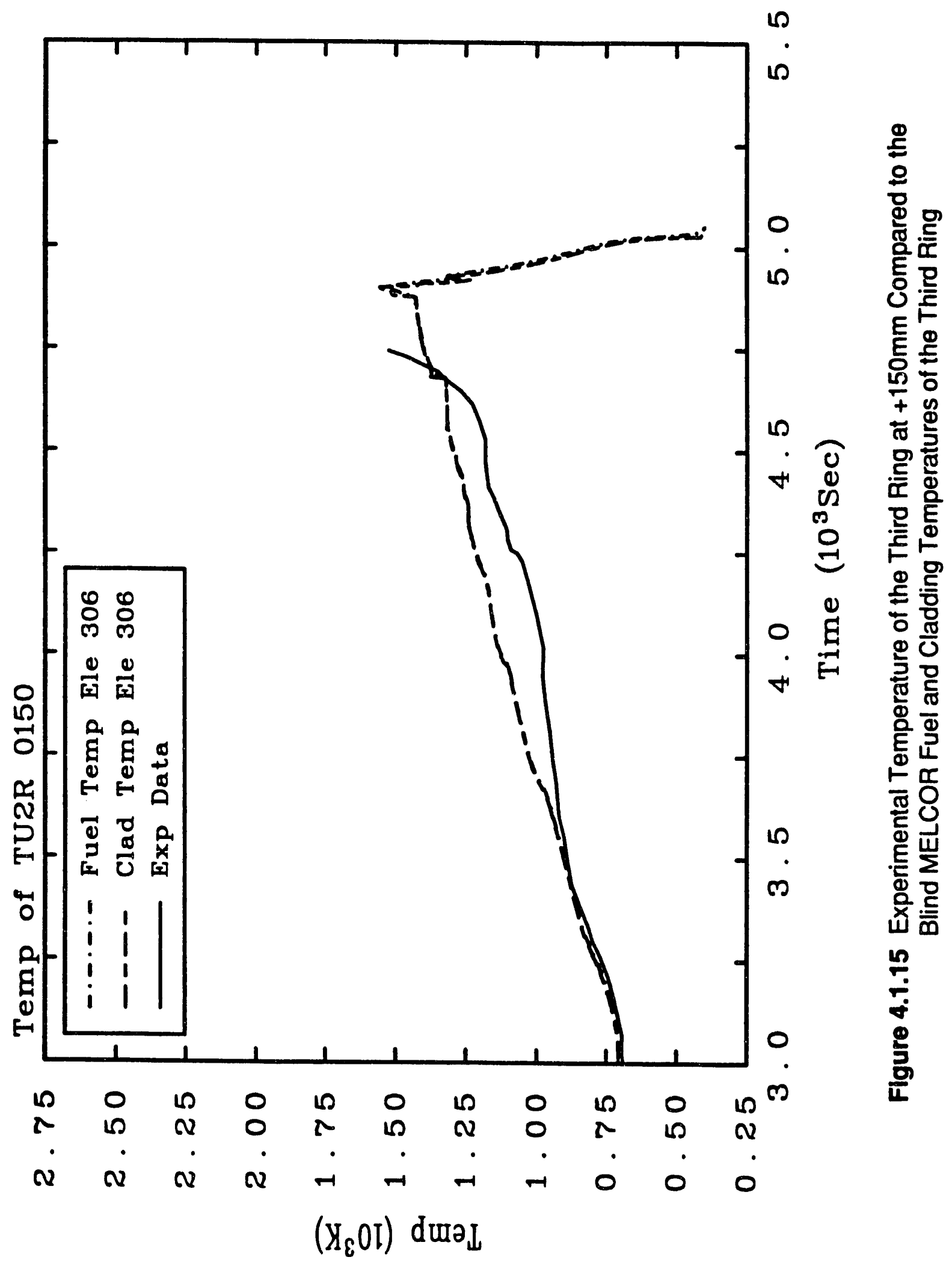




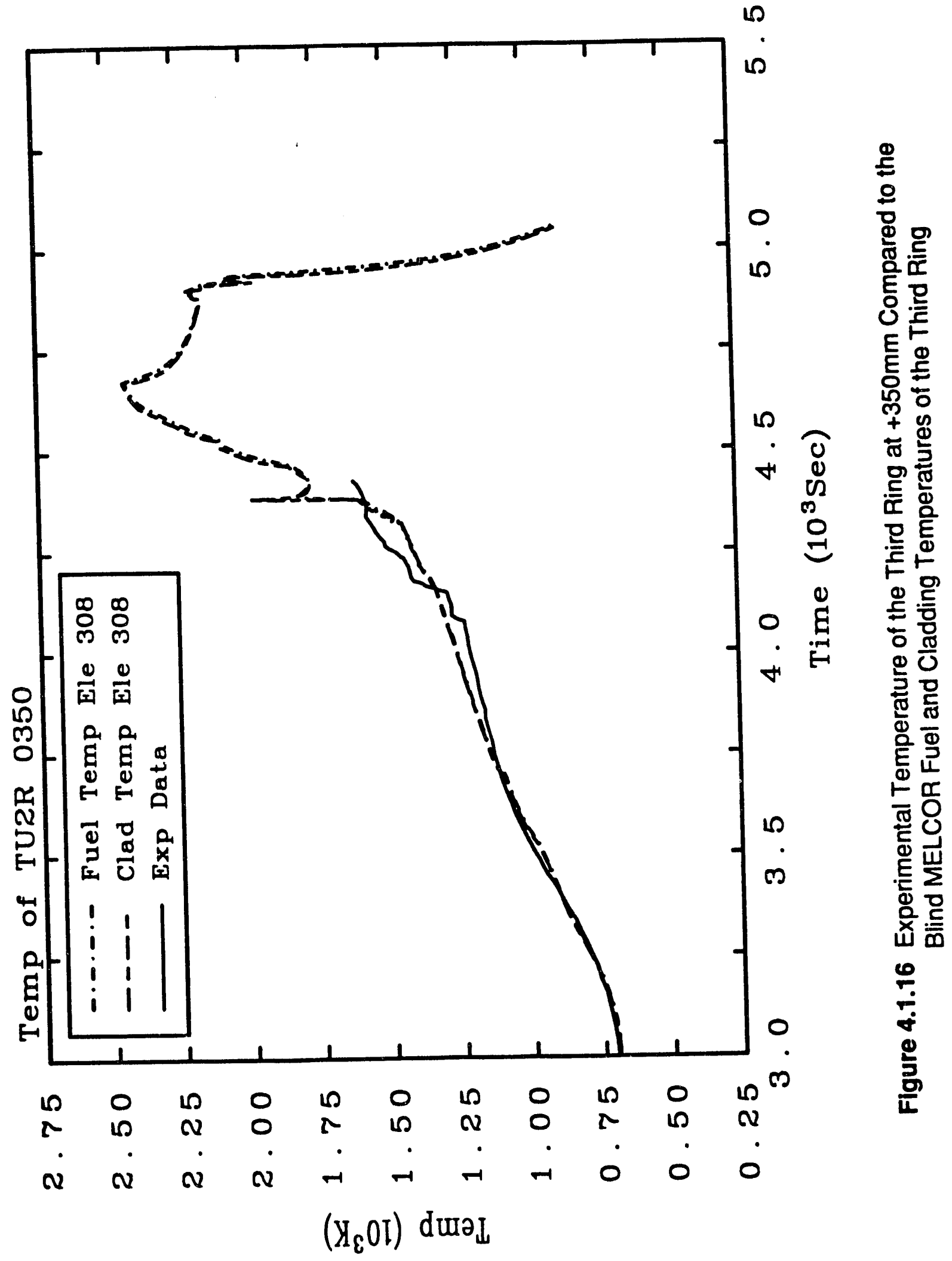




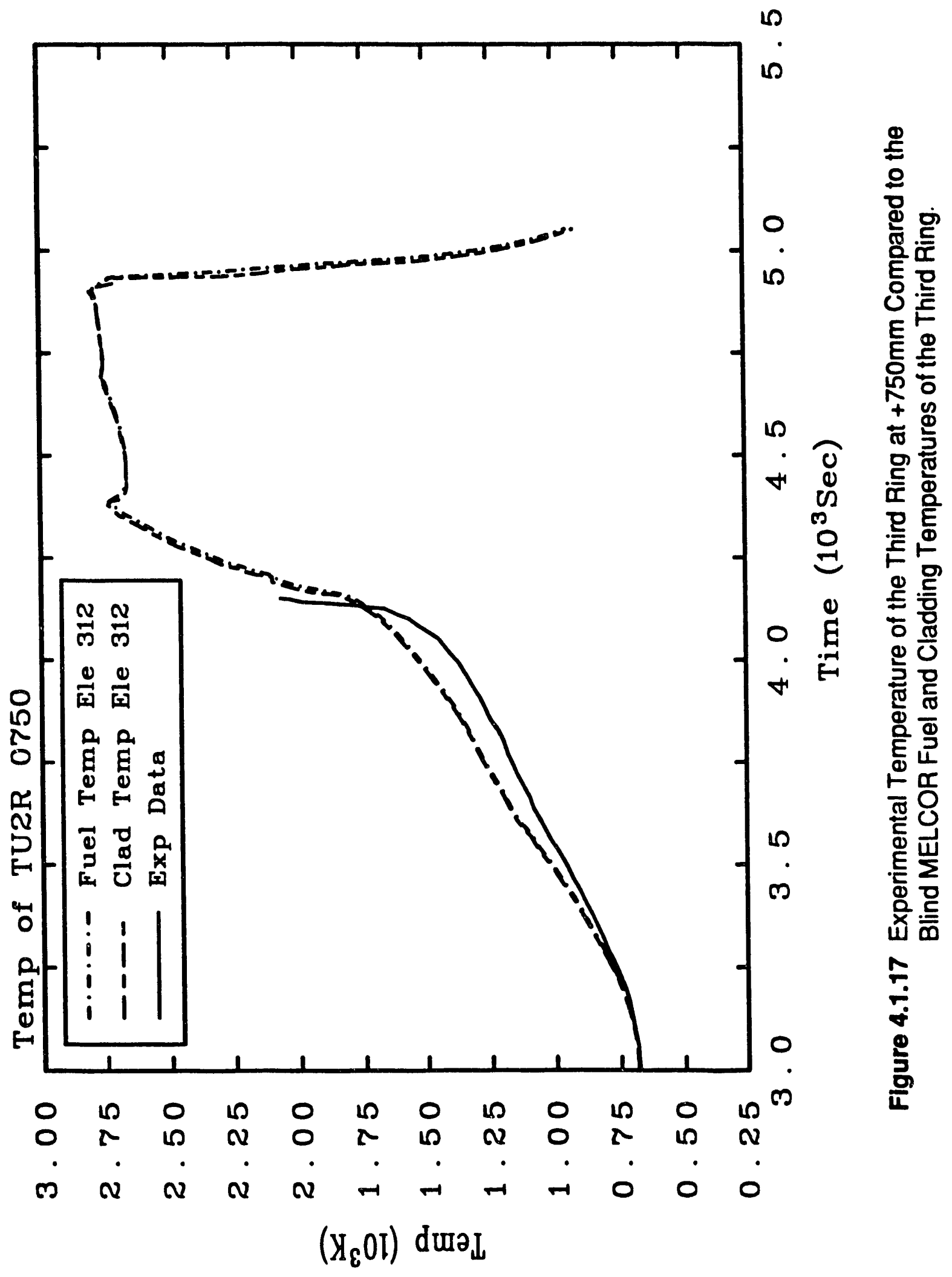




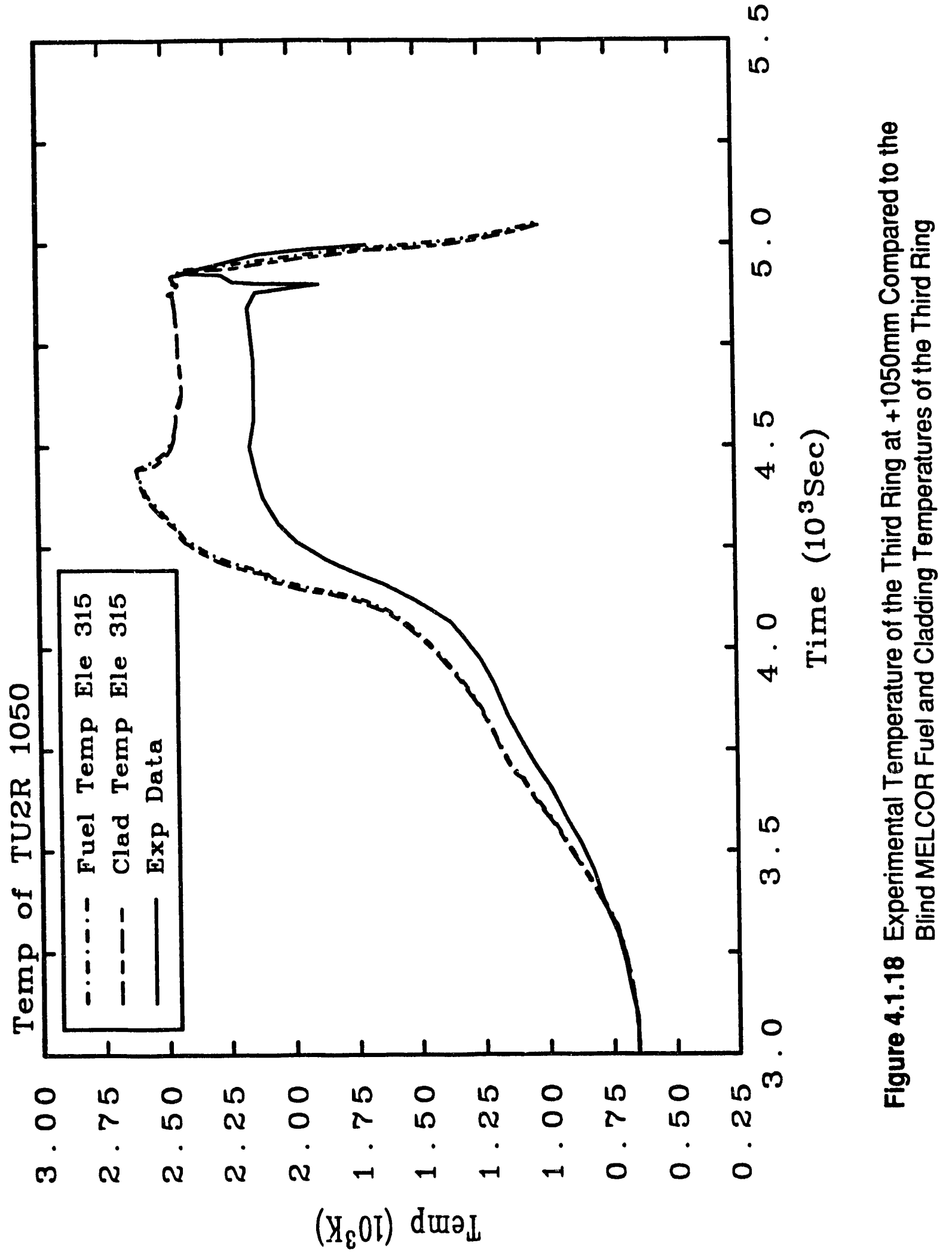




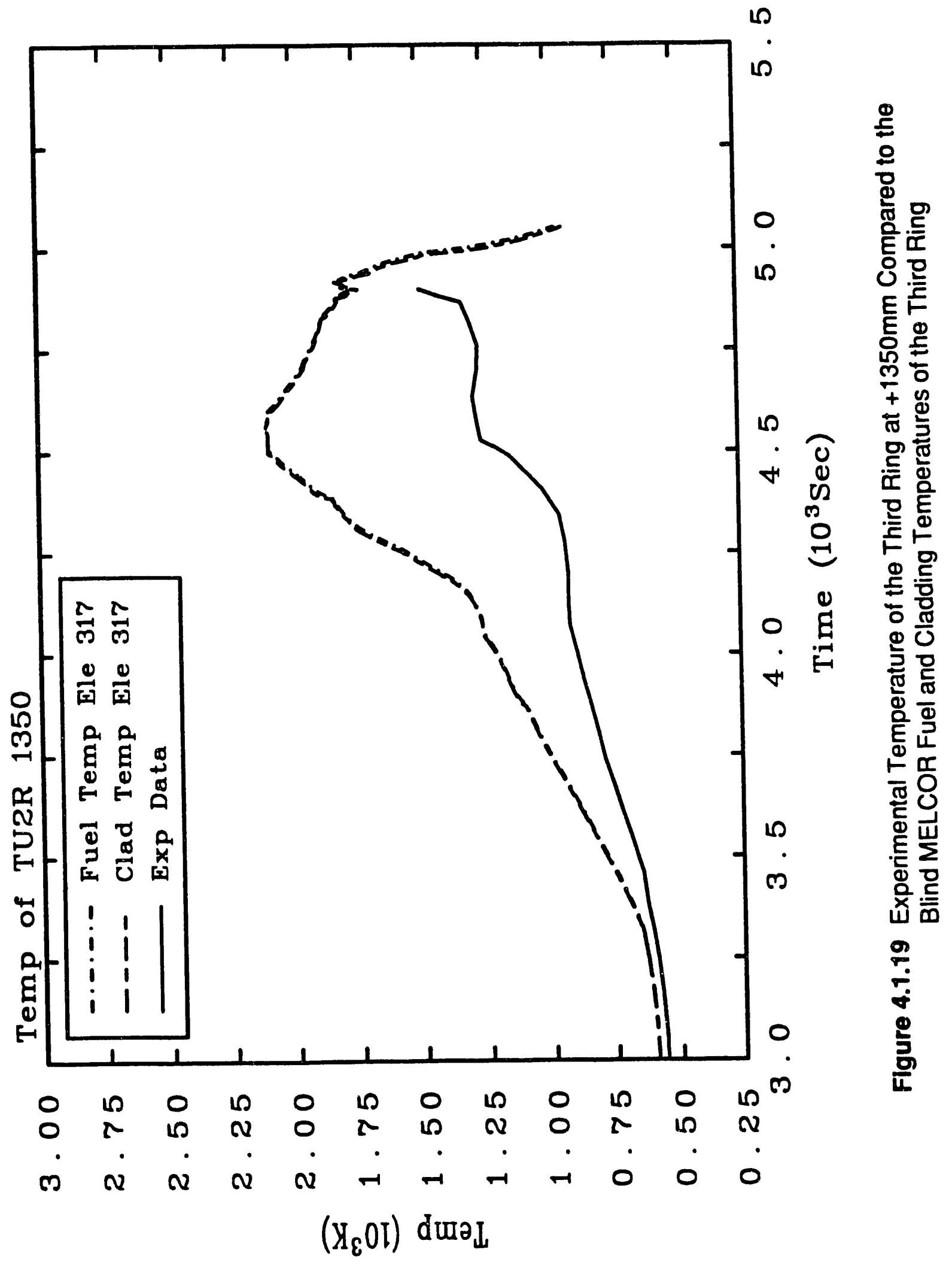




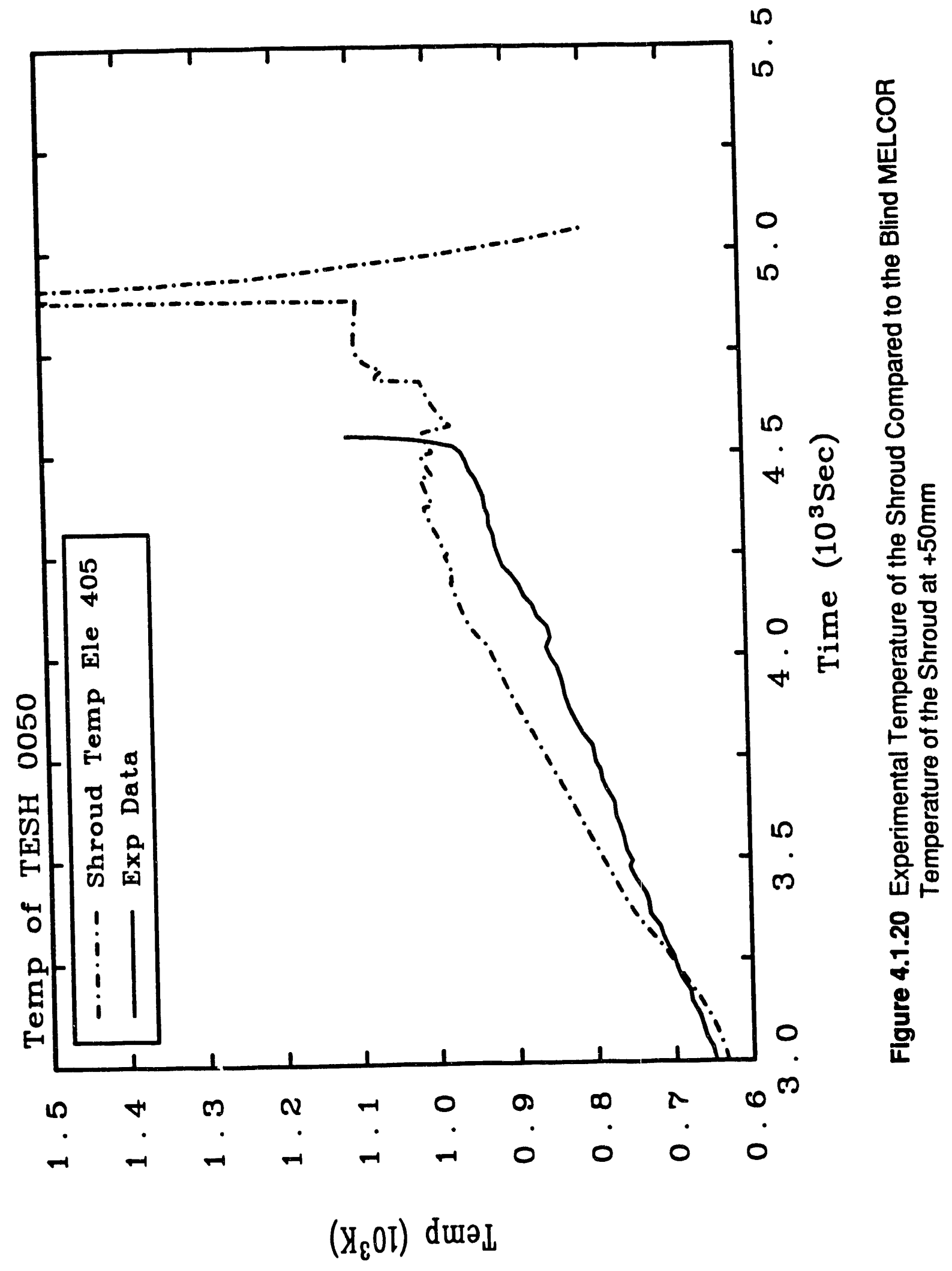




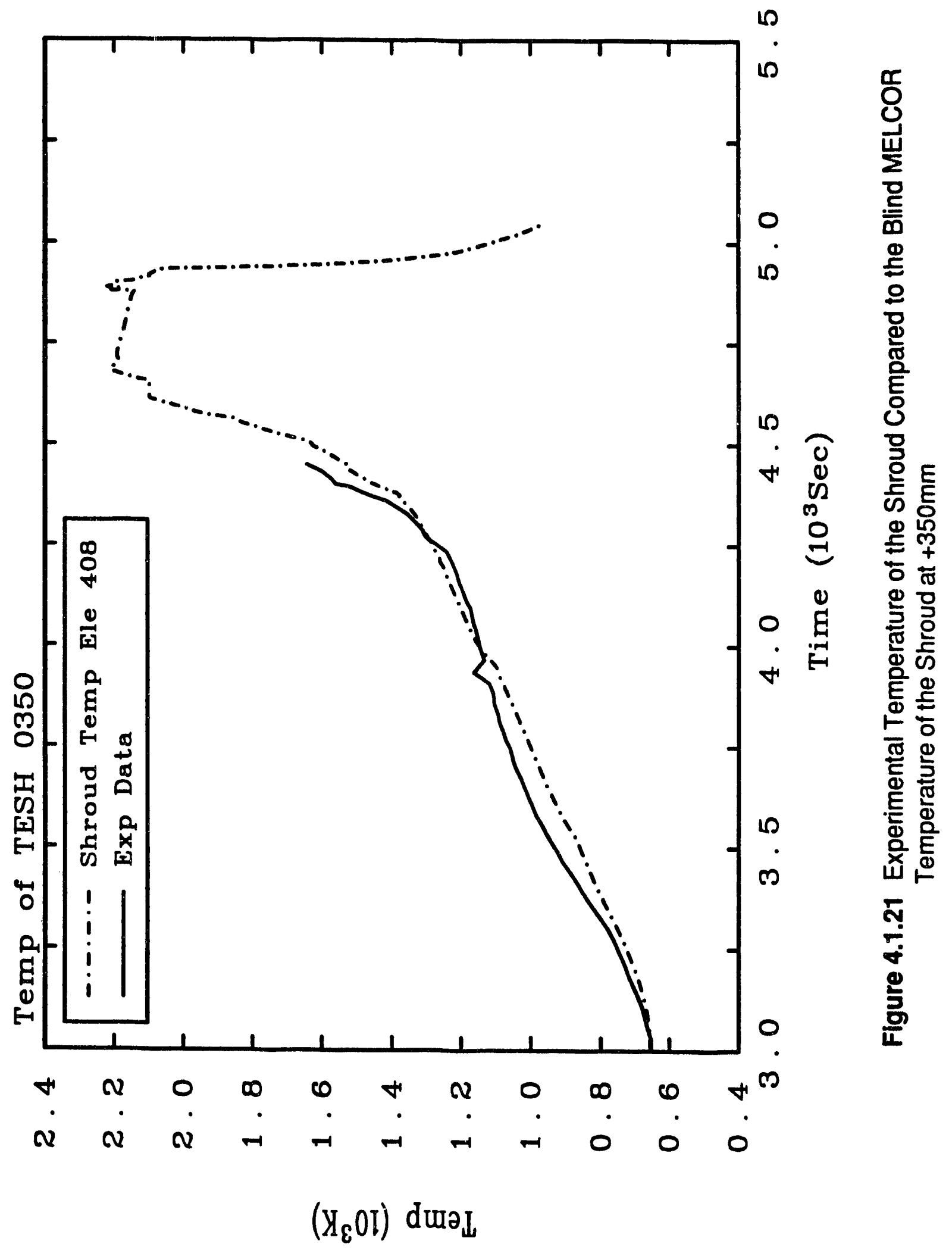




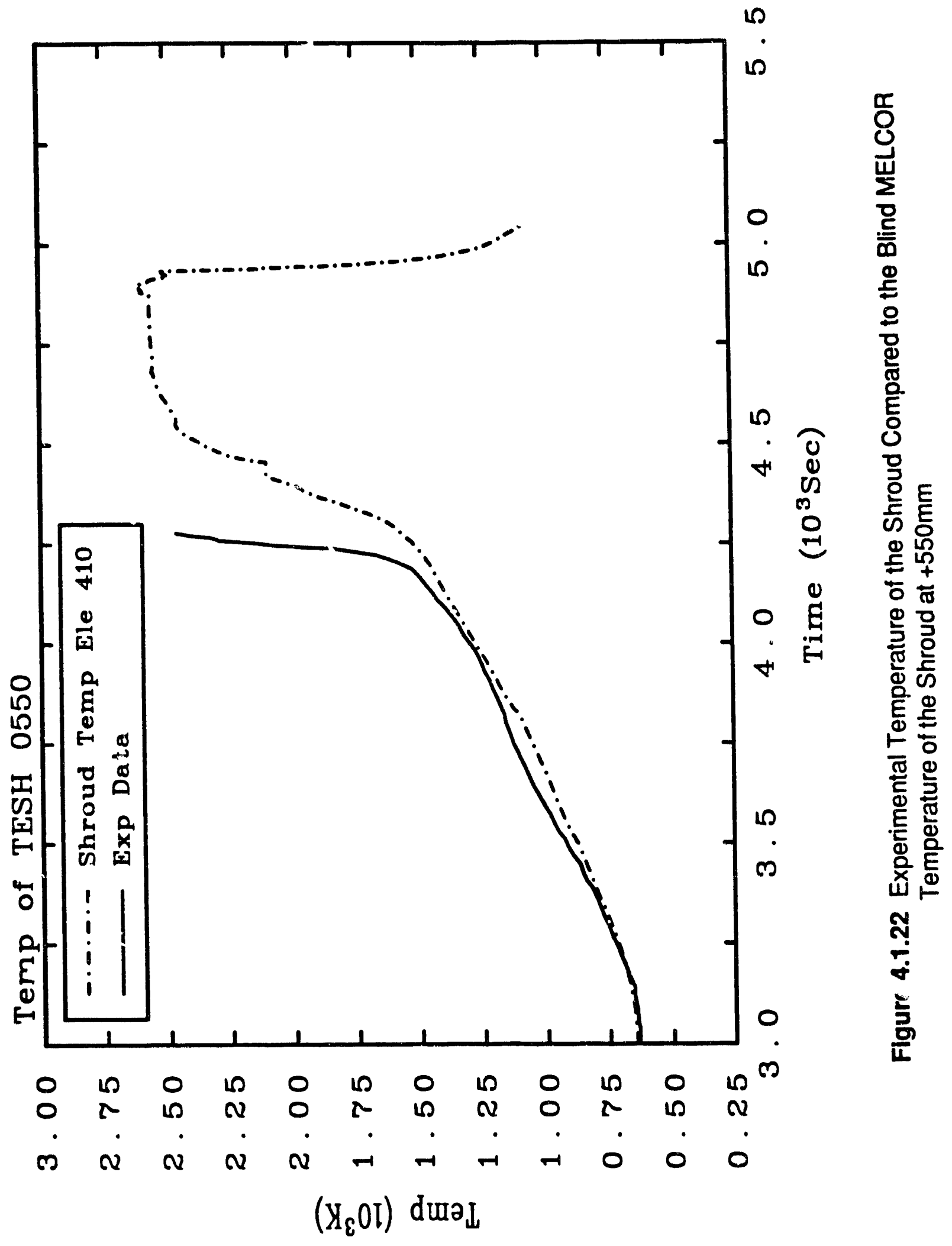




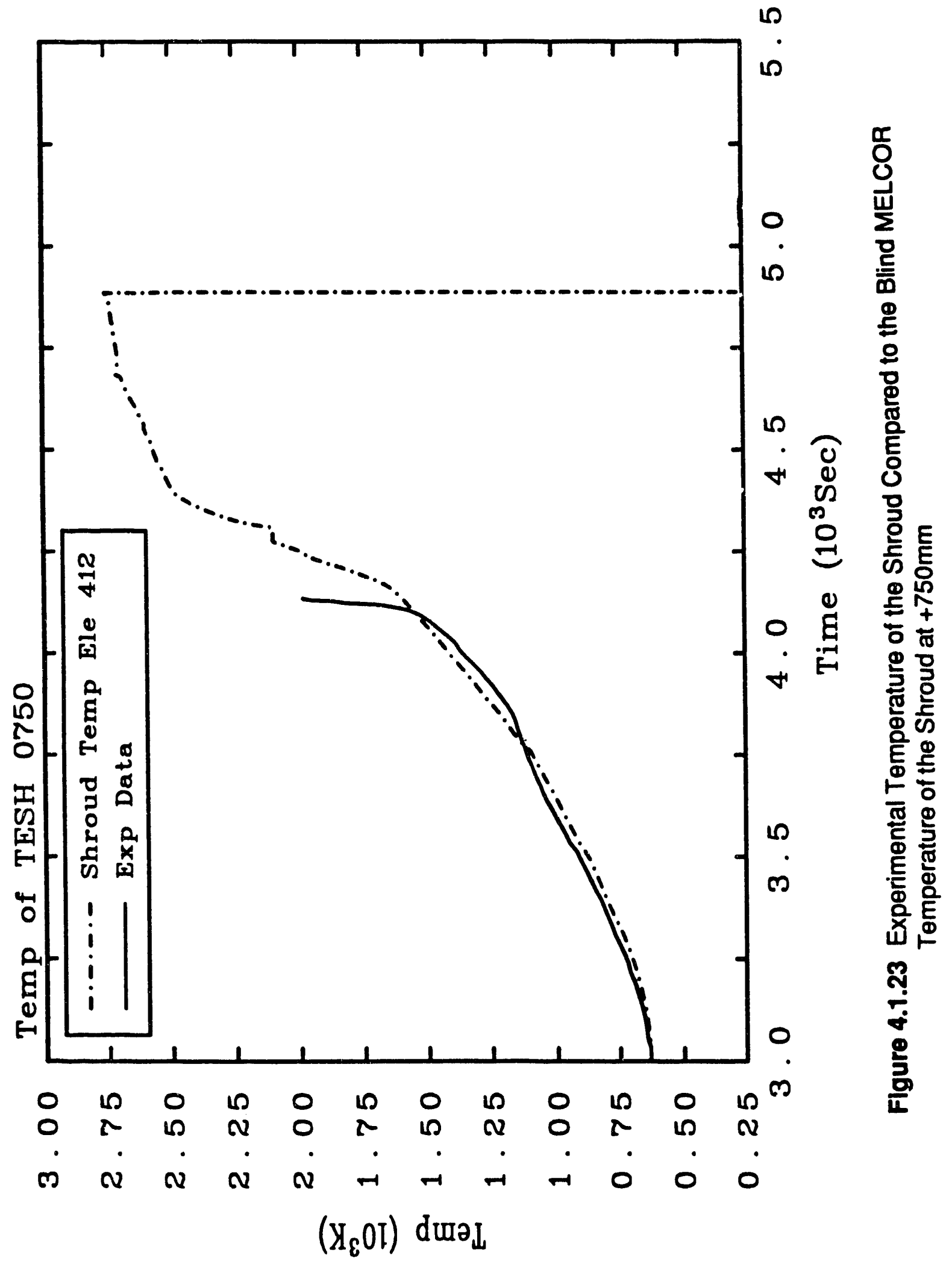




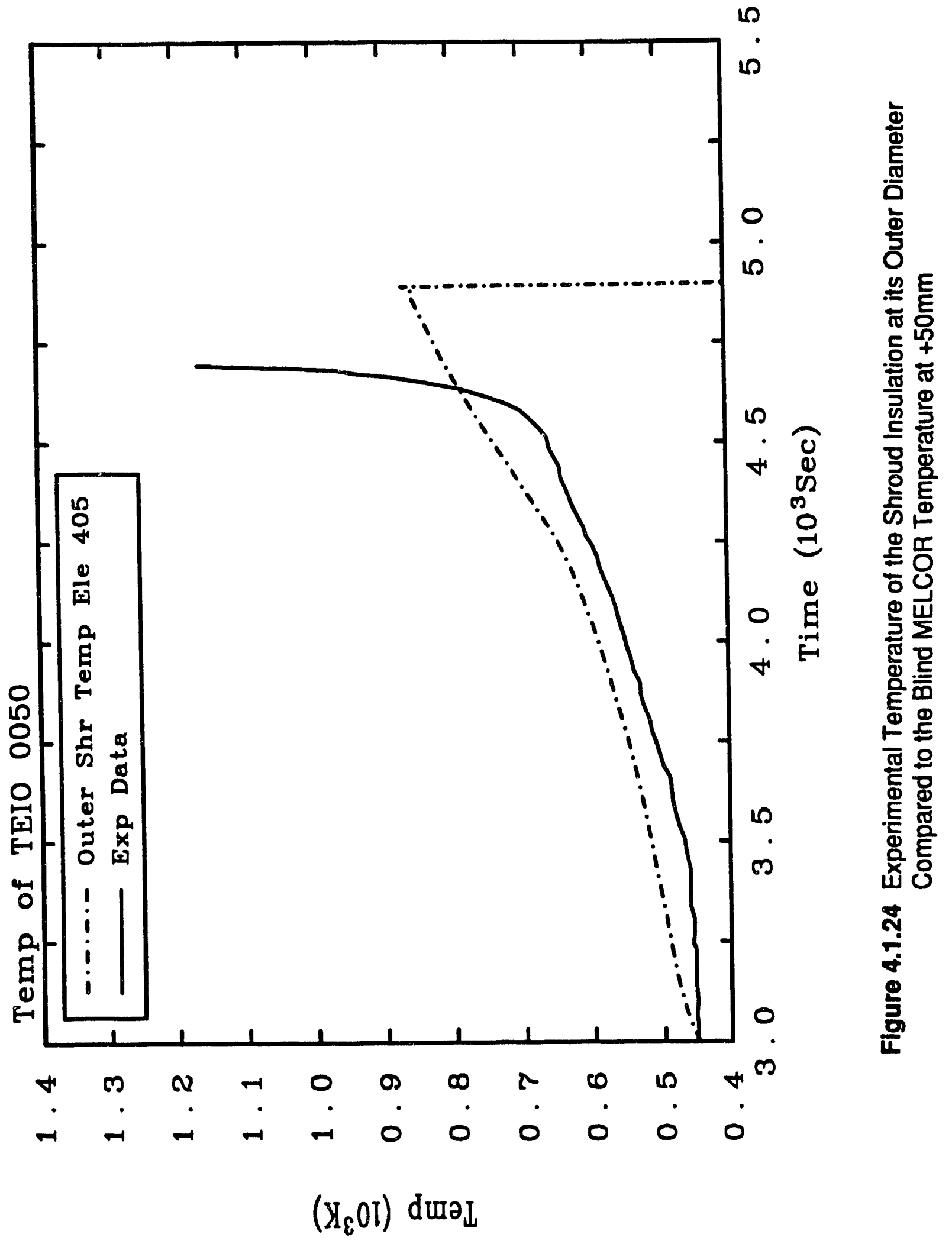




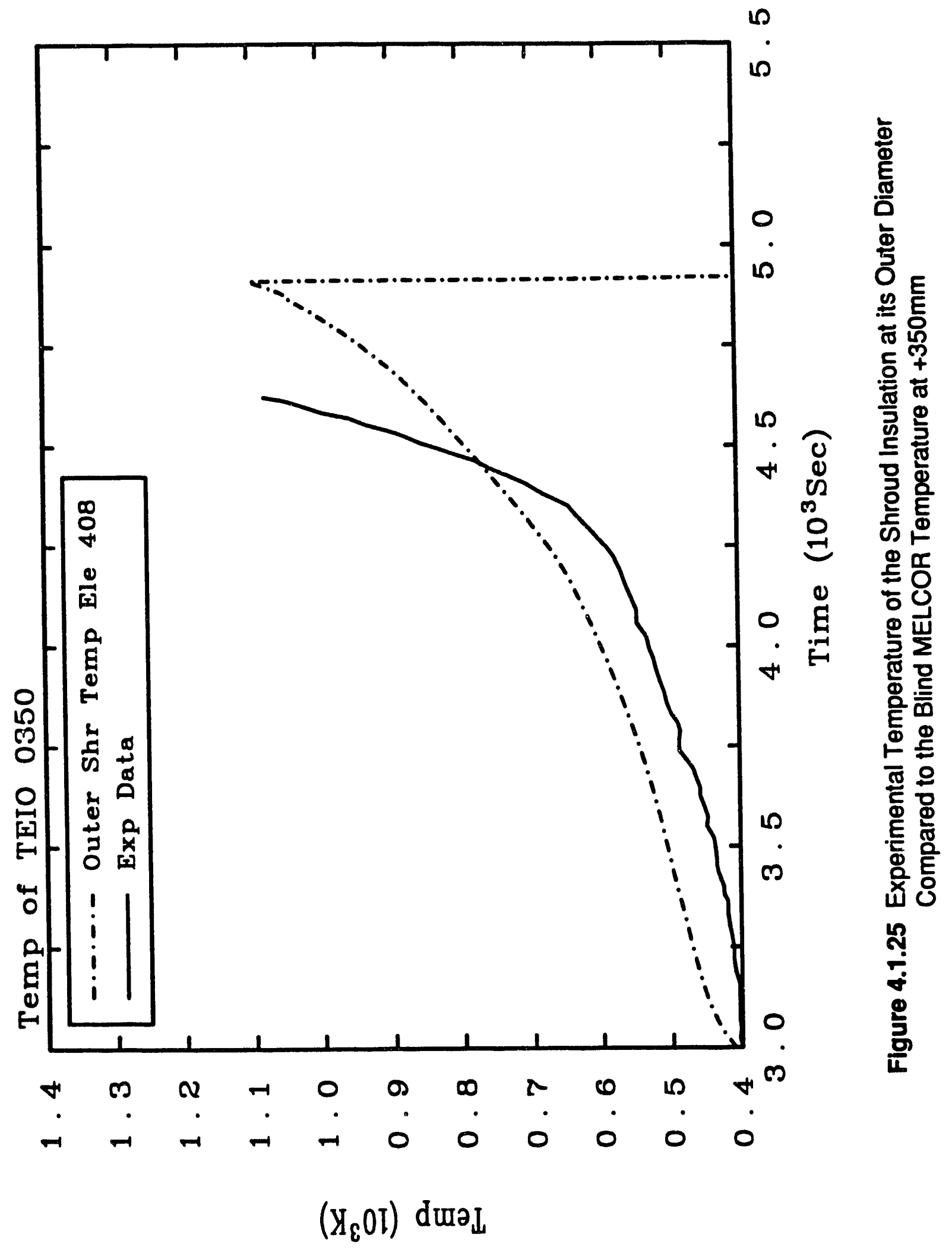




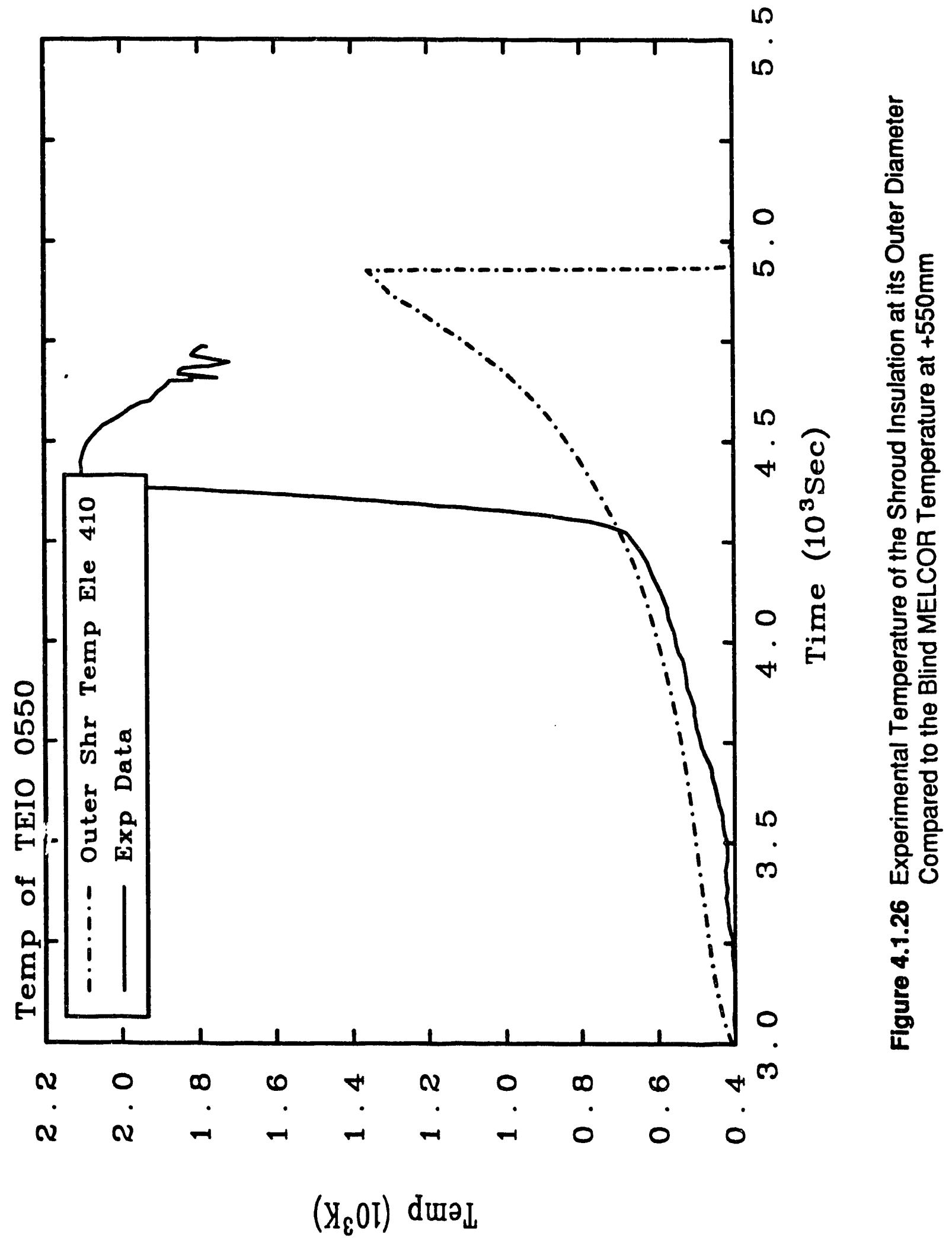




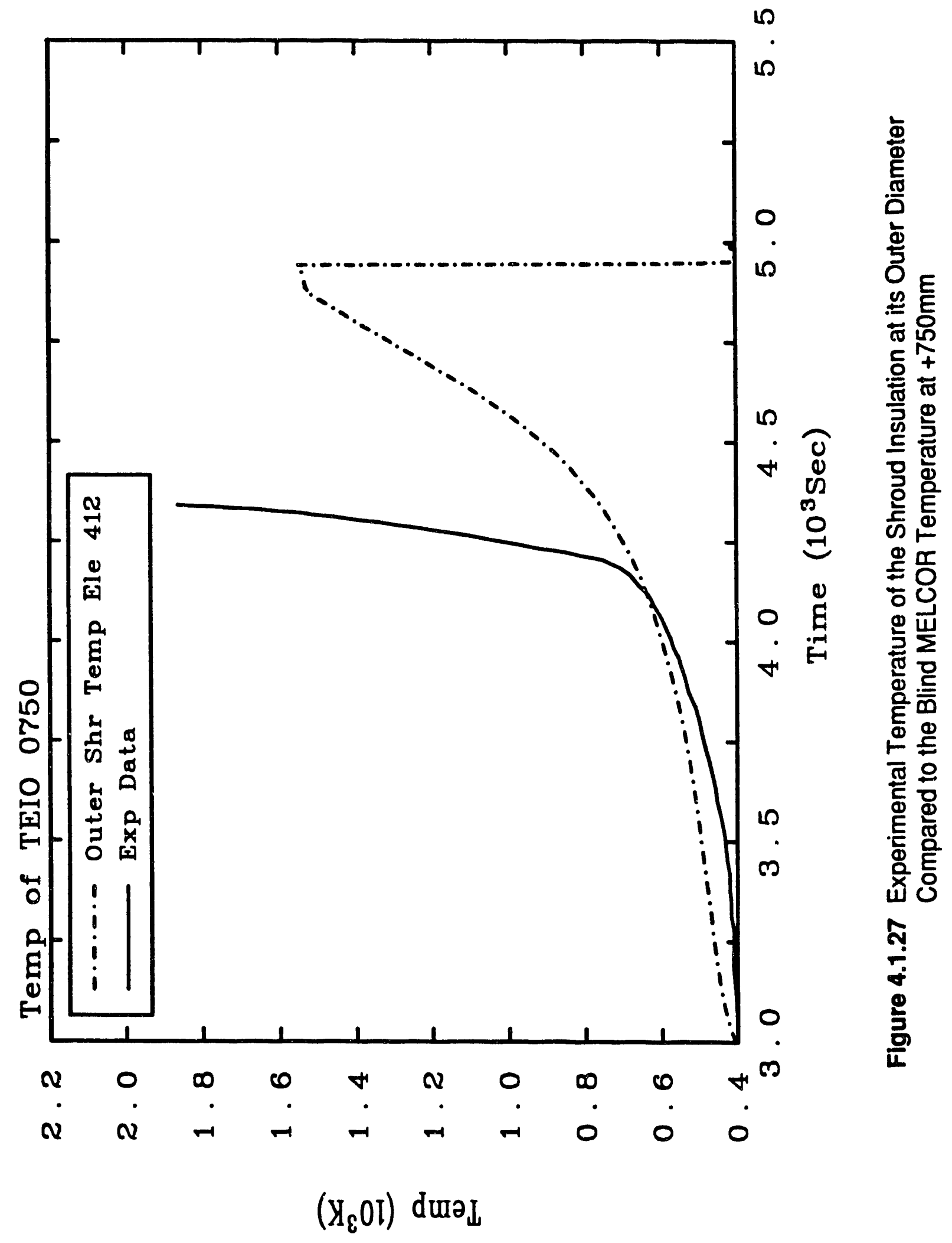


Table 4.1.1 Experimental and MELCOR Calculated Core Blockage

\begin{tabular}{c|c|c} 
Height & $100 *\left\{A_{i}(0)-A_{i}(t)\right\} / A_{i}(0)[E x p]$ & $100 *\left\{A_{i}(0)-A_{i}(t)\right\} / A_{i}(0)$ [MELCOR] \\
\hline$-150 \mathrm{~mm}$ & NA & +5.15 \\
$-50 \mathrm{~mm}$ & $N A$ & +11.82 \\
$+50 \mathrm{~mm}$ & $N A$ & +58.37 \\
$+150 \mathrm{~mm}$ & +13.7 & +47.14 \\
$+250 \mathrm{~mm}$ & +12.2 & +1.33 \\
$+350 \mathrm{~mm}$ & -2.2 & -10.64 \\
$+450 \mathrm{~mm}$ & +39.1 & -22.45 \\
$+550 \mathrm{~mm}$ & -15.1 & -24.34 \\
$+650 \mathrm{~mm}$ & -10.8 & -24.30 \\
$+750 \mathrm{~mm}$ & -7.9 & -24.33 \\
$+850 \mathrm{~mm}$ & -16.5 & -29.15 \\
$+950 \mathrm{~mm}$ & -15.1 & -24.22 \\
$+1050 \mathrm{~mm}$ & -7.9 & -6.62 \\
$+1150 \mathrm{~mm}$ & -3.6 & -0.62 \\
$+1250 \mathrm{~mm}$ & +0.7 & +3.35
\end{tabular}

Time-dependent experimental core blockage data was not available. A post-test epoxy process was used to determine the core blockage axially through the core. This process only gave the core blockage at the end of the experiment, and data below about $+75 \mathrm{~mm}$ in the core could not be obtained. Table 4.1.1 compares the final experimental and MELCOR core blockage. The experimental values were given in [7]. As specified in [5], the percentage of core blockage was defined as:

$$
100 *\left\{A_{i}(0)-A_{i}(t)\right\} / A_{i}(0)
$$

where $A_{i}(t)$ is the open flow area available for the fluid at level $i$ and time $t$, and $A_{i}(0)$ is the initial flow area available for the fluid at level $i$. Note that the above definition is not that used in [7], which provides a curve showing the ratio of solid area to the total available area in a cross section.

The experimental data showed that, as expected, a significant amount of material relocated from an axial height of +550 to about $+1050 \mathrm{~mm}$ to the lower grid spacer in the +400 to $+500 \mathrm{~mm}$ region and also in the +75 to $+350 \mathrm{~mm}$ region. MELCOR predicted that material in the +350 to $+1050 \mathrm{~mm}$ region relocated primarily in the +50 to $+150 \mathrm{~mm}$ axial height region, which was, on average, lower than experiment. Also, MELCOR predicted that somewhat more material was relocated. 
Energy loss radially in the experiment through the shroud and thence to bypass flow and heat transfer through the high temperature insulation was about $10 \%$ of the total, thus supporting the claim that the experiment was well-insulated. There was a significant axial temperature gradient at the inner surface of the high temperature insulation, as Figure 4.1.28 shows. Furthermore, because of the windows and perhaps for other unknown reasons, there was a significant circumferential temperature variation in the high temperature insulation. The MELCOR model used only one heat structure for the entire axial extent of the high temperature insulation - from -200 to $+1000 \mathrm{~mm}$. Thus, only one MELCOR temperature was available to compare to the rather extensive results from [7] available for the high temperature insulation. In comparing Figure 4.1.29, which shows the MELCOR result, to Figure 4.1.28, note that the MELCOR temperature curves follows the result for the $+590 \mathrm{~mm}$ curve fairly well. The $590 \mathrm{~mm}$ level temperature curve in Figure 4.1.28 appears to be close to the axial temperature average for the high temperature insulation. The fact that the MELCOR result agrees with this "average" so well at least implies that, on average, MELCOR agreed with experiment fairly well for the radial heat loss. 


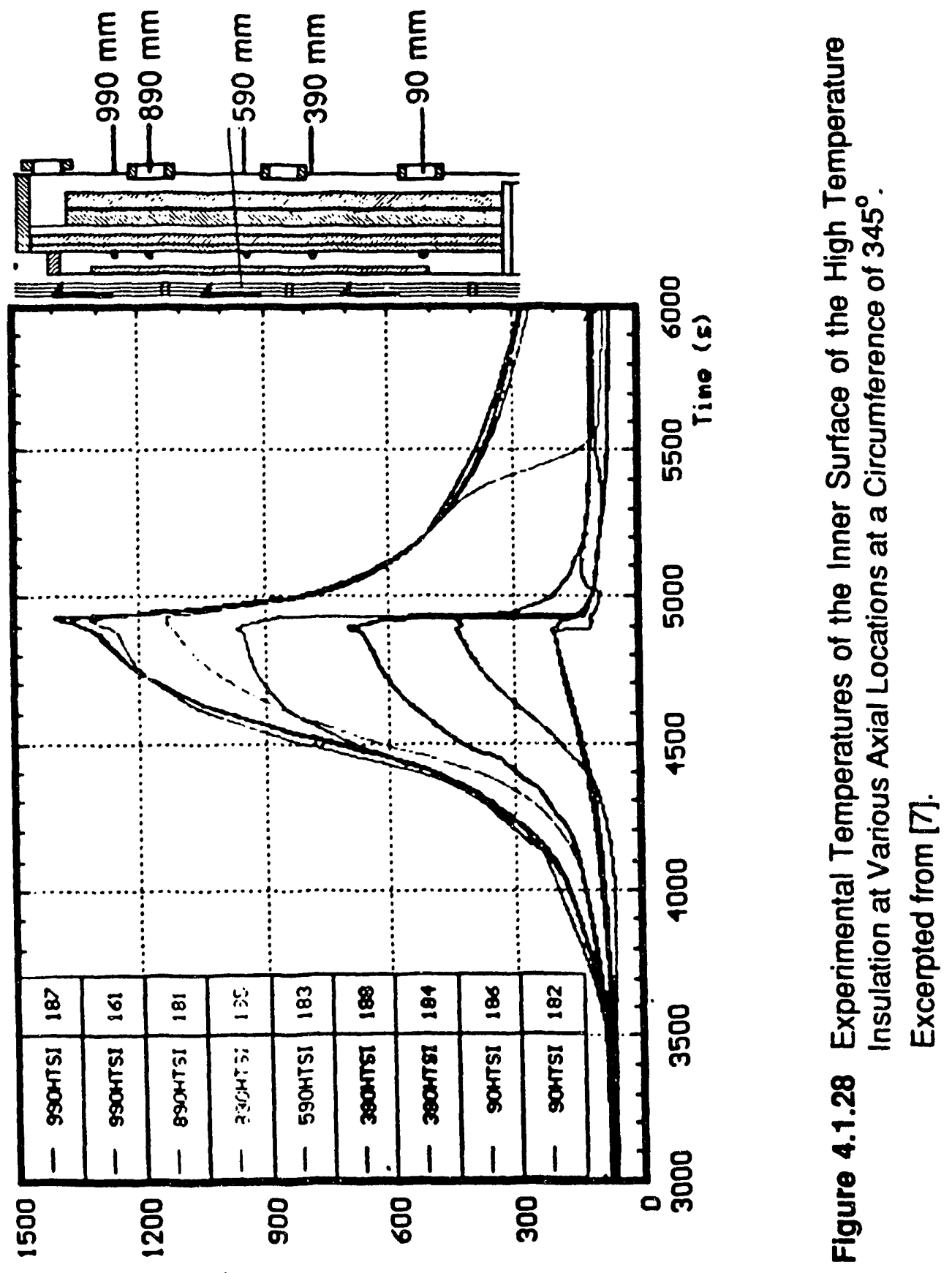




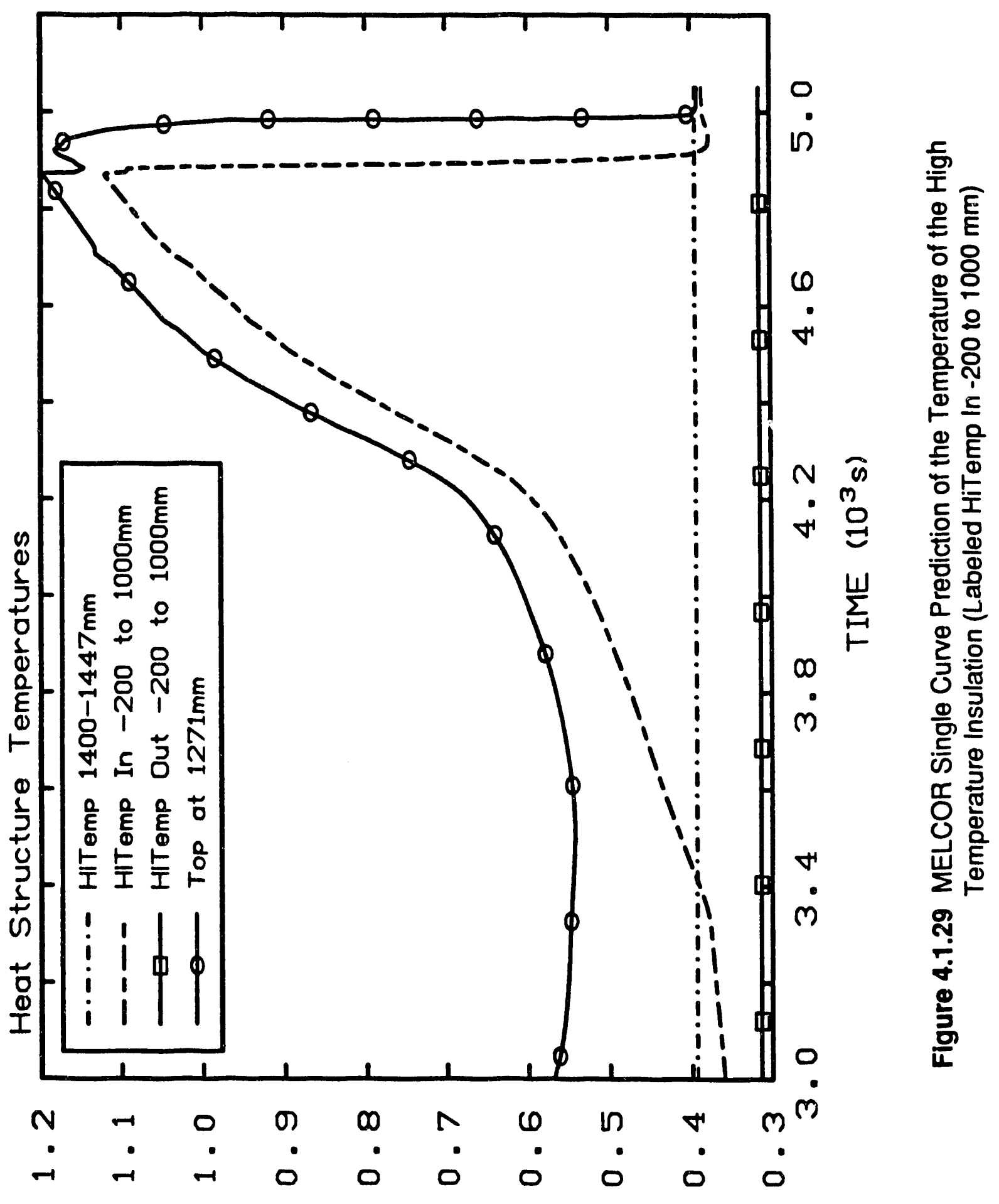

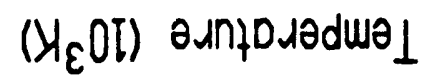


A general observation concerning almost of the MELCOR data, including the rod temperatures, was that they ran higher than the experimental data up to the point of quench, especially in the upper regions. After oxidation become important, some time after 4100 seconds depending on the axial level in the core, the higher temperatures can be explained by the earlier and higher oxidation rates (See Figure 4.1.3). It does not, however, explain the consistently higher MELCOR temperatures prior to oxidation. Global energy production in the core up to oxidation was matched very well. As also seen, MELCOR predicted radial heat losses fairly well, so the model did not over-insulate the core.

\subsection{Comparison to Other Codes}

Other codes used to predict the ISP31 Problem were SCDAP/RELAP5, a code developed by the Idaho National Engineering Laboratory, USA; ICARE2, a code developed by the Commisariat à L'Energie Atomique in France; KESS-III, a code from the Institut für Kemenergetik und Energiesysteme in Germany; and FRAS-SFD, from the Nuclear Research Institute Rez in Czechoslovakia. Five participants from the United Kingdom, Netherlands, Japan, Korea, and Finland used the SCDAP/RELAP5 code. A limited number of results comparing the results of all the participants along with the experimental data in some cases were published in [7]. Table 4.2.1 identifies the three-letter designator used in the figures to the country and which code was used.

Figure 4.2.1 shows the measured bundle power and the corresponding results of the various submittals. Only two others (ECN, IKE) besides the SNL MELCOR results included the external resistance. Five of the calculations (AEA, ECN, IKE, NRI, SNL) followed the measured data quite well, while two others (CEA, JAE) used a lower estimate of heating power and two (KAE, VTT) deviated considerably and shut power off considerably earlier than the time specified.

Steam inlet flow resulted from a water feed flow of $6 \mathrm{~g} / \mathrm{s}$ between 3300 and 4900 seconds with a time constant of about 100 seconds. Figure 4.2.2 shows that NRI used this value. Five participants (AEA, IKE, JAE, KAE, SNL) chose a shorter time constant, while three (CEA, ECN, VTT) used a much larger time constant which underestimated the steam flow. Although not shown, the inlet temperature was correctly used by all but one (ECN) participant. 


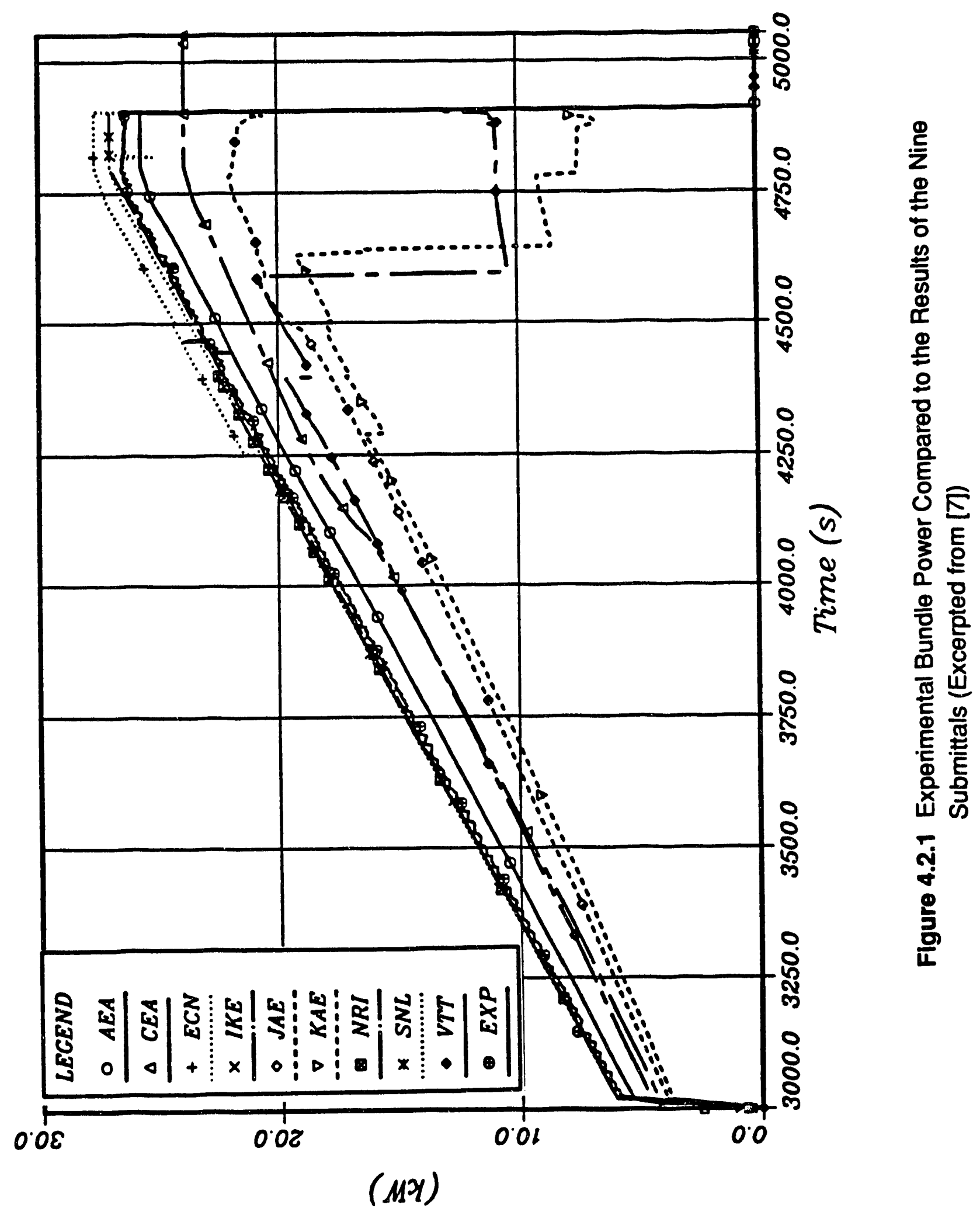




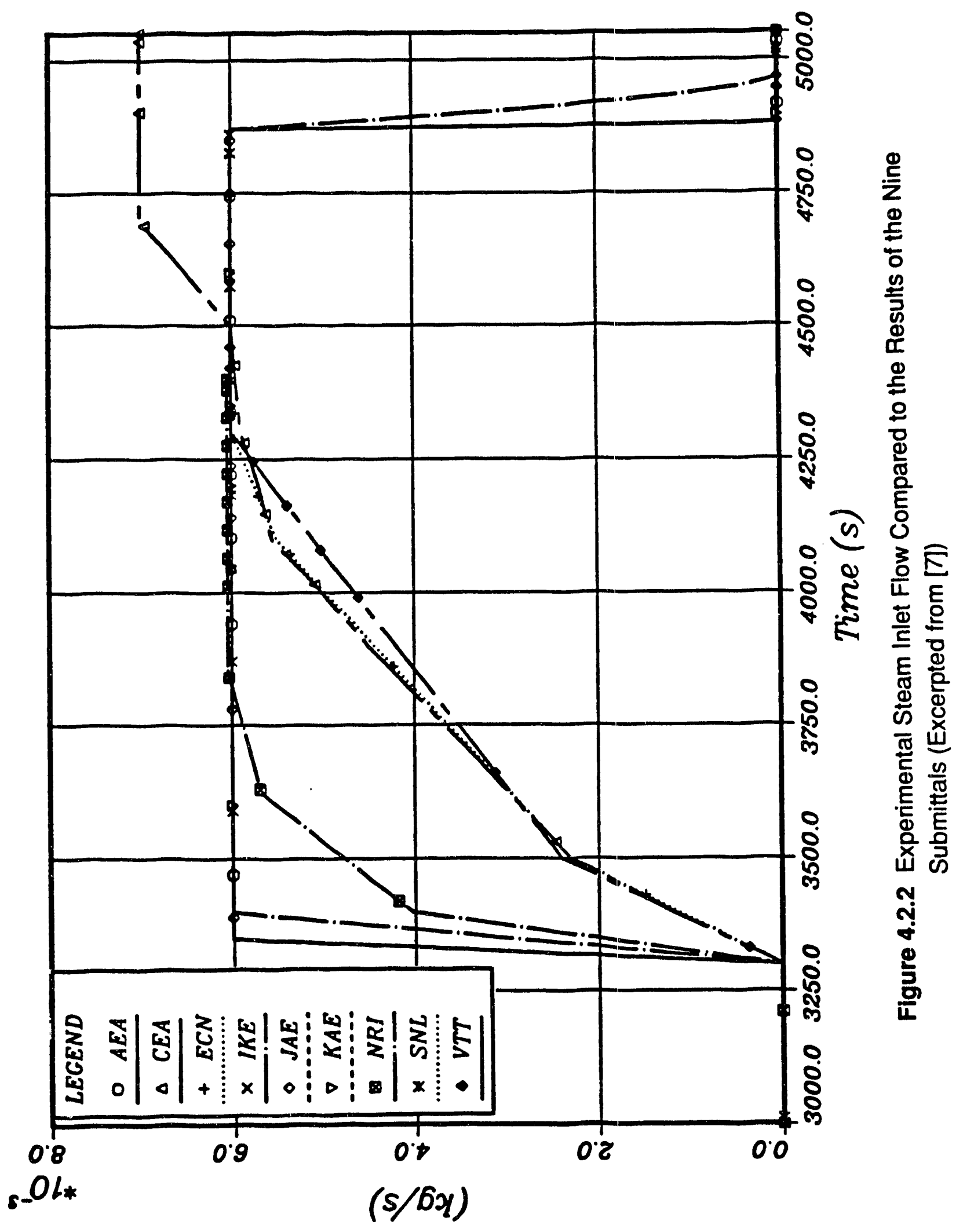


Table 4.2.1 Organizations and Computer Codes Used for ISP31

Organization

AEA Reactor Services, UK

Commisariat à L'Energie Atomique

France

Netherlands Energy Research

Foundation

Institut für Kernenergetik und

Energiesysteme, Germany

Japan Atomic Energy

Research Institute

Korea Atomic Energy

Research Institute

Nuclear Research Institute Rez

Czechoslovakia

Sandia National Laboratories

USA

Technical Research Centre of Finland
Computer Code

Designator

SCDAP/RELAP5/MOD2.5 AEA

ICARE.2

CEA

SCDAP/RELAP5/MOD3

ECN

KESS-III

IKE

SCDAP/RELAP5

JAE

SCDAP/RELAP5/MOD2.5 KAE

FRAS-SFD

NRI

MELCOR 1.8.0

SNL

SCDAP/RELAP5/MOD2.5

VTT

Figure 4.2.3 shows the temperature of a heated rod (second MELCOR ring) at an axial level of $+750 \mathrm{~mm}$. As mentioned in [7], the experiment was quite well predicted during the heat up period. Figures 4.2.4 to 4.2.7 display further fuel temperature at different axial heights in the bundle. A comparison of Figure 4.2.3 and 4.2.7 shows that ECN and JAE predicted large temperature difference between the heated and unheated rods, while the other codes predicted temperature differences of about $100 \mathrm{~K}$, which agreed fairly well with the measured temperature differences. KAE and VTT underpredicted rod temperatures, which was surmised in [7] to perhaps their underprediction of bundle power. AEA, CEA, IKE, NRI, and SNL were in good agreement with the experimental data. 


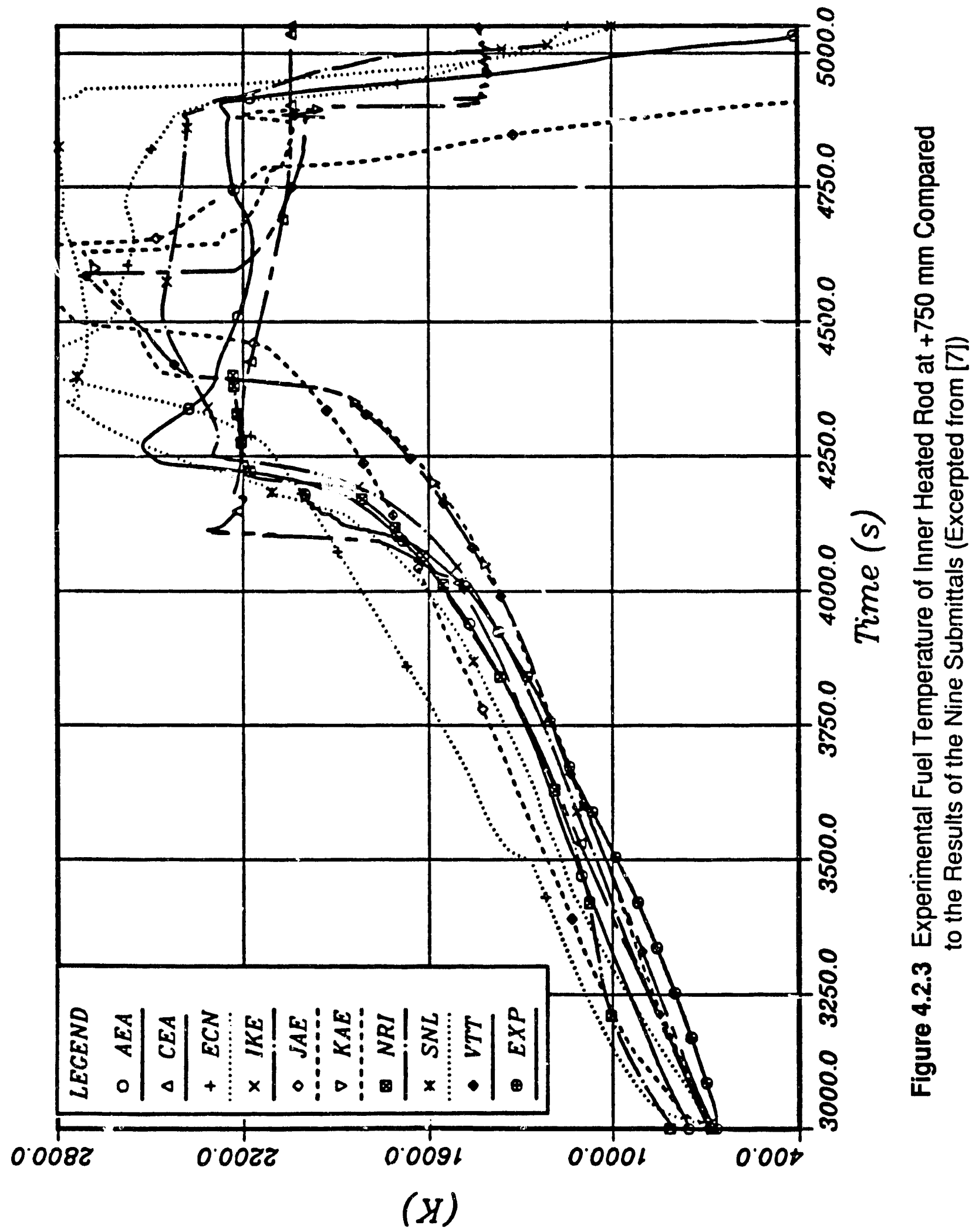




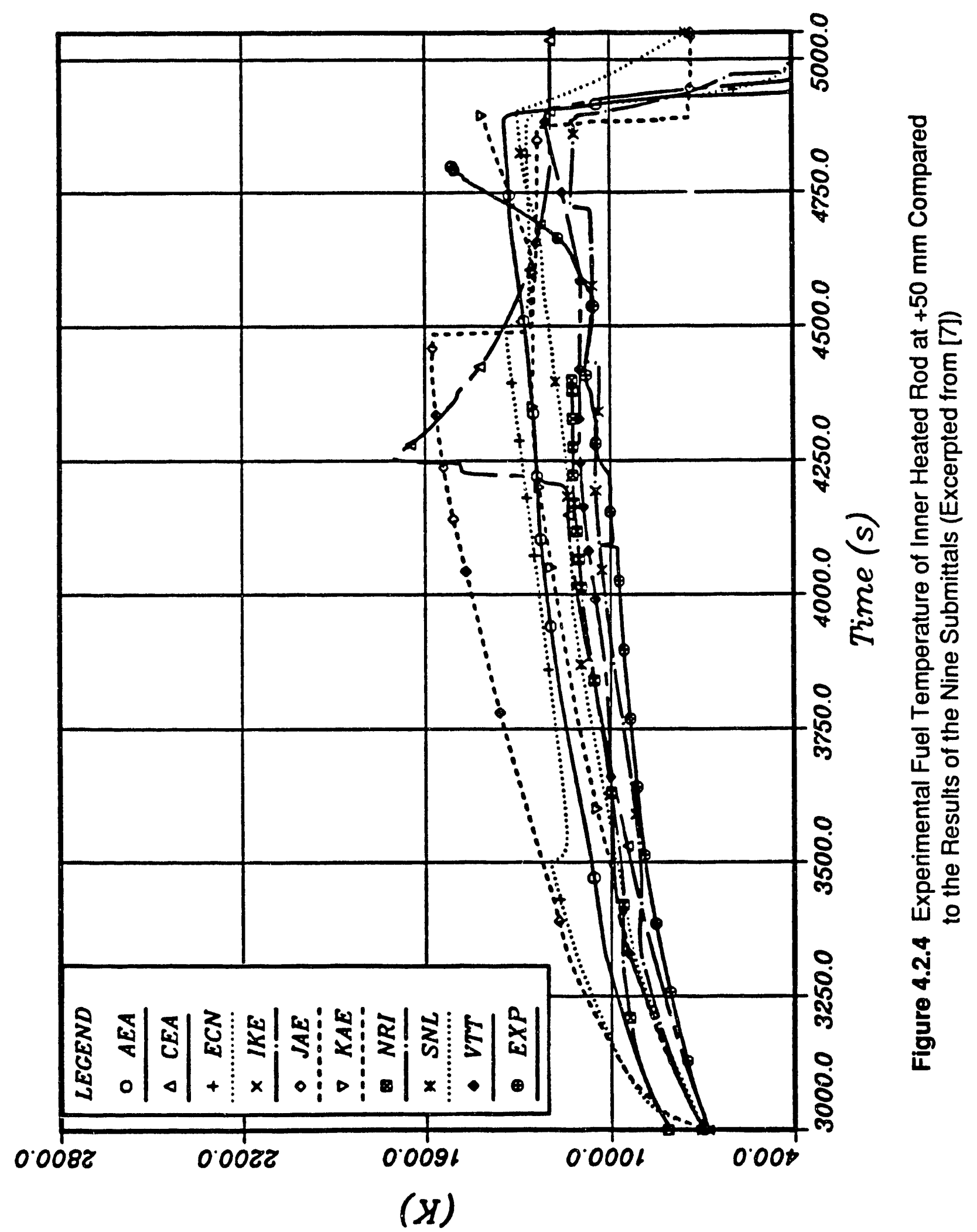




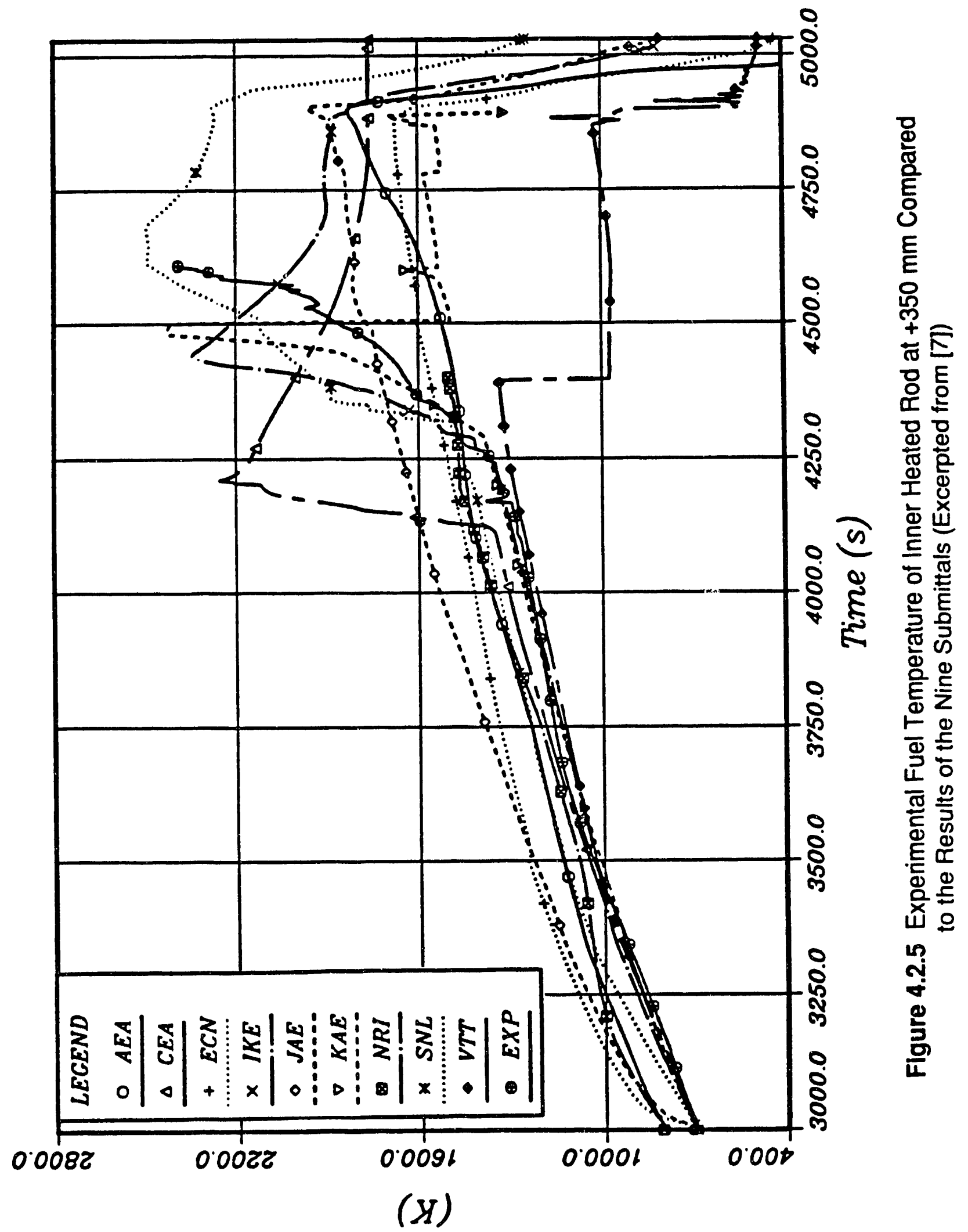




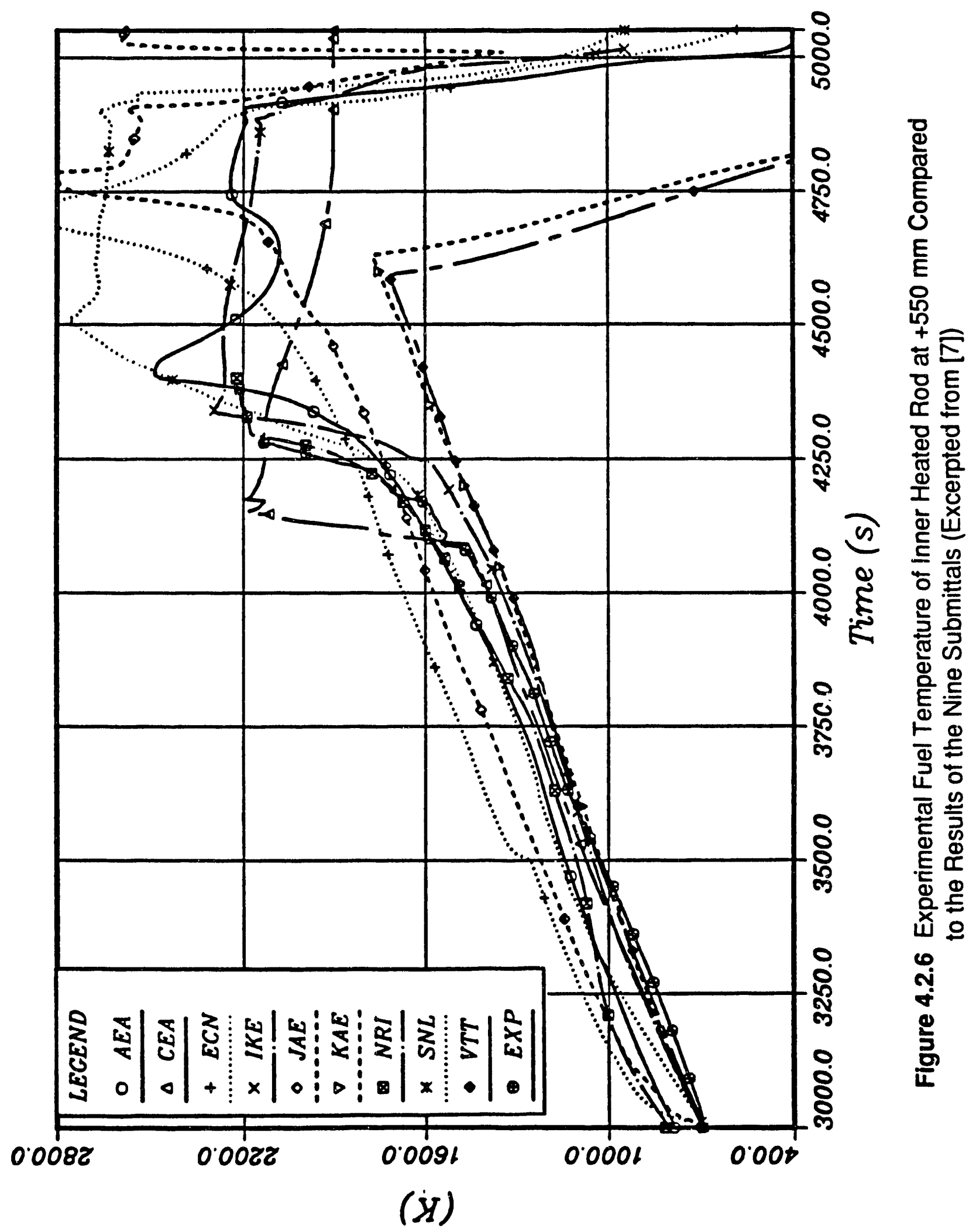




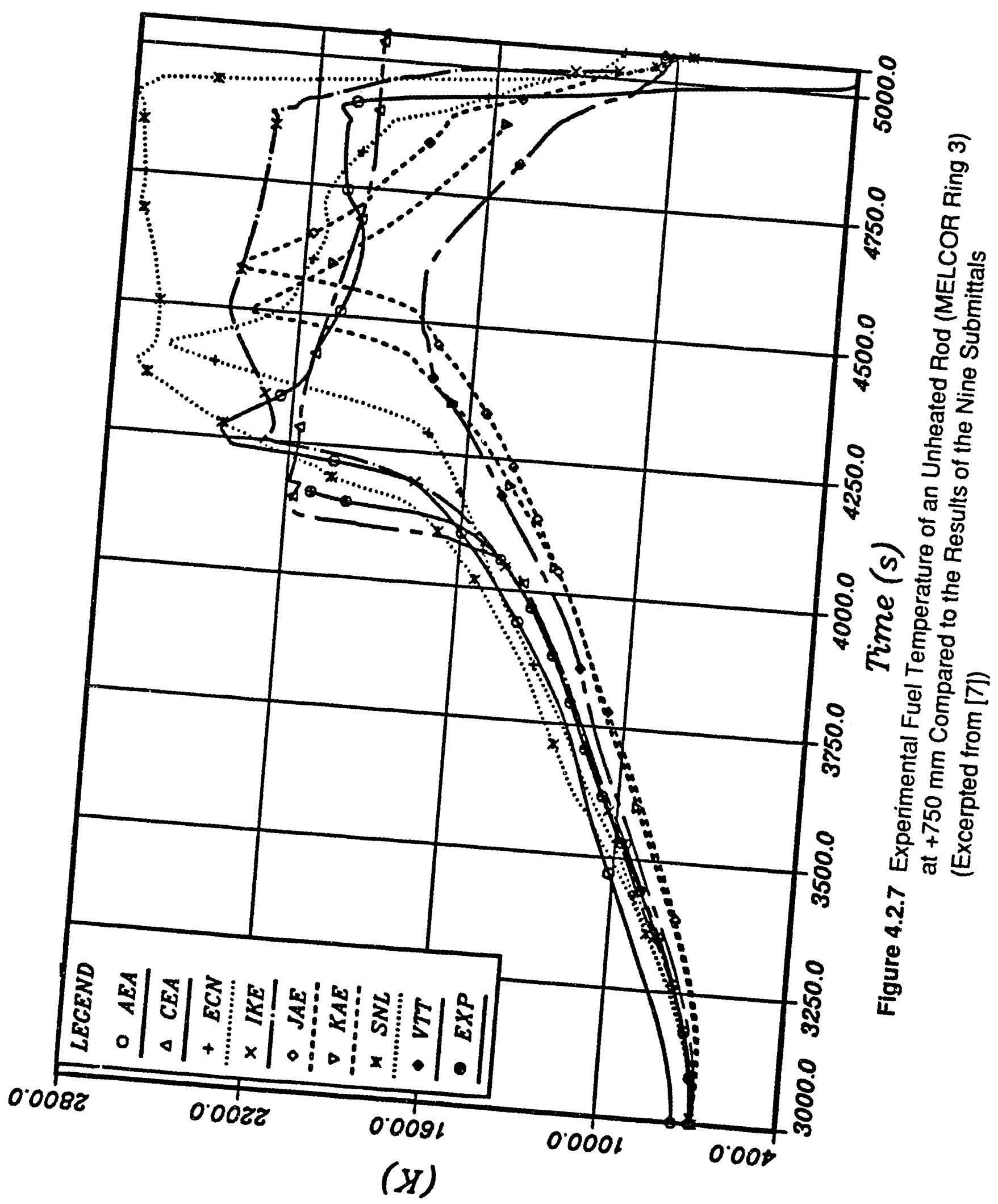


Cladding temperatures at various axial heights in the bundle are shown in Figures 4.2.8 to 4.2.12. In four of the predictions, the temperature is underpredicted and the temperature escalation was significantly delayed (ECN, JAE) or not even reached (KAE, VTT). Although the experimental results is shown only in Figure 4.2.8, the MELCOR prediction was in very good agreement with the data.

The inner high-temperature insulation temperature at an axial height of $+550 \mathrm{~mm}$ is shown in Figure 4.2.13. As reported in [7], two calculations (IKE, SNL) follow the measured data quite well, while AEA and KAE do not show the temperature increase at 4300 seconds.

The fluid temperature at axial height $+750 \mathrm{~mm}$ is shown in Figure 4.2.14. Qualitatively, in four calculations (AEA, CEA, NRI, SNL) the fluid temperature followed the shroud temperature quite well, while the others (IKE, JAE, KAE, VTT) showed much lower temperatures.

Figures 4.2.15 to 4.2.20 display some of the quantities describing the core degradation. Experimental data at the present time was not available. Some of the submittals obviously did not provide results for some of this requested data. There was a considerable scattering of data in the predictions. The one result that several codes seemed to agree was the $\mathrm{UO}_{2}$ total mass (Figure 4.2.18).

Finally, the accumulated hydrogen generation in the bundle and shroud is shown in Figure 4.2.21. For the codes, most of the hydrogen was produced during the time of the temperature excursion during initial oxidation, and very little during the quench phase. Only ECN and SNL appeared to predict close to proper quantities of hydrogen. Rates (the slopes) were matched fairly well by these two codes, although they were early in their prediction.

As reported in [7], all the codes: (1) overpredicted the oxidation during the temperature escalation phase; (2) underpredicted the oxidation during the high temperature phase when melting and relocation occurred; and (3) did not simulate the oxidation during quench when embrittlement and fragmentation took place. 


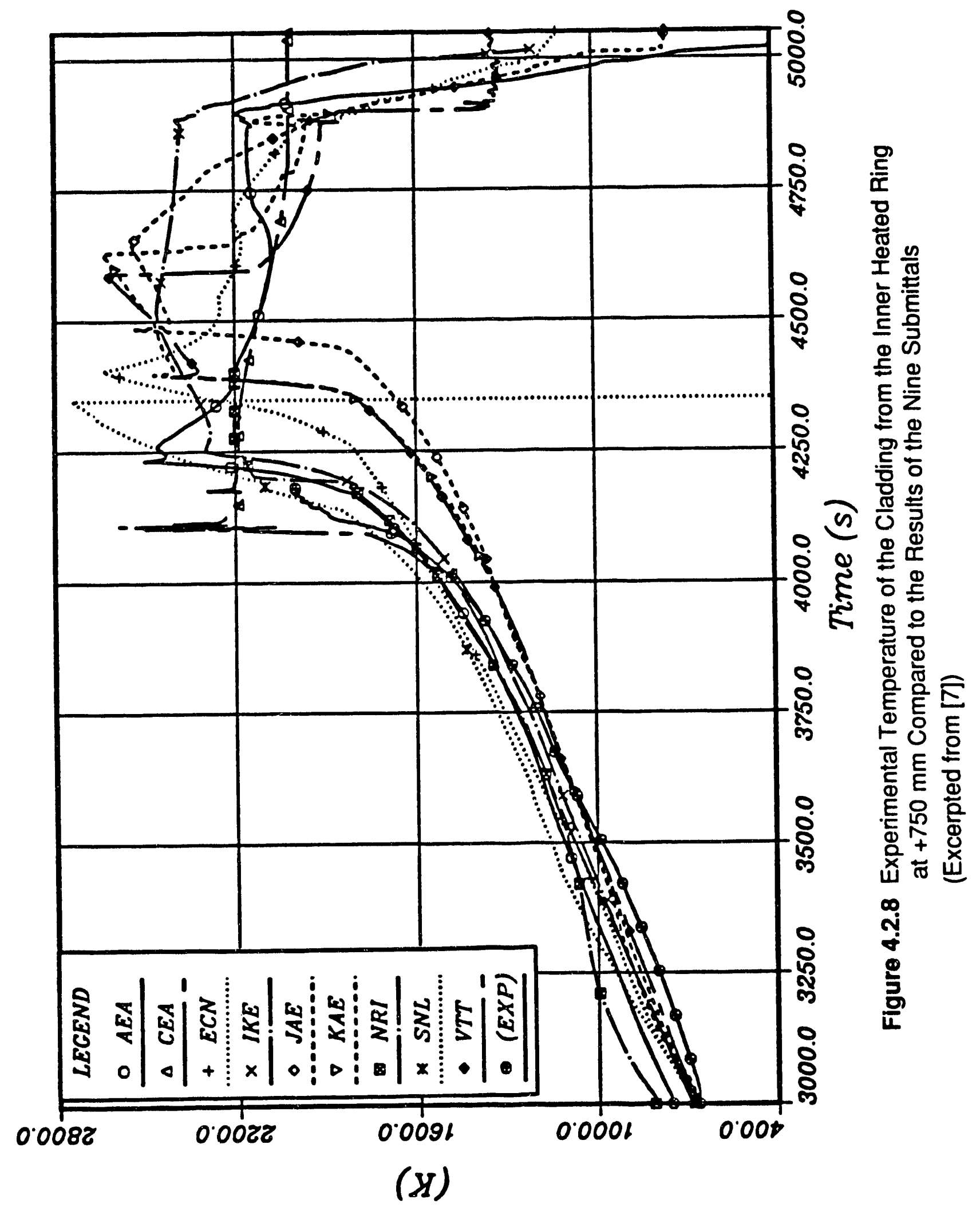




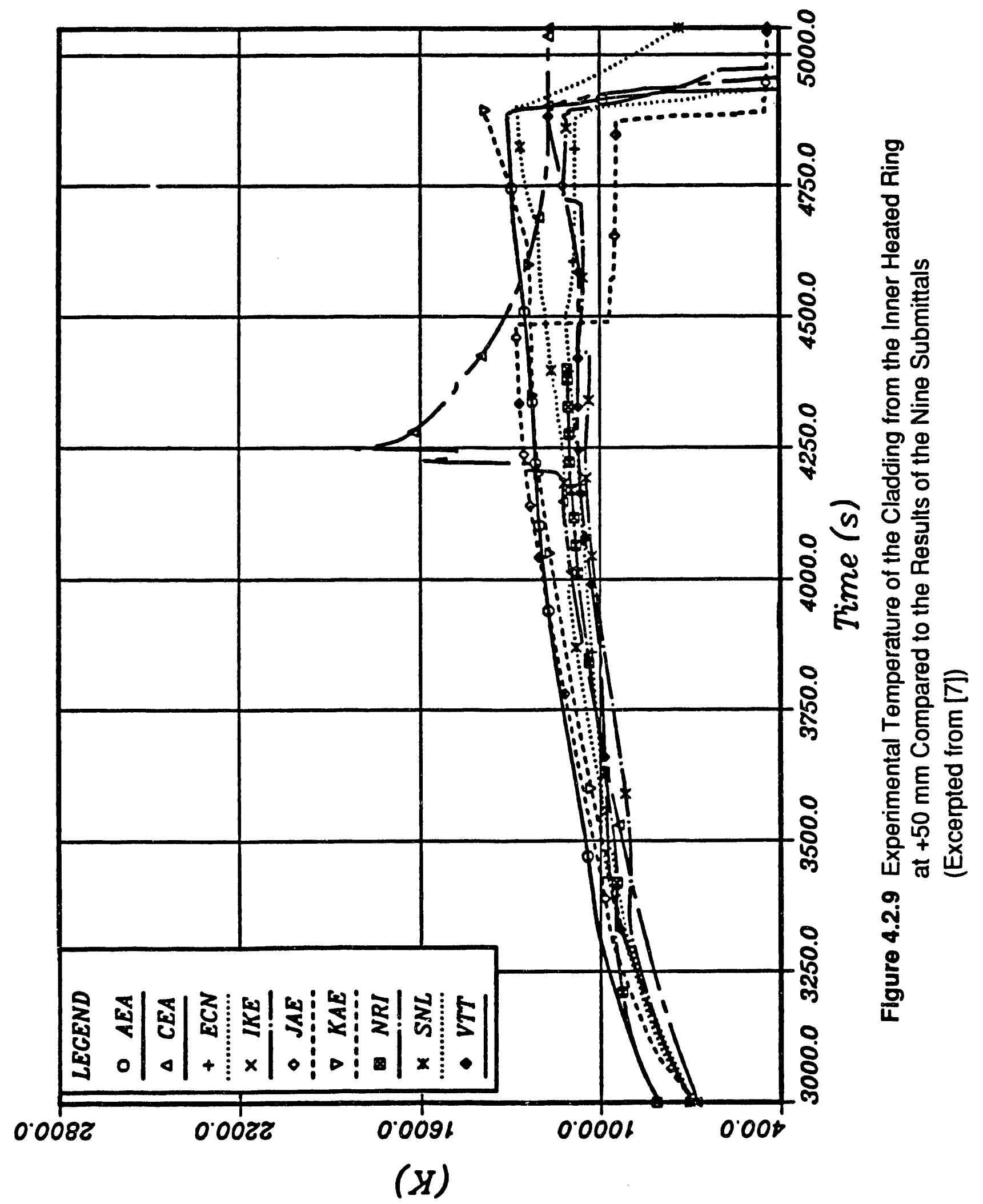




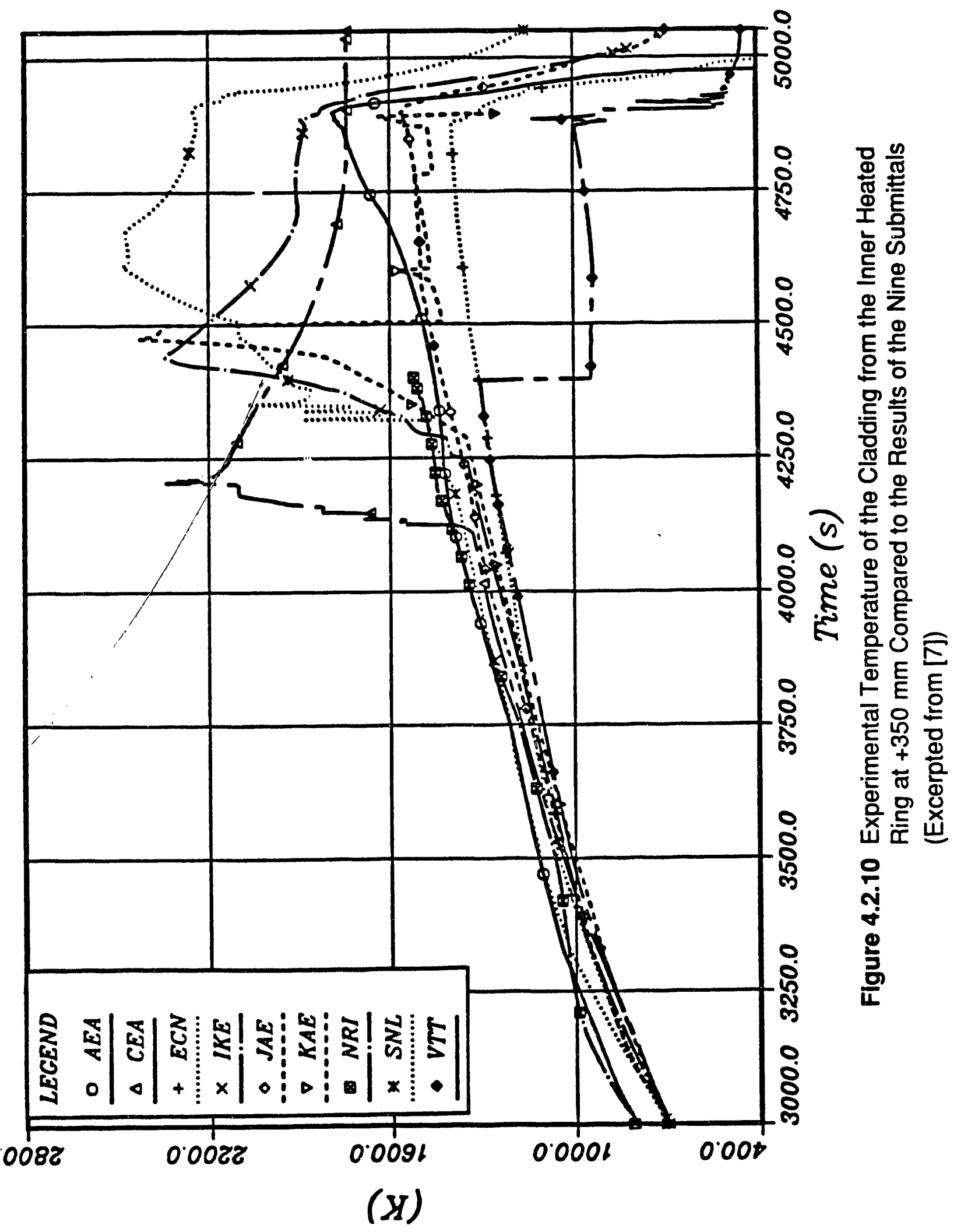




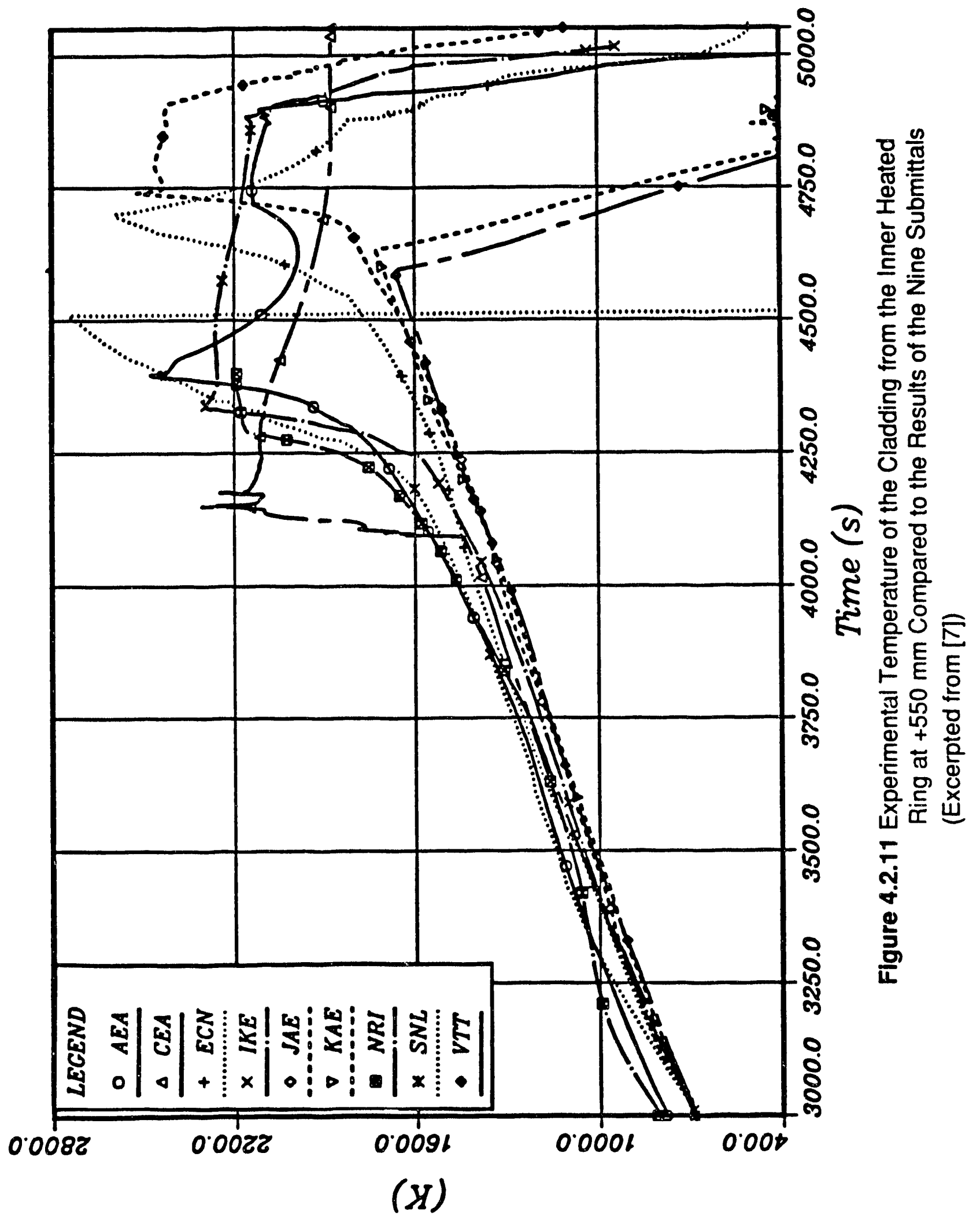




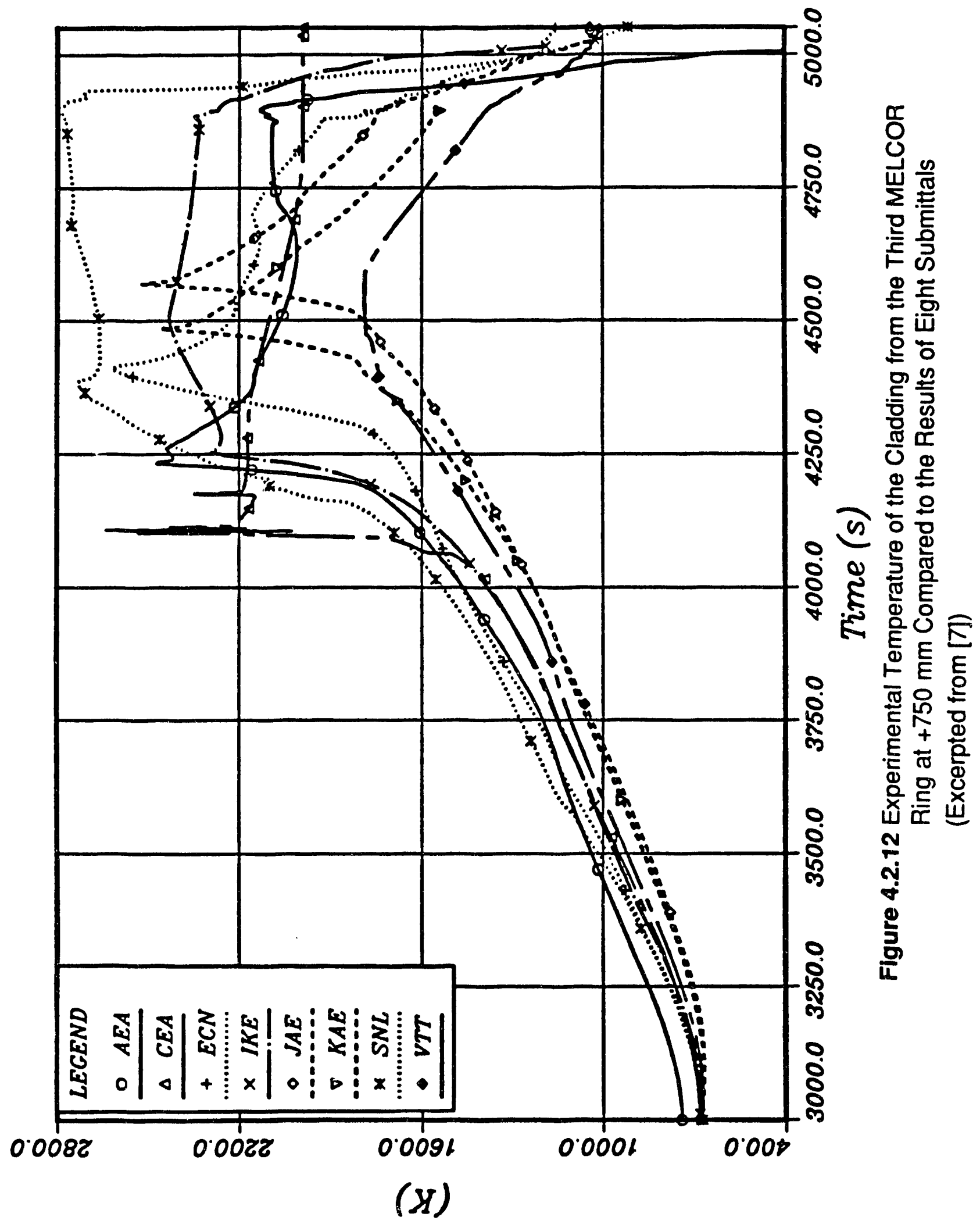




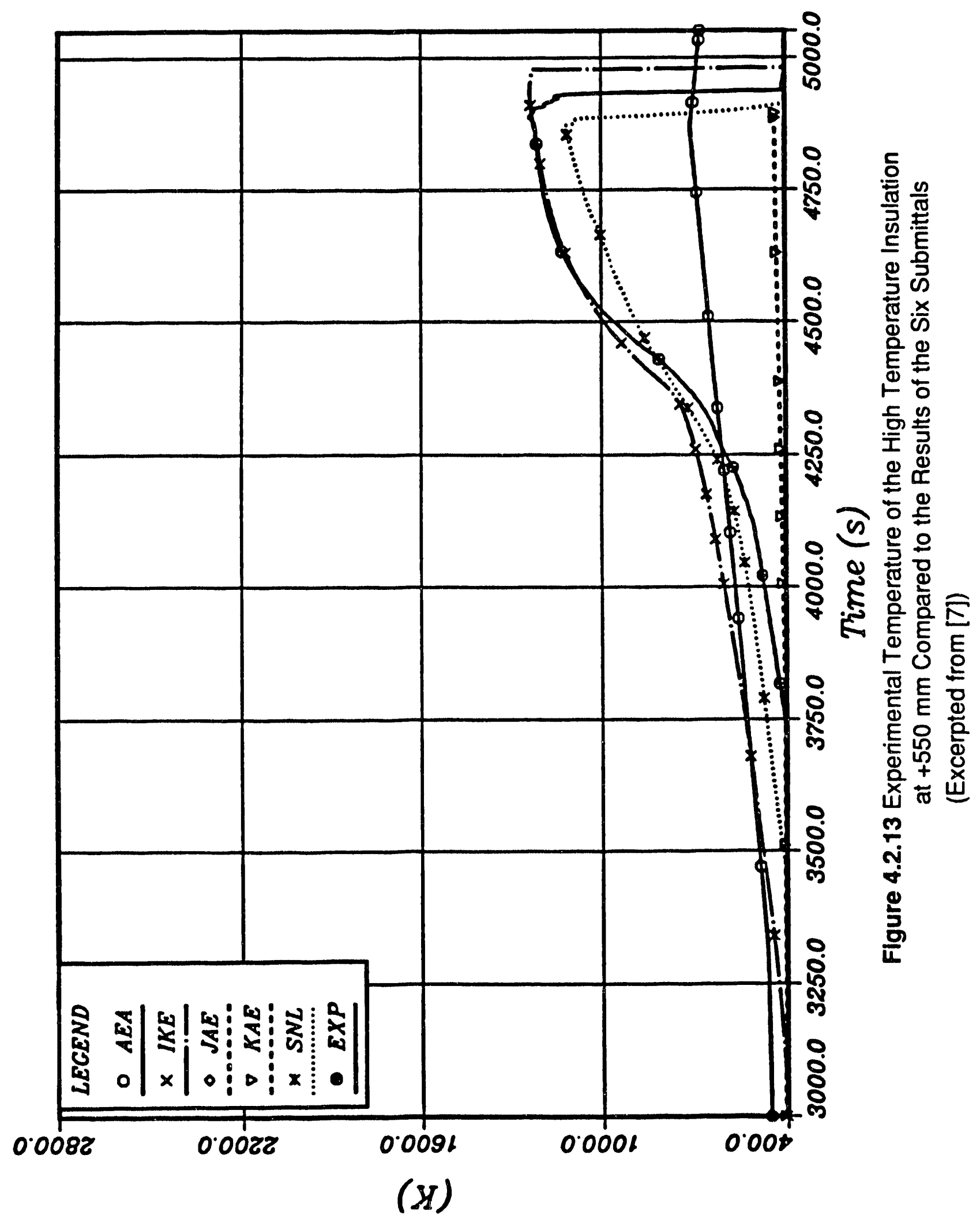




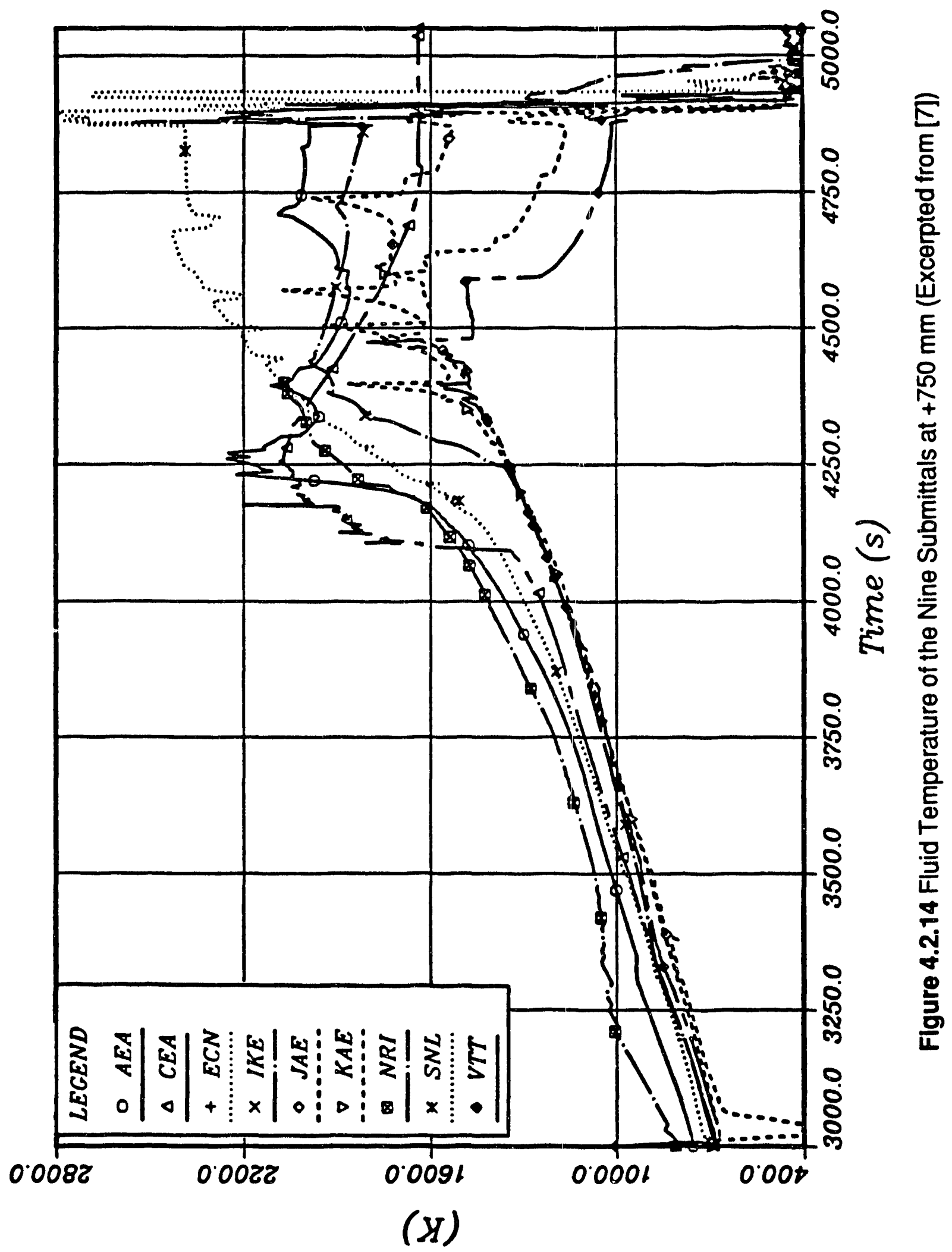




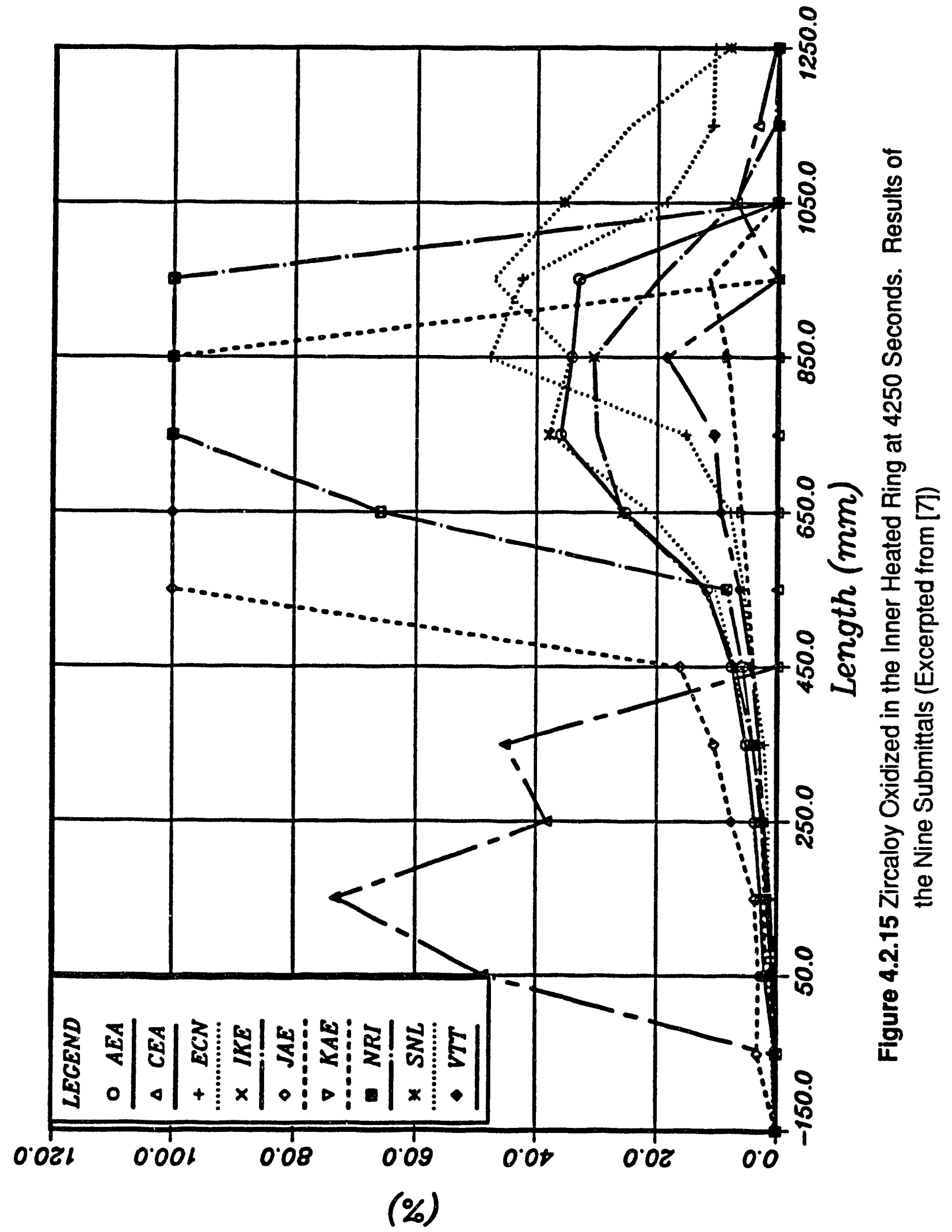




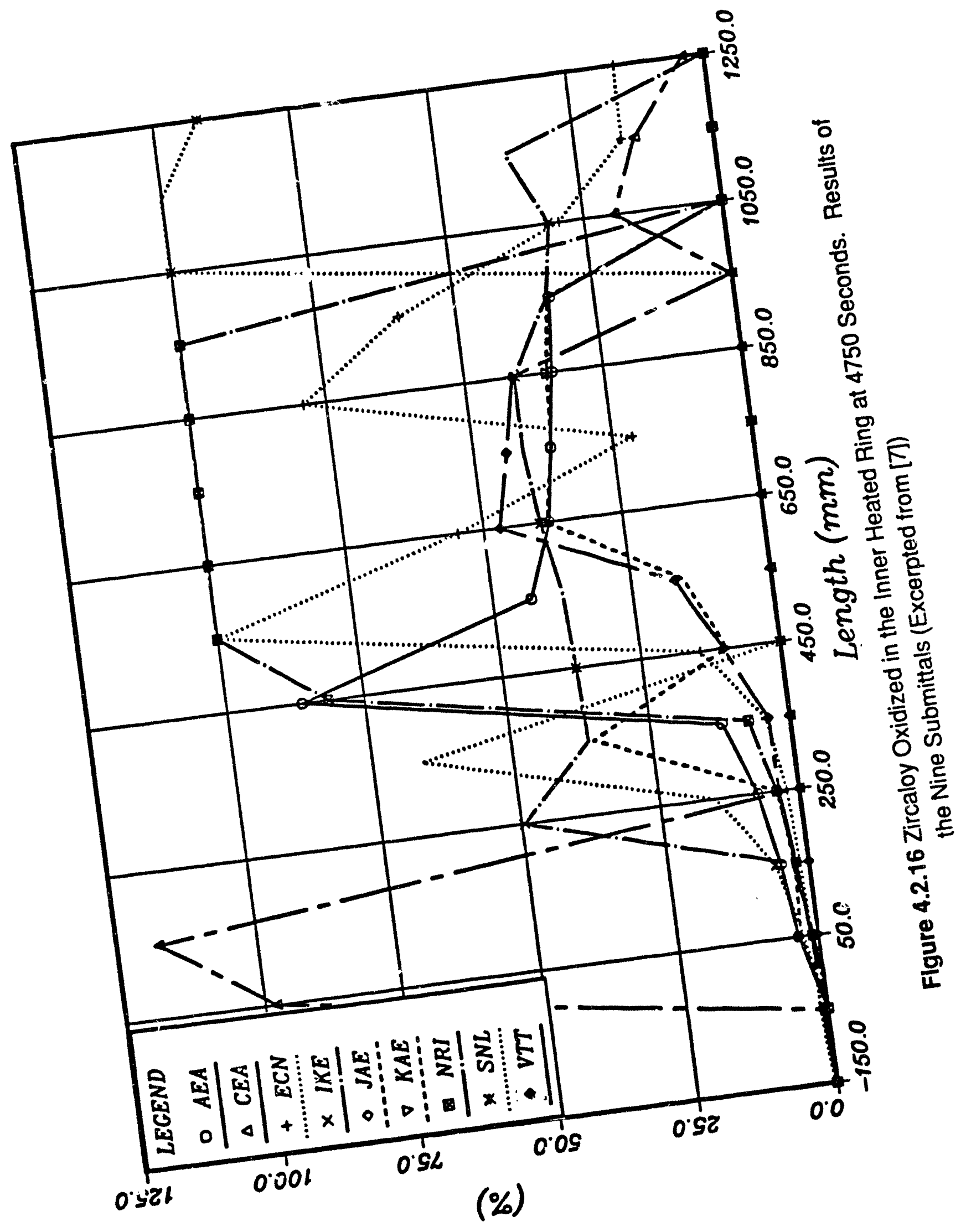




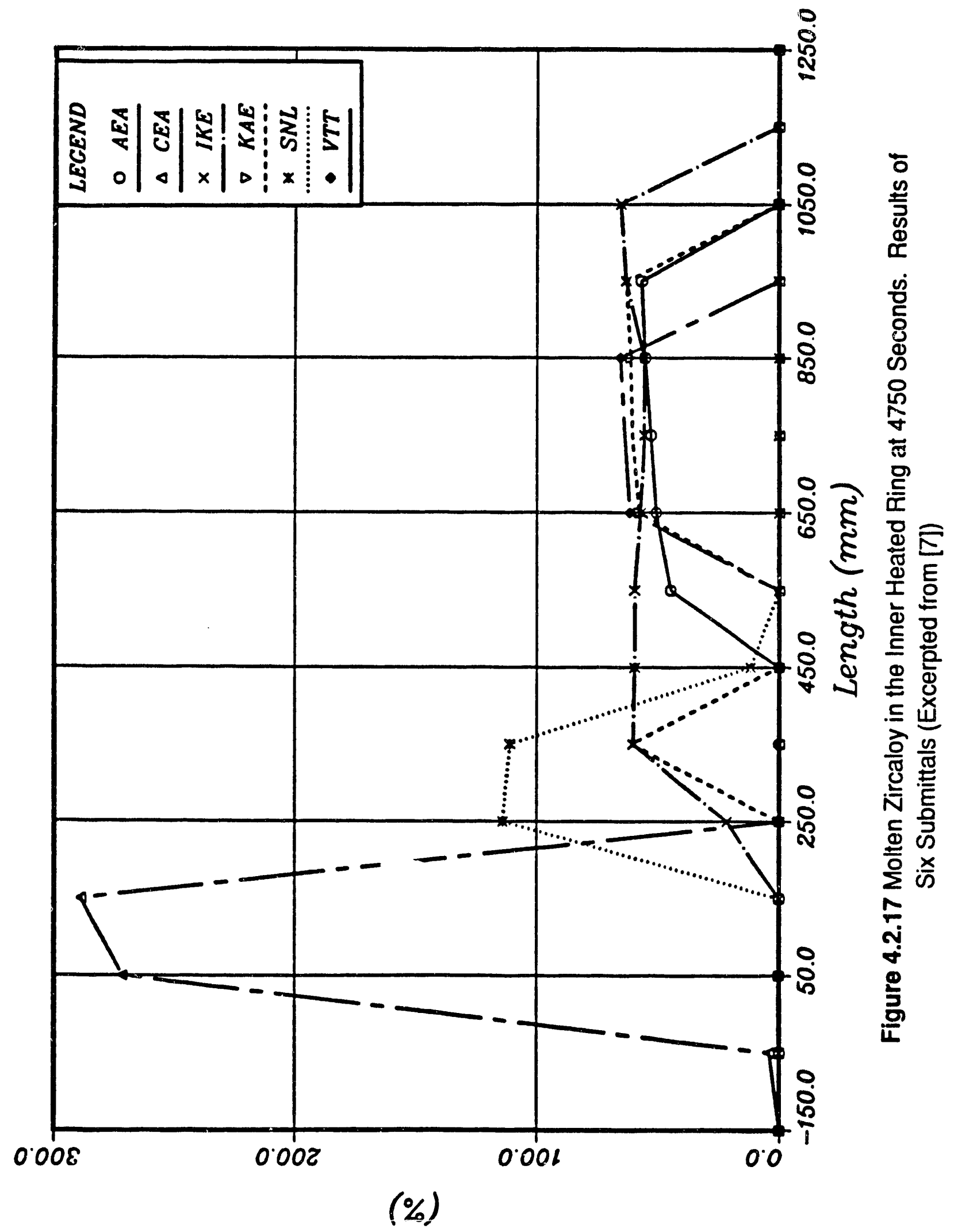




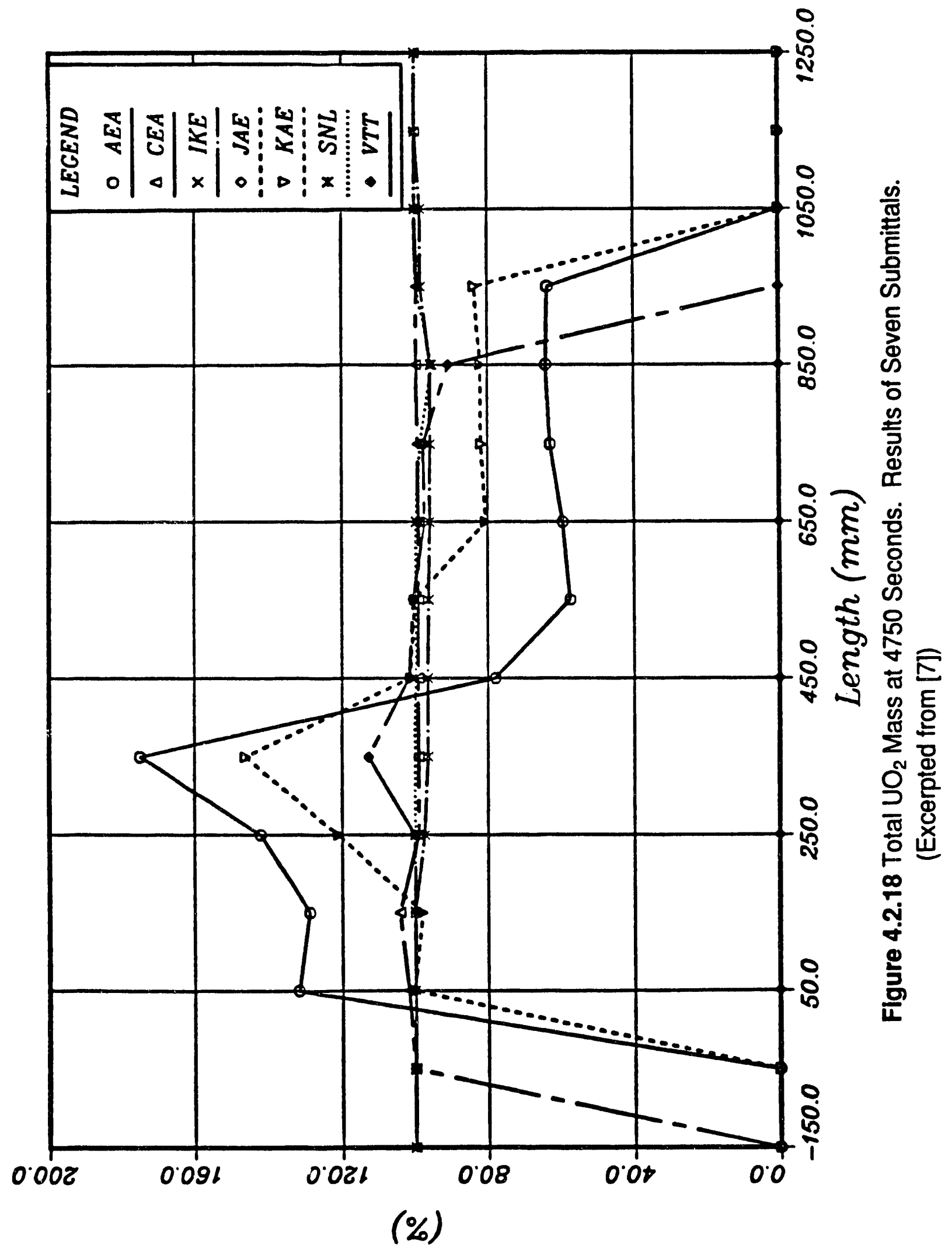




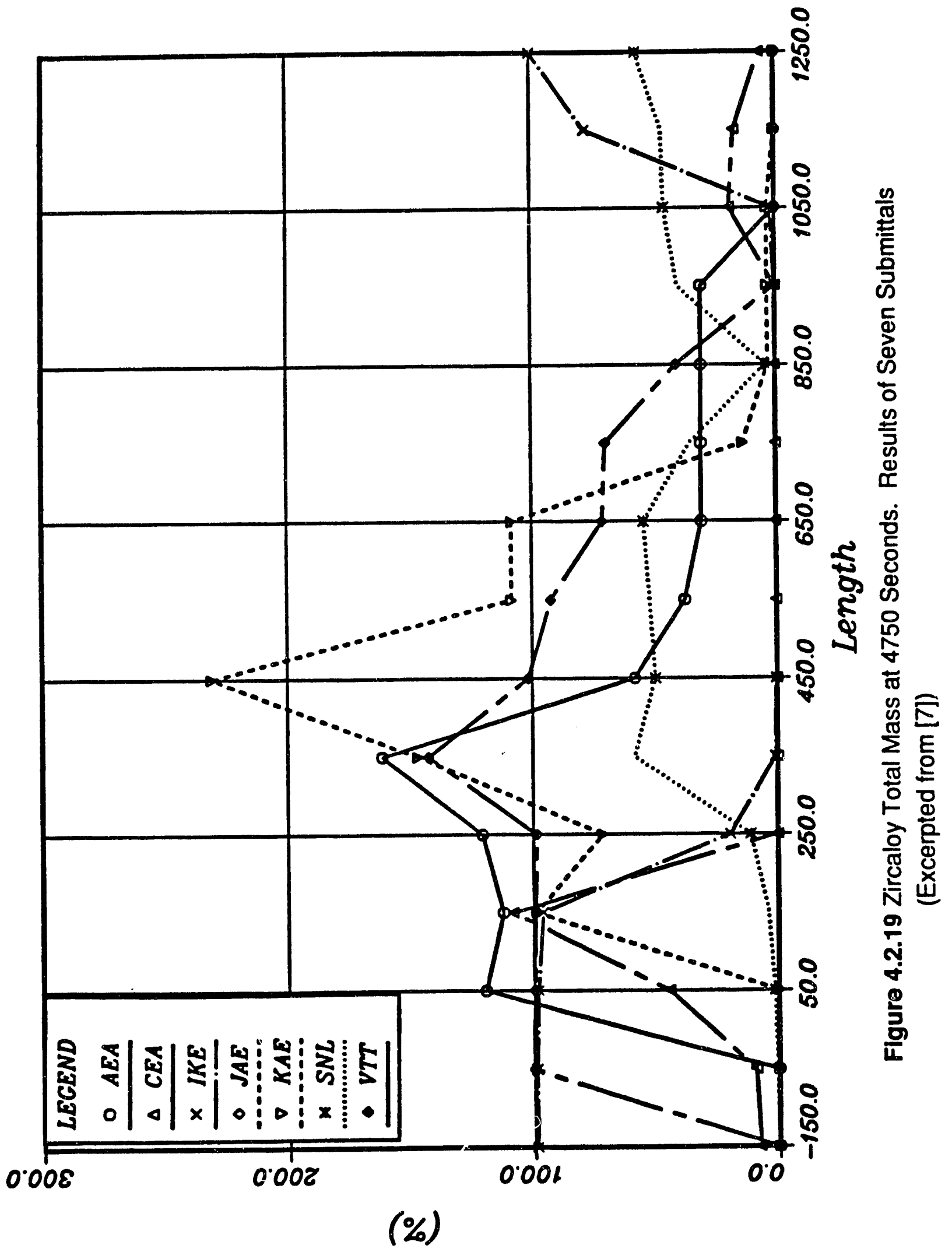




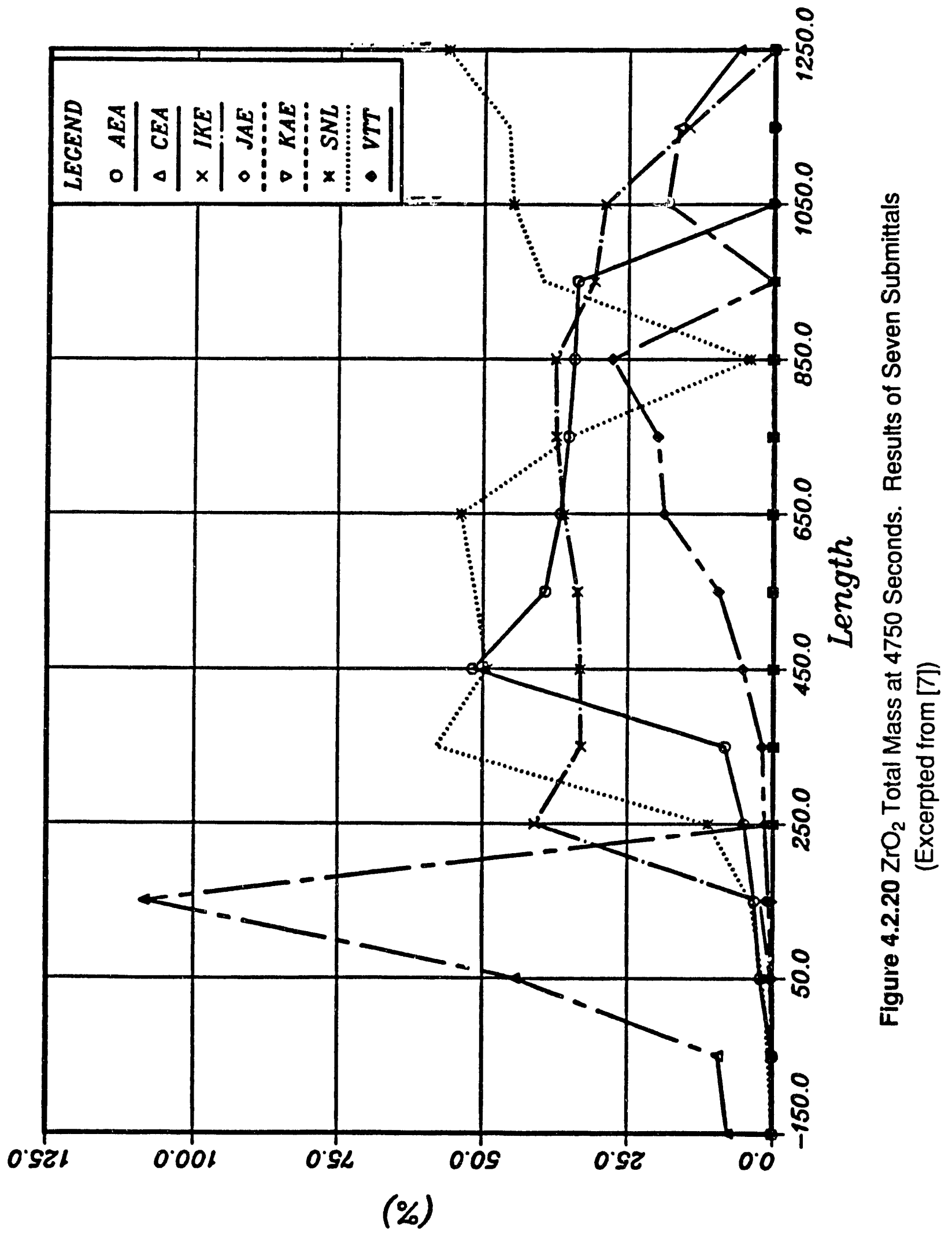




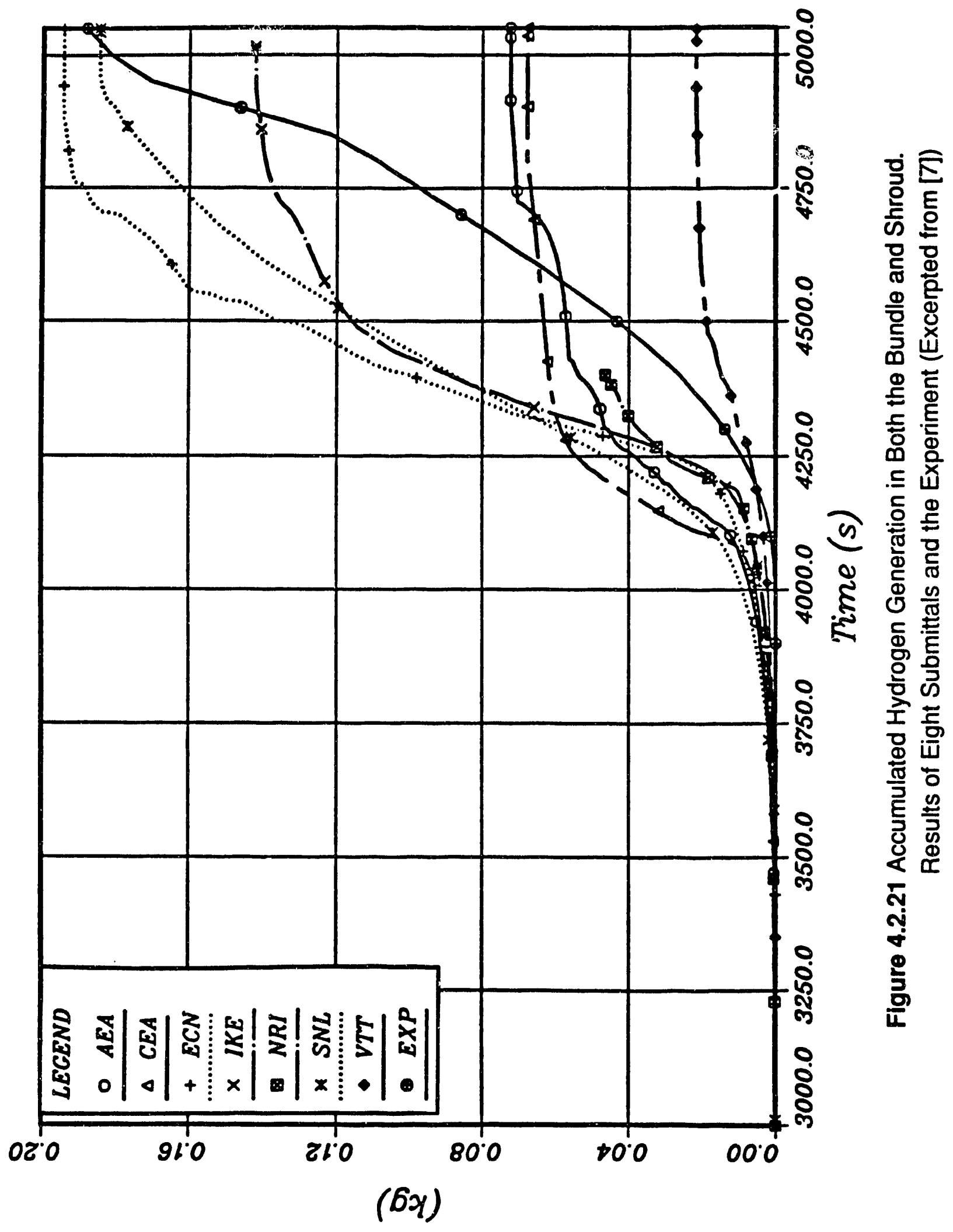




\section{Code Limitations and User Guidelines}

Most of the code limitations concerning MELCOR in simulating the ISP31 experiment were related to the COR Package. Many of them have been addressed or are in the process of being addressed since these simulations were performed.

As a part of this project, a model for electrical heater rods was added to MELCOR. A prototype version was created for the ISP31 experiment. In the present implementation, included in the MELCOR 1.8.2 version release, the COR package input is provided to specify electrical heating, and a COR array has been created to receive calculated power. The user must provide the FORTRAN subroutines that specify these power values in time and space. The current core temperature distribution is provided to these routines so that temperature-dependent resistance can be determined. It is assumed that the heater rods do not melt, but all other rod materials can relocate. Development of these routines for a specific experiment can be a moderate programming task mainly involving modeling of the electrical circuit and experimentally defined boundary conditions. The subroutines used for ISP31 are shown in Appendix B. These routines should be sufficient to model other CORA tests with appropriate modification of the electrical boundary conditions.

The MELCOR COR Package at the time of these calculations lacked the ability to compute $\mathrm{UO}_{2}$ dissolved, $\mathrm{ZrO}_{2}$ dissolved, $\mathrm{Zr}$ dissolved by $\mathrm{Ag}-\mathrm{In}-\mathrm{Cd}$, and other important bundle degradation variables. Most of these limitations have been addressed with the addition of a eutectic model in later versions of MELCOR, but the upgraded models have not been used to model ISP31.

The version of the MELCOR COR Package used in these calculations did not allow the transfer of mass between rings. Thus, melted and debris materials could not spread radially, which occurred in the CORA experiments. This limitation has been addressed with the addition of a radial relocation model in later versions of MELCOR but the upgraded model has not been used to model ISP31.

In the current MELCOR ISP31 model, the $\mathrm{ZrO}_{2}$ failure temperature used for relocation was set to $2750 \mathrm{~K}$, which is thought to be unrealistically high. This was necessary to obtain the desired agreement with experiment for a number of important variables. A major reason necessitating the high temperature was that MELCOR oxidation occurred too quickly and, more important, at a faster rate than experiment. Thus, the higher temperature delayed the early relocation of material caused by the excess oxidation. All of the submittals for the ISP31 experiment displayed the trends for early and excess oxidation. Two obvious possibilities exist. First, most of the submittals used similar oxidation models and these models might be inappropriate for the ISP31 experiment. Second, conditions in the experiment were not as the experimenters thought they were, and thus the modelers were provided inaccurate experimental specifications. The major possibility in this area concerns the flow split between the heater bundle and the bypass resulting from the presence of the view ports. The MELCOR calculation (and all other 
submitted calculations) used time-independent geometrical factors for the bypass. This is unlikely to be correct as temperatures change and materials relocate. Redistribution of flows could cause local steam starvation to limit the oxidation. There is insufficient information to build a time-dependent model (which would vary from one CORA experiment to another).

Another issue concerning oxidation was that none of the codes, including MELCOR, predicted the massive oxidation that occurred during quench. The codes predicted most of the available material was oxidized during the first part of the experiment, leaving little material to oxidize during the reflood. However, in the MELCOR calculation, a significant quantity of unoxidized zircaloy still existed beneath the oxide crust that was assumed to form on the cladding. MELCOR lacks a model to remove the oxide crust caused by stress failure during the rapid cooling that occurs during reflood, thereby uncovered new zircaloy for further oxidation. A simple MELCOR model could be constructed to model this failure and the resulting "enhanced" oxidation. This area should be addressed in future MELCOR development.

A minor problem with the COR Package manifested itself during the modeling of ISP31. The Package is incapable of having two materials with the exact same melt temperature (the solution of the material equations is not unique). Although this deficiency was easily worked around by specifying the second material with a melt temperature $0.1 \mathrm{~K}$ less than that of the first material, MELCOR stopped ungracefully when this problem occurred and additional time was spent in discovering the cause of the problem and correcting it. This quirk needs to be documented in the MELCOR manuals.

MELCOR presently requires additional control volumes to be created specifically for mass and energy sources and sinks. For instance, in the ISP31 MELCOR model, if the steam/argon mixture has been entered directly into Control Volume 210 (Figure 3.1), then unacceptable flow and temperature oscillations occur. Adding extra control volumes alleviates the problem, but it does make model larger than necessary and adds computer processing time. This should be documented in the MELCOR manuals.

Another concern is the artificially high flow loss coefficients that the FL Package must use to obtain flows that match observed bypass flows in the experiment. The best solution would be to eliminate the view ports from the experiments that are used for code verification. The coefficients required to match the flow would have to be time-dependent to account for flow blockage due to material relocation. The difficulty and uncertainty associated with this effort seem counter-productive to the code verification purpose of the experiment.

Many of the user guidelines for the ISP31 problem are applicable to MELCOR modeling in general. The user should use a minimum reasonable number of control volumes. For ISP31, twelve control volumes were used, which is a typical number. Second, the user must place sufficient detail in regions where it is required. For the ISP31 problem, the 
specification document virtually dictated that core cells $100 \mathrm{~mm}$ in height be used, and it may be noted that eight of the nine ISP31 submittals, including MELCOR, used the 100 $\mathrm{mm}$ core cell dimension. One submittal used a resolution double that, $50 \mathrm{~mm}$. It was obvious for ISP31 that the COR Package input was the most critical. The small size of the core demanded that material masses be computed very accurately, as well as the dimensions of the geometries of various components and heat transfer areas.

Another MELCOR capability that proved useful for ISP31 was the External Data File Package. By specifying control functions representing variables demanded by the ISP31 Specification [5], these variables could be placed in a file of the proper format also required by the Specification. Thus, every time the ISP31 problem was run, two EDF files were created that corresponded to Table I and Table II in the Specification. Because certain variables such as bundle power and bundle resistance were available only from the four custom heater routines and not in MELCOR, an auxiliary program was written to properly compute these variables from the output of the electrical heater rod routines and include them in the tables. Using the EDF Package saved much time and effort for the ISP31 calculation because it was included early in the input and it was carefully planned. The main difficulty, particularly for a new user, is the extent of the input required to define the control functions to collect the proper EDF data. 


\section{Conclusions and Recommendations}

The International Standard Problem 31, which is the CORA-13 Experiment, has been successfully modeled using the MELCOR computer code. Four FORTRAN subroutines were added to the standard MELCOR coding to incorporate electrical heating in the core. The COR Package was also modified to receive the data from these additional routines. This capability has since been added to latest standard MELCOR version (Version 1.8.2).

Agreement of MELCOR with the CORA-13 experiment was, in general, good, especially considering the fact that it was a totally blind calculation. The methodology used to enter electrical energy assured accurate input of energy and provided a check on bundle temperatures in a global, integrated sense. In this global sense, the MELCOR temperatures were within $10 \%$ of experiment for the entire length of the experiment (except for very early time). Temperatures of the rods, both heated and unheated, the cladding, the shroud, and the high temperature insulation were in fairly good agreement with the experiment; however, MELCOR temperatures near the top of bundle were higher than those measured. Because energy input was well-predicted, the disagreement was probably caused by underpredicting energy loss from core components and the gas mixture in the upper portion of the bundle. The source of this energy loss is presently unknown.

MELCOR predicted rapid oxidation to occur about 100 seconds earlier than experiment and at a higher rate. However, 210 grams of hydrogen were generated in the experiment, while MELCOR predicted 184 grams. The more rapid oxidation, of course, affected temperatures so that after oxidation became important the MELCOR temperatures did not agree as well with experiment as compared to pre-oxidation times. MELCOR also predicted a higher temperature gradient radially across the rings than was observed in the experiment.

MELCOR prediction of core blockage was somewhat on the high side. Further, since MELCOR does not have a core component that represents a grid spacer as a physical impediment to melt and debris, the major blockage occurred at a lower level. In the experiment, major core blockage occurred at an axial height of about $+450 \mathrm{~mm}$, approximately where the lower grid spacer was located. In MELCOR, the blockage occurred at +50 to $+150 \mathrm{~mm}$.

A preliminary report has been published by GFS and KfK [7] comparing all nine submittals made to ISP31 to the experiment. Very little information is presently available on the degradation variables. Concerning both initial and boundary conditions and temperatures, MELCOR, unlike some of the submittals, recorded no major errors or disagreement from experiment. In fact, the MELCOR submittal was one of the most accurate in terms of temperature prediction. Although this statement is subjective, an examination of Figures 4.2.1 to 4.2.8 and Figure 4.2.13 (figures that include experimental data) serve to justify it. Also, although none of the codes correctly predicted oxidation and hydrogen generation timing and rates, MELCOR provided one of the better integral hydrogen pro- 
duction predictions. All of the codes: (1) overpredicted hydrogen production in the early phase and underpredicted it in the latter phase, and (2) did not predict the intensive hydrogen production during quench. The first observation, coupled with the fact that the rod resistance rescale factor early in the experiment was consistently greater than one (See Section 4.1) strongly suggests that initial and/or boundary conditions given the analysts for ISP31 were not representative of actual experimental conditions. The second fact was due to the lack of a reflood model in MELCOR to account for the stress fracture of oxidated zircaloy and the consequent uncovering of unoxidated zircaloy.

Many of the bundle degradation variables, such as $\mathrm{UO}_{2}$ dissolved, $\mathrm{ZrO}_{2}$ dissolved, and $\mathrm{Zr}$ dissolved by AG-IN-CD poison were unavailable or crudely inferred from other quantities in MELCOR. A eutectics model has recently been placed in MELCOR (Version 1.8.2) that is currently undergoing testing. This should greatly improved the capability of MELCOR to provide additional and more accurate information concerning these quantities. It should be noted that, judging from the decrease in submittals for many of the bundle degradation variable, MELCOR was not the only code that had difficulty in supplying this type of information.

Another conclusion of the ISP31 Program serves to further underscore the positive synergism that usually occurs between calculations and experiment. This experiment clearly pointed out some of the problem that today's best predictive tools have concerning oxidation, chemistry, debris formation, and relocation in abnormal events. The inverse is also true -- that the calculations can often point the experimentalists to inconsistencies in their experiments. For instance, Figure 4.2.3 shows that all of the codes predicted early fuel temperatures that were too high. The experimental result is the bottom most curve. The cause of this result can only be speculated, but the data suggest that perhaps thermal mass was larger than given in the initial conditions or there was some unknown additional or larger heat loss. Also, the three large windows in the experiment, although serving a minor data-gathering capability, was impossible to model correctly with MELCOR or other existing codes. Most reactor cores do not have this type of energy loss path, and most analysts would have suggested removing it. The fact is that experiment and calculation are both useful tools that operate in a supportive, positive feedback manner.

The present MELCOR calculation has been criticized for using a $2750 \mathrm{~K}$ temperature for failure of oxidized zircaloy, and that a $2500 \mathrm{~K}$ failure temperature is more appropriate. Also, a version of MELCOR that includes the eutectic models is now available. Various constraints have precluded performing additional calculations using the $2500 \mathrm{~K}$ failure criterion with the latest MELCOR improvements, but it is highly recommended that this be done. Also, a number of informal sensitivity studies were performed in the course of this work. One was a variation in loss coefficients to obtain realistic flowrates in the bypass region of the experiment. It is recommended that a more formal and extensive matrix of sensitivity studies be performed, also with the latest MELCOR version. 
Finally, it has been pointed out [7] that modeling problems such as CORA-13 using large, complex computer codes is an art, and is very dependent on the user. A corollary of this is that, every time the user makes a run of the model, something additional is learned. Rarely is the answer obtained in one try. Thus, code efficiency is important. MELCOR required 6.2 hours to perform this calculation on a two-year-old workstation and it gave results that were at least as good if not better than other codes. Although the information on other codes is not available for this report, it would be instructive to investigate the processing requirements of all the codes used for ISP31 for comparison.

In summary, the ISP31 experiment represented a non-prototypic blind test that was extremely small scale and included large windows that could not be modeled (and do not exist in prototypic reactors), causing unquantified heat losses and unnecessary gas coolant leakage paths. In addition, for unknown reasons, MELCOR temperatures early in time were higher than indicated by the experiment, and the reasons could as much be due to experimental uncertainties as MELCOR modeling inaccuracies. For the author, ISP31 represented the first MELCOR applications work that entailed the creation of a large MELCOR input deck. Given these facts, we feel that the agreement between the MELCOR predictions and the experimental data was excellent. 


\section{References}

1. Summers, R.M., et. al., "MELCOR 1.8.0: A Computer Code for Severe Nuclear Reactor Accident Source Term and Risk Assessment Analyses," NUREG/CR-5531, SAND90-0364, Sandia National Laboratories, January 1991.

2. Kmetyk, L.N., "Survey of MELCOR Assessment", SAND92-1273, Sandia National Laboratories, January 1993.

3. Kmetyk, L.N., "MELCOR Assessment at SNL," NUREG/CP-0125, Transactions of the Twentieth Water Reactor Safety Information Meeting, Bethesda, Maryland, October 21-23, 1992, p. 10-15..

4. Martinez, G.M., "MELCOR Calculations of ISP28: SFD Phebus B9+ Experiment," Letter Report to the USNRC dated December 1991.

5. Firnhaber, M., et. al., "Specification of the International Standard Problem ISP-31: CORA 13 Experiment on Severe Fuel Damage," Gesellschaft für Reaktorsicherheit(GRS) mbH, Revision 1, October 1991.

6. Ball, A., et. al., "Determination of Boundary Conditions for Test CORA 13 using ATHLET-SA," ISP-31 Workshop, Kernforschungszentrum Karlsruhe (KfK), June 13, 1991.

7. Firnhaber, M., et. al., "Draft of the Preliminary Comparison Report, International Standard Problem No. 31, CORA-13 Experiment on Severe Fuel Damage," GRS and KfK, August 1992.

8. Fluid Flow Data Book, Genium Publishing Company, September 1984. 


\section{Appendix A - CORA-13 Calculation Input Deck Does Not Include External Data File Input}

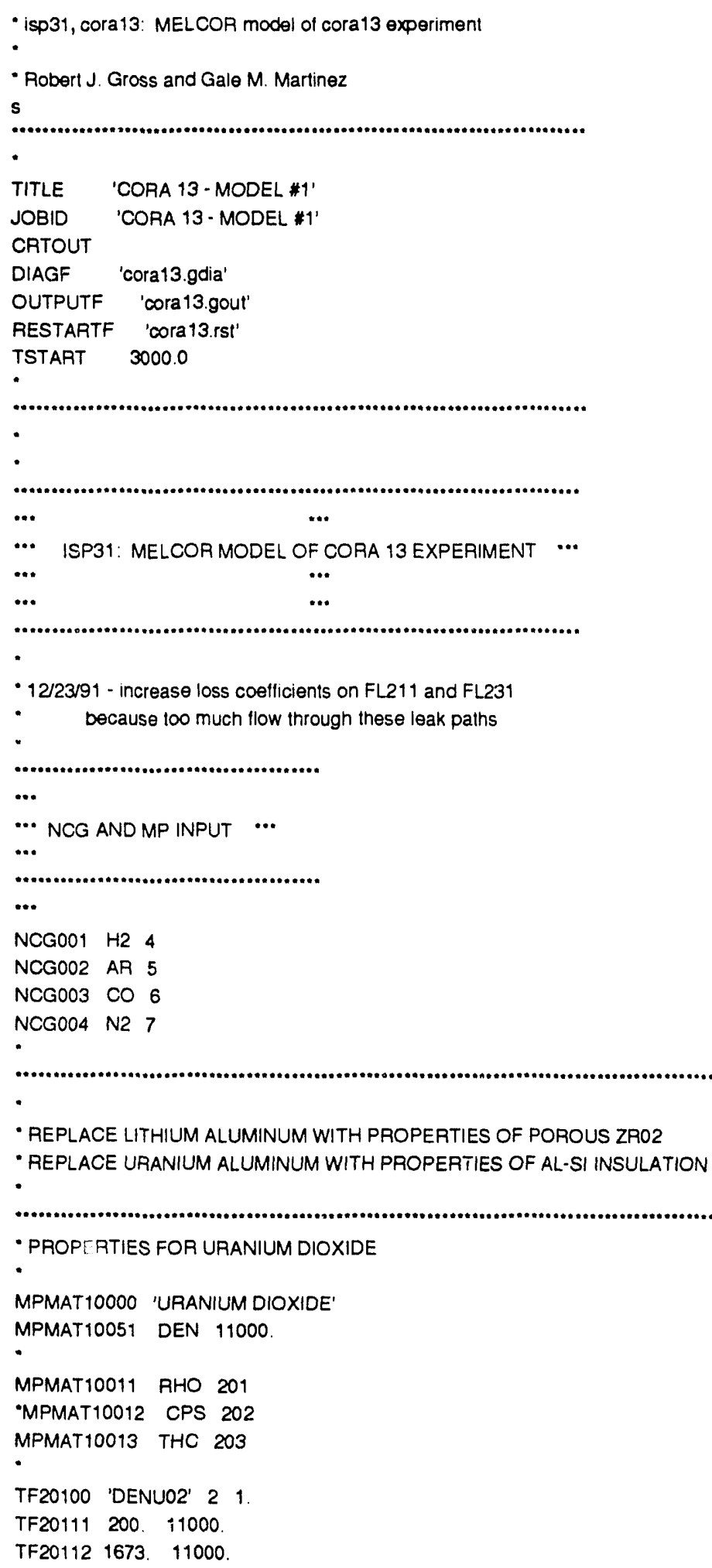




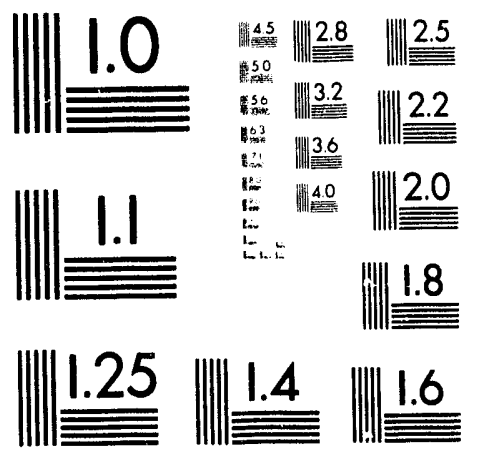



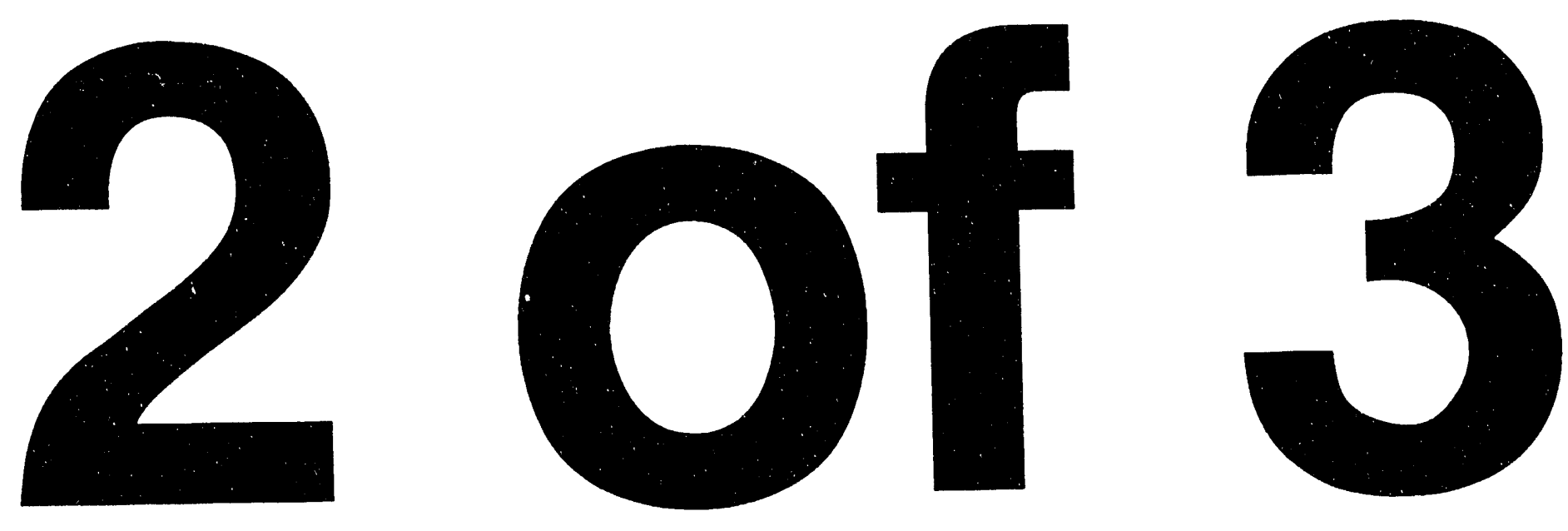
-TF20200 'CPU02' 101.

- TEMP (K) CP HEAT (J/(KG-K))

$\begin{array}{lll}\text {-TF20210 } 295 \quad 235.0 & \end{array}$

-TF20211 373. 260.0

-TF20212 573. 2900

-TF20213 773. 3050

-TF20214 1023. 315.0

-TF20215 $1273 \quad 325.0$

-TF20216 1523. 335.0

-TF20217 1773. 350.0

-TF20218 2023. 380.0

-TF20219 $2273 \quad 425.0$

TF20300 'THCUO2' $11 \quad 1$

- TEMP (K) COND (W/(Kg-K))

- Too much heat is escaping - lower by $30 \%$ - rjg - 10/16/92

-TF20310 573. 5.3

$\begin{array}{lll}\text {-TF20311 } 673 . \quad 4.7 & \end{array}$

-TF20312 773.4 .3

-TF20313 873. 3.9

-TF20314 1073. 3.3

-TF20315 $1173 . \quad 3.0$

$\begin{array}{lll}\text { TTF20316 } 1373 . & 2.7\end{array}$

TF20317 1573. 2.3

-TF20318 2573.2 .4

-TF20319 2973. 30

-TF20320 3173. 3.2

$\begin{array}{lll}\text { TF20310 } & 573 \quad 37\end{array}$

TF20311 673. 3.3

TF20312 773. 3.0

TF20313 873. 2.7

TF20314 1073. 2.3

TF20315 1173. 2.0

TF20316 1373. 1.9

TF20317 1573. 1.6

TF20318 2573. 1.7

TF20319 2973. 2.0

TF20320 3173. 2.2

….......................

- PROPERTIES FOR TUNGSTEN - SUBSTITUTE WITH URANIUM METAL

- MUMETL $=13$ IN THE MP DATABASE

MPMAT11000 'URANIUM METAL'

MPMAT11011 RHO 204

MPMAT11012 CPS 205

MPMAT11013 THC 206

MPMAT11014 ENH 219

MPMAT11015 TMP 220

MPMAT11051 DEN 19600

MPMAT11052 MLT 3473.

MPMAT11053 LHF 192556

TF20400 'DENW' 21.

$\begin{array}{llll}T F 20411 & 200.19600\end{array}$

TF20412 3000. 19600

TF20500 'CPW' 13

- TEMP (K) HT CAP (J/(KG-K))

TF20510 $295 \quad 138.2$

$\begin{array}{lll}\text { TF20511 } & 373 & 141.2\end{array}$

TF20512 573.148 .6

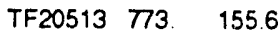

TF20514 $1023 \quad 163.9$ 


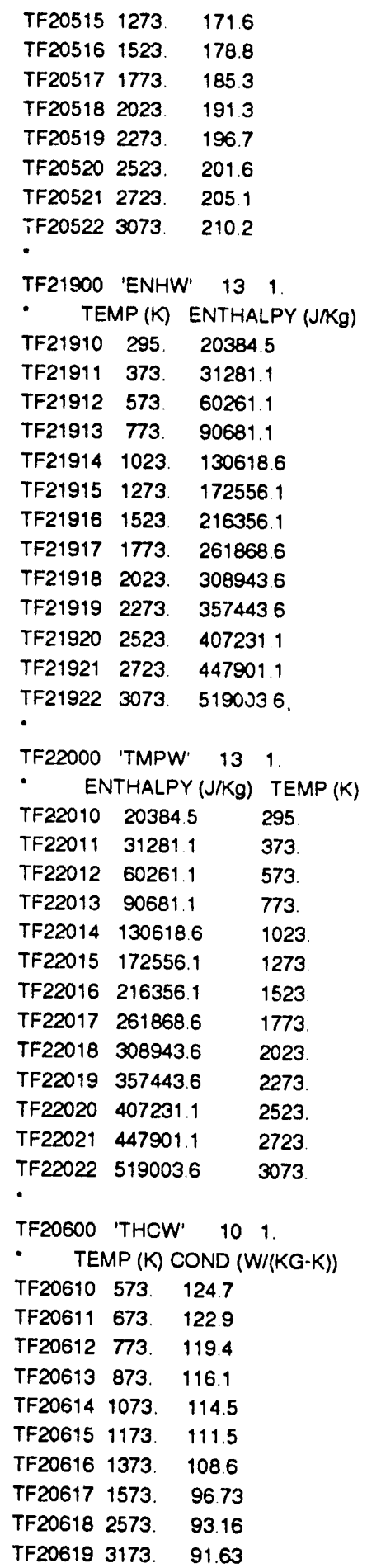




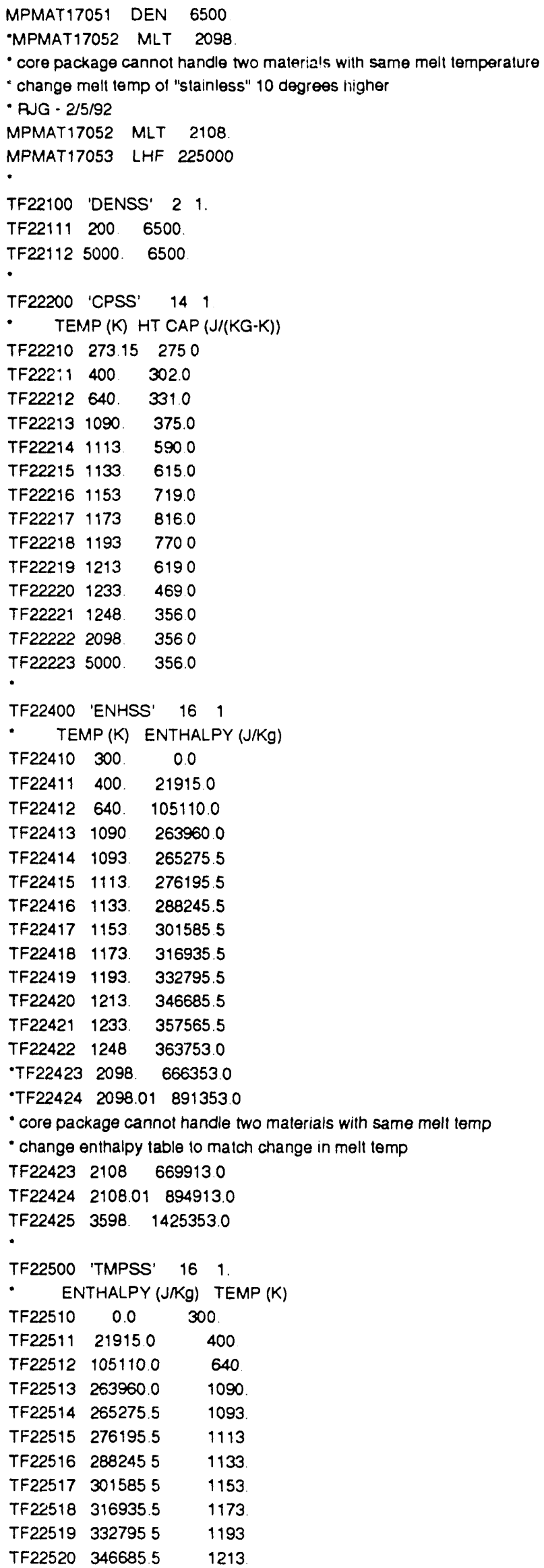




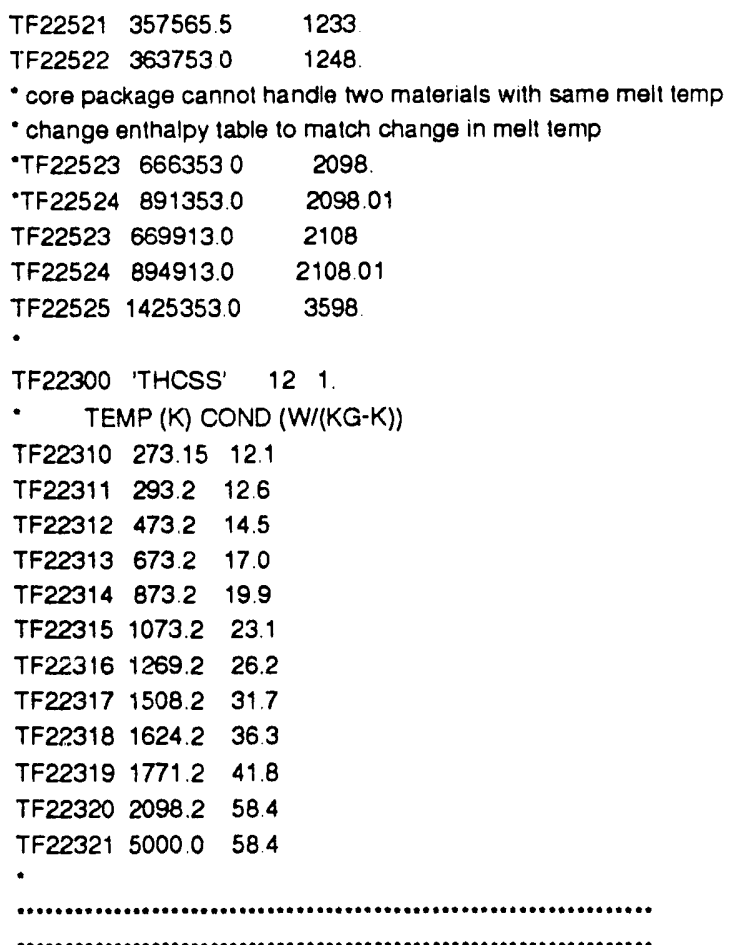

- core package cannot handle two materials with same melt temp

- change enthalpy table to match change in melt temp

-TF22523 $6663530 \quad 2098$.

-TF22524 $891353.0 \quad 2098.01$

TF22523 $669913.0 \quad 2108$

TF22524 894913.0 2108.01

TF22525 $1425353.0 \quad 3598$.

TF22300 'THCSS' 121

- TEMP (K) COND (W/(KG-K))

$\begin{array}{lll}T F 22310 & 273.15 \quad 12.1\end{array}$

TF22311 $293.2 \quad 12.6$

$\begin{array}{lll}\text { TF22312 } & 473.2 \quad 14.5\end{array}$

$\begin{array}{llll}\text { TF22313 } 673.2 \quad 17.0 & 0\end{array}$

$\begin{array}{lll}\text { TF22314 } & 873.2 \quad 19.9\end{array}$

TF22315 $1073.2 \quad 23.1$

$\begin{array}{lll}\text { TF22316 } & 1269.2 \quad 26.2\end{array}$

$\begin{array}{llll}\text { TF22317 } & 1508.2 \quad 31.7\end{array}$

TF22.318 $1624.2 \quad 36.3$

TF22319 $1771.2 \quad 41.8$

TF22320 $2098.2 \quad 58.4$

TF22321 $5000.0 \quad 58.4$



- PROPERTIES FOR ZIRCONIUM OXIDE

'MPMAT12000 'ZIRCONIUM OXIDE'

"MPMAT12011 RHO 207

-MPMAT12012 CPS 208

-MPMAT12013 THC 209

-TF20700 DENZRO 51

-TF20711 300. 5800

-TF20712 1475.5640

-TF20713 1480. 6050.

-TF20714 2970. 5710.

-TF20715 2975. 5990

-

-TF20800 CPZRO 91.

- TEMP (K) HT CAP (J/(KG-K))

-TF20810 300. 460

.TF20811 305.550

"TF20812 400. 610

-TF20813 500. 640

-TF20814 700. 680

-TF20815 $1475 \quad 740$

•TF20816 1480. 600

-TF20817 2000. 600

-TF20818 2970. 820

-TF20900 THCZRO 21

- TEMP (K) COND (W/(KG-K))

-TF20910 300. 0.9

•TF20911 2975. 1.4

- PROPERTIES FOR MOLYBDENUM

'MPMAT14000 'MOLYBDENUM'

MPMAT14011 RHO 210

MPMAT14012 CPS 211

MPMAT14013 THC 212 


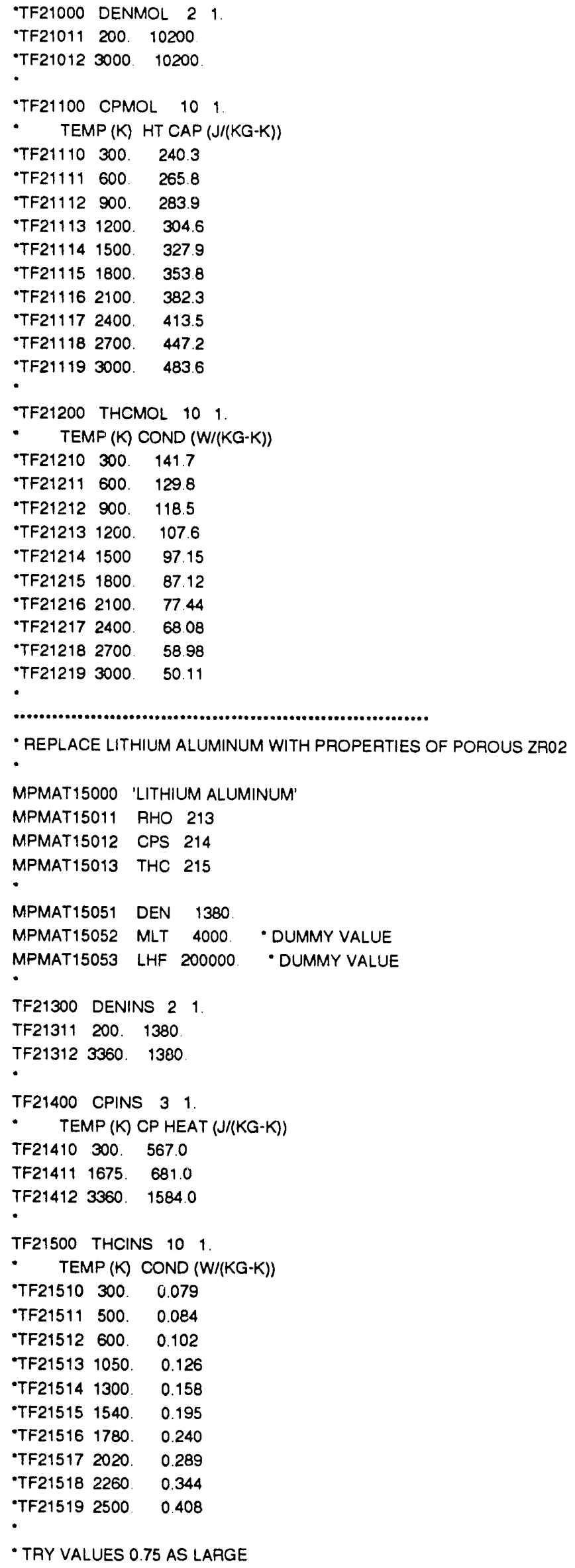

- tRy values 0.75 as large 


\begin{tabular}{lll} 
TF21:10 & 300. & 0.056 \\
TF21511 & 500. & 0.063 \\
TF21512 & 600. & 0.077 \\
TF21513 & 1050 & 0.095 \\
TF21514 & 1300. & 0.119 \\
TF21515 & 1540. & 0.146 \\
TF21516 & 1780. & 0.180 \\
TF21517 & 2020 & 0.217 \\
TF21518 & 2260. & 0.258 \\
TF21519 & 2500. & 0.306 \\
\hline & &
\end{tabular}

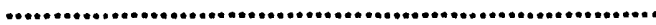

- replace uRaNium aluminUm WITH PRoperties of al-sI INSULATION$$
\text { MPMAT16000 'URANIUM ALUMINUM' }
$$$$
\text { MPMAT16011 RHO } 216
$$$$
\text { MPMAT16012 CPS } 217
$$$$
\text { MPMAT16013 THC } 218
$$$$
\text { - }
$$ 


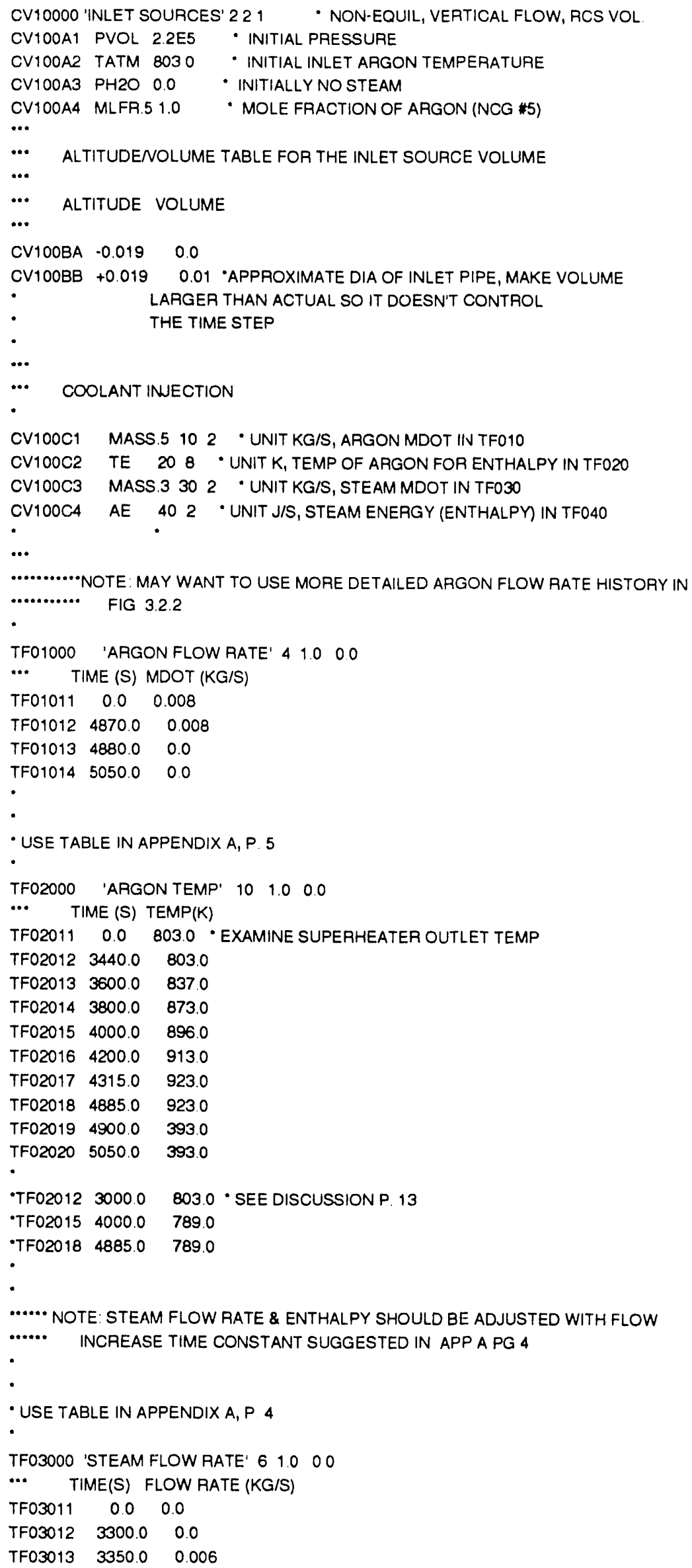$$
\text { TF03000 'STEAM FLOW RATE' } 61.000
$$ 


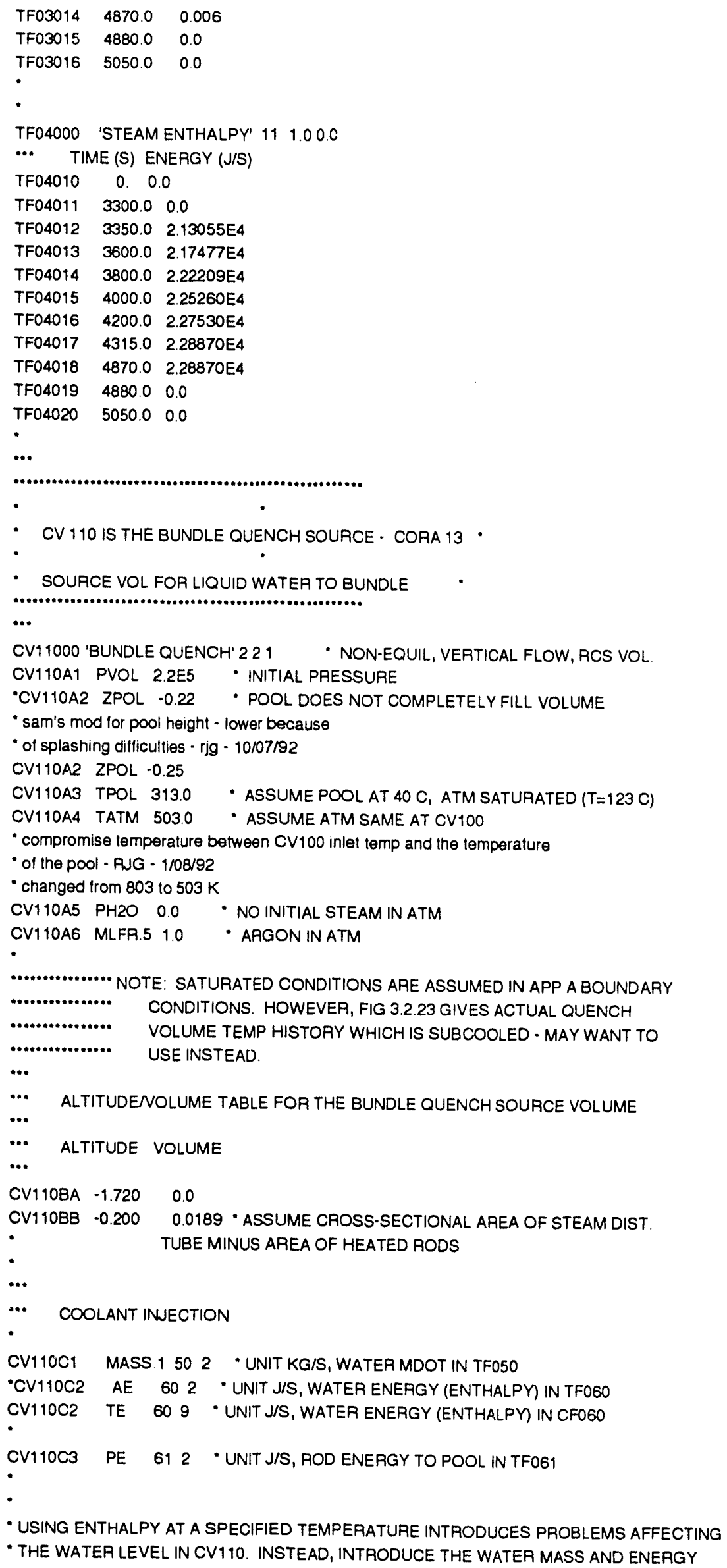


- SOURCE AT THE PRESENT TEMPERATURE OF THE POOL. THIS SHOULD MAINTAIN THE

- WATER LEVEL. REMOVE TABULAR FUNCTION 60, AND INTRODUCED CONTROL FUNCTION

$\cdot 60$.

- PUT IN STEAM INTO CV210 FRoM WATER TAKEN OUT OF CV110

-CV110C4 MASS.1622 -UNIT KG/S, STEAM EVAP IN TF062

•CV110C5 PE $6322^{\circ}$ UNIT J/S, STEAM ENERGY (ENTHALPY) IN TF063

- comment out for now - RWG - 1/292

- USE TABLE IN APPENDIX A, P. 4

TF05000 'BUNDLE QUENCHM' $61.0 \quad 0.0$

... TIME(S) FLOW RATE (KG/S)

$\begin{array}{lll}\text { TF05011 } & 0.0 & 0.0\end{array}$

TF05012 $4870.0 \quad 0.0$

TF05013 $4880.0 \quad 0.060$

TF05014 $4993.0 \quad 0.060 \quad$ - NOTE DIFFERENCE IN TIMING FROM CV111

- changed from 0075 to 0.060 - RJG - 2/27/92

TF05015 $4993.5 \quad 0.0$

TF05016 $50500 \quad 0.0 \quad$ BOTH TAKEN FROM APPEND A

$\cdot$

-TF06000 'BUNDLE QUENCHE' $5 \quad 1.00 .0$

... TIME (S) ENERGY (J/S)

$\begin{array}{lll}-T F 06010 & 0.0 .0\end{array}$

$\begin{array}{llll}\cdot T F 06011 \quad 4870.0 & 0.0\end{array}$

-TF06012 $4880.0 \quad 3.88316 E 4$

-TF06013 $5000.0 \quad 3.88316 E 4$

$\begin{array}{llll}\cdot T F 06014 & 5050.0 & 0.0\end{array}$

CF06000 'WATERENERGY' EQUALS 11.0

CF06010 $1.0 \quad 0.0 \quad$ CVH.TLIQ.110

TF06100 'RODE TO POOL' $4 \quad 1.0 \quad 0.0$

- TIME(S) ENERGY (J/S)

$\begin{array}{lll}\text { TF06111 } & 0.0 & 46.6\end{array}$

TF06112 $3000.0 \quad 46.6$

TF06113 $3005.0 \quad 171.9$

TF06114 $5050.0 \quad 171.0$

-

TF06200 'EVAPMASS' $11 \quad 1.0 \quad 0.0$

$\begin{array}{lll}\text { TF06211 } & 0.0 & -0.000015\end{array}$

TF06212 $1300.0 \quad-0.000015$

TF06213 $1310.0 \quad-0.00004$

$\begin{array}{lll}\text { TF06214 } & 2000.0 & -0.00004\end{array}$

$\begin{array}{lll}\text { TF06215 } 2010.0 & -0.00009\end{array}$

$\begin{array}{lll}\text { TF06216 } & 4300.0 & -0.00009\end{array}$

TF06217 $4305.0 \quad-0.00014$

TF06218 $4700.0 \quad-000014$

TF06219 $4705.0 \quad-0.001$

$\begin{array}{llll}T F 06220 & 4870.0 & -0.001\end{array}$

$\begin{array}{lll}\text { TF06221 } & 4872.0 & -0.0\end{array}$

TF06300 'EVAP ENERGY' $11 \quad 1.0 \quad 0.0$

$\begin{array}{lll}\text { TF06311 } & 0.0 & -7.766\end{array}$

TF06312 $1300.0 \quad-7.766$

$\begin{array}{lll}\text { TF06313 } & 1310.0 & -20.71\end{array}$

TF06314 $2000.0 \quad-20.71$

TF06315 $2010.0 \quad-46.60$

TF06316 $\quad 4300.0 \quad-46.60$

TF06317 $4305.0 \quad-72.49$

$\begin{array}{lll}\text { TF06318 } & 4700.0 & -72.49\end{array}$ 


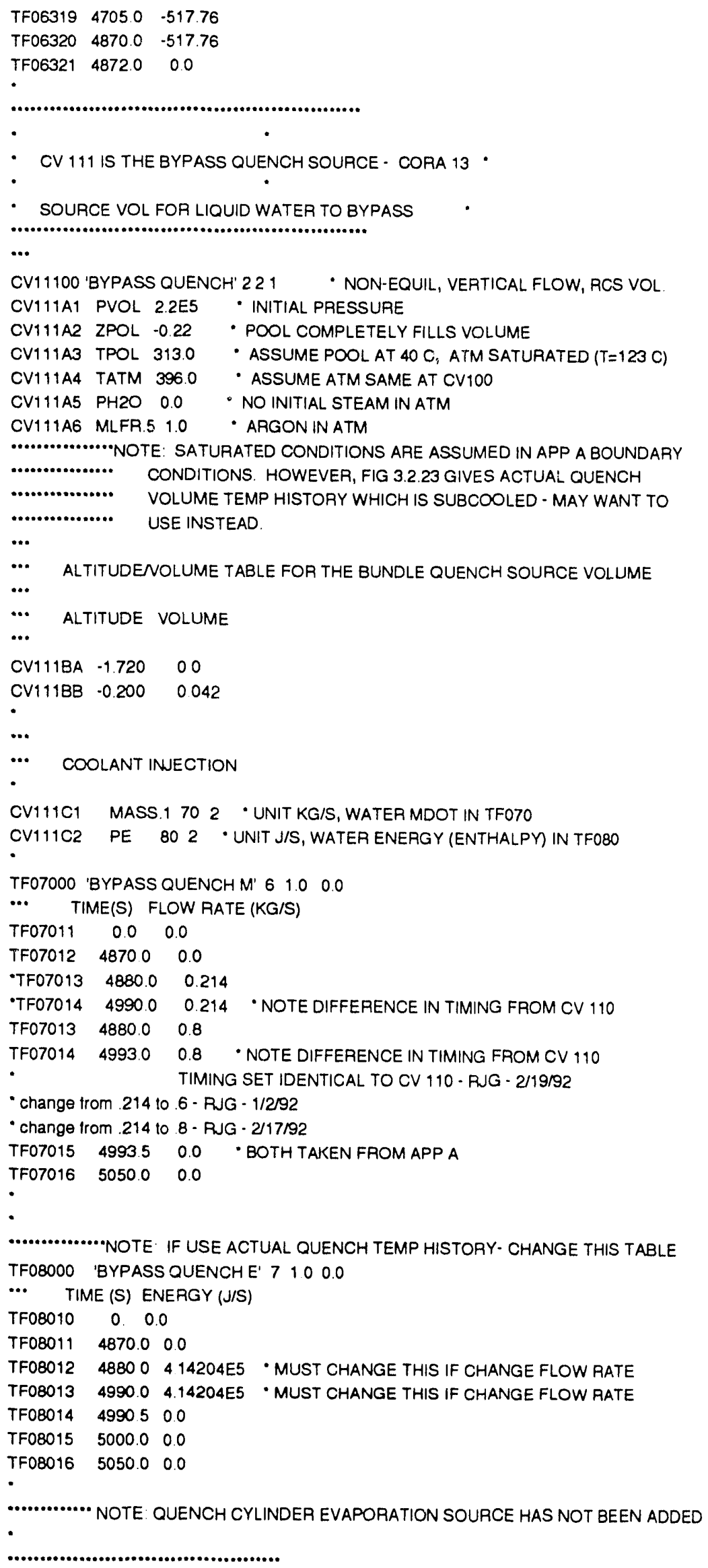




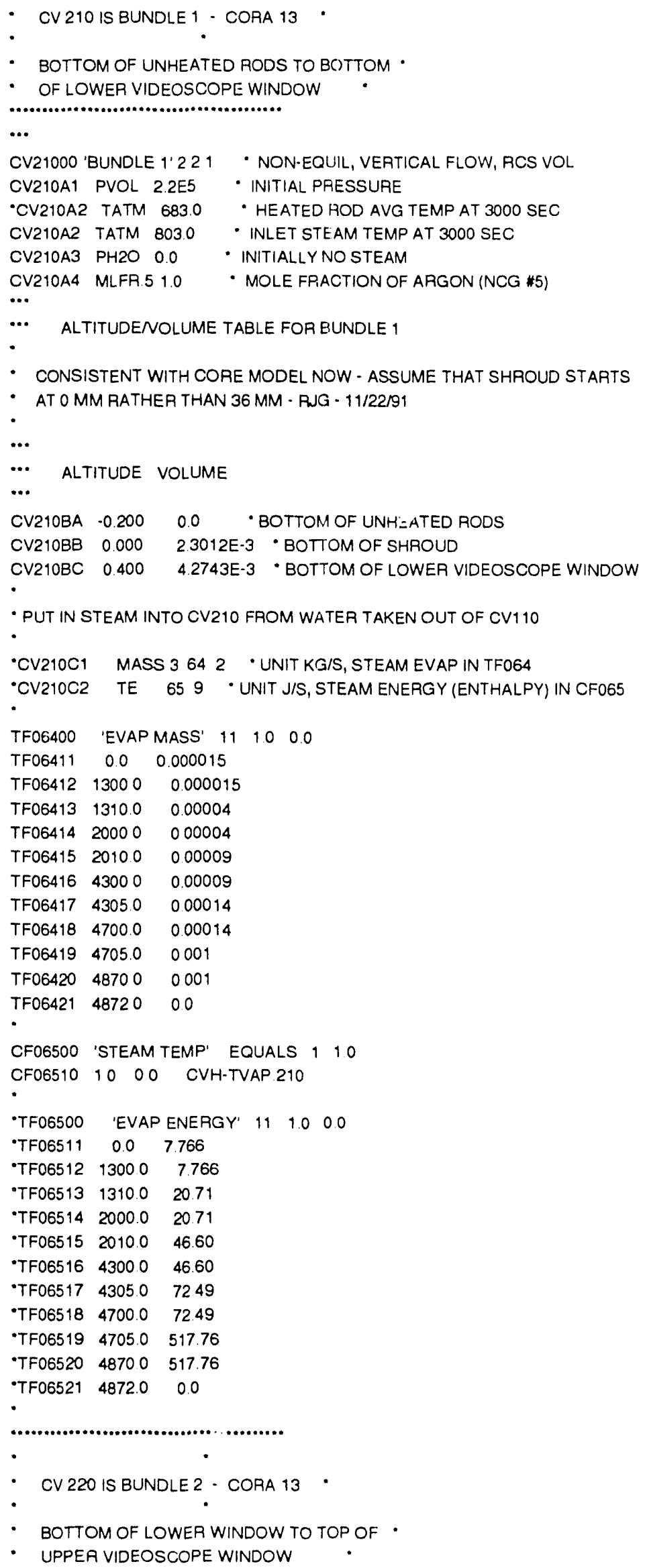




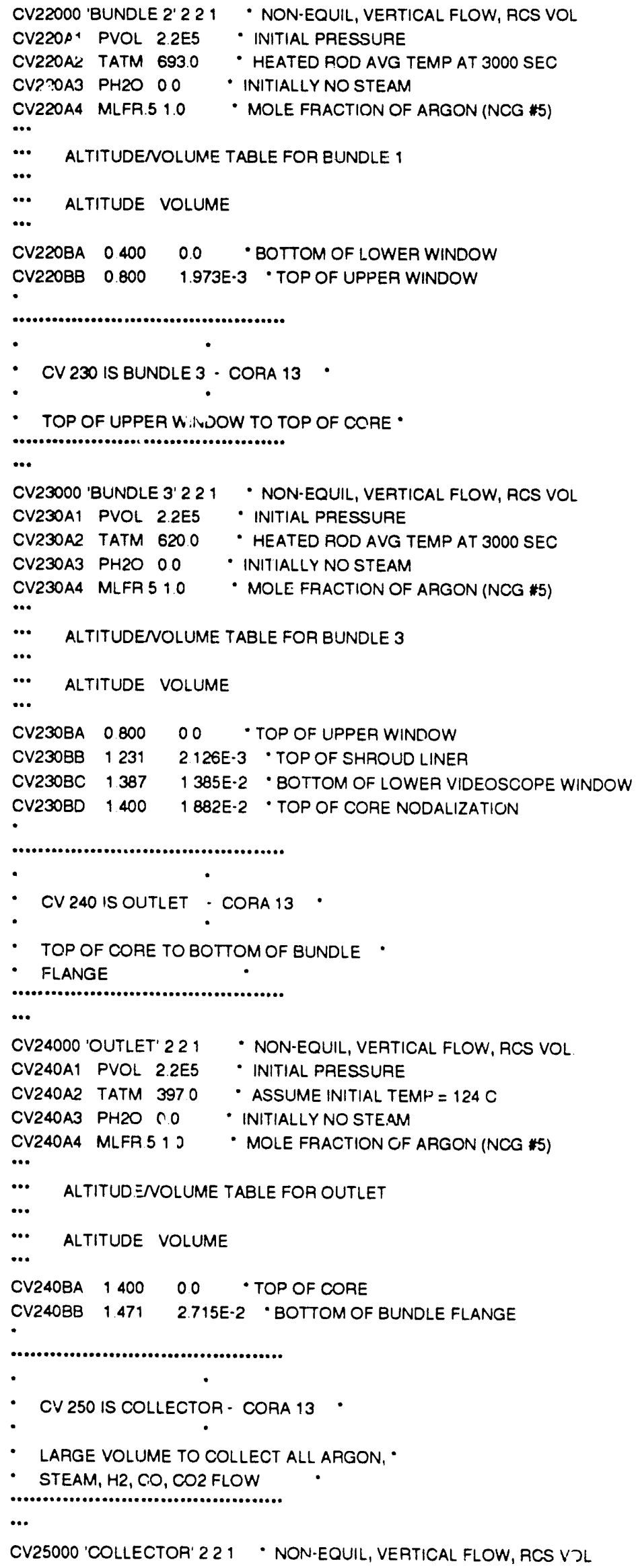




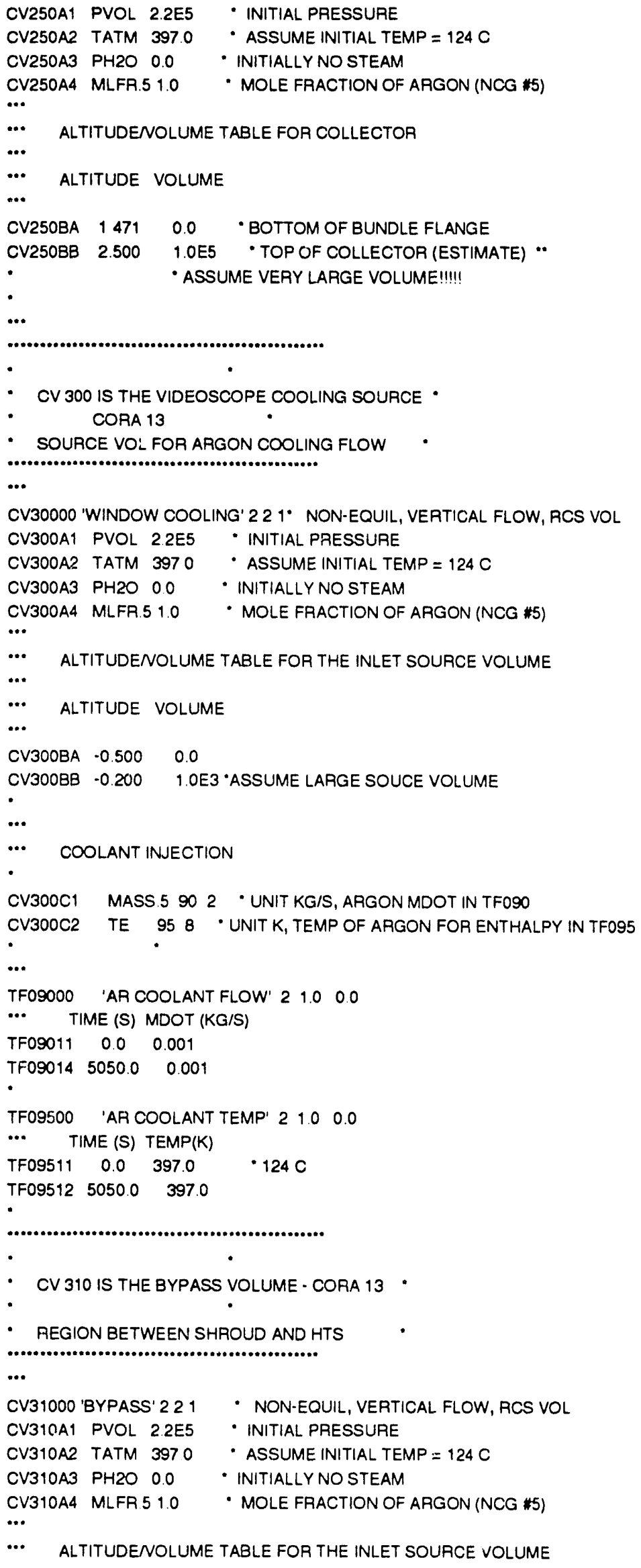




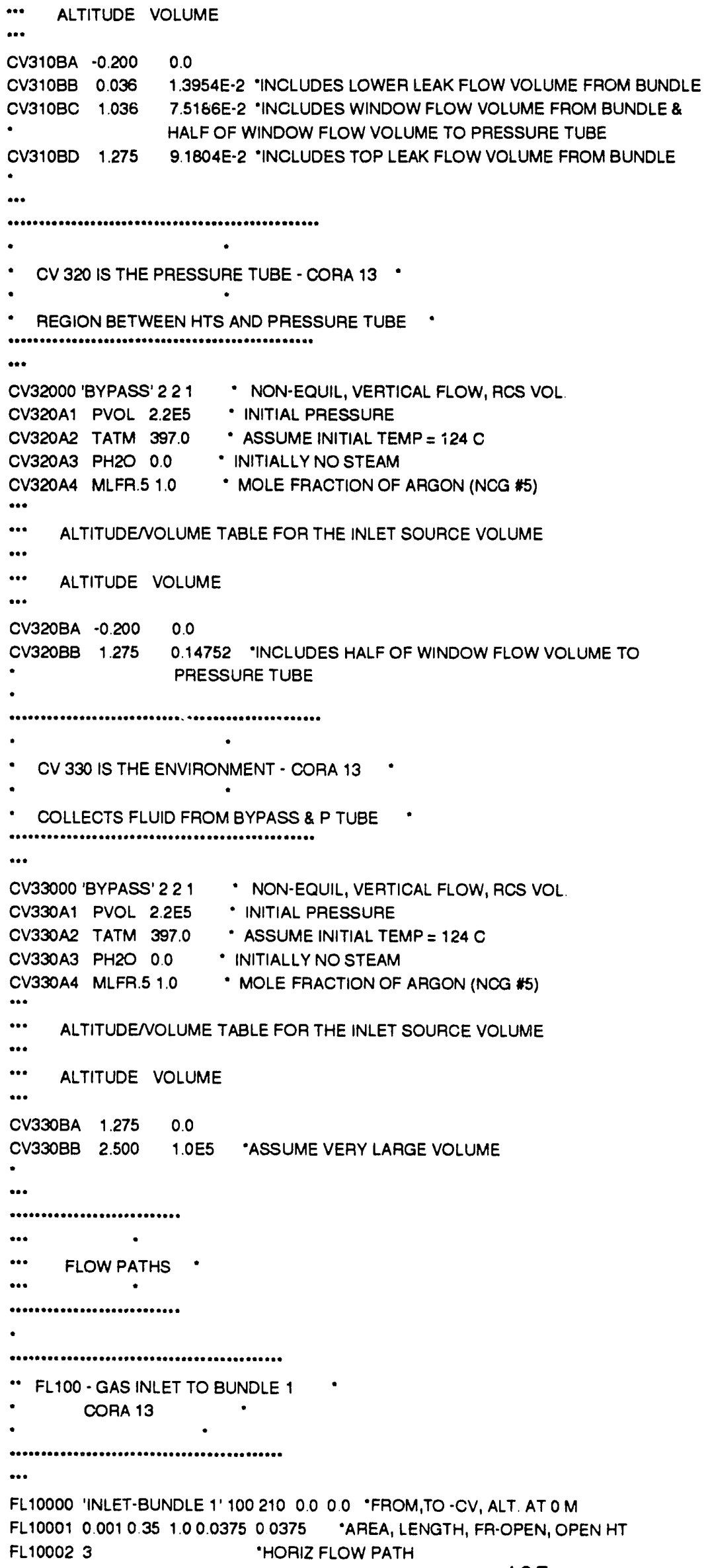




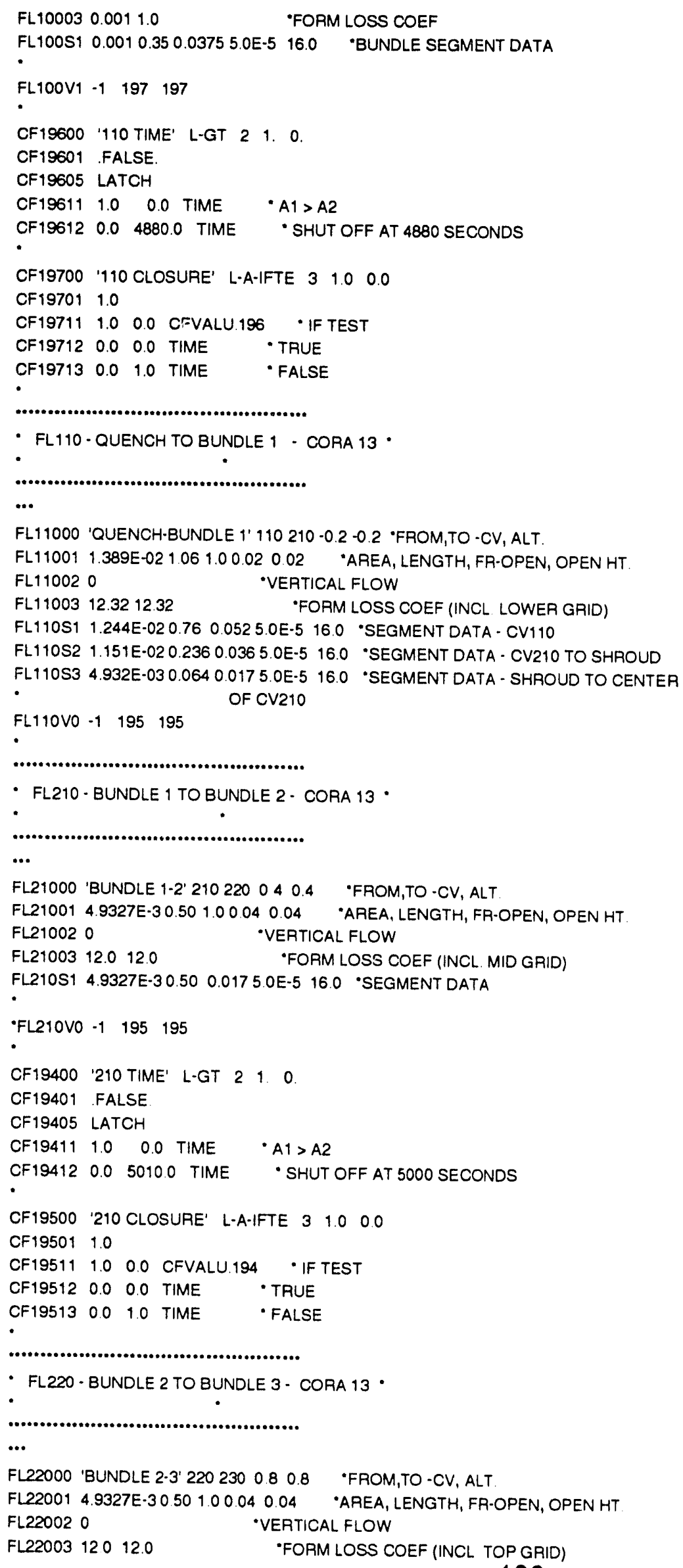




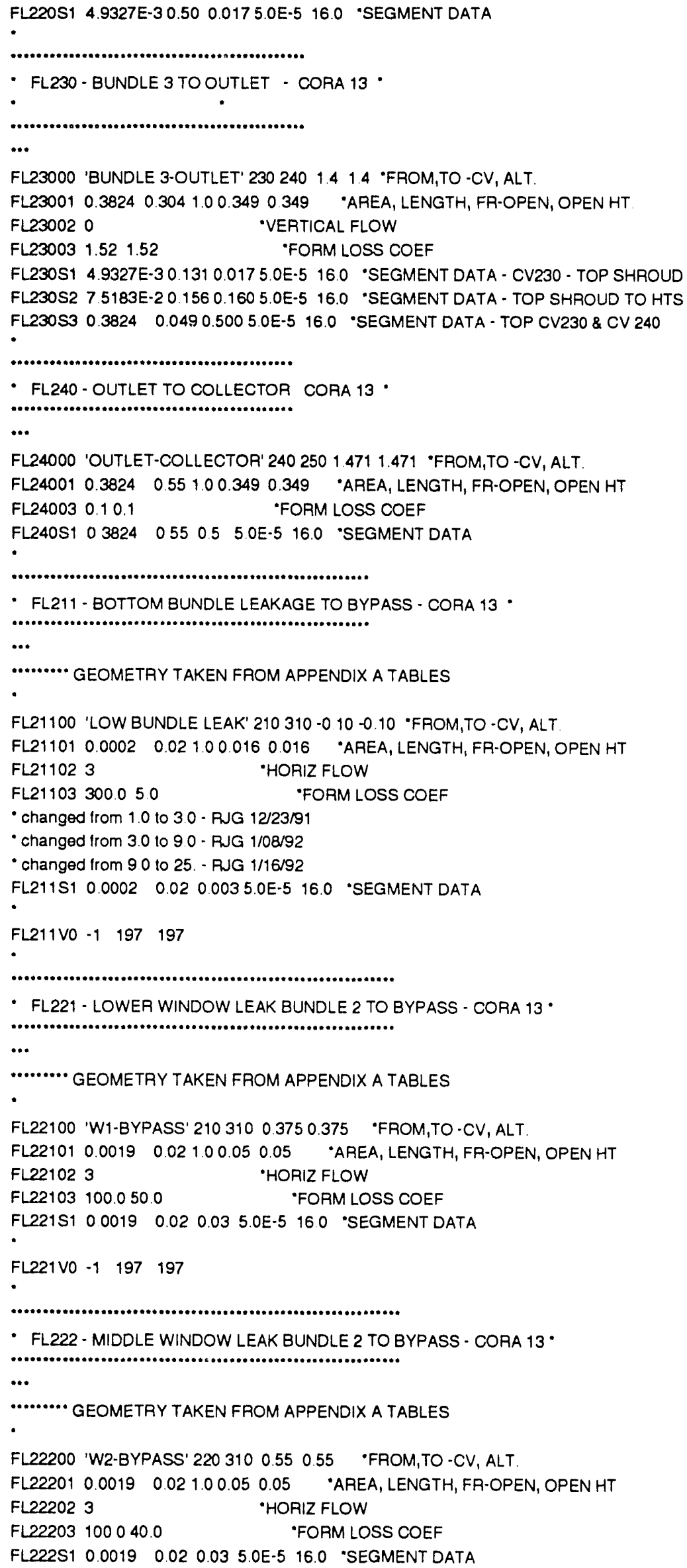




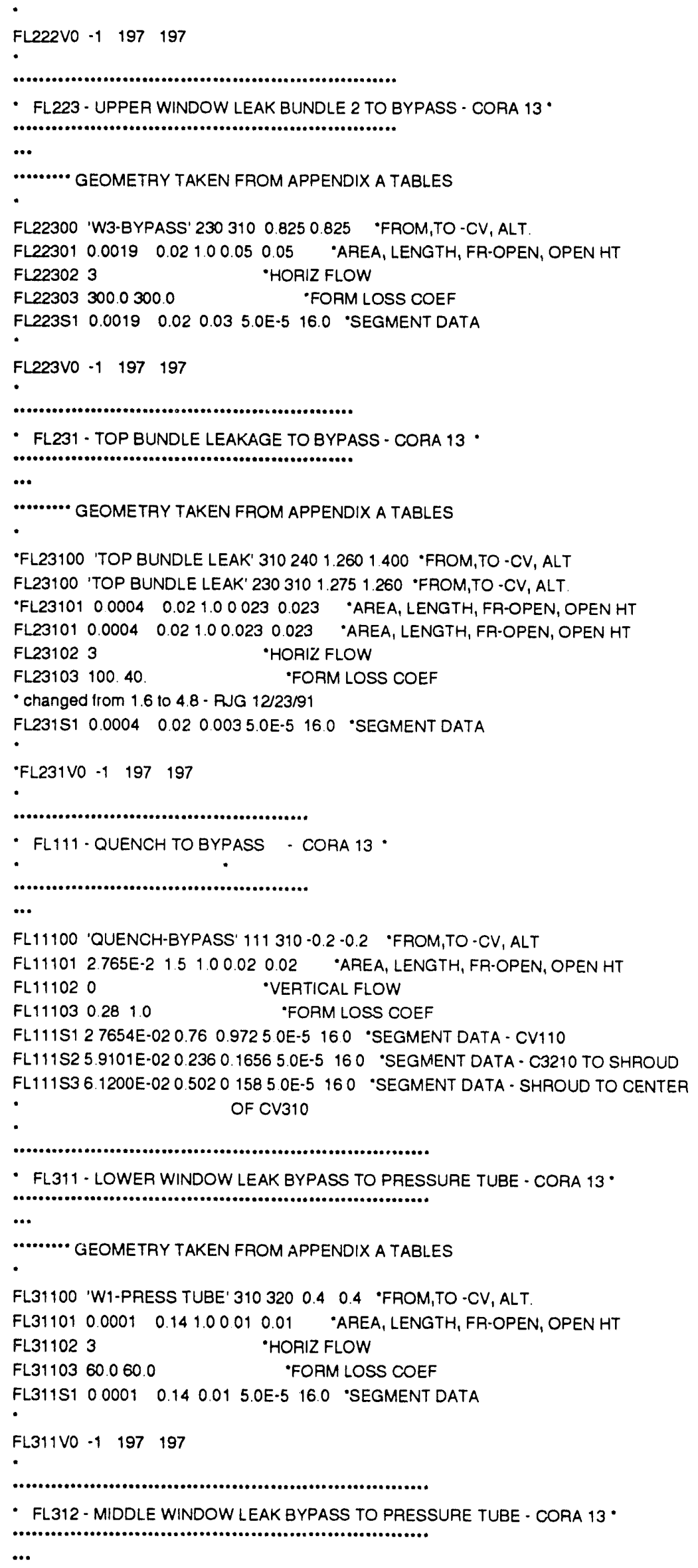




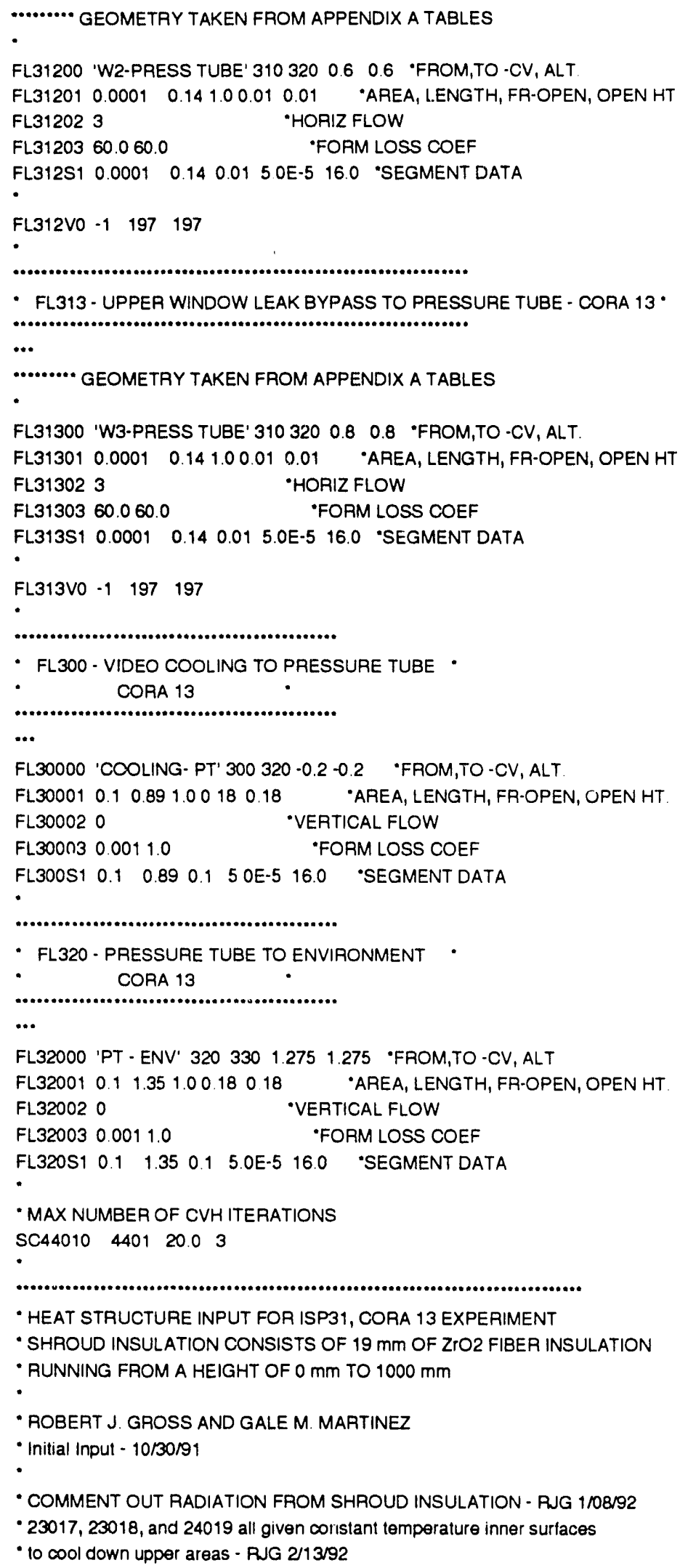




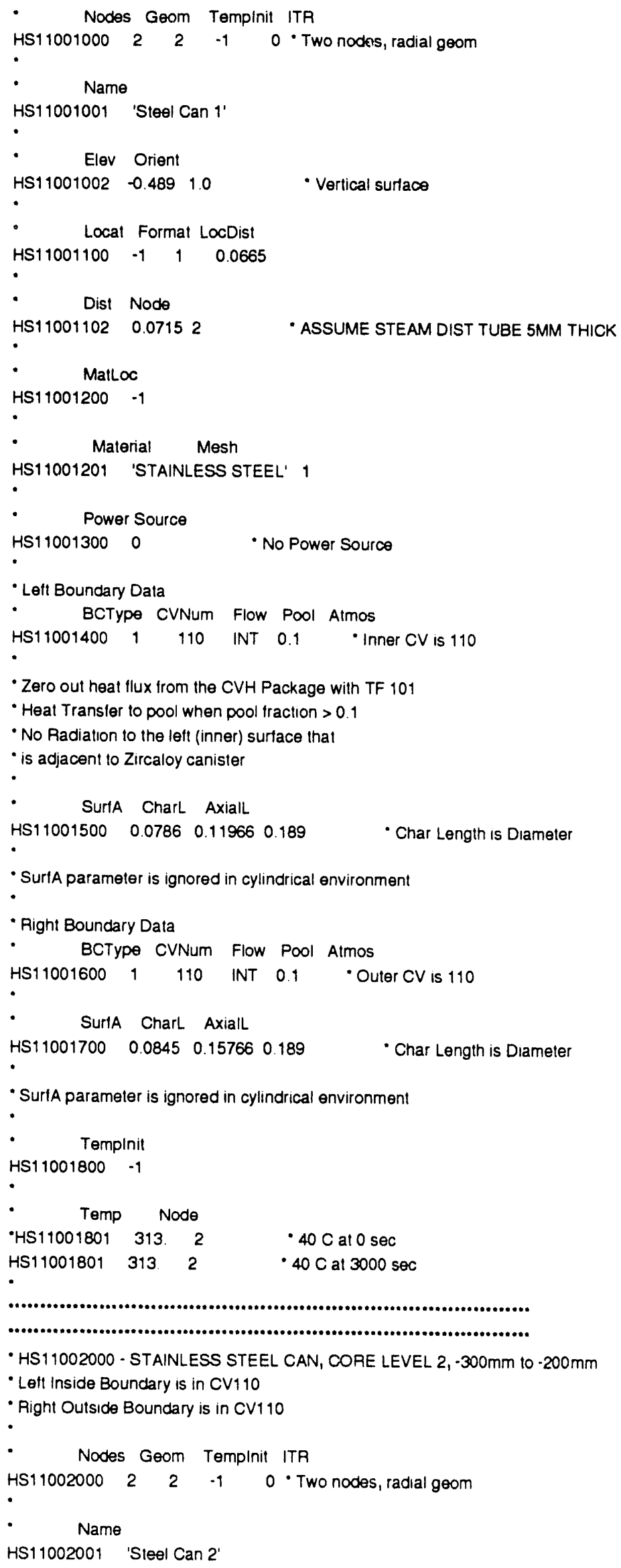




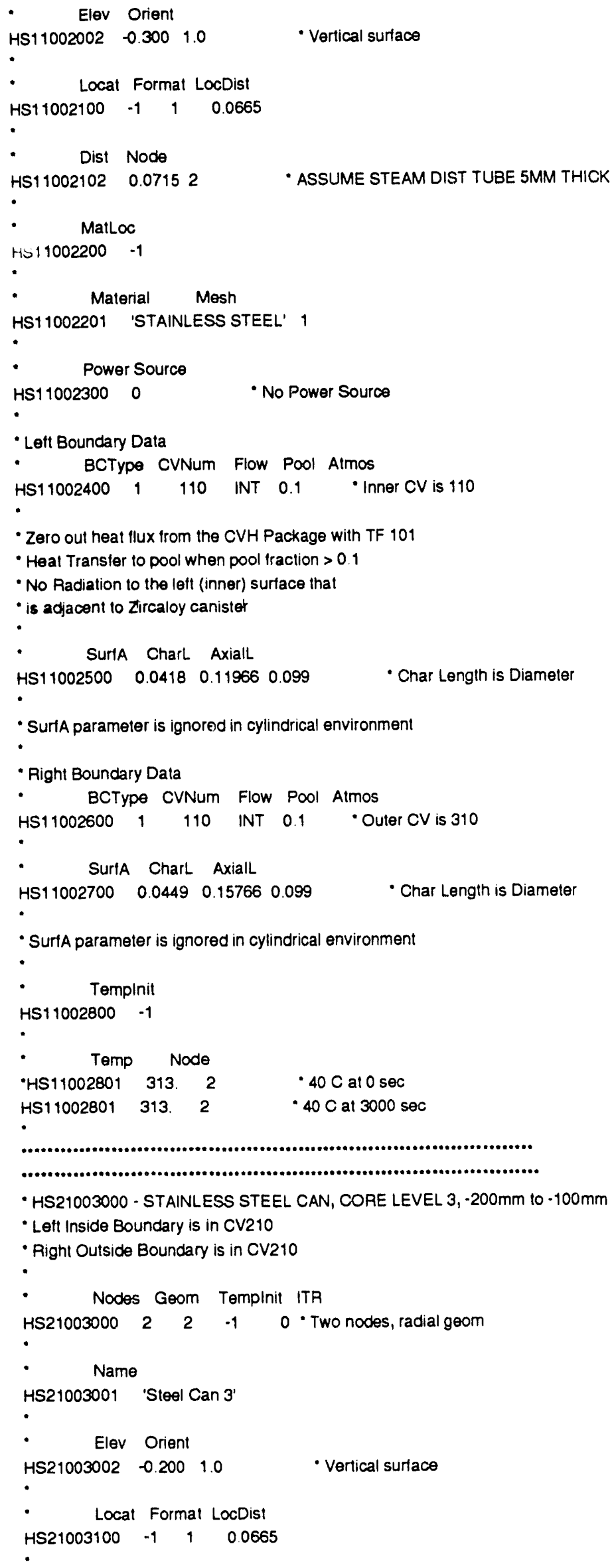




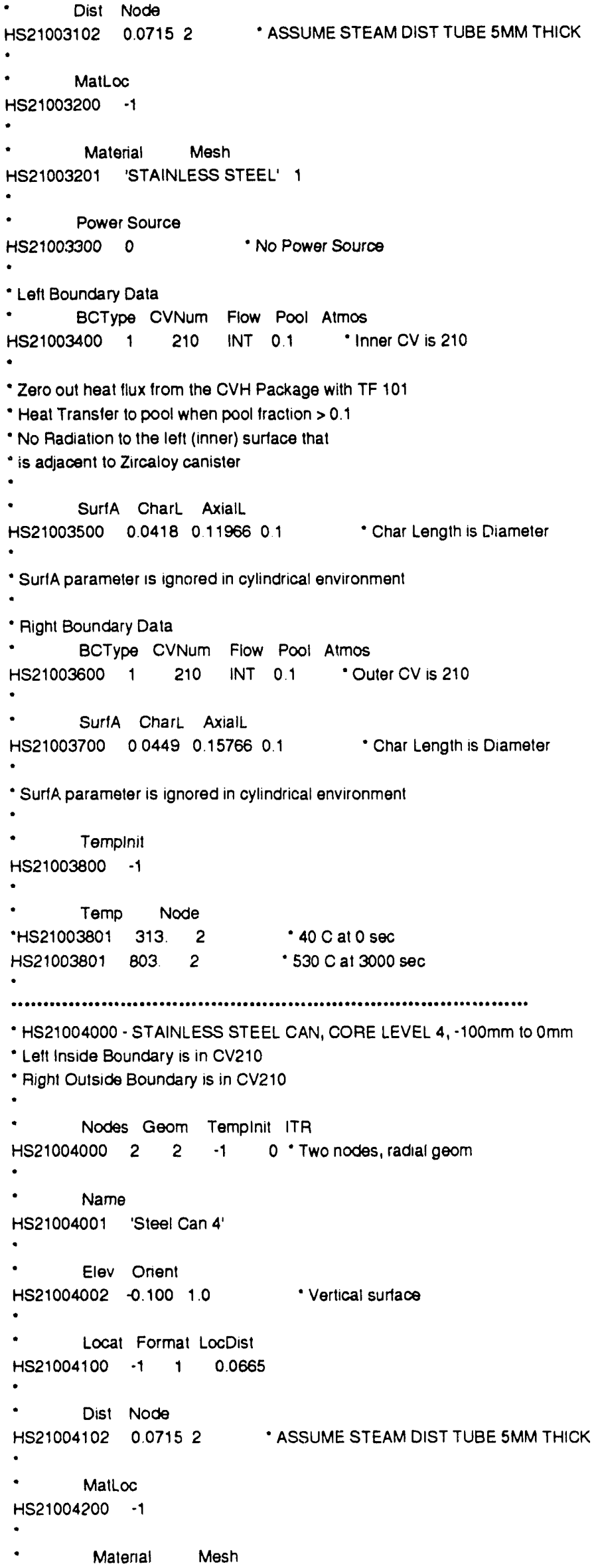




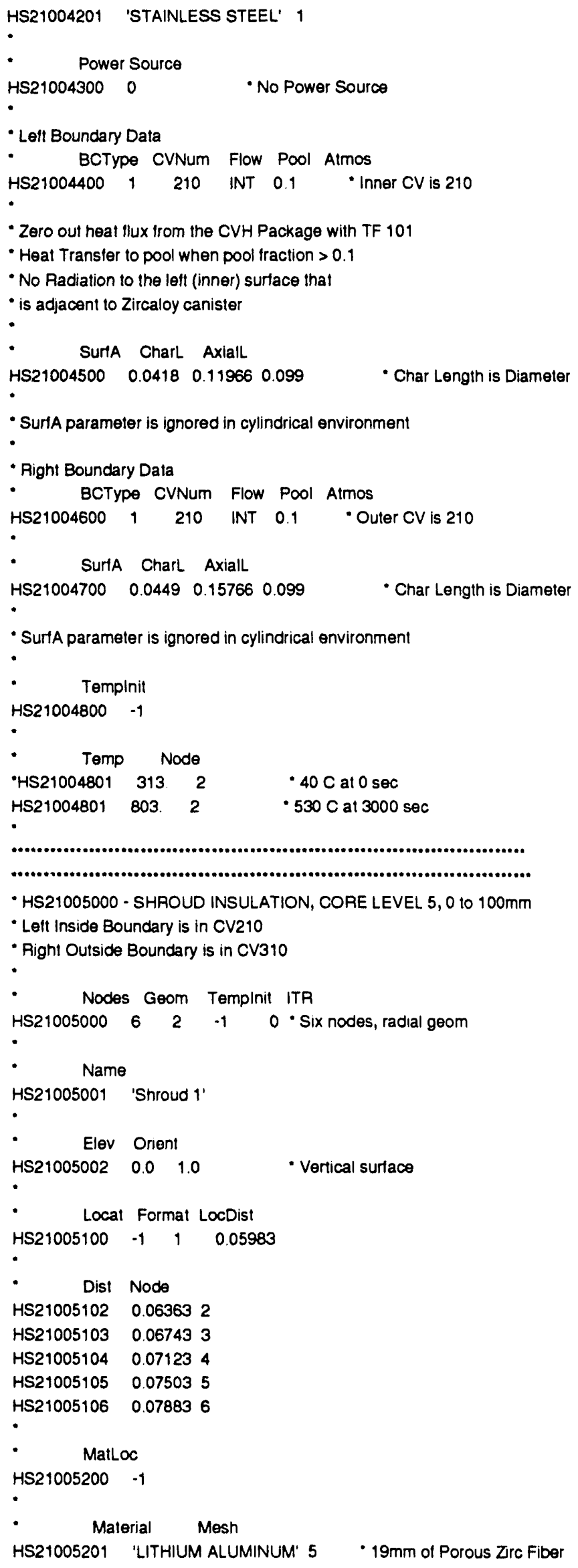




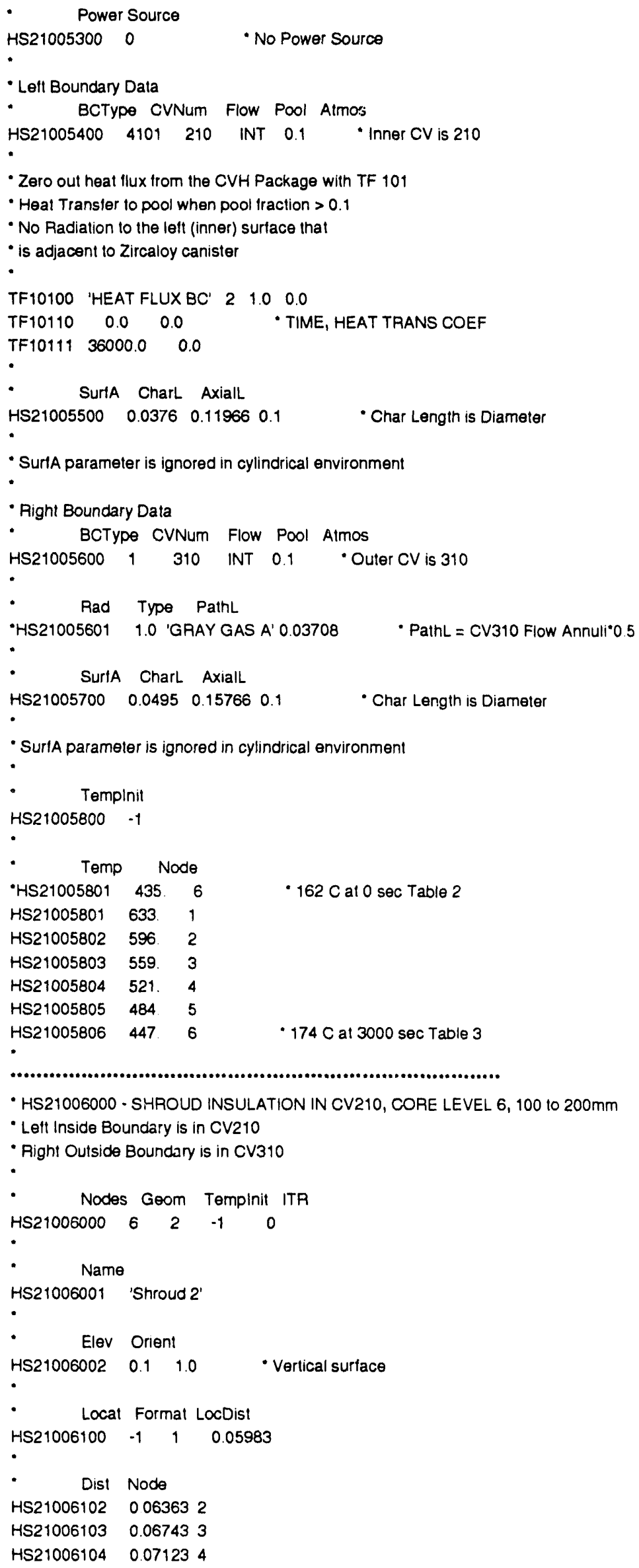




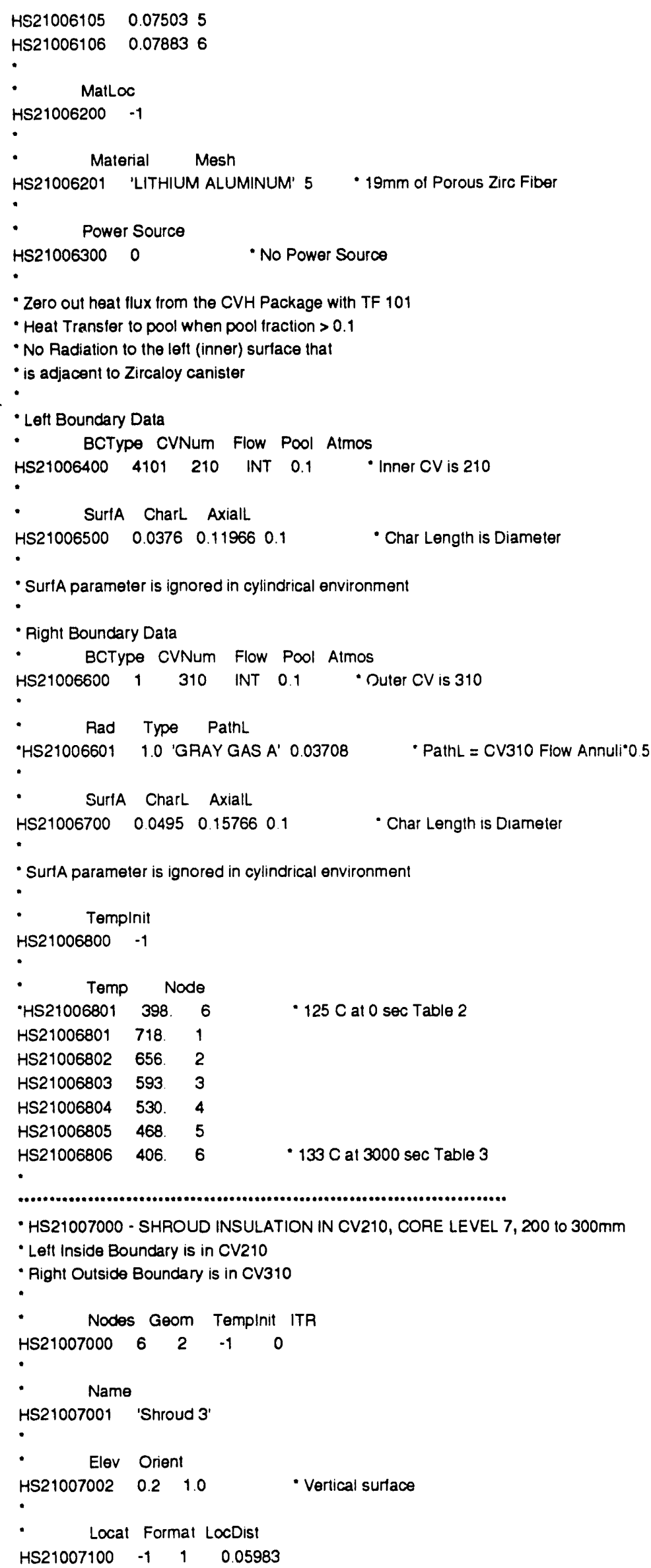




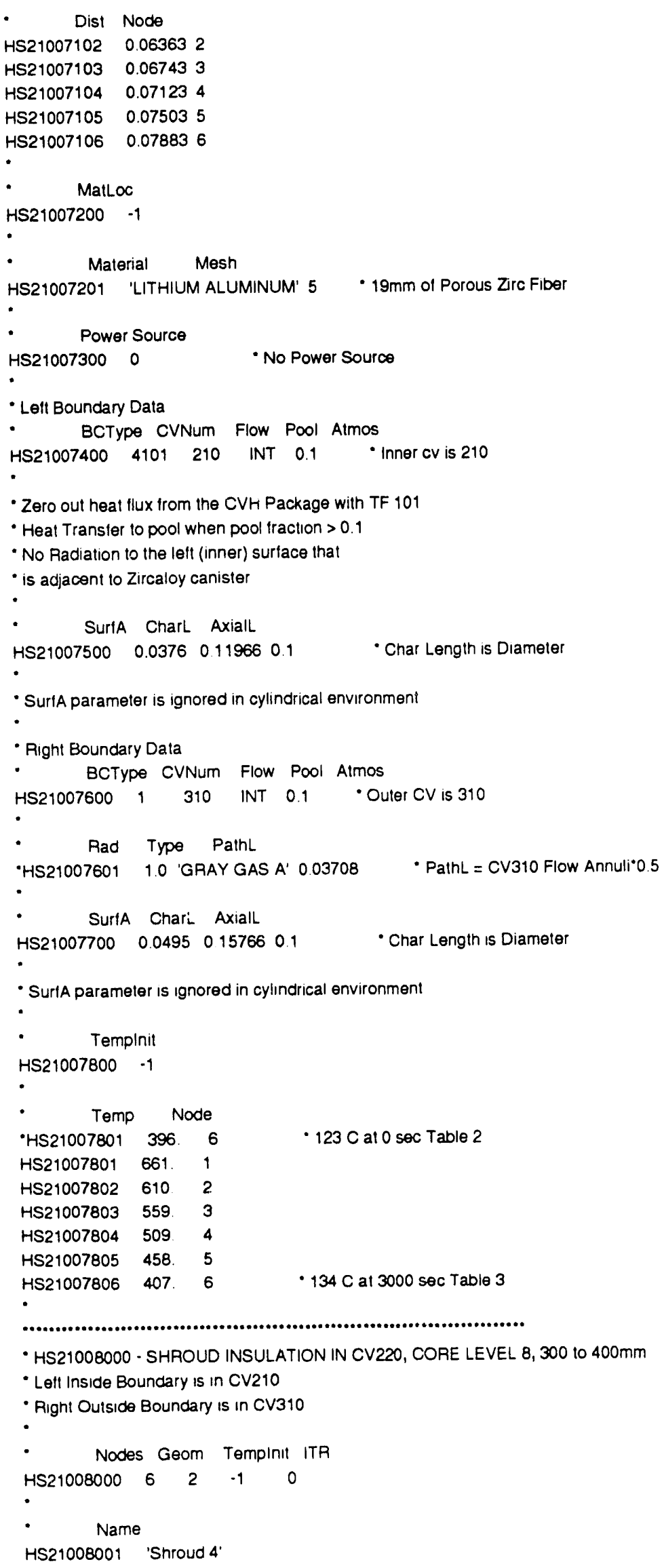




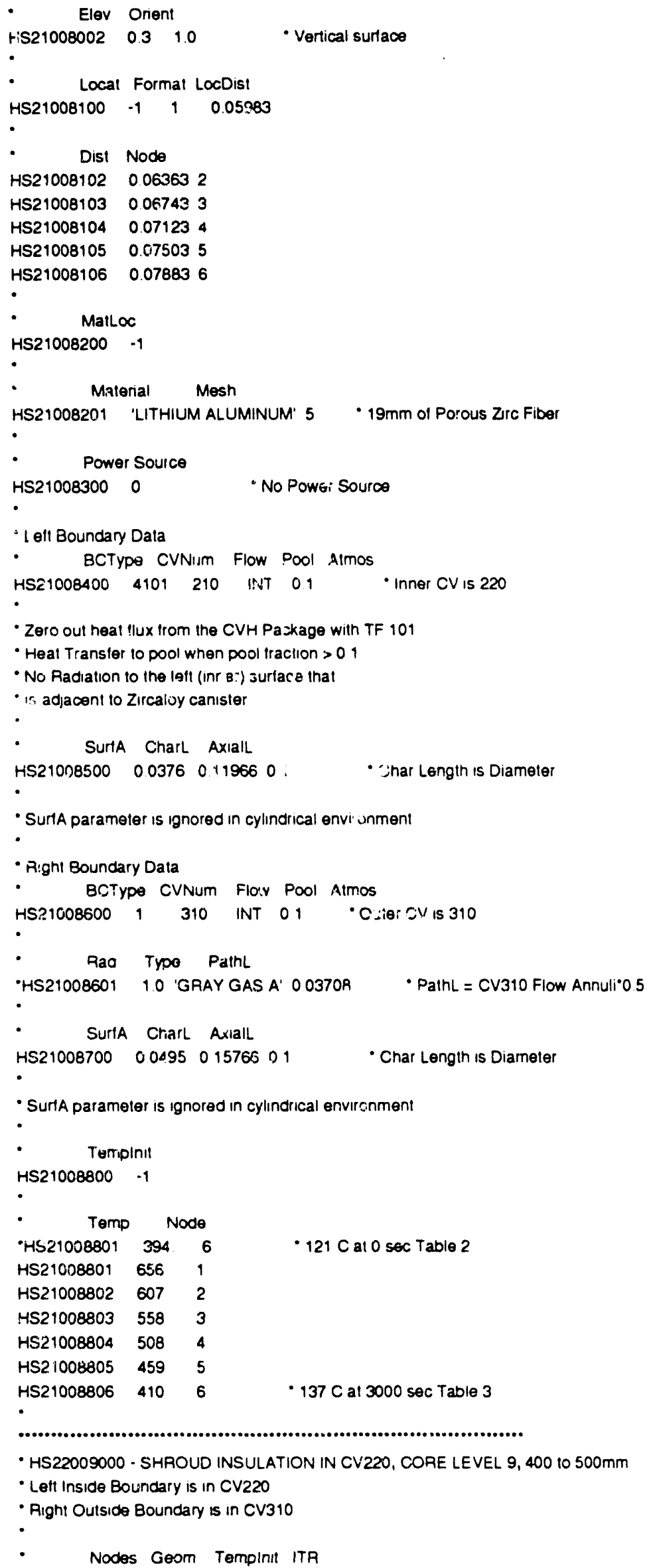




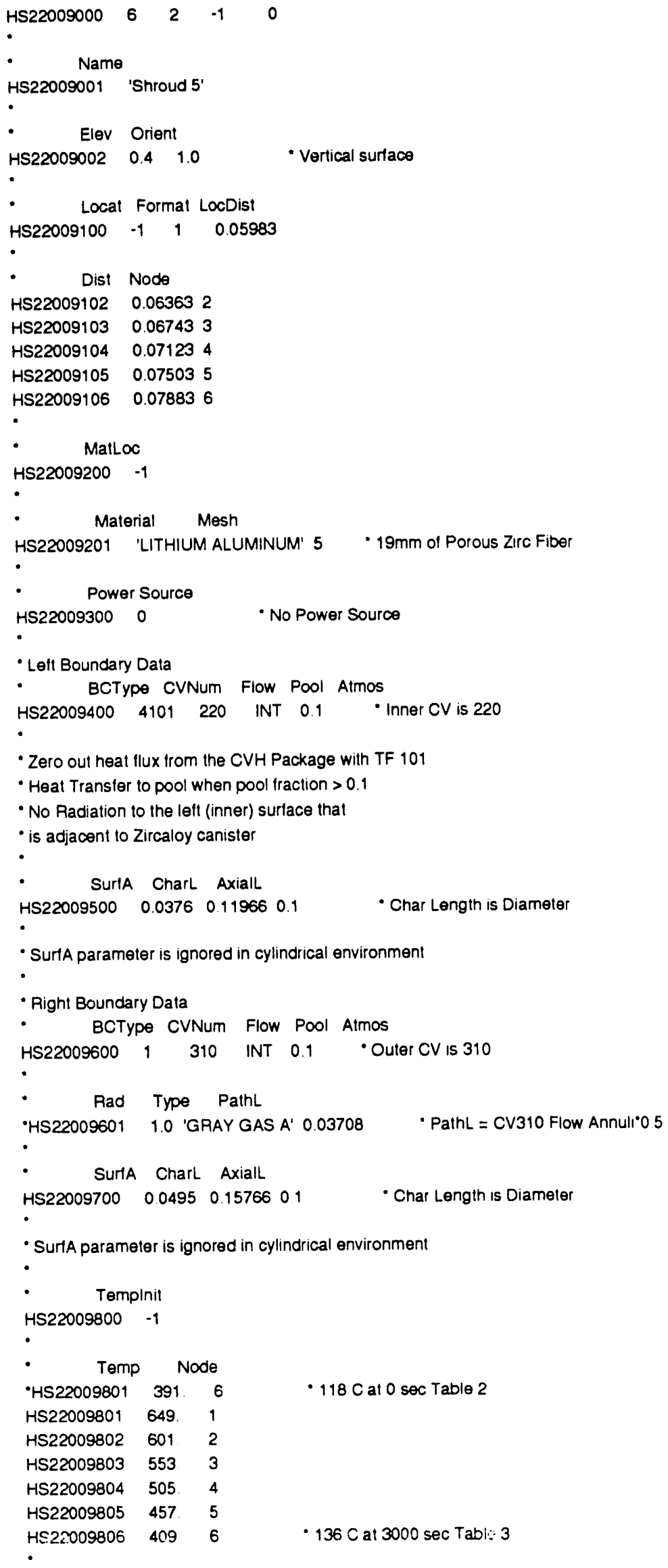


- HS22010000 - SHROUD INSULATION IN CV220, CORE LEVEL 10,500 $10600 \mathrm{~mm}$

- Left inside Boundary is in CV2zo

- Right Outside Boundary is in CV310

- Nodes Geom Templnit ITR

$\begin{array}{llllll}H S 22010000 & 6 & 2 & -1 & 0\end{array}$

- Name

HS22010001 'Shroud 6'

- Elev Orient

HS22010002 $0.5 \quad 1.0$

- Vertical surtace

- Locat format LocDist

$\begin{array}{llll}\text { HS22010100 } & -1 & 1 & 0.05983\end{array}$

- Dist Node

HS22010102 0.063632

HS22010103 0.067433

HS22010104 0.071234

HS22010105 0.075035

HS22010106 0.078836

- Matloc

HS22010200 -1

- Material Mesh

HS22010201 'LITHIUM ALLUMINUM' $5 \quad$ • 19mm of Porous Zirc Fiber

HS22010300 $0 \quad$ No Power Source

- Zero out heat flux from the CVH Package with TF 101

- Heat Transter to pool when pool fraction $>0.1$

- No Radiation to the left (inner) surface that

- is adjacent to Zircaloy canister

- Left Boundary Data

- BCType CVNum flow Pool Atmos

HS22010400 $4101220 \quad$ INT $0.1 \quad *$ Inner CV is 220

- Surta parameter is ignored in cylindrical environment

- Suria Charl axiall

HS22010500 $0.03760 .119660 .1 \quad$ Char Length is Diameter

- Right Boundary Data

- BCTypo CVNum Flow Pool Almos

HS22010600 1310 INT $0.1 \quad$ Outer CV is 310

- Rad Type Pathl

•HS22010601 1.0 'GRAY GAS A' $0.03708 \quad$ PathL $=$ CV310 Flow Annuli॰0.5

- Suría Charl axiall

HS22010700 $0.04950 .1576601 \quad$ Char Length is Diameter

- Surfa parameter is ignored in cylindrical environment

- Templnit

HS22010800 -1

- Temp Node

.HS22010801 389. 6

HS22010801 $643 \quad 1$

HS22010802 596. 2

HS22010803 549. 3 


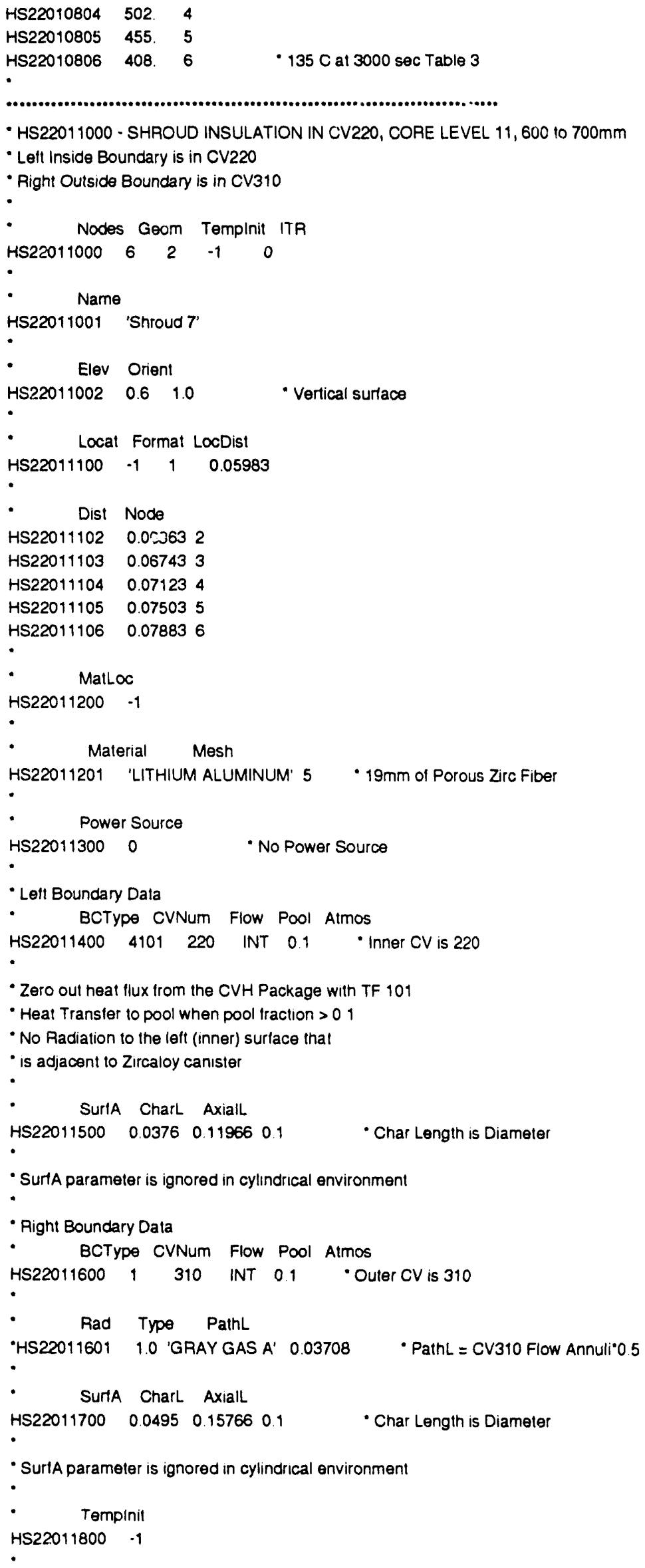




\begin{tabular}{|c|c|c|c|}
\hline Temp & \multicolumn{2}{|c|}{ Node } & \\
\hline •HS22011801 & 388. & 6 & - $115 \mathrm{C}$ al 0 sec Table 2 \\
\hline HS22011801 & 636. & 1 & \\
\hline HS22011802 & 590. & 2 & \\
\hline HS22011803 & 544 & 3 & \\
\hline HS22011804 & 499. & 4 & \\
\hline HS22011805 & 453. & 5 & \\
\hline HS22011806 & 407. & 6 & - $134 \mathrm{C}$ at 3000 sec Table 3 \\
\hline
\end{tabular}

- HS22012000 - SHROUD INSULATION IN CV220, CORE LEVEL 12, $70010800 \mathrm{~mm}$

- Left Inside Boundary is in CV2zo

- Right Outside Boundary is in CV310

- Nodes Geom Templnit ITR

$\begin{array}{lllll}H S 22012000 & 6 & 2 & -1 & 0\end{array}$

-

- Name

HS22012001 'Shroud 8'

-

- Eler Orient

$\begin{array}{llll}\text { HS22012002 } & 0.7 & 1.0 & \text { V Vertical surlace }\end{array}$

- Locat Format LocDist

$\begin{array}{llll}H S 22012100 & -1 & 1 & 0.05983\end{array}$

-

- Dist Node

HS22012102 0.063632

HS22012103 0.067433

HS22012104 0.071234

HS22012105 0.075035

HS22012106 0.078836

-

- MatLoc

HS22012200 -1

.

- Material Mesh

HS22012201 'LITHIUM ALUMINUM' $5 \quad$ • 19mm of Porous Zirc Fiber

-

- Power Source

HS22012300 0 "No Power Source

-

- Left Boundary Data

- BCType CVNum Flow Pool Atmos

$\begin{array}{lllll}\text { HS22012400 } & 4101 & 220 & \text { INT } 0.1 \quad \text { Inner CV is } 220\end{array}$

-

- Zero out heat flux from the CVH Package with TF 101

- Heat Transter to pool when pool fraction > 0.1

- No Radiation to the left (inner) surtace that

- is adjacent to Zircaloy canister

- Surta Charl axiall

HS22012500 $0.03760 .119600 .1 \quad$ Char Length is Diameler

-

- Surta parameter is ignored in cylindrical environment

-

- Right Boundary Data

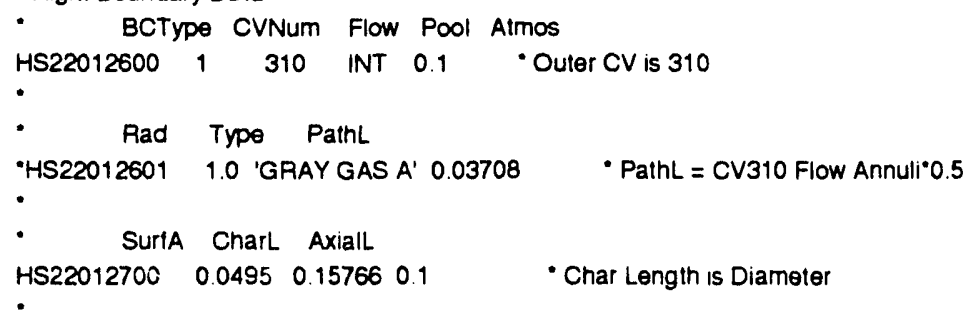




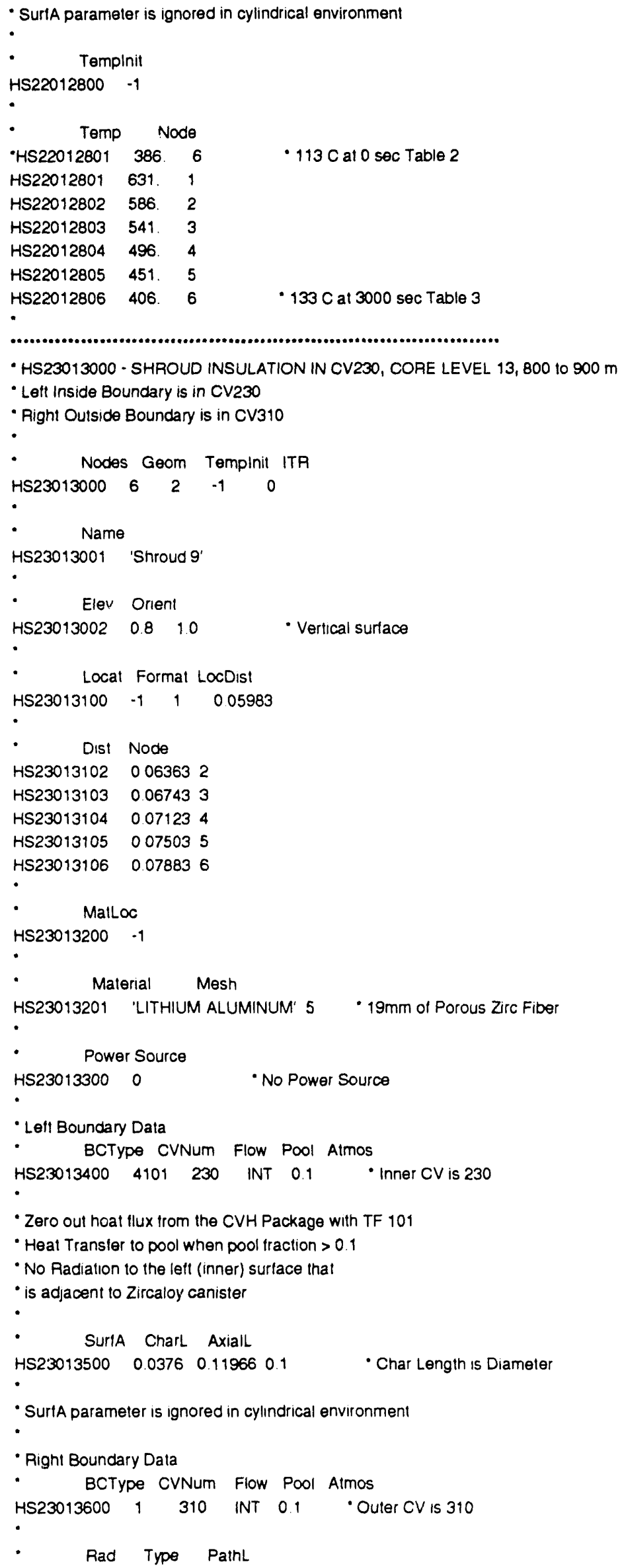




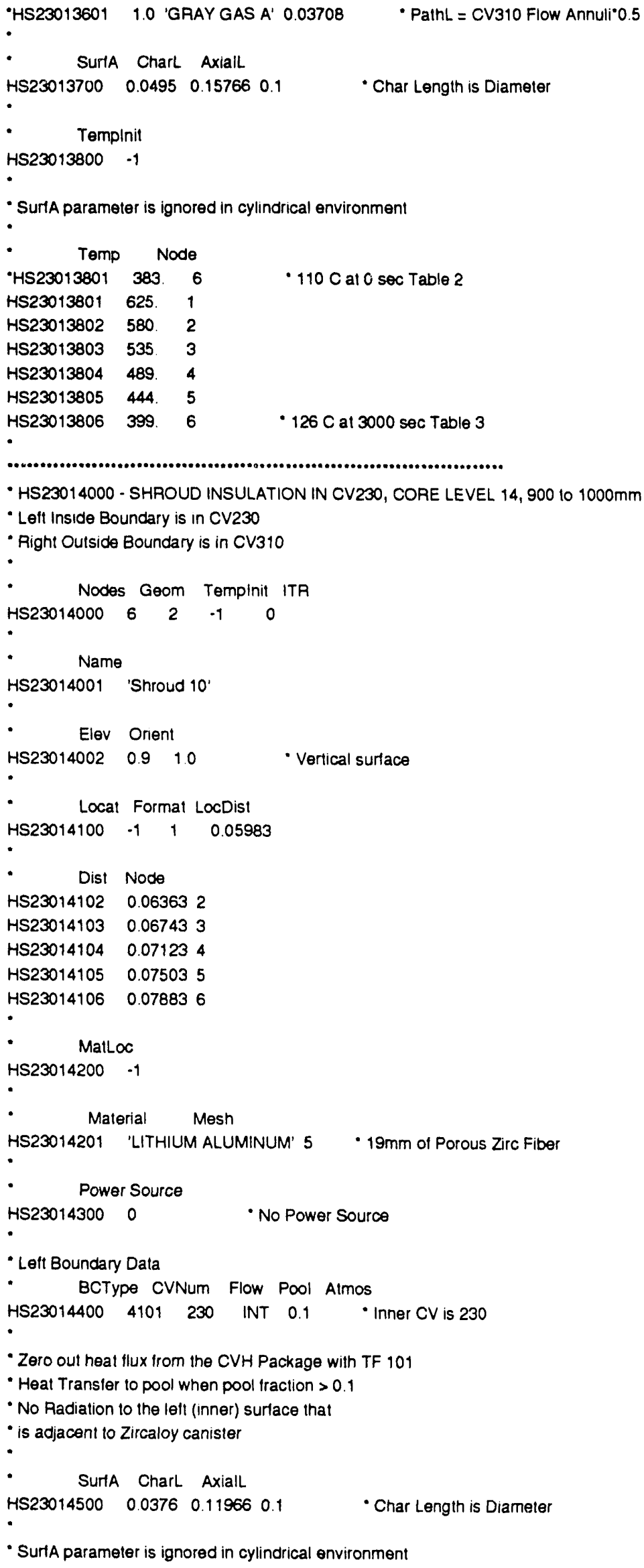




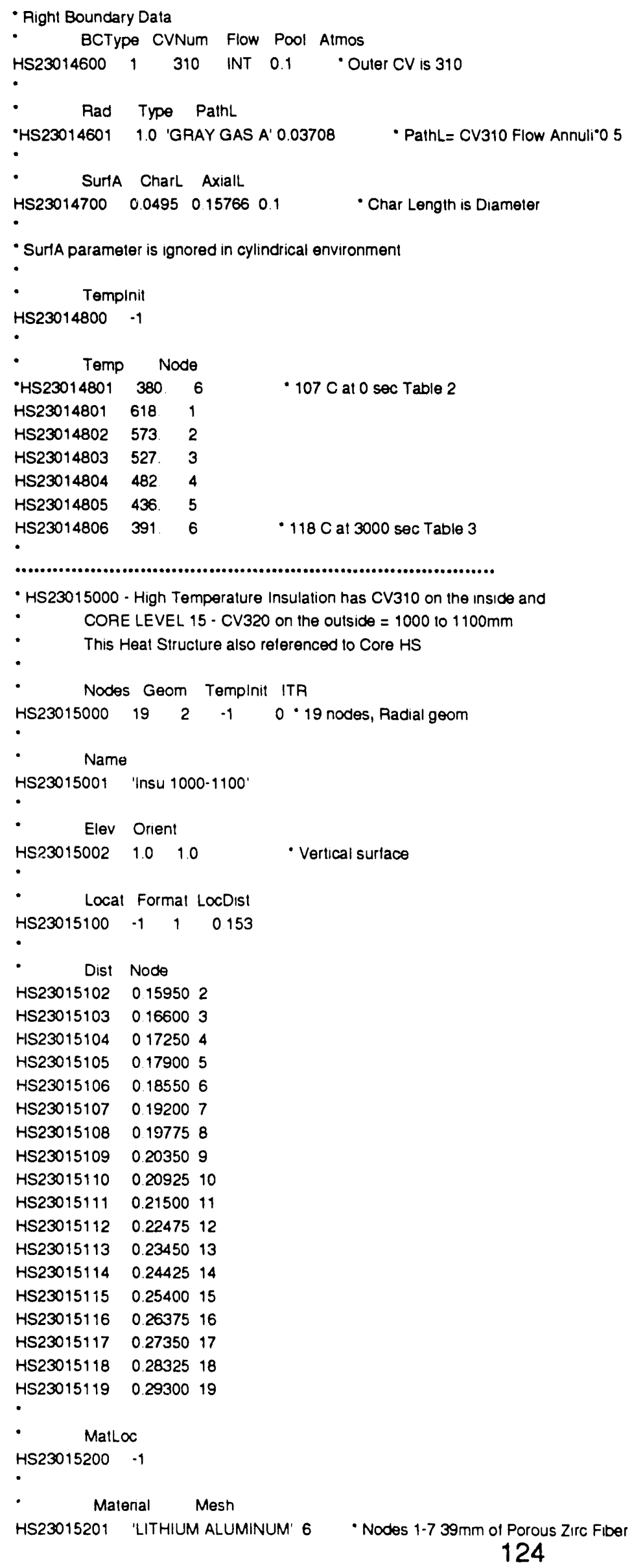




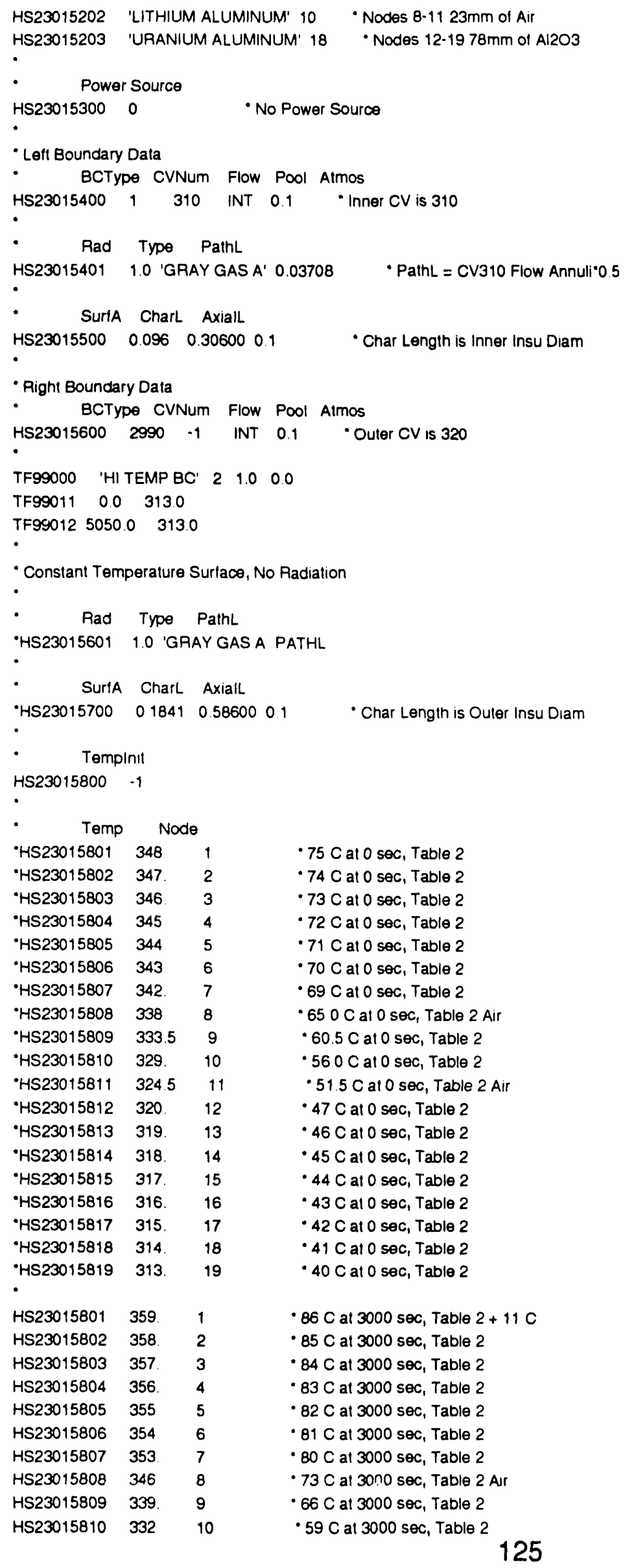




\begin{tabular}{|c|c|c|c|}
\hline HS23015811 & 325 & 11 & - $52 \mathrm{C}$ at $3000 \mathrm{sec}$, Table $2 \mathrm{~A}$ \\
\hline HS23015812 & 320 & 12 & - $47 \mathrm{C}$ at $3000 \mathrm{sec}$, Table 2 \\
\hline HS23015813 & 319 & 13 & - $46 \mathrm{C}$ at 3000 sec, Table 2 \\
\hline HS23015814 & 318. & 14 & - $45 \mathrm{C}$ at 3000 sec, Table 2 \\
\hline HS23015815 & 317. & 15 & - $44 \mathrm{C}$ at $3000 \mathrm{sec}$, Table 2 \\
\hline HS23015816 & 316. & 16 & - $43 \mathrm{C}$ at 3000 sec, Table 2 \\
\hline HS23015817 & 315 & 17 & - $42 \mathrm{C}$ at 3000 sec, Table 2 \\
\hline HS23015818 & 314 & 18 & - $41 \mathrm{C}$ at 3000 sec, Table 2 \\
\hline HS23015819 & 313 & 19 & - $40 \mathrm{C}$ at 3000 sec, Table 2 \\
\hline
\end{tabular}

- HS23016000 - High Temperature Insulation has CV310 on the inside and

- CV320 on the outside $=1100101200 \mathrm{~mm}$

- This Heat Structure also referenced to Core HS

$\cdot$

- Nodes Geom Templnit ITA

\begin{tabular}{llllll} 
HS23016000 & 19 & 2 & -1 & 0 & \\
\hline & 19 nodes, Radial geom
\end{tabular}

-

- Name

HS23016001 'Insu 1100-1200'

-

- Elev Orient

$\begin{array}{llll}\text { HS23016002 } & 1.1 & 1.0 & \text { V Vertical surface }\end{array}$

-

- Locat Format LocDist

$\begin{array}{llll}H S 23016100 & -1 & 1 & 0.153\end{array}$

.

- Dist Node

HS23016102 0.159502

HS23016103 0166003

HS23016104 0172504

HS23016105 0.179005

HS23016106 0.185506

$\begin{array}{ll}H S 23016107 & 0.192007\end{array}$

HS23016108 0.197758

$\begin{array}{lll}H S 23016109 & 0.203509\end{array}$

HS23016110 0.2092510

HS23016111 0.2150011

HS23016112 0.2247512

HS23016113 $0.23450 \quad 13$

HS23016114 02442514

HS23016115 0.2540015

HS23016116 0.2637516

HS23016117 0.2735017

HS23016118 $0.28325 \quad 18$

HS23016119 02930019

-

- MatLoc

HS23016200 -1

-

- Malerial Mosn

HS23016201 'LITHIUM ALUMINUM' 6 -Nodes $1.739 \mathrm{~mm}$ ol Porous Zirc Fiber

HS23016202 'LITHIUM ALUMINUM' 10 'Nodes 8-11 23mm of Air

HS23016203 'URANIUM ALUMINUM' 18 'NOdes $12-1978 \mathrm{~mm}$ ol AlZO3

-

- Power Source

HS23016300 0 - No Power Source

-

- Left Boundary Data

- BCType CVNum flow Pool Almos

HS23016400 1310 INT $01 \quad \cdot$ Inner CV is 310

.

- Rad Type Pathl

HS23016401 10 'GRAY GAS A' $003708 \quad$ PathL = CV310 Flow Annull 05

-

- Surla Charl axiall 
HS23016500 $0.09603060001 \quad$ Char Length is Inner Insu Diam

- Right Boundary Data

- BCTypo CVNum flow pool Atmos

$\begin{array}{llllll}\text { HS23016600 } & 2990 & -1 & \text { INT } & 0.1 & \end{array}$

-

- Constant Temperature Surface, No Radiation

-

Rad Type PathL

-HS23016601 1.0 'GRAY GAS A PATHL

•

- Surla Charl Axiall

•HS23016700 $0.1841058600 \quad 0.1 \quad$ Char Length is Outer Insu Diam

-

- Templnit

HS23016800 - -1

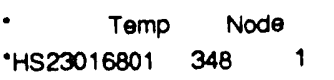

-HS23016802 $347 \quad 2$

-HS230168C3 346.3

.HS23016804 345. 4

-HS23016805 $344 \quad 5$

-HS23016806 $343 \quad 6$

-HS23016807 $342 \quad 7$

-HS23016808 $338 \quad 8$

-HS23016809 33359

-HS23016810 $329 \quad 10$

-HS23016811 $3245 \quad 11$

-HS23016812 $320 \quad 12$

-HS23016813 $319 \quad 13$

•HS23016814 $318 \quad 14$

-HS23016815 $317 \quad 15$

HSS23016816 $316 \quad 16$

$\begin{array}{lll}\text { HS } & 3016817 \quad 315 \quad 17\end{array}$

•HS23016818 $314 \quad 18$

•HS23016819 $313 \quad 19$

- 75 C at 0 sec, Table 2

- $74 \mathrm{C}$ al 0 sec, Table 2

- $73 \mathrm{C}$ at 0 sec, Table 2

- $72 \mathrm{C}$ at 0 sec, Table 2

- $71 \mathrm{C}$ at 0 sec, Table 2

- $70 \mathrm{C}$ at 0 sec, Table 2

- $69 \mathrm{C}$ al 0 sec, Table 2

- 65. 0 C at 0 sec, Table 2 Air

- $605 \mathrm{C}$ at 0 sec, Table 2

- $560 \mathrm{C}$ at 0 sec, Table 2

- $51.5 \mathrm{C}$ at 0 sec, Table 2 Air

- $47 \mathrm{C}$ at 0 sec, Table 2

- $46 \mathrm{C}$ al 0 sec, Table 2

- $45 \mathrm{C}$ at 0 sec, Table 2

- $44 \mathrm{C}$ at 0 sec, Table 2

- $43 \mathrm{C}$ at 0 sec, Table 2

- $42 \mathrm{C}$ al 0 sec, Table 2

- $41 \mathrm{C}$ at 0 sec, Table 2

- $40 \mathrm{C}$ at 0 sec, Table 2

HS23016801 $359 \quad 1 \quad \cdot 86 \mathrm{C}$ at $3000 \mathrm{sec}$, Table $2+11 \mathrm{C}$

HS23016802 $358 \quad 2 \quad \cdot 85 \mathrm{C}$ al $3000 \mathrm{sec}$, Table 2

$\begin{array}{llll}H S 23016803 & 357 & 3 & \cdot B 4 \mathrm{C} \text { at } 3000 \mathrm{sec}, \text { Table } 2\end{array}$

HS23016804 $356 \quad 4 \quad \cdot 83 \mathrm{C}$ at $3000 \mathrm{sec}$, Table 2

HS23016805 $355 \quad 5 \quad \cdot 82 \mathrm{C}$ al $3000 \mathrm{sec}$, Table 2

HS23016806 354. $6 \quad \cdot 81 \mathrm{C}$ at $3000 \mathrm{sec}$, Table 2

HS23016807 353. $7 \quad \cdot 80 \mathrm{C}$ at $3000 \mathrm{sec}$, Table 2

HS23016808 $346 \quad 8 \quad \cdot 73 \mathrm{C}$ al $3000 \mathrm{sec}$, Table 2 Air

HS23016809 $339 \quad 9 \quad \cdot 66 \mathrm{C}$ at $3000 \mathrm{sec}$, Table 2

HS23016810 $332 \quad 10 \quad \cdot 59 \mathrm{C}$ at $3000 \mathrm{sec}$, Table 2

HS23016811 $325 \quad 11 \quad .52 \mathrm{C}$ at $3000 \mathrm{sec}$, Table 2 Air

HS23016812 $320 \quad 12 \quad \cdot 47 \mathrm{C}$ at $3000 \mathrm{sec}$, Table 2

HS23016813 $319 \quad 13 \quad-46 \mathrm{C}$ at $3000 \mathrm{sec}$, Table 2

$\begin{array}{llll}\text { HS23016814 } & 318 & 14 & \cdot 45 \mathrm{C} \text { al } 3000 \mathrm{sec} \text {, Table } 2\end{array}$

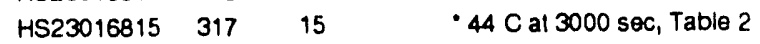

HS23016816 $316 \quad 16 \quad-43 \mathrm{C}$ at $3000 \mathrm{sec}$, Table 2

$\begin{array}{llll}H S 23016817 & 315 & 17 & \cdot 42 \mathrm{C} \text { at } 3000 \text { sec, Table } 2\end{array}$

$\begin{array}{llll}\text { HS23016818 } & 314 & 18 & \cdot 41 \mathrm{C} \text { al } 3000 \mathrm{sec}, \text { Table } 2\end{array}$

HS23016819 $313 \quad 19 \quad \cdot 40 \mathrm{C}$ at $3000 \mathrm{sec}$, Table 2

-

- HS23017000 - High Temperature Insulation has CV310 on the inside and

- CV320 on the outside $=1200101300 \mathrm{~mm}$

- This Heat Structure also relerenced to Core HS

-

- Nodes Geom Tempinit ITR

$\begin{array}{llllll}\text { HS23017000 } & 7 & 2 & -1 & 0 & \end{array}$ 


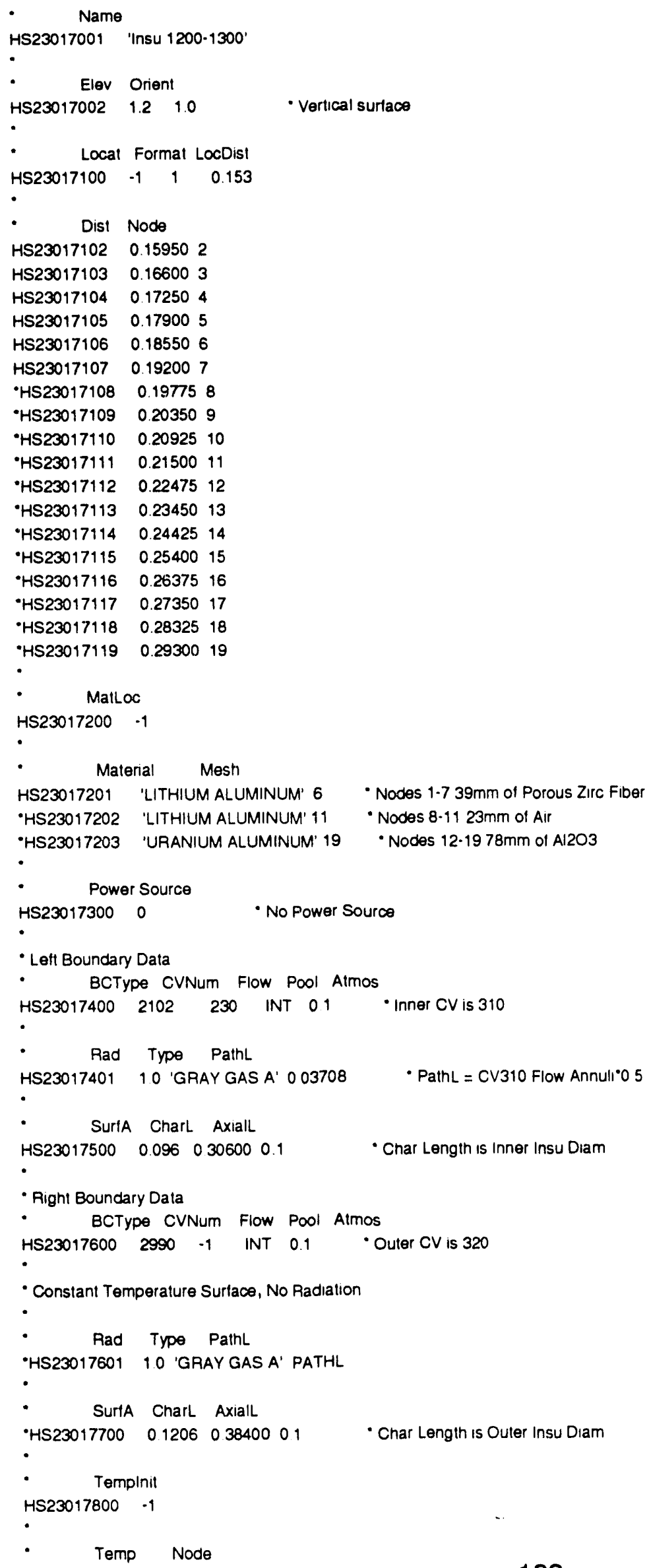




\begin{tabular}{|c|c|c|c|}
\hline •HS23017801 & 348. & 1 & - 75 C at 0 sec, Table 2 \\
\hline •HS23017802 & 347. & 2 & - $74 \mathrm{C}$ at 0 sec, Table 2 \\
\hline •HS23017803 & 346. & 3 & - $73 \mathrm{C}$ at 0 sec, Table 2 \\
\hline •HS23017804 & 345 & 4 & - 72 C at 0 sec, Table 2 \\
\hline •HS23017805 & 344 & 5 & - $71 \mathrm{C}$ at 0 sec, Table 2 \\
\hline -HS23017806 & 343 & 6 & - $70 \mathrm{C}$ al 0 sec, Table 2 \\
\hline •HS23017807 & 342. & 7 & - $69 \mathrm{C}$ at 0 sec, Table 2 \\
\hline HS23017801 & 359 & 1 & - $86 \mathrm{C}$ al $3000 \mathrm{sec}$, Table $2+11 \mathrm{C}$ \\
\hline HS23017802 & 358. & 2 & - $85 \mathrm{C}$ at 3000 sec, Table 2 \\
\hline HS23017803 & 357 & 3 & - $84 \mathrm{C}$ al $3000 \mathrm{sec}$, Table 2 \\
\hline HS23017804 & 356 & 4 & - $83 \mathrm{C}$ at 3000 sec, Table 2 \\
\hline HS23017805 & 355 & 5 & - $82 \mathrm{C}$ at 3000 sec, Table 2 \\
\hline HS23017806 & 354 & 6 & - $81 \mathrm{C}$ at $3000 \mathrm{sec}$, Table 2 \\
\hline HS23017807 & 353. & 7 & - $80 \mathrm{C}$ al $3000 \mathrm{sec}$, Table 2 \\
\hline
\end{tabular}

- HS23018000 - High Temperature Insulation has CV230 on the inside and

- CV230 on the outside $=1300$ to $1400 \mathrm{~mm}$

- Nodes Geom Tempinit ITR

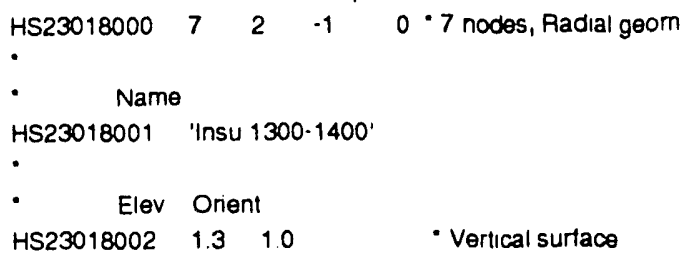




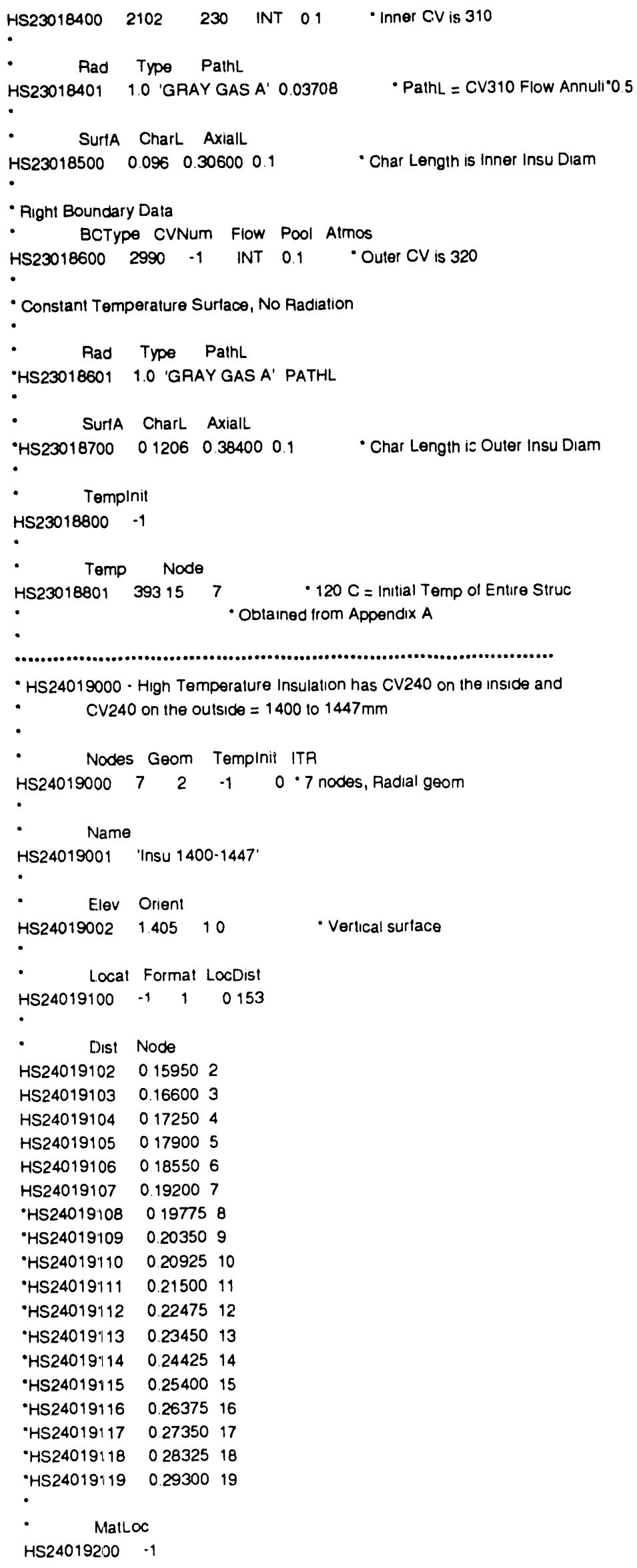




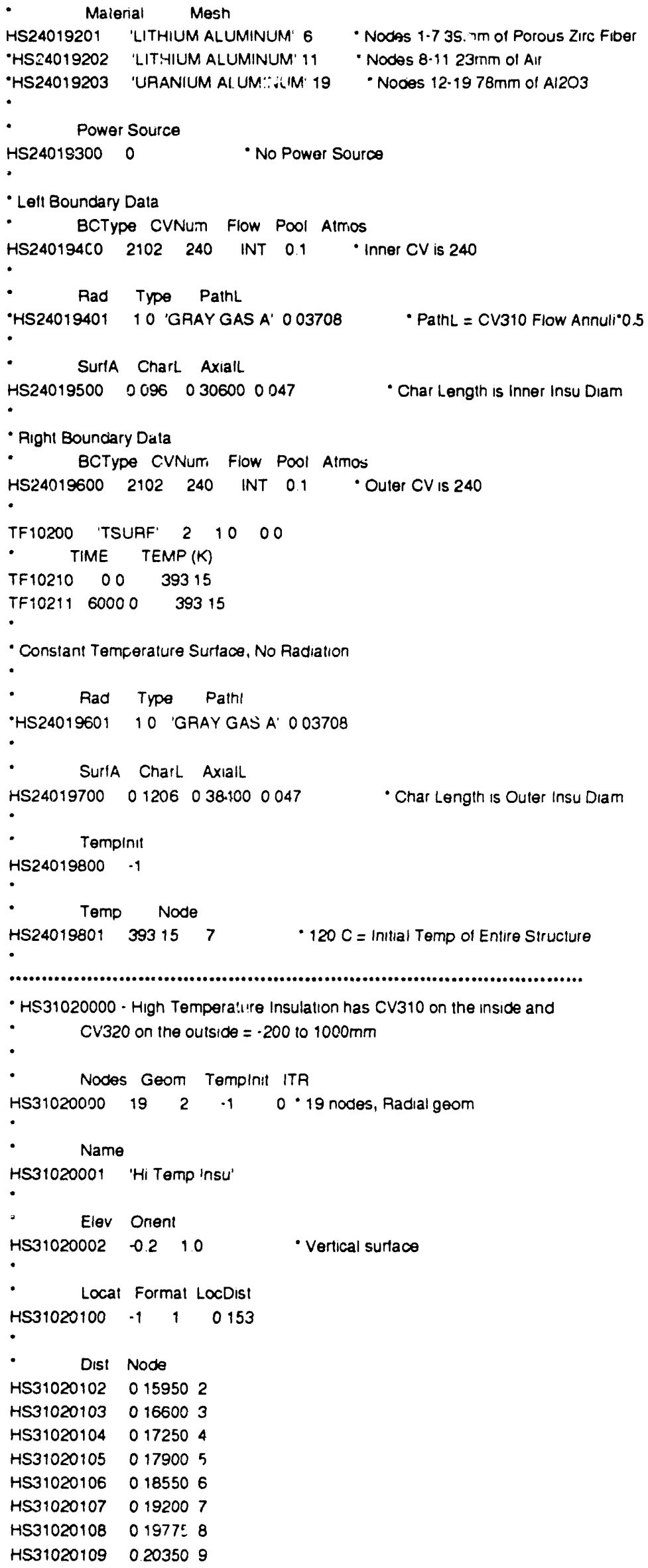




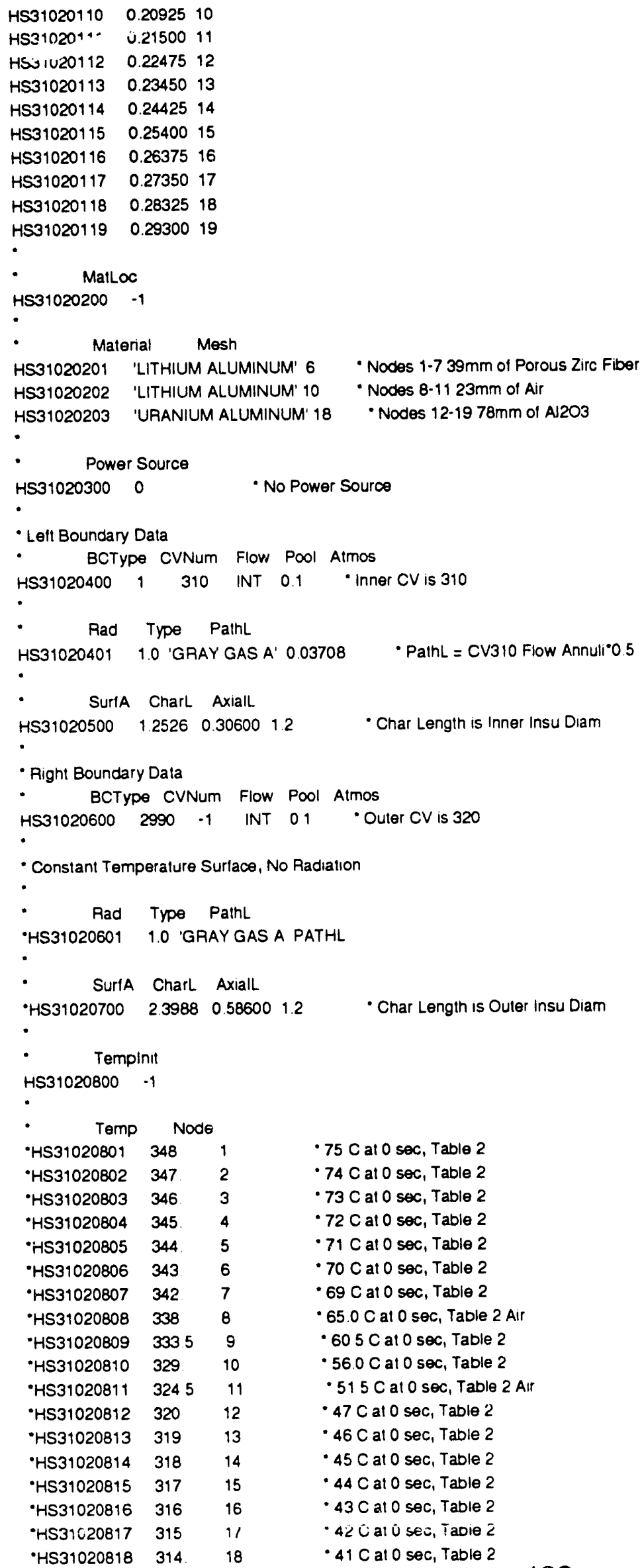




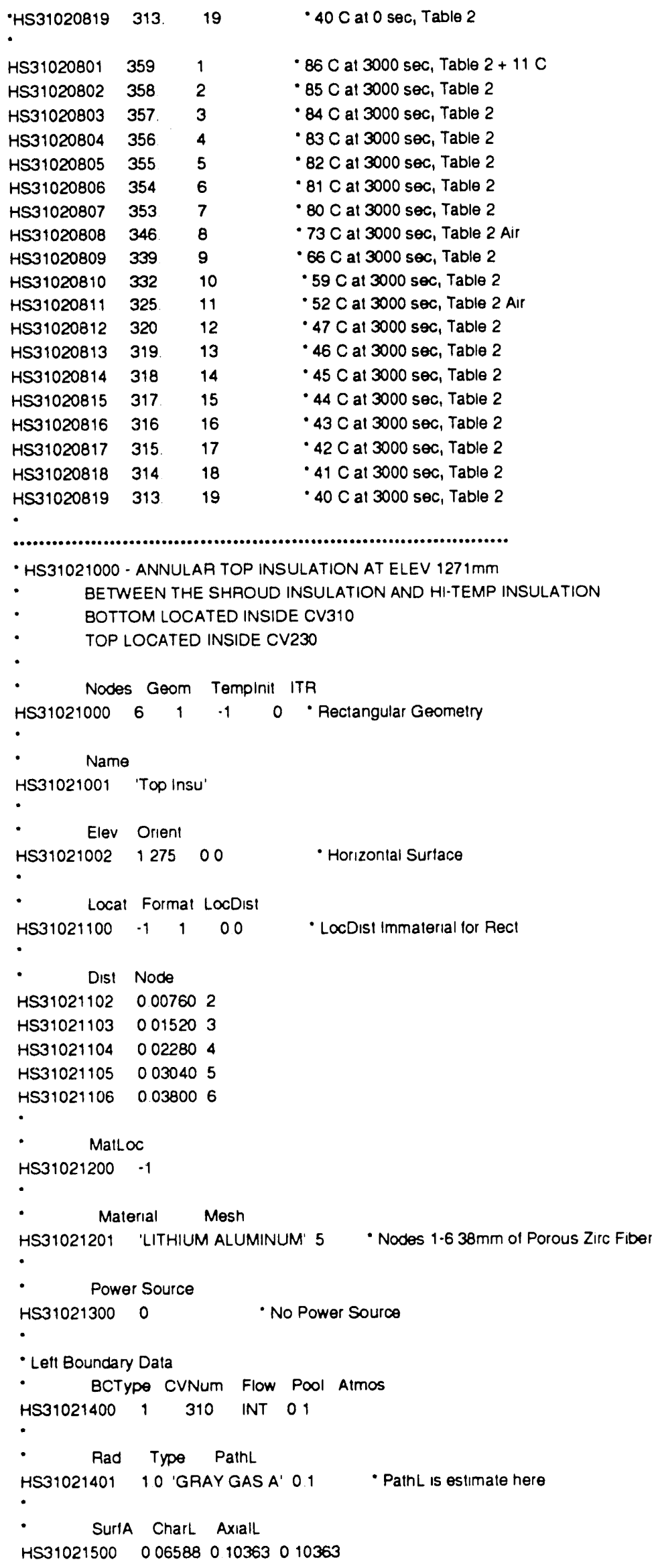




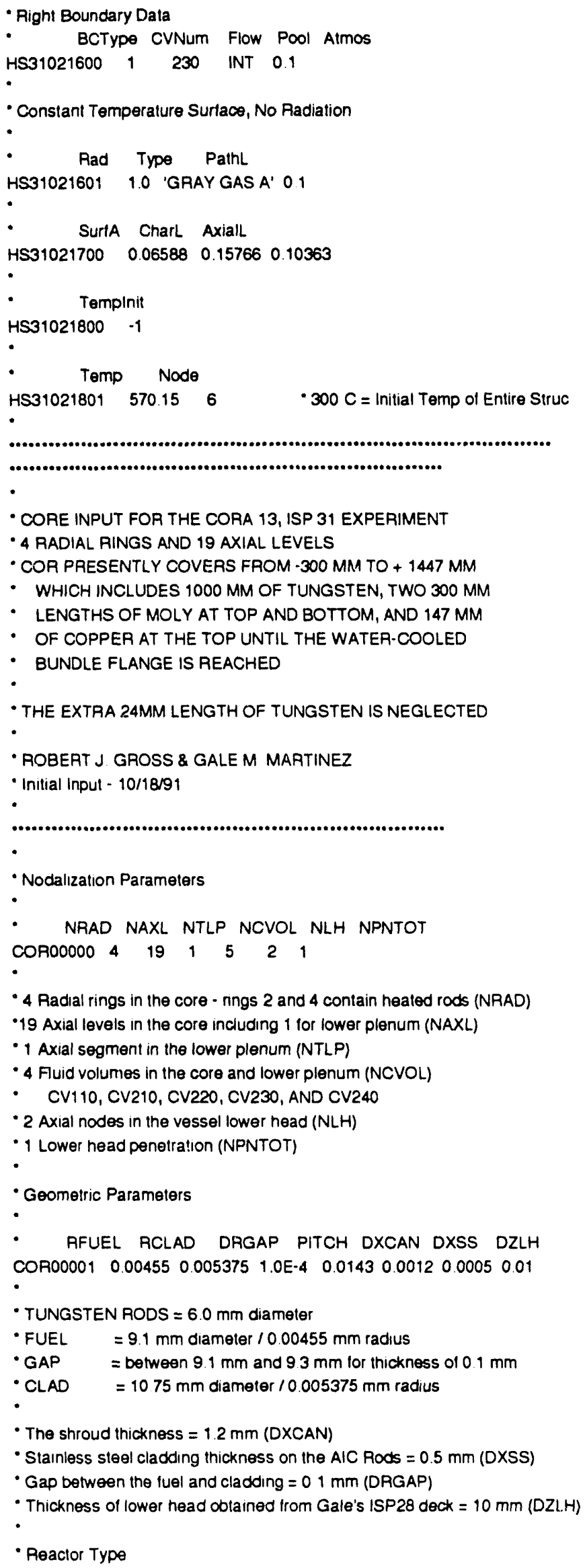


IRTYP MCRP

COR00002 BWR 'AG-IN-CD' 'URANIUMMETAL'

-

- Reactor type - Boiling Water Reactor (IRTYP) - see p. COR-UG-23

- Control Rod poison material - AG-IN-CD (MCRP)

- Radiative Exchange Factors

- fCNCl fSSCN fCELR fCela flPup

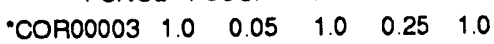

$\begin{array}{llllll}\text { COROOOO3 } & 0.25 & 0.25 & 1.0 & 0.25 & 1.0\end{array}$

-

- Heat Structures are getting too hot. Change 1.0 values

- to 0.25 - RJG - 1/2/92

- Refine view factors - RJG - 2/13/92

- All of these view factors are guesses for now

- Radiation from canister wall to cladding (FCNCL)

- Radiation from poison to canister (FSSCN)

- control rods cannot "see" shroud for the most part

- Radiation from cell boundary to next radially adjacent cell (FCELR)

- Radiation from cell boundary to next axially adjacent cell (FCELA)

- Radiation from pool to the core components (FLPUP)

-

- NTPCOR ICFFis ICFGap

COR00004 $101001 \quad 0$

-

- IN TRANSFer pRocess NUMBer IS 101 (NTPCOR)

- Fission power control function number (ICFFIS)

- Fission power is set to 0.0

- Fuel-cladding gap conductance control function number (ICFGAP)

- No additional gap resistance is calculated $=0$

CF00100 'FISSION POWER' EQUALS $1 \quad 1.0 \quad 0.0$

CF00101 0

$\begin{array}{llll}\text { CF00110 } & 0.0 & 0.0 & \text { TIME }\end{array}$

-

- hFRzUO hFRzZR hFRzSS hFRzZX hFRZSX hFRZCP

COR00005 1000. 1000. 1000. 1000. 1000. 100000

-

- Refreezing heat transter coefficients for relreezing

- Coefficient tor vO2 = 1000 - Gale used value of 300

- Coefficient for Zircaloy $=1000$ - Gale used value of 300

- Coefficient tor Steel = 1000 Gale used value ol 300

- Coefficient for ZrO2 = 1000 - Gale used value of 300

- Coefficient for Steel oxide $=1000$ - Gale used value of 300

- Coefficient for AG-IN-CD = 1000 - Gale used value of 300

-

- Change coefficient for AG-IN-CD to 10000. - rjg - 1/28/92

- Temperatures at bottom are $100 \mathrm{cool}$ - change $105000-\mathrm{rjg}-27 / 92$

- Temperatures at bottorn are too hot - change to $100000-\mathrm{rjg}-2 / 11 / 92$

-

- Keep in mind for cells in front of windows

- These are guesses for now

- Candling Secondary Material Transport Parameters

- mTUozR mTZXZR MTSXSs mTCPSS fuozR fZXzR fXCSS fCPSS

$\begin{array}{lllllllll}\text { COR00007 } & 1 & 2 & 2 & 2 & 0.2 & 1.0 & 1.0 & 0.0\end{array}$

-

- Transport flag for UO2 in molten Zircaloy (MTUOZR)

- Transport flag for ZrO2 in molten Zircaloy (MTZXZR)

- Transport flag for steel oxide in molten steel (MTSXSS)

- Transport flag for AG-IN-CD in molten steel (MTCPSS)

- Transport parameter for UO2 in molten Zircaloy (FUOZR) 


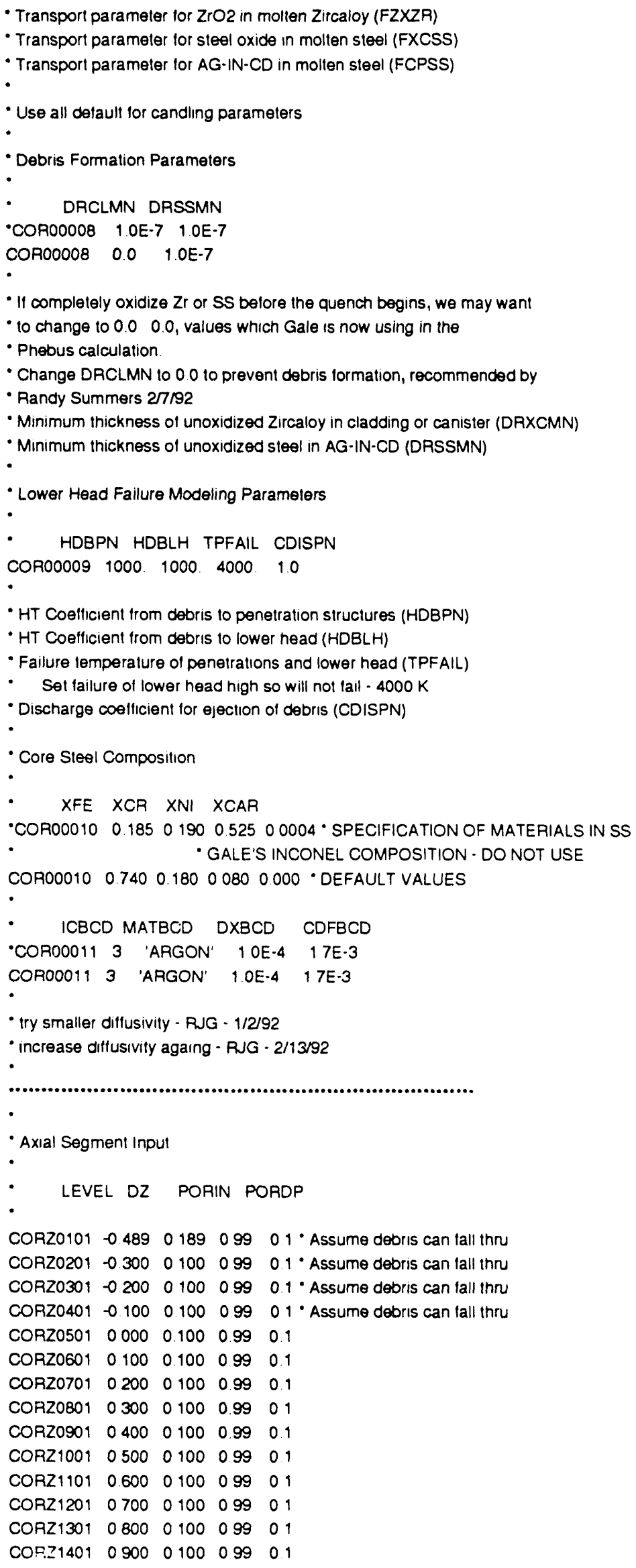




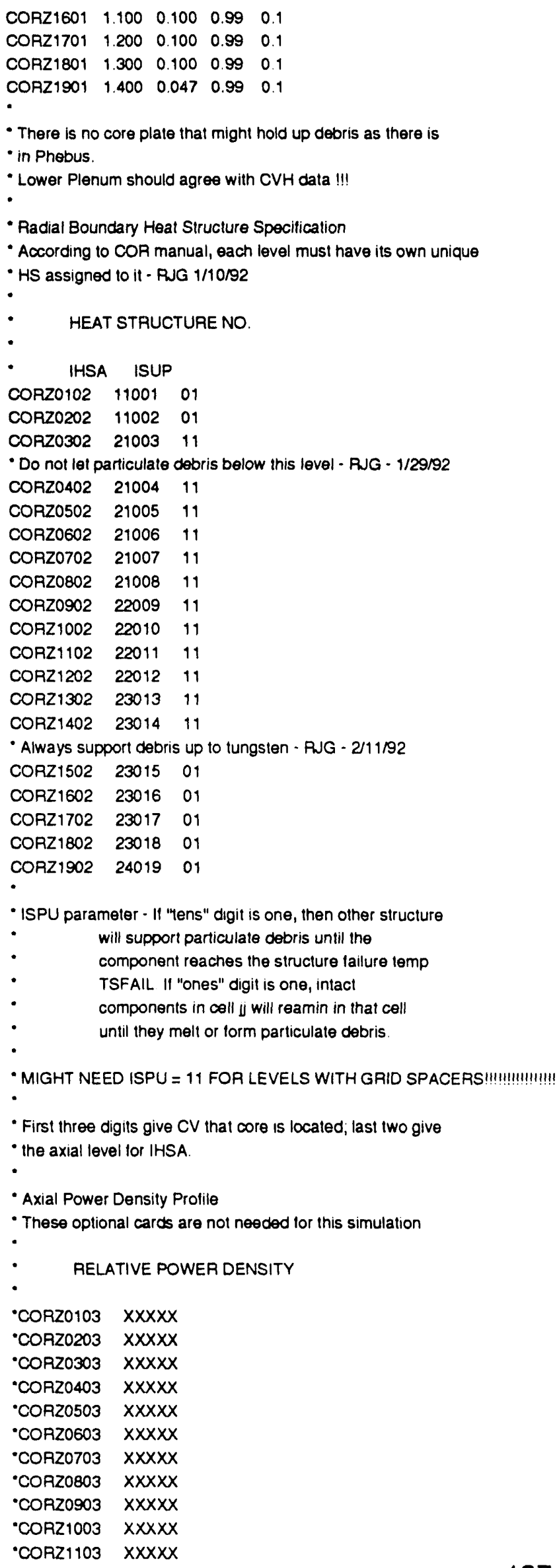




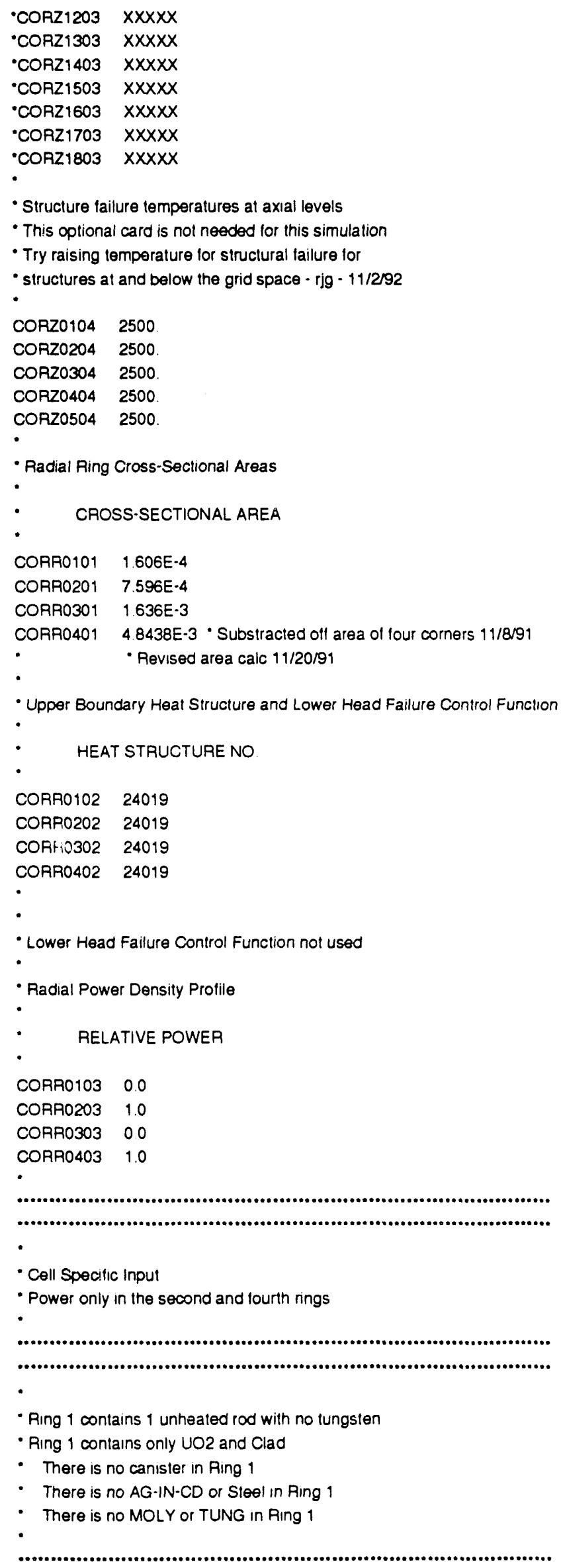


- LEVEL 1 IS THE LOWEA PLENUM, -489 TO $-300 \mathrm{~mm}$

- REPRESENTS 189 MM OF COPPER

- IN IREFN ICVHC ICVHB

$\begin{array}{lllll}\text { COR10101 } & -1 & 110 & 110 & \text { - Lower Pleunum in CV110 }\end{array}$

- XMFU XMCL XMSS XMCP XMCN MOLY TUNG

$\begin{array}{llllllll}\text { COR10102 } & 0.0 & 0.0 & 0.0 & 0.0 & 0.0 & 0.0 & 0.0\end{array}$

- TFU TCLAD TSS TCAN

$\begin{array}{llllll}\text { COR10103 } & 593.15 & 593.15 & 59315 & 593.15 & \cdot 320 \text { C AT } 3000 \text { SEC }\end{array}$

- DHCLAD DHYSS DHYDP DHYCNC DYNCNB

COR10104 1.0E-6 1.0E-6 $0.025 \quad 1.0 E-6 \quad 1.0 \mathrm{E}-6$ • EQUIV DIAS

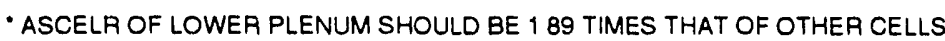

- because of LARGER DZ

- ascela aflowc aflowb

COR10105 $84908 E-3 \quad 1606 E-4 \quad 0.0 \quad$ FLOW AREAS

-

- total flow area for aflowC since no ROD here

- asfly ascl asss ascN

$\begin{array}{llllll}\text { COR10106 } & 0.0 & 00 & 00 & 00 & \text { - SURFACE AREAS }\end{array}$

-

- RING 1, LEVEL $2, \cdot 300$ TO $-200 \mathrm{~mm}$

- NO ROD YET IN THIS LEVEL FOR UNHEATED ROD

- iN IREFN ICVHC ICVHB

$\begin{array}{llll}\text { COR10201 } & -1 & 110 \quad 110\end{array}$

- XMFU XMCL XMSS XMCP XMCN MOLY TUNG

$\begin{array}{llllllll}\text { COR10202 } & 0.0 & 0.0 & 0.0 & 00 & 00 & 0.0 & 00\end{array}$

- tFu tClad tSs tCAN

COR10203 $59315 \quad 59315 \quad 59315 \quad 59315 \quad \cdot 320$ C AT 3000 SEC

- DHCLAD DHYSS DHYDP DHYCNC DYNCNB

COR10204 1.0E-6 1.0E-6 OOO25 1.0E- $10 \mathrm{E}-6 \cdot$ - EQUIV DIAS

- ascelr aflowc aflowb

COR10205 4.493E-3 1 606E-4 $00 \quad$ FLOW AREAS

- asfu ascl asss ascN

$\begin{array}{llllll}\text { COR10206 } & 0.0 & 00 & 0.0 & 0.0 & \cdot \text { SURFACE AREAS }\end{array}$

-

- RING 1, LEVEL 3,-200 TO $-100 \mathrm{~mm}$

- FIRST LEVEL WITH FUEL ON AN UNHEATED ROD

- IW IREFN ICVHC ICVHB

$\begin{array}{llll}\text { COR10301 } & -1 & 210 & 210\end{array}$

- XMFU XMCL XMSS XMCP XMCN MOLY TUNG

$\begin{array}{lllllllllll}\text { COR10302 } & 0.071542700150701 & 0.0 & 00 & 0.0 & 00 & 0 & 0\end{array}$

- TFU TCLAD tSS TCAN

$\begin{array}{llllll}\text { COR10303 } 59315 & 593.15 & 59315 & 593.15 & -320 \text { C AT } 3000 \text { SEC }\end{array}$

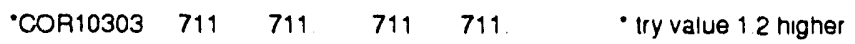

- DHCLAD DHYSS DHYDP DHYCNC DYNCNB

$\begin{array}{llllll}\text { COR10304 2.633E-3 } & 10 E-6 & 0 & 025 & 1.0 E-6 & 10 E-6\end{array}$ - EQUIV DIAS

- ascelr aflowc aflowb

COR10305 4.493E-3 $698374 E-500$-FLOW AREAS

- ASFU ASCL ASSS ASCN

COR10306 2.8588E-33.3772E-3 $00 \quad 0.0 \quad$ SURFACE AREAS

-

- RING 1, LEVEL 4,-100 to $0 \mathrm{~mm}$

- iN IREFN ICVHC ICVHB

COR10401 $103 \quad 210 \quad 210$

- 


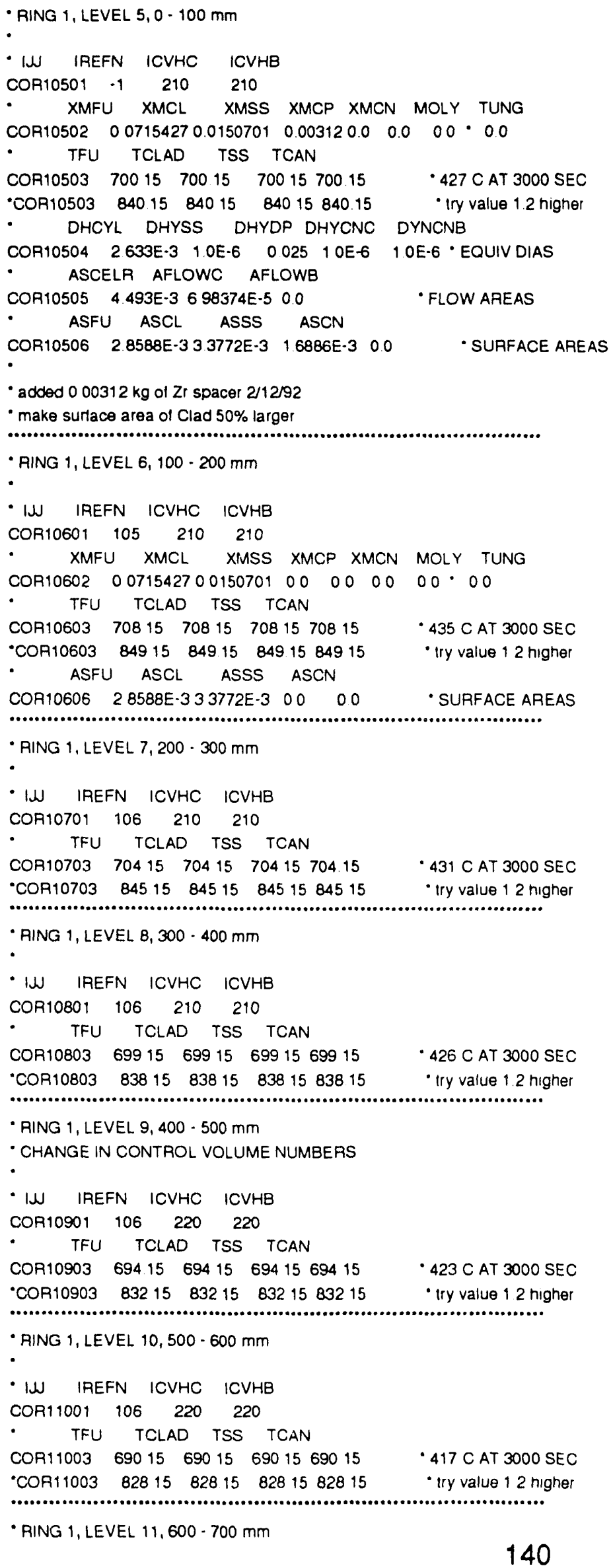


-

- IJ IREFN ICVHC ICVHB

COR11101 $106 \quad 220 \quad 220$

- TFU TClad tSS TCAN

$\begin{array}{lllll}\text { COR11103 } 687.15 \quad 687.15 & 687.15687 .15 & 414 \text { C AT } 3000 \text { SEC }\end{array}$

\begin{tabular}{lllll}
\hline COR $11103 \quad 824.15 \quad 824.15 \quad 824.15 \quad 824.15$ & $* 414$ C AT 3000 SEC
\end{tabular}

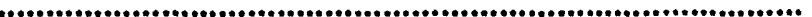

- AING 1, LEVEL $12,700 \cdot 800 \mathrm{~mm}$

- IN IREFN ICVHC ICVHB

COR $11201 \quad 106 \quad 220 \quad 220$

TFU TCLAD TSS TCAN

$\begin{array}{lllll}\text { COR11203 } 683.15 & 683.15 & 683.15683 .15 & 410 \text { C AT } 3000 \text { SEC }\end{array}$

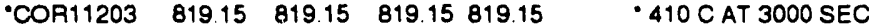

.

- RING 1, LEVEL 13,800-900 mm

- change IN CONTROL Volume Numbers

- IN IREFN ICVHC ICVHB

COR11301 $106 \quad 230 \quad 230$

- XMFU XMCL XMSS XMCP XMCN MOLY TUNG

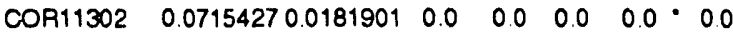

- TFU TCLAD TSS TCAN

$\begin{array}{lllll}\text { COR11303 } 678.15 & 678.15 & 67815678.15 & 405 \mathrm{C} \text { AT } 3000 \mathrm{SEC}\end{array}$

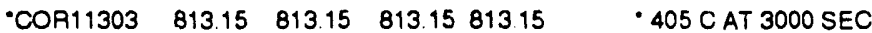

- add mass of Zr spacer 2/12/92

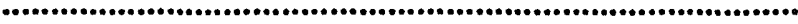

- RING 1, LEVEL 14,900 $\cdot 1000 \mathrm{~mm}$

- IN IREFN ICVHC ICVHB

COR11401 $106 \quad 230 \quad 230$

- tFu tClad tSS tCAN

COR11403 670.15 67015 67015 67015 *397 C AT 3000 SEC

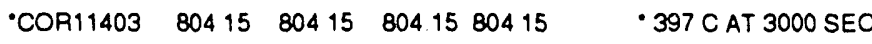

- RING 1, LEVEL $15,1000 \cdot 1100 \mathrm{~mm}$

- IJJ IREFN ICVHC ICVHB

COR11501 $106 \quad 230 \quad 230$

- TFU tCLAD tSS TCAN

$\begin{array}{lllll}\text { COR11503 648.15 } 648.15 & 648.15648 .15 & 375 \text { C AT } 3000 \text { SEC }\end{array}$ •COR11503 $777.15 \quad 777.15 \quad 777.15777 .15 \quad$ 375 C AT 3000 SEC

- RING 1, LEVEL 16, $1100-1200 \mathrm{~mm}$

- IN IREFN ICVHC ICVHB

$\begin{array}{llll}\text { COR11601 } & 106 \quad 230 \quad 230\end{array}$

- TFU tClad tSS tCAN

$\begin{array}{lllll}\text { COR11603 } 618.15 & 618.15 & 618.15 & 618.15 & 345 \mathrm{C} \text { AT } 3000 \mathrm{SEC}\end{array}$

$\begin{array}{llllll}\text {-COR11603 } 741.15 & 741.15 & 741.15741 .15 & -345 \text { C AT } 3000 \text { SEC }\end{array}$

- RING 1, LEVEL 17, $1200-1300 \mathrm{~mm}$

- IN IREFN ICVHC ICVHB

$\begin{array}{llll}\text { COR11701 } 106 \quad 230 & 230\end{array}$

- tFu tClad tSS tCAN

$\begin{array}{lllll}\text { COR11703 } 593.15 & 593.15 & 593.15 & 593.15 & 320 \mathrm{C} \text { AT } 3000 \mathrm{SEC}\end{array}$

$\begin{array}{lllll}\cdot C O R 11703 \quad 711.15 & 711.15 & 711.15 & 711.15 & \cdot 320 \text { C AT } 3000 \text { SEC }\end{array}$

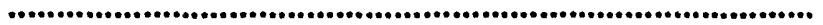

- RING 1, LEVEL 18, $1300 \cdot 1400 \mathrm{~mm}$

- UNHEATED ROD ONLY GOES TO $1295 \mathrm{MM}$

-

- ascelR is 1.0 times that of normal leVel to RefLect 147 MM

- OF HEIGHT OF THIS LEVEL 


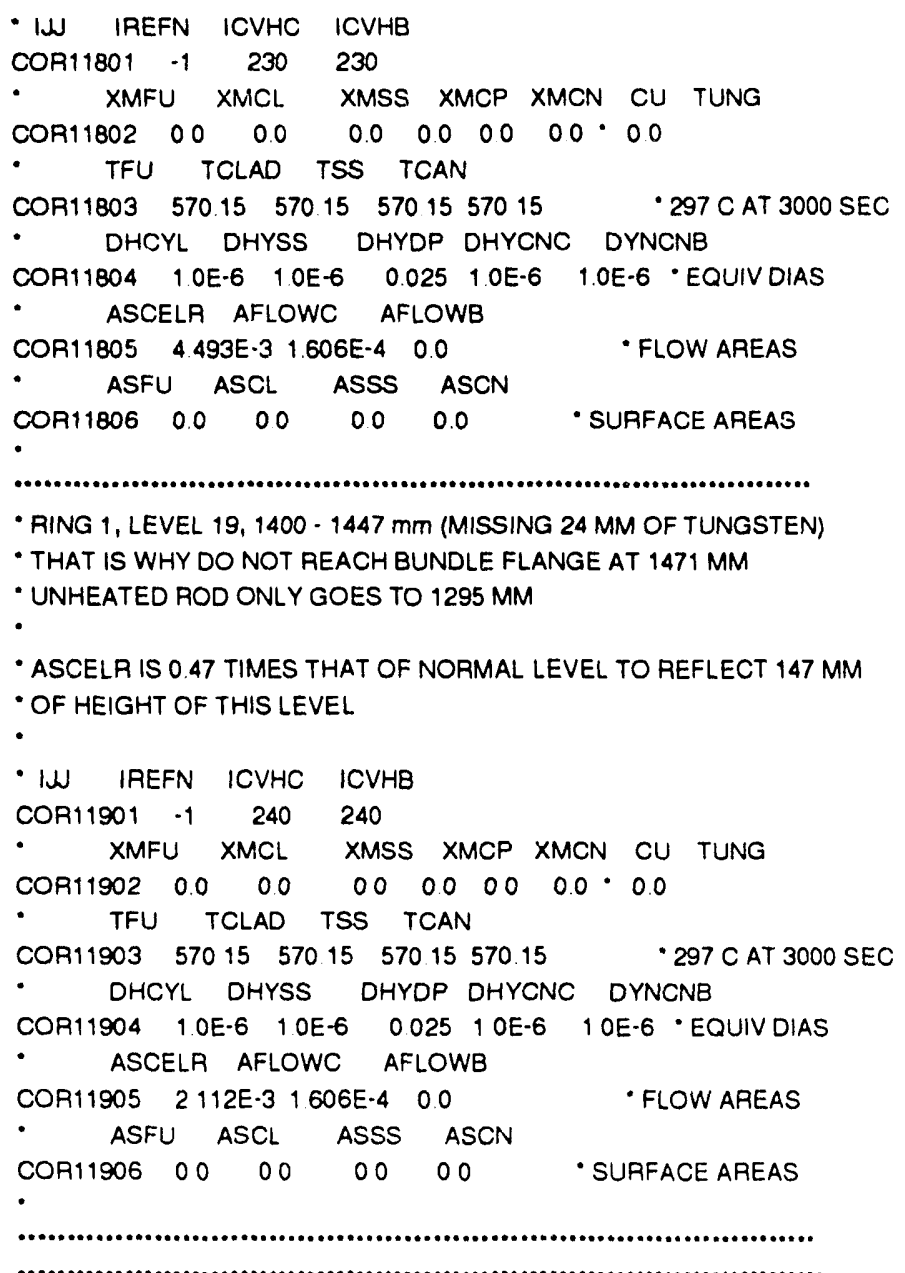




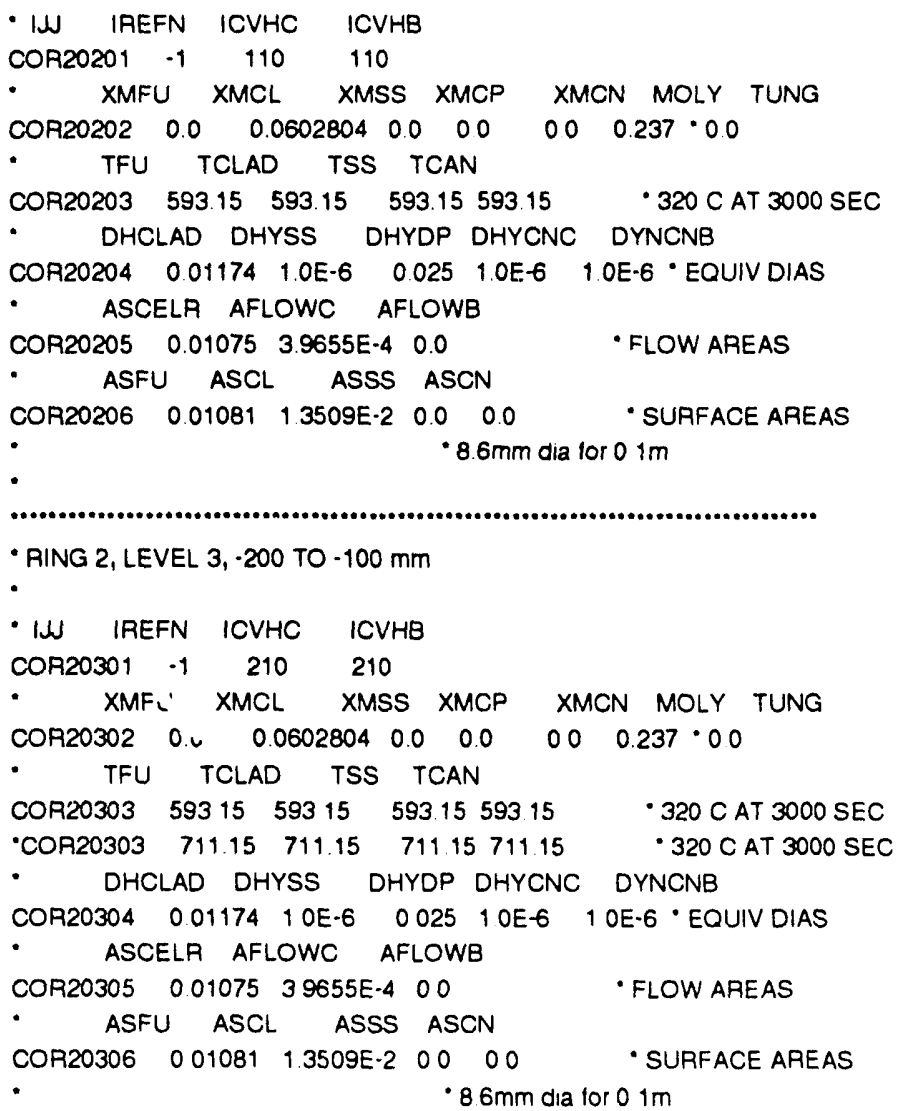




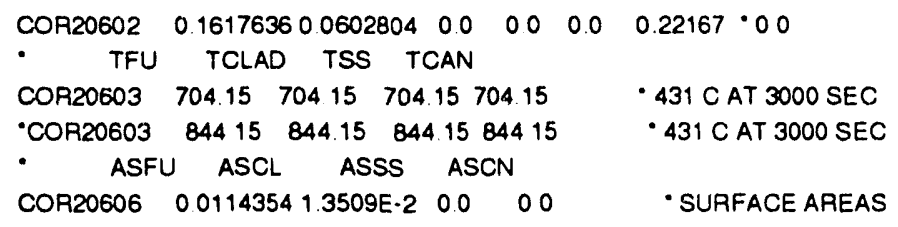


- RING 2, LEVEL 14,900 $1000 \mathrm{~mm}$

- IJ IREFN ICVHC ICVHB

COr:21401 $206 \quad 230 \quad 230$

- tFU tClad tSS tCAN

$\begin{array}{llllll}\text { COR214C3 } 668.1566815 & 668.15668 .15 & 395 & \text { I AT } 3000 \text { SEC }\end{array}$

•COR21403 801.15 $801.15 \quad 801.15801 .15 \quad \cdot 395$ C AT 3000 SEC

..............

- RING 2, LEVEL 15, $1000-1100 \mathrm{~mm}$

- IN IREFN ICVHC ICVHB

COR21501 $206 \quad 230 \quad 230$

- XMFU XMCL XMSS XMCP XMCN MOLY TUNG

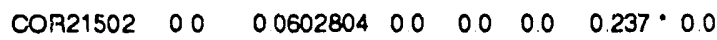

- TFU TCLAD TSS TCAN

COR21503 $6531565315 \quad 6531565315 \quad \cdot 380$ C AT 3000 SEC

$\begin{array}{lllll}\cdot \text { COR21503 } 78315 & 78315 & 783.15783 .15 & \end{array}$

- ASfu ascl asss asciN

COR21506 $001801 \quad 13509 E-2 \quad 00 \quad 00 \quad$ SURFACE AREAS

- $\quad 86 \mathrm{~mm}$ dia for $01 \mathrm{~m}$

- RING 2, LFVEL 16, $1100-1200 \mathrm{~mm}$

- IJ IREFN ICVHC ICVHB

$\begin{array}{llll}\text { COR21601 } 215 \quad 230 & 230\end{array}$

- tFu tClad tSS tCAN

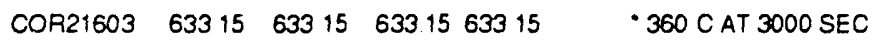

•COR21603 75915 75915 7591575915 • 360 C AT 3000 SEC

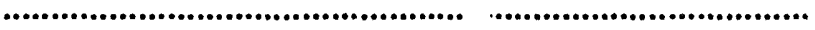

- RING 2, LEVEL 17, $1200 \cdot 1300 \mathrm{~mm}$

- IN IREFN ICVHC ICVHB

COR21701 $215 \quad 230 \quad 230$

- TFU tCLAD tSS TCAN

$\begin{array}{llllll}\text { COR21703 } 57815 \quad 578.15 & 578.15 & 57815 & 305 \text { C AT } 3000 \text { SEC }\end{array}$

"COH21703 $69315693156931557815 \quad$ 305 C AT 3000 SEC

- RING 2, LEVEL 18, $1300-1400 \mathrm{~mm}$

- IN IREFN ICVHC ICVHB

COR2'P01 $215 \quad 230 \quad 230$

- AMAFU XMCL XMSS XMCP XMCN CU TUNG

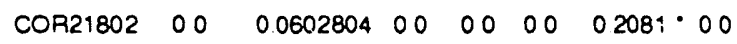

- tFu tClad tSS tCAN

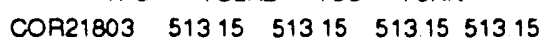

•COR21803 $69315 \quad 69315 \quad 693.15693 .15$

- 240 C AT 3000 SEC

- ascela aflowe aflowb

COR21805 $00107539655 E-4 \quad 00$

- try 12 limes higher

- AING 2, LEVEL 19, $1400-1447 \mathrm{~mm}$

•

- IN IREFN ICVHC ICVHB

COR21901 $205 \quad 240 \quad 240$

- XMFU XMCL XMSS XMCP XMCN CU TUNG

$\begin{array}{llllllll}\text { COR21902 } & 00 & 00283318 & 00 & 0.0 & 0.0 & 0.09781 \cdot 00\end{array}$

- ifu tClad tSS tCAN

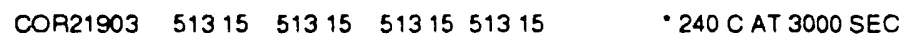

.COR21903 69315 $693156931569315 \quad$ try 12 times higher

- ASCELP AFLONIC AFIONIE

$\begin{array}{llll}\text { COR21905 } 0.00505 \quad 39555 E-4 & 00 & 0\end{array}$

- 


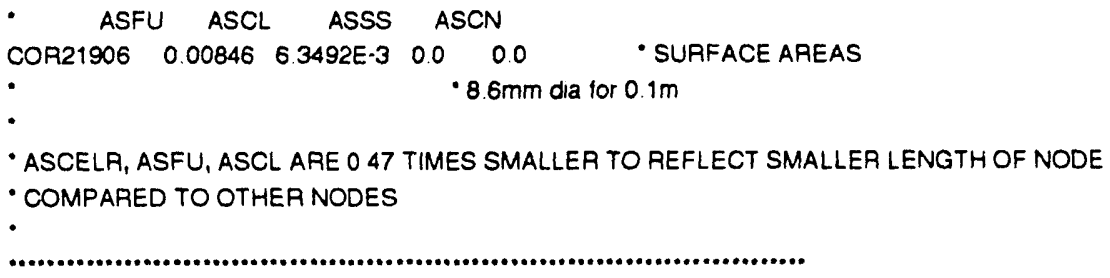




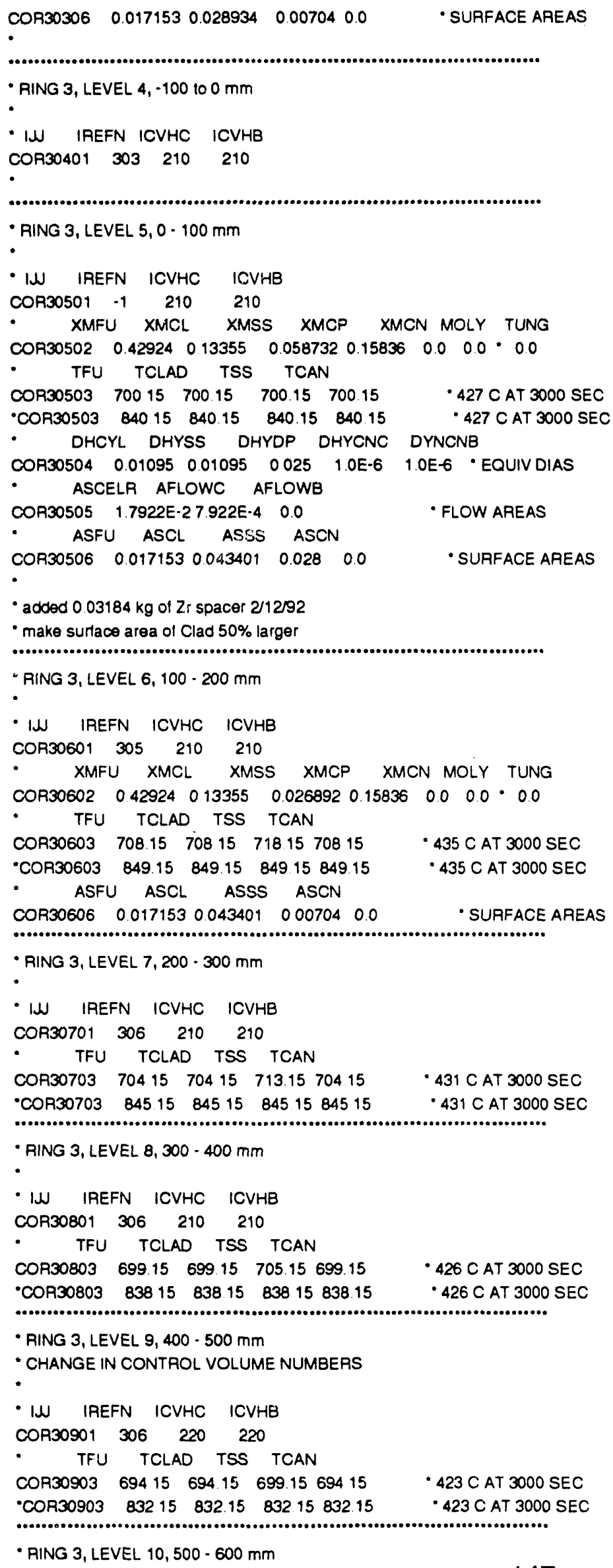


- W INEFN ICVHC ICVHB COR31001 $306 \quad 220 \quad 220$

- RING 3, LEVEL 16, $1100 \cdot 1200 \mathrm{~mm}$

- RING 3, LEVEL 17, $1200 \cdot 1300 \mathrm{~mm}$

- IN IAEFN ICVHC ICVHB COR31701 $306 \quad 230 \quad 230$ 
- RING 3, LEVEL 18, $1300-1400 \mathrm{~mm}$

- UNHEATED ROD ONLY GOES TO $1295 \mathrm{MM}$

- ascelr IS 1.47 times that of normal leVel to Reflect 147 MM

- OF HEIGHT OF THIS LEVEL

- IN IREFN ICVHC ICVHB

$\begin{array}{llll}\text { COR31801 } & -1 & 230 & 230\end{array}$

- XMFU XMCL XMSS XMCP XMCN CU TUNG

$\begin{array}{llllllll}\text { COR31802 } & 0.0 & 0.0 & 0.0 & 0.0 & 0.0 & 0.0 & 0.0\end{array}$

- TFU tClAD tSS TCAN

$\begin{array}{lllll}\text { COA31803 } 570.15 & 570.15 & 570.15 & 570.15 & 297 \text { C AT } 3000 \text { SEC }\end{array}$

- DHCYL DHYSS DHYDP DHYCNC DYNCNB

COR31804 1.0E-6 $1.0 E-6 \quad 0.025 \quad 1.0 \mathrm{E}-6 \quad 1.0 \mathrm{E}-6 \cdot{ }^{-}$EQUIV DIAS

- ascelr aflowc aflowb

COR31805 1.7922E-2 1.636E-3 0.0

- ASFU ASCL ASSS ASCN

$\begin{array}{llllll}\text { COR31806 } & 0.0 & 0.0 & 0.0 & 0.0 & \text { S SURFACE AREAS }\end{array}$

- RING 3, LEVEL 19, 1400 - 1447 mm (MISSING 24 MM OF TUNGSTEN)

- THAT IS WHY DO NOT REACH BUNDLE FLANGE AT $1471 \mathrm{MM}$

- UNHEATED ROD ONLY GOES TO 1295 MM

- AsCELR IS 0.47 TIMES THAT Of NORMAL LEVEL TO REFLECT 147 MM

- OF HEIGHT OF THIS LEVEL

- IN IREFN ICVHC ICVHB

COR31901 $-1 \quad 240 \quad 240$

- XMFU XMCL XMSS XMCP XMCN CU TUNG

$\begin{array}{llllllll}\text { COR31902 } & 0.0 & 0.0 & 00 & 00 & 00 & 0.0 & 00\end{array}$

- TFU TCLAD TSS TCAN

COR31903 $5701557015 \quad 5701557015 \quad$ 297 C AT 3000 SEC

- DHCYL DHYSS DHYDP DHYCNC DYNCNB

COR31904 1.0E-6 1 OEE-6 $0.025 \quad 1$ OE-6 $\quad 1.0 E-6 \cdot$ EQUIV DIAS

- ascela aflowc aflowb

COR31905 8.4232E-31.636E-3 00 • FLOW AREAS

- ASFU ASCL ASSS ASCN

$\begin{array}{llllll}\text { COR31906 } & 00 & 0.0 & 0.0 & 00 & \text {-SURFACE AREAS }\end{array}$

-

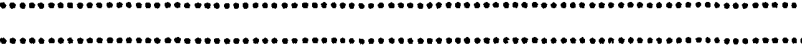

- RING 4 - 12 HEATED RODS

- RING 4 CONTAINS 12 HEATED RODS WITH TUNGSTEN CORES AND U02 SLEEVES

(

- aING 4, LeVEL 1 is The lower PLENUM, -489 TO $\cdot 300$ mm

- IN IREFN ICVHC ICVHB

COR40101 -1 $110 \quad 110$

- XMFU XMCL XMSS XMCP XMCN MOLY TUNG

$\begin{array}{llllllll}\text { COR40102 } & 0.0 & 0.0 & 0.0 & 0.0 & 0.0 & 0.0 & 0.0\end{array}$

- tFu tClad tSS tCAN

COR40103 $59315 \quad 59315 \quad 5931559315 \quad$ 320 C AT 3000 SEC

- DHCYL DHYSS DHYDP DHYCNC DYNCNB

COR40104 1.OE-6 $\quad 1.0 E-6 \quad 0.025 \quad 1.0 E-6 \quad 1.0 E-6 \cdot$ EQUIV DIAS

- Actually, there is $052263 \mathrm{~kg}$ of Zircaloy clad in this cell, but since

- water is always (mostly) present, do not make it available for oxidation

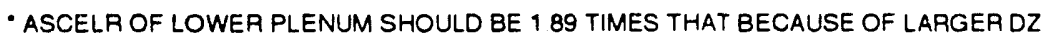

- AFLOWC REFLECTS LARGER AREA OF STEAM DISTRIBUTION TUBE MINUS THE TWELVE

- HEATED RODS THAT EXTEND INTO THE LOWER PLENUM

ASCELA AFLOWC AFLOWB 


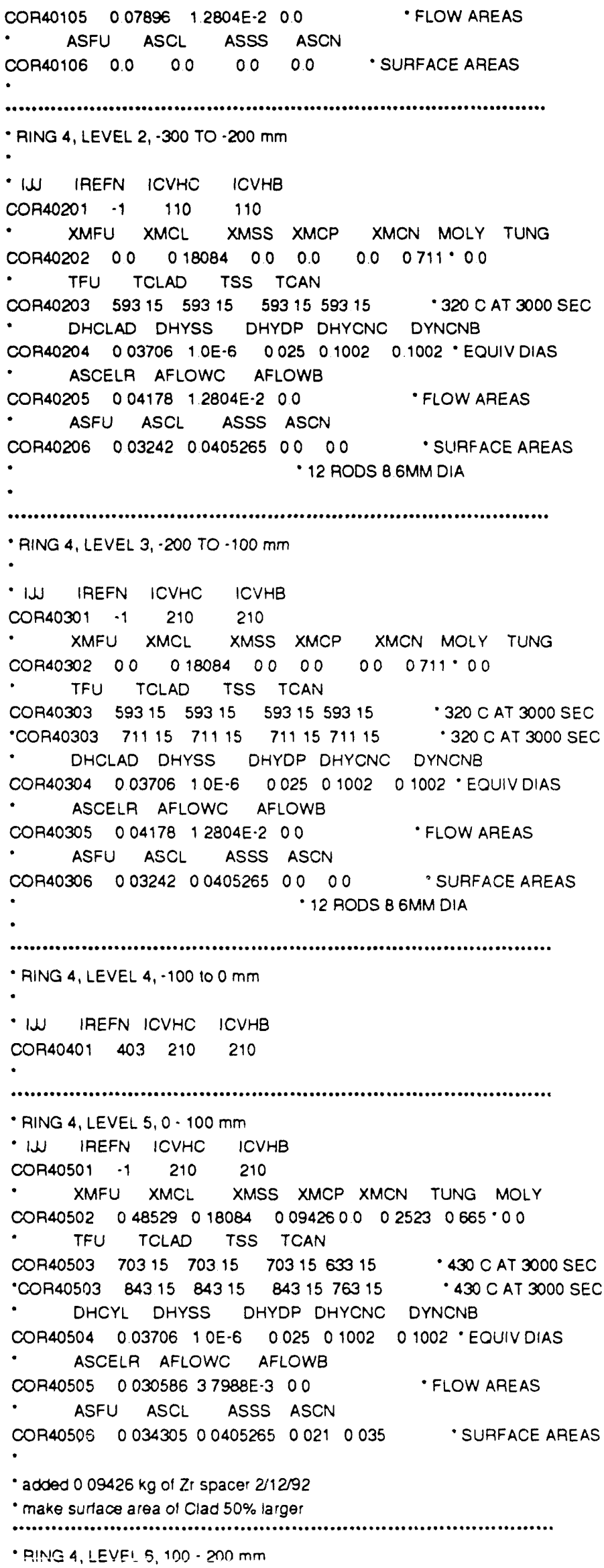




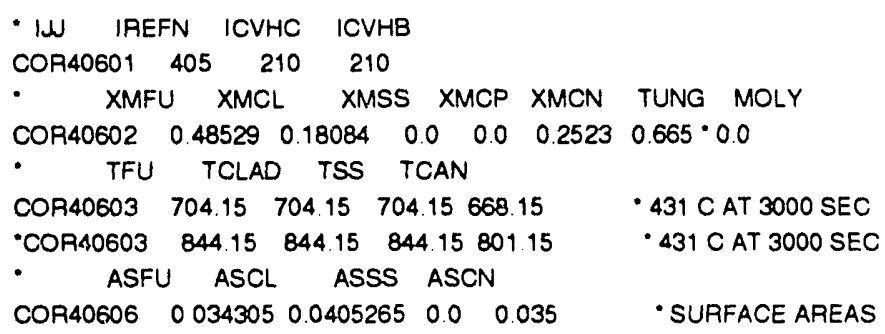

- RING 4, LEVEL 12,700-800 mm

- IN IREFN ICVHC ICVHB 


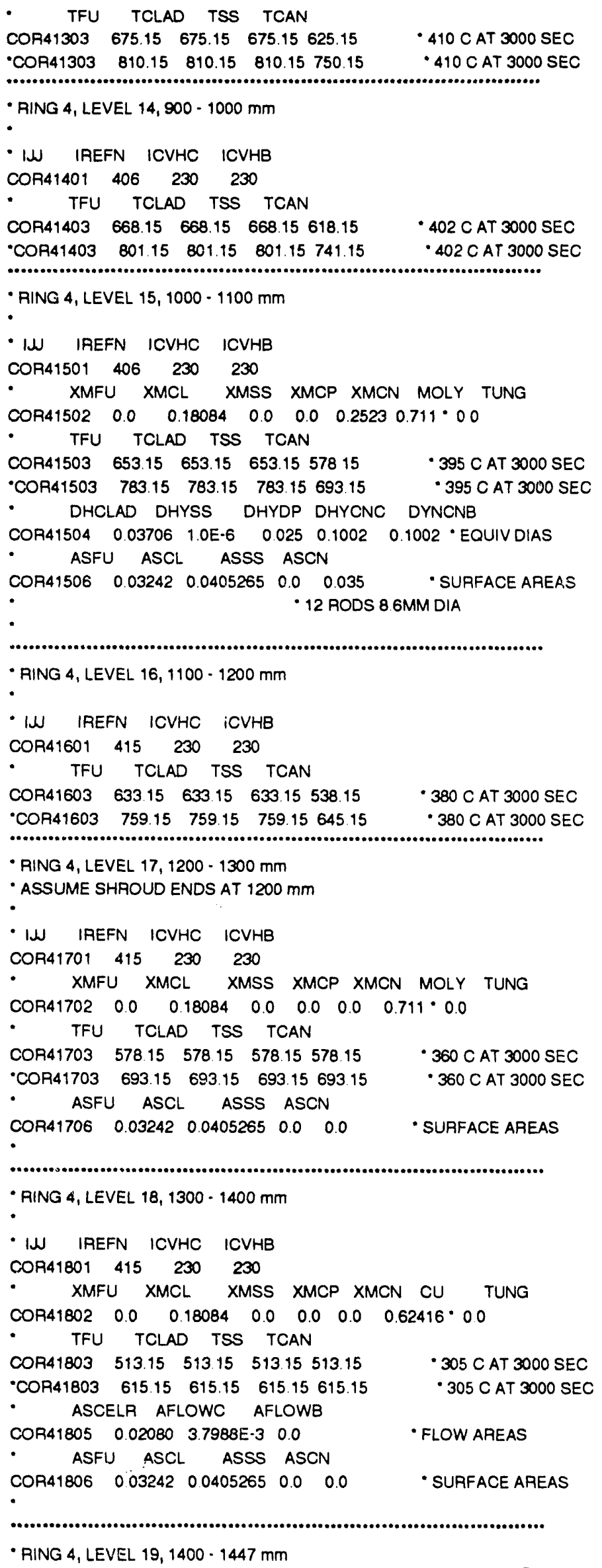

- RING 4, LeVel 19, $1400 \cdot 1447 \mathrm{~mm}$ 
- ASCELA, ASFU, AND ASCl ARE 0.47 TIMES SMALLER TO REFLECT SMALLER

- LENGTH OF THIS CELL

•

- IN IREFN ICVHC ICVHB

COR41901 $415 \quad 240 \quad 240$

- XMFU XMCL XMSS XMCP XMCN CU TUNG

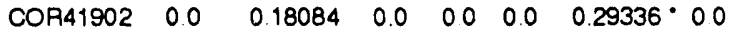

- TFU TCLAD tSS TCAN

$\begin{array}{llllll}\text { COR41903 } 513.15 & 513.15 & 513.15 & 513.15 & -305 \text { C AT } 3000 \text { SEC }\end{array}$

$\begin{array}{llllll}\cdot C O R 41903 & 615.15 & 615.15 & 615.15 & 5615.15 & * 305 \text { C AT } 3000 \text { SEC }\end{array}$

- ascela aflowc aflowb

$\begin{array}{llllll}\text { COR41905 } 0.00978 & 3.7988 E-3 & 0.0 & \text { FLOW AREAS }\end{array}$

- ASFU ASCL ASSS ASCN

$\begin{array}{llllll}\text { COR41906 } & 0.01524 & 0.0190475 & 0.0 & 0.0 & \cdot S U R F A C E\end{array}$

$\cdot \quad \cdot 12$ RODS $8.6 \mathrm{MM}$ DIA

-

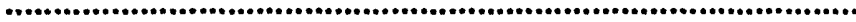

- LOWER HEAD INPUT

- REQUIRED, BUT NOT NECESSARY TO MODEL ISP31, CORA 13

- IRs ire xMLh tLh aslh icVlh icvcav

$\begin{array}{llllllllll}\text { CORLHDO1 } & 1 & 4 & 1.0 & 593 & 1.0 E-3 & 110 & 100 & \text { •TEMP NUMBERS }\end{array}$

- IPNREFIRP XMPN TPN ASPN AXPN AFLPN

$\begin{array}{llllllllll}\text { CORPENO1 } & -1 & 1 & 0.1 & 593 & 0.01 & 0.01 & 0.01 & \text { - TEMP NUMBERS }\end{array}$



- CVH INLET SPECIFICATION

- IVOL TIN

CORTINOO $110 \quad 110$

CORTINO1 $210 \quad 100$

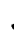

- transfer process package

-

- 'IN' TRANSFER PROCESS For THE CORE PACKAGE

$\cdot$

- NMSIN NTHRM

TPIN10100 $6 \quad 9 \quad$ See UserGuide on COR00004 input card

-

- 'OUT transfer pRocess for cavity Package

- NMSOT NPOTOI IOTMTX

TPOT10200 5101 UIN.103 - See UserGuide on CAVnnTP inpul card

-

- NROW NCOL

TPM1030000 $5 \quad 6 \quad$ See UserGuide on COR00004 inpul card

-

- Row/Col VAlue

TPM1030001 1/1 1. See UserGuide on CAVnnTP input card

TPM1030002 2/2 1. - Se日 UserGuide on CAVnnTP input card

TPM1030003 3/3 1. See UserGuide on CAVnnTP input card

TPM1030004 4/4 1. - See UserGuide on CAVחnTP input card

TPM1030005 5/5 1. See UserGuide on CAVnnTP input card

-

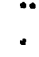

- SENSITIVITY COEFFICIENT CHANGES

-

- ORIGINAL RUN HAd ABOUT 50\% TOO MUCh hYDROgen PRODUCTION AND LATEST

- MELCOR OXIDIZES TOO QUICKLY. REDUCE EXPONENTIAL CONSTANTS ON LOW

- AND HIGH TEMPERATURE RATE CONSTANT SENSITIVITY COEFFICIENTS BY ABOUT

- 50\% - PNG - 10/13/92

- 
- SC1001 ZIRCALOY OXIDATION RATE CONSTANT COEFFICIENTS

Sc10011 $1001296 \quad 1$ - Low temp range constant coeff (delault)

-SC10012 10011682002 - Low temp range exponential coefl

-sc10013 10019793 • High temp range constant coelf (default)

SC10013 $1001779 \quad 3$ - High temp range constant coefl (delault)

"Sc10014 10011661004 - High temp range exponential coell

-sc10015 $100118530 \quad 5 \cdot$ Temp boundary between low and high range (default)

SC10015 $1001 \quad 1750.0 \quad 5 \quad$ Temp boundary belween low and high range

- SC1002 STEEL OXIDATION RATE CONSTANT COEFFICIENTS

SC10021 $1002101 \cdot$ Temp range constant coeff

-SC10022 100242400.2 'Temp range exponential coelf

$\cdot$

- SC1131 MOLTEN HOLDUP PARAMETERS

$\cdot$

SC11311 1131 6.0E-5 1 "Min ZrO2 Thickness to hold up melt

-SC11312 11312750.02 -Max ZrO2 Temp to hold up melt-onginal calc

SC11312 1131250002 - Max ZrO2 Temp to hold up melt

SC11313 $113100013 \cdot M i n$ SSOX to hold up melt

-SC11314 $1131 \quad 170004$-Max SSOX Temp to hold up melt-original calc

SC11314 $113125000 \quad 4$ - Max SSOX Temp to hold up melt

- SC1151 CONGLOMERATE DEBRIS SURFACE AREA COEFFS

SC11511 $115110 \quad 3 \quad 5^{\circ} \cdot \operatorname{FAMIN}(\mathrm{CAN})=10$

SC11512 $11510036 \cdot \operatorname{FBMAX}(\mathrm{CAN})=00$

- SC1501 CANISTER MASSISURFACE AREA SPLITS

SC15011 $150100 \quad 1$

SC15012 $150100 \quad 2$

SC15013 $150100 \quad 3$

SC15014 $1501 \quad 1.0 \quad 4$

SC15015 $150100 \quad 5$

- SC1502 MINIMUM COMPONENT MASSES

SC15021 1502 1.0E-6 1 - Min Total Mass ol Component

SC15022 150200012 - Min Mass Subject to Time Step

- SC1003 GASEIOUS DIFFUSION OXIDATION COEFFS

SC10031 $100300027 \quad 1 \quad$ ZZircaloy Oxidation Coeff

-

- CORA 13, ISP31 CONTROL FUNCTION INPU

- ROBERT J GROSS AND GALE M MARTINEZ

- NOVEMBER 13, 1991



- CONSTANT CONTROL FUNCTION CONTAINING

- the INITIAL TIME

- THIS CAN BE EITHER ZERO OR 3000 - CHANGE ACCORDINGLY!!!!!

- CF198

.

CF19800 'TIME CONST' EQUALS $10.0 \quad 0.0$

CF19810 $0.0 \quad 30000$ TIME

-CF19810 $00 \quad 00$ TIME

-

- cONSTANT CONTROL FUNCTION CONTAINING 


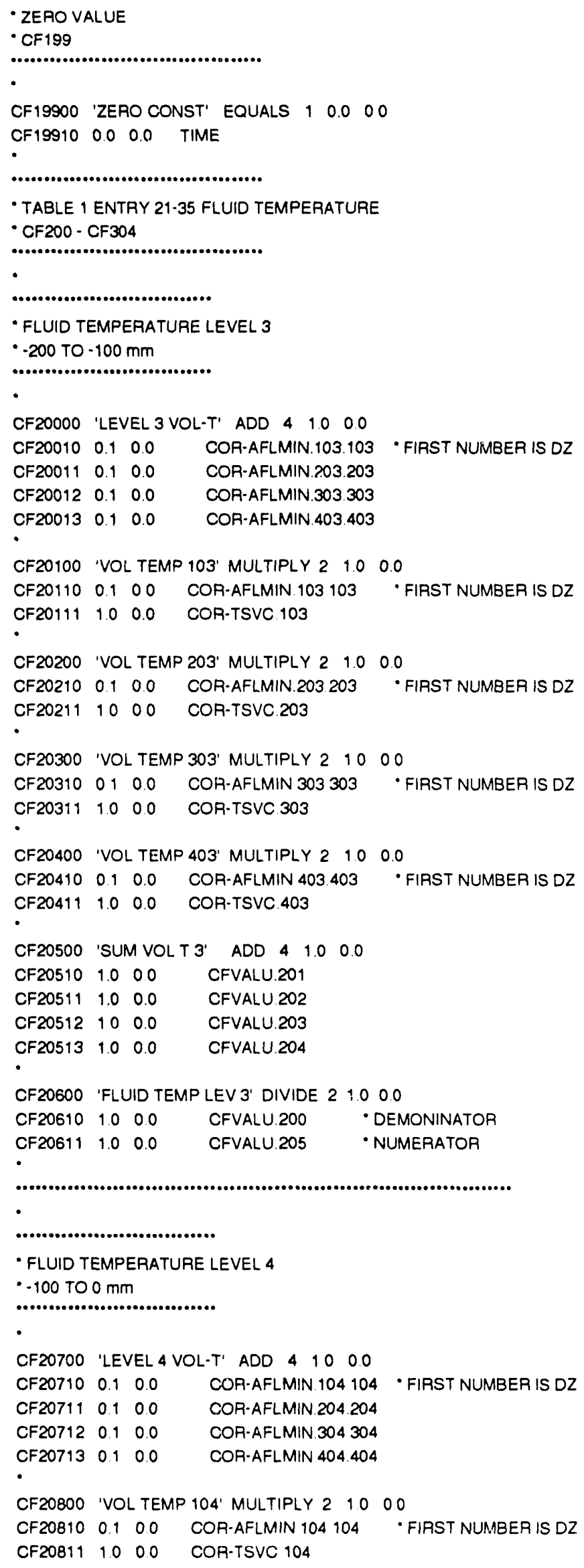




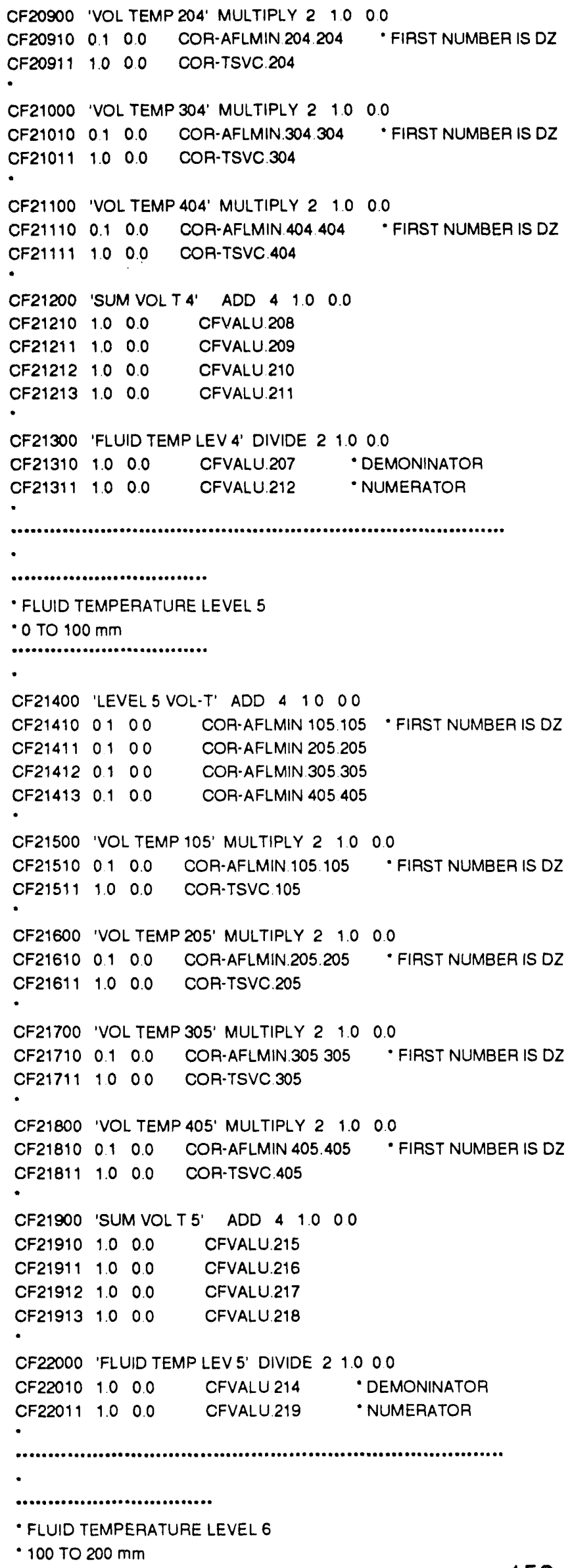




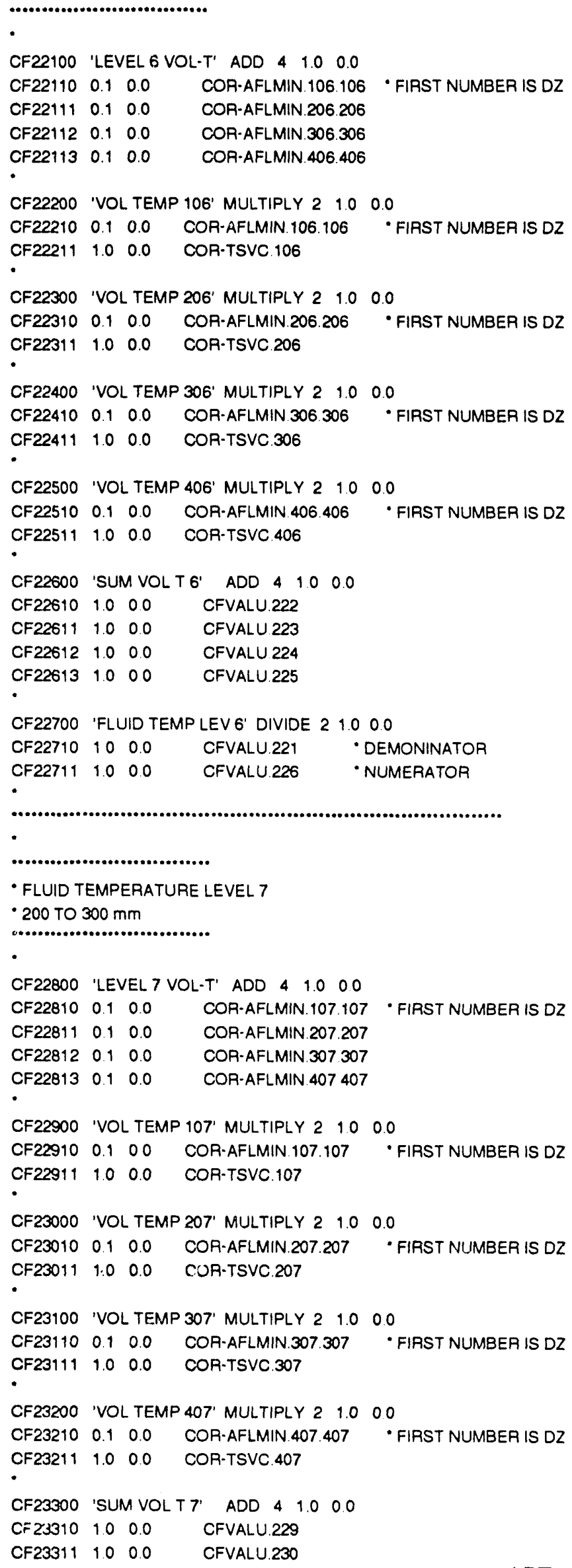




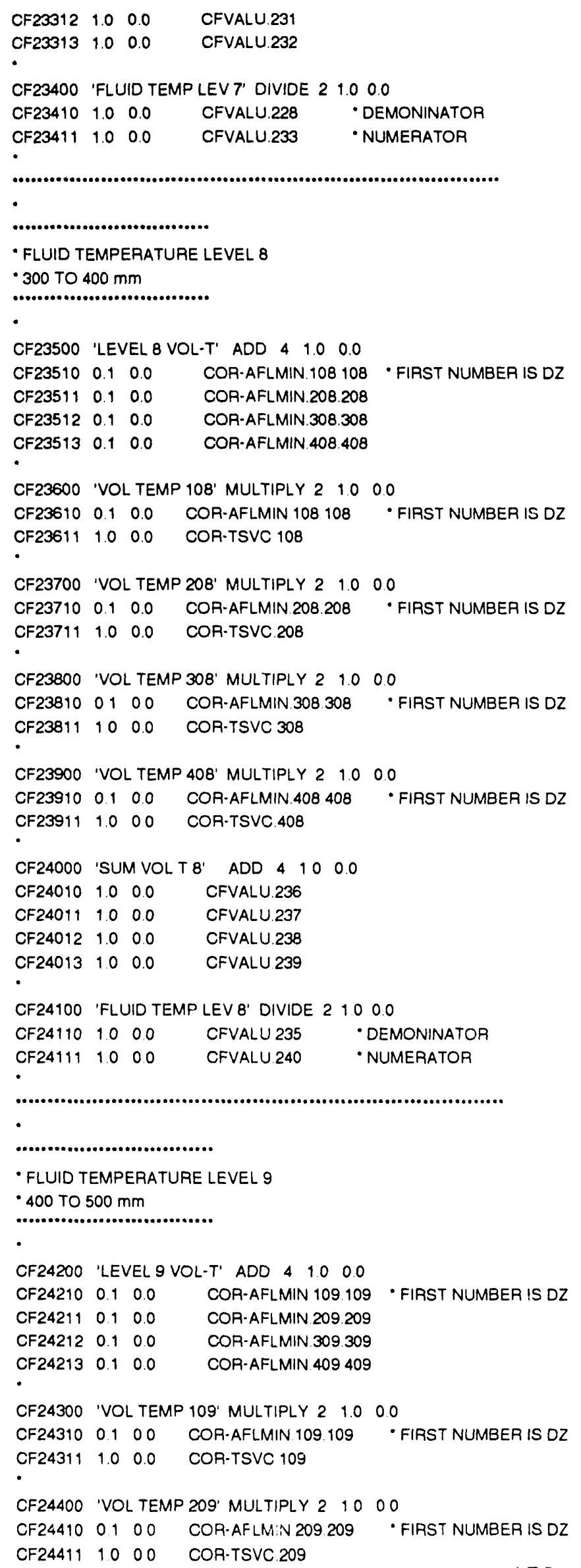




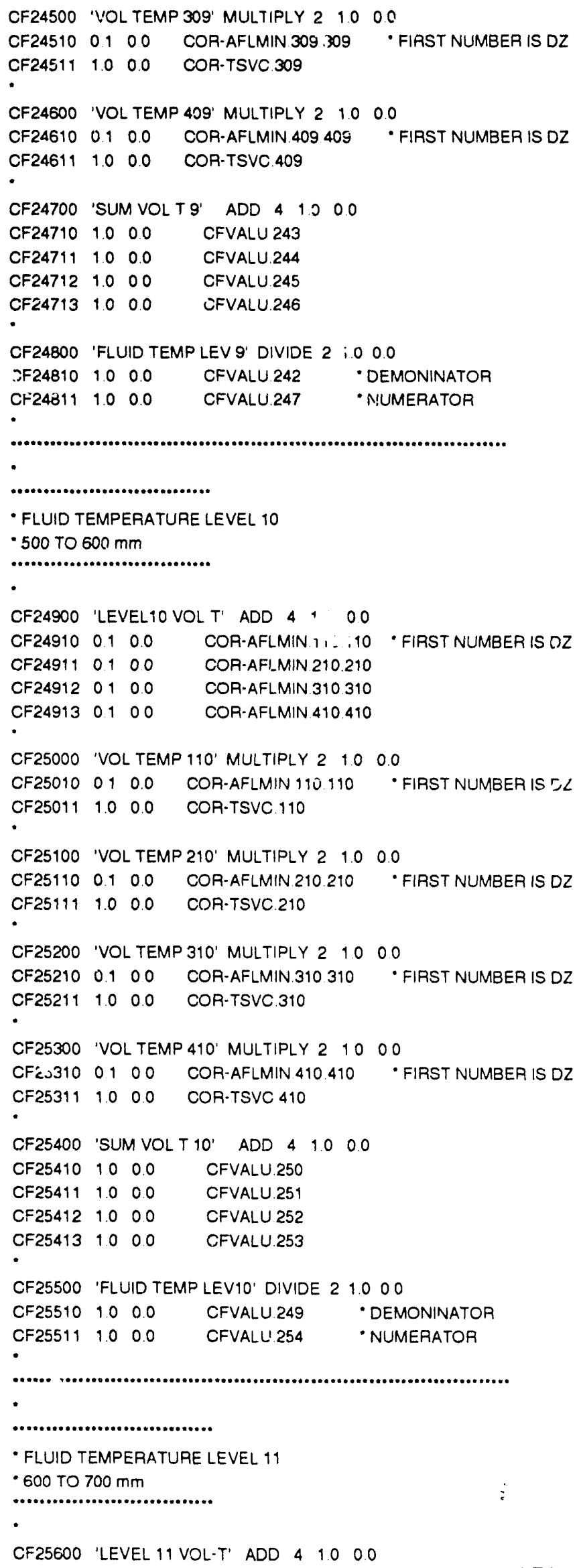




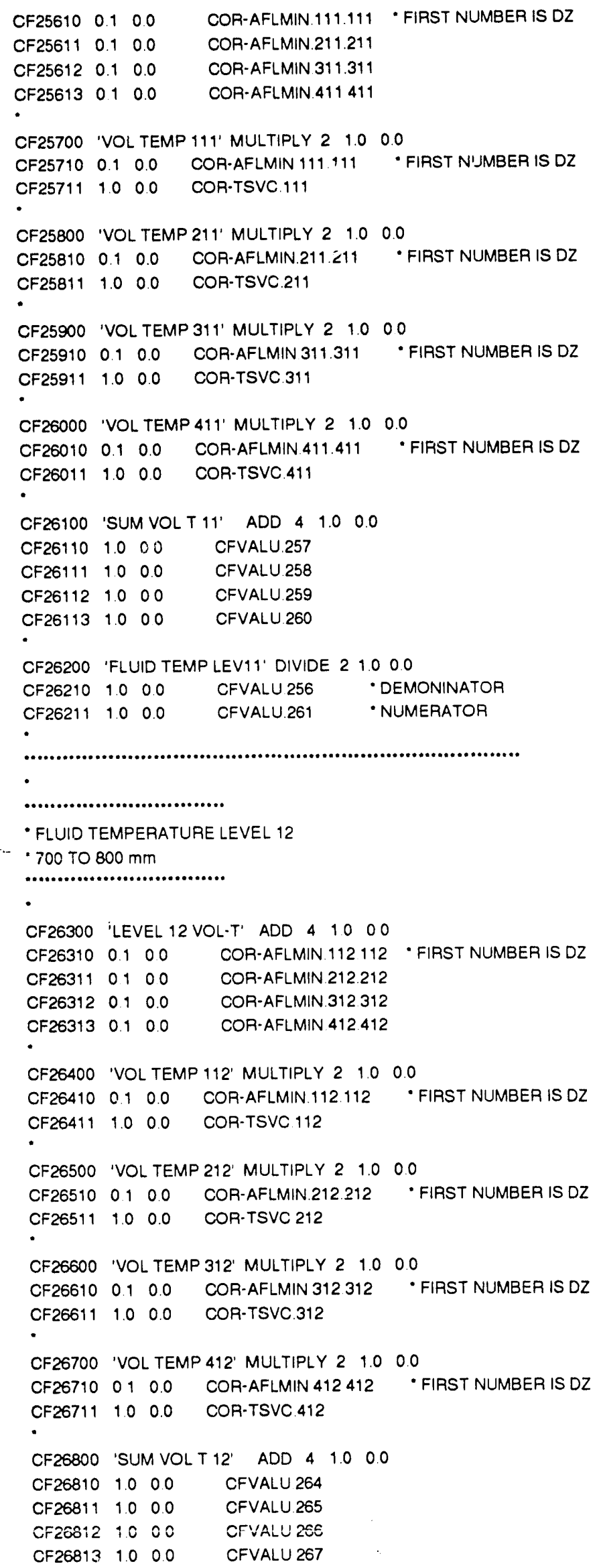




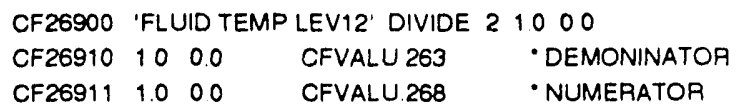




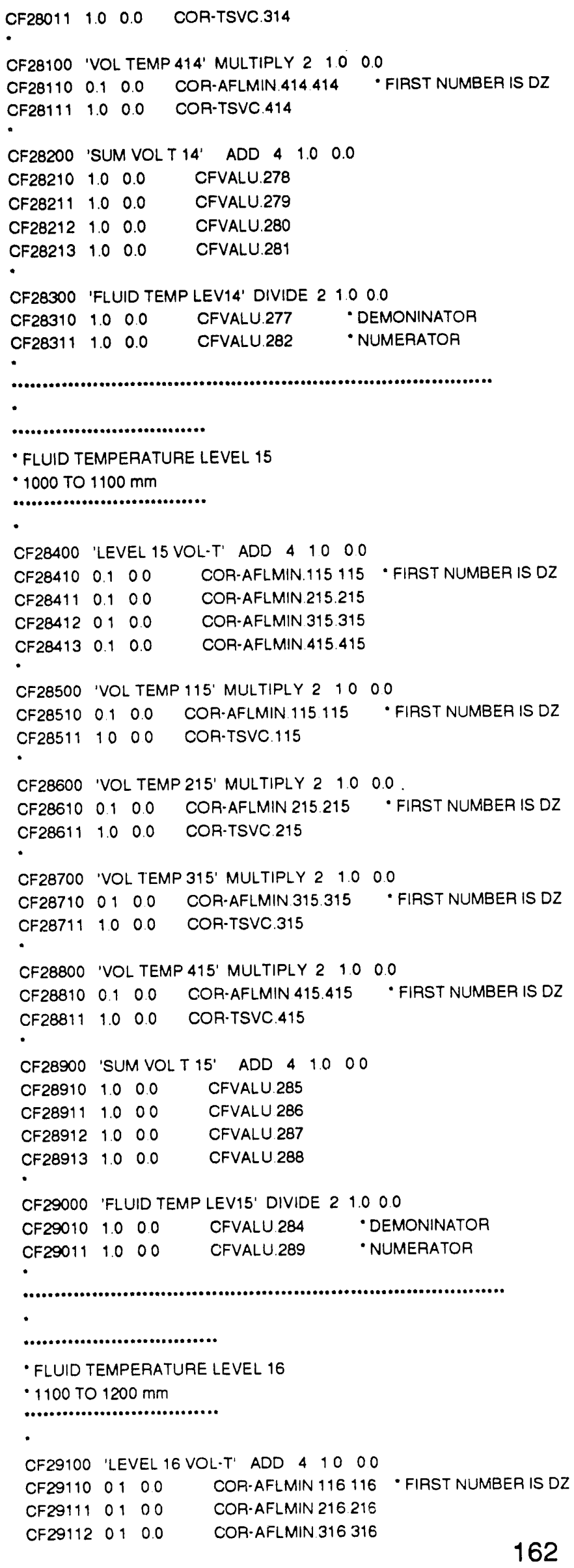




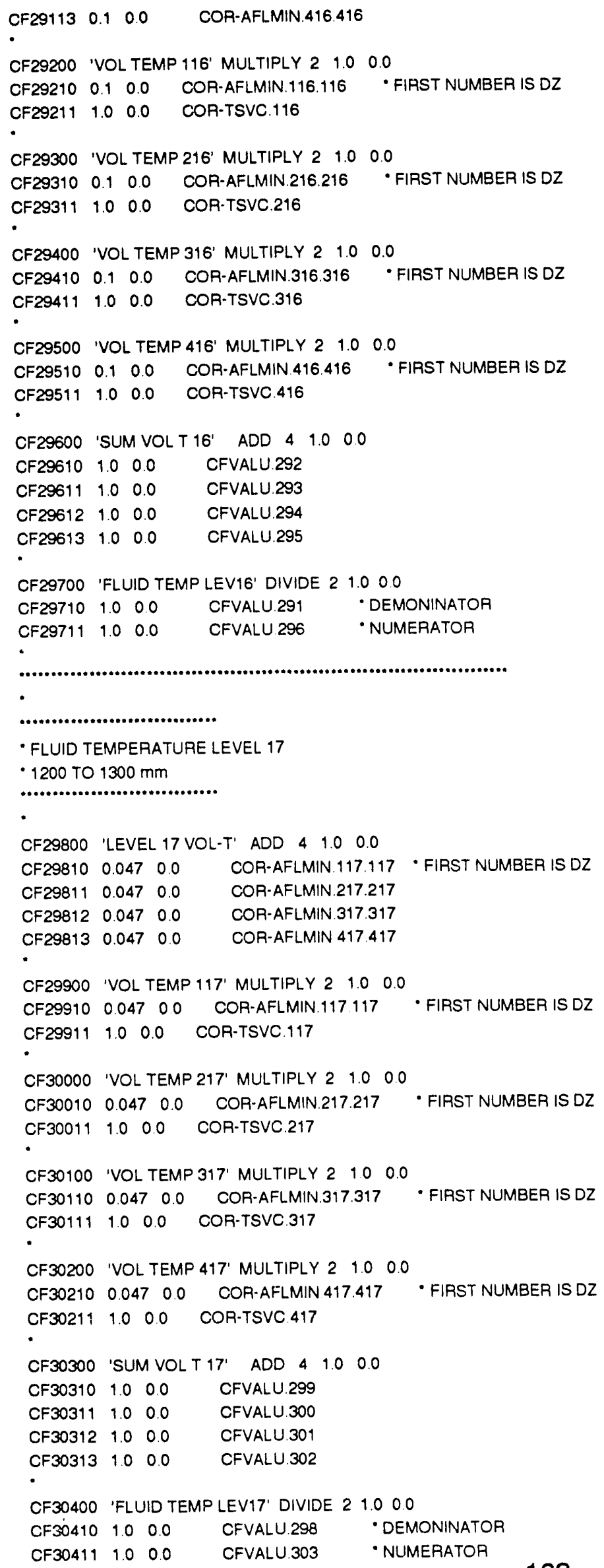




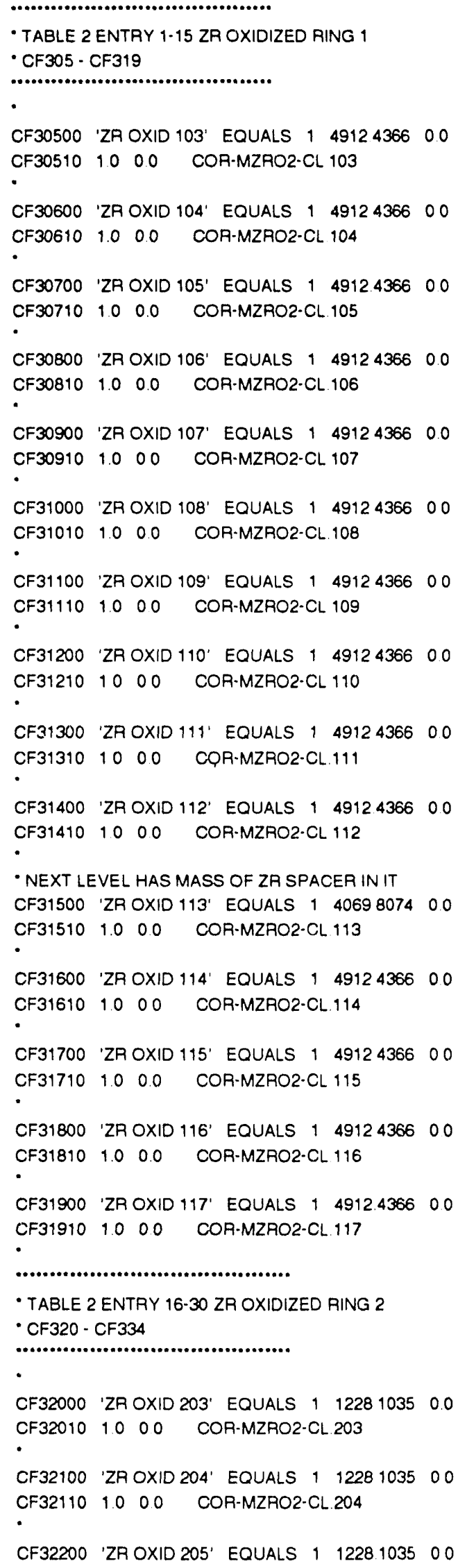




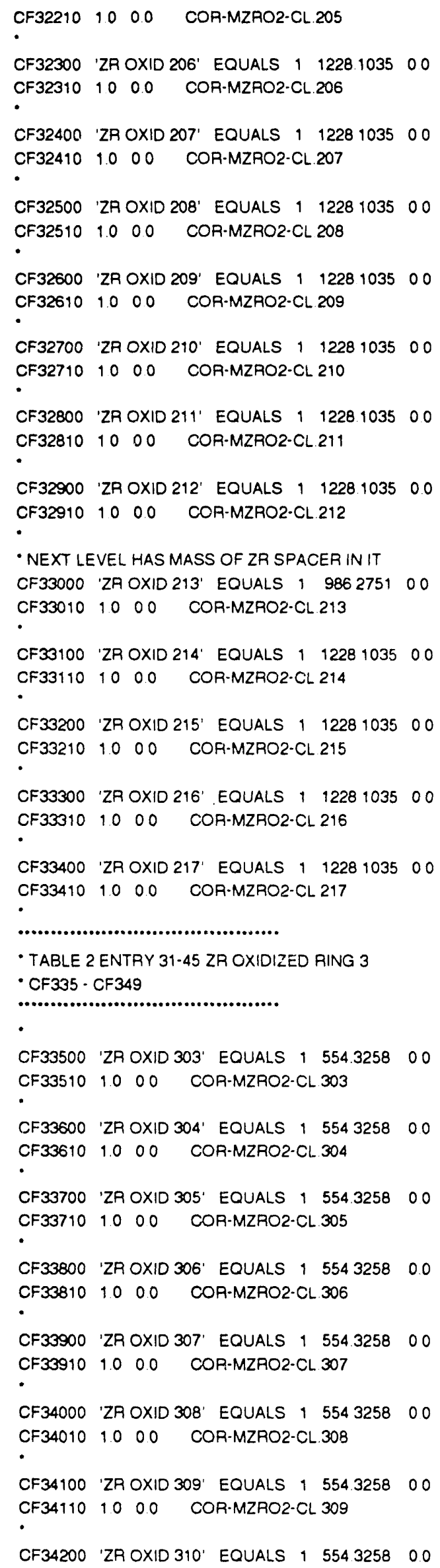




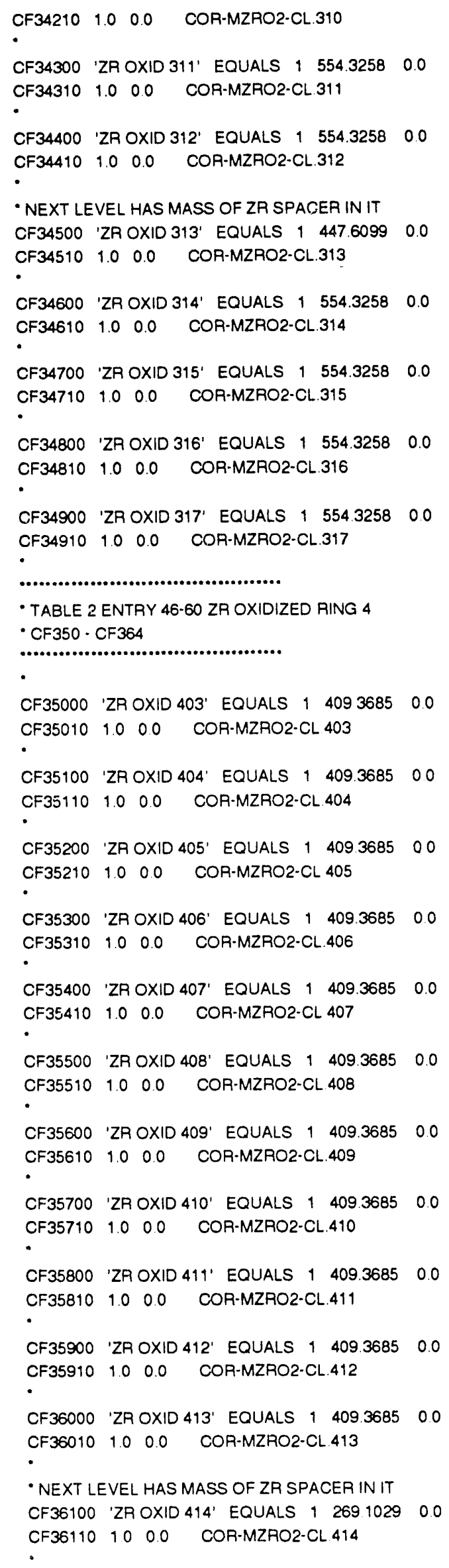


CF36200 'ZR OXID 415' EQUALS 1409.36850 .0

CF36210 $1.0 \quad 0.0 \quad$ COR-MZRO2-CL 415

-

CF36300 'ZR OXID 416' EQUALS 140936850.0

CF36310 $1.0 \quad 0.0 \quad$ COR-MZRO2-CL 416

-

CF36400 'ZR OXID 417' EQUALS 1409.36850 .0

CF36410 $1.0 \quad 0.0 \quad$ COR-MZRO2-CL.417

-

(......................................

- TABLE 2 ENTRY 61-75 ZR OXIDIZED SHROUd

- CF365 - CF379

.....................................

-

CF36500 'ZR OXID CAN3' EQUALS 10.0

0.0

CF36510 $1.0 \quad 0.0 \quad$ COR-MZRO2-CN 403

-

CF36600 'ZR OXID CAN4' EQUALS $10.0 \quad 0.0$

CF36610 $1.0 \quad 0.0 \quad$ COR-MZRO2-CN.404

-

CF36700 'ZR OXID CAN5' EQUALS $12934213 \quad 0.0$

$\begin{array}{llll}\text { CF36710 } & 1.0 & 0.0 & \text { COR-MZRO2-CN } 405\end{array}$

-

CF36800 'ZR OXID CANG' EQUALS $1293.4213 \quad 00$

CF36810 $1.0 \quad 0.0 \quad$ COR-MZRO2-CN 406

CF36900 'ZR OXID CAN7' EQUALS $12934213 \quad 0.0$

CF36910 $1.0 \quad 0.0 \quad$ COR-MZRO2-CN 407

CF37000 'ZR OXID CAN8' EQUALS $12934213 \quad 0.0$

CF37010 $1.0 \quad 00$ COR-MZRO2.CN 408

CF37100 'ZR OXID CAN9' EQUALS $12934213 \quad 00$

CF37110 1.0 OO COR-MZRO2.CN 409

CF37200 'ZR OXIDCAN10' EQUALS 1293421300

CF37210 $10 \quad 00$ COR-MZRO2.CN 410

-

CF37300 'ZR OXIDCAN11' EQUALS $12934213 \quad 0.0$

CF37310 $1.0 \quad 0.0 \quad$ COR-MZRO2-CN 411

CF37400 'ZR OXIDCAN12' EQUALS $12934213 \quad 00$

$\begin{array}{llll}\text { CF37410 } & 1.0 & 0.0 & \text { COR-MZRO2-CN } 412\end{array}$

CF37500 'ZR OXIDCAN13' EQUALS $12934213 \quad 00$

CF37510 $1.0 \quad 0.0 \quad$ COR-MZRO2-CN 413

CF37600 'ZR OXIDCAN14' EQUALS $1293.4213 \quad 00$

CF37610 $1.0 \quad 00 \quad$ COR.MZRO2.CN 414

$$
\text { - }
$$

CF37700 'ZR OXIDCAN15' EQUALS $12934213 \quad 0.0$

CF37710 $1.0 \quad 00$ COR-MZRO2-CN 415

-

CF37800 'ZR OXIDCAN16' EQUALS $1293.4213 \quad 00$

CF37810 $1.0 \quad 00 \quad$ COR-MZRO2-CN 416

-

CF37900 'ZR OXIDCAN17' EQUALS $100 \quad 00$

CF37910 $10 \quad 00$ COR-MZRO2-CN 417

-

-

.............................................

- table 2 entry 361-375 INTACT vo2 total Mass

- CF380 - CF394

............................................ 


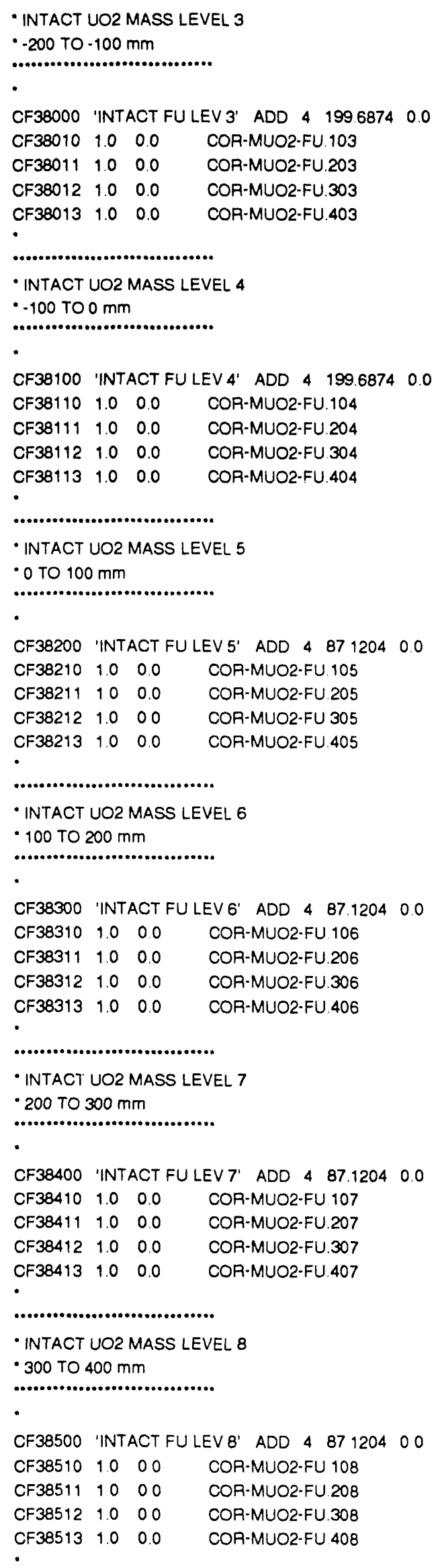


b................................

- INTACT UO2 MASS LEVEL 9

- 400 TO $500 \mathrm{~mm}$

.

CF38600 'INTACT FU LEV 9' ADD $4 \quad 87.1204 \quad 00$

CF38610 $1.0 \quad 0.0 \quad$ COR-MUO2-FU.109

CF38611 $1.0 \quad 0.0 \quad$ COR-MUO2-FU.209

CF38612 $1.0 \quad 0.0 \quad$ COR-MUO2-FU 309

$\begin{array}{llll}\text { CF38613 } & 1.0 & 0.0 & \text { COR-MUO2-FU.409 }\end{array}$

(3)

- INTACT UO2 MASS LEVEL 10

- 500 TO $600 \mathrm{~mm}$

.................................

CF38700 'INTACT FU LEV10' ADD $4 \quad 871204 \quad 0.0$

CF38710 $1.0 \quad 0.0 \quad$ COR-MUO2-FU 110

CF38711 $1.0 \quad 0.0 \quad$ COR-MUO2-FU.210

$\begin{array}{llll}\text { CF38712 } & 1.0 & 0.0 & \text { COR-MUO2-FU } 310\end{array}$

CF38713 $1.0 \quad 0.0 \quad$ COR-MUO2-FU.410

- INTACT vo2 MASS LEVEL 11

- 600 TO $700 \mathrm{~mm}$

(10............

CF38800 'INTACT FU LEV11' ADD $487.1204 \quad 00$

CF38810 $1.0 \quad 0.0 \quad$ COR-MUO2-FU 111

CF38511 $10 \quad 0.0$ COR-MUO2-FU.211

CF38912 1.0 00 COR-MUO2-FU311

CF38813 $1.0 \quad 0.0 \quad$ COR-MUO2-FU 411

- INTACT UO2 MASS LEVEL 12

- 700 TO $800 \mathrm{~mm}$

n.........

CF38900 'INTACT FU LEV12' ADD $4 \quad 87.1204 \quad 00$

CF38910 $1.0 \quad 00 \quad$ COR-MUO2-FU.112

CF38911 $1.0 \quad 0.0 \quad$ COR-MUO2-FU.212

$\begin{array}{llll}\text { CF38912 } & 1.0 & 0.0 & \text { COR-MUO2-FU.312 }\end{array}$

CF38913 $1.0 \quad 0.0 \quad$ COR-MUO2-FU 412

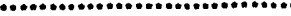

- INTACT UO2 MASS LEVEL. 13

- 800 TO $900 \mathrm{~mm}$

(...............................

CF39000 'INTACT FU LEV13' ADD $487.1204 \quad 0.0$

CF39010 $10 \quad 0.0 \quad$ COR-MUO2-FU.113

CF39011 $1.0 \quad 0.0 \quad$ COR-MUO2-FU 213

CF39012 $1.0 \quad 0.0 \quad$ COR-MUO2-FU.313

CF39013 $1.0 \quad 0.0$ COA-MUO2-FU 413

- INTACT UO2 MASS LEVEL14

- 900 TO $1000 \mathrm{~mm}$

........................................

CF39100 'INTACT FU LEV14' ADD $4 \quad 87.1204 \quad 0.0$

CF39110 $1.0 \quad 00$

COR-MUO2-FU 114

CF.39111 $1.0 \quad 0.0$ COR-MUO2-FU 214

CF39112 $1.0 \quad 0.0$ COR-MUO2-FU 314

CF39113 $10 \quad 00$

COR-MUO2-FU 414 


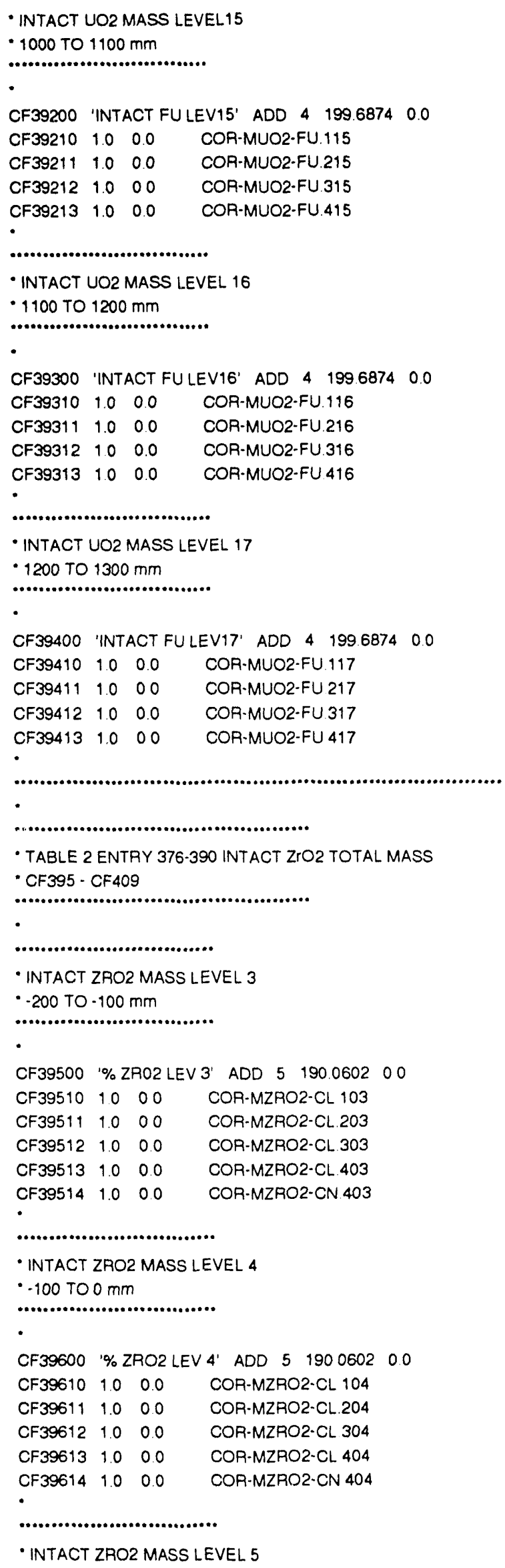


- 0 TO $100 \mathrm{~mm}$

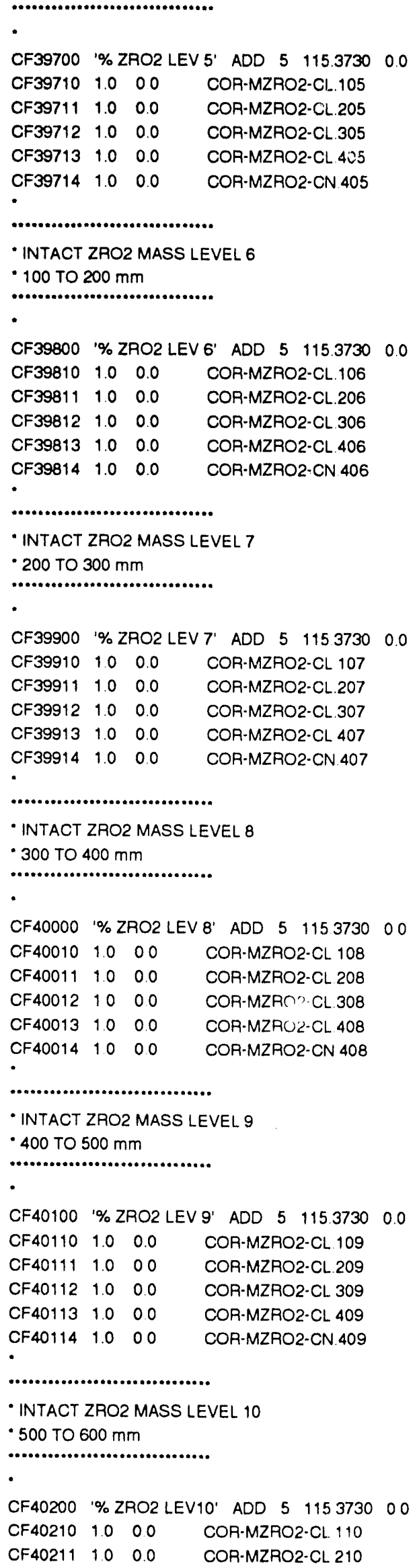




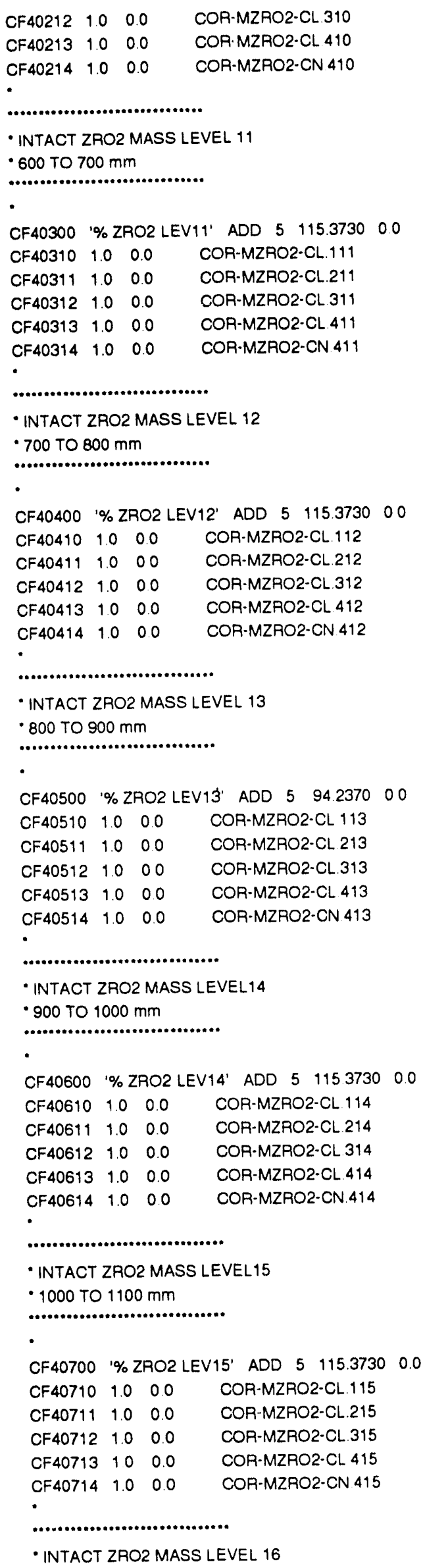

- INTACT ZRO2 MASS LEVEL 16 


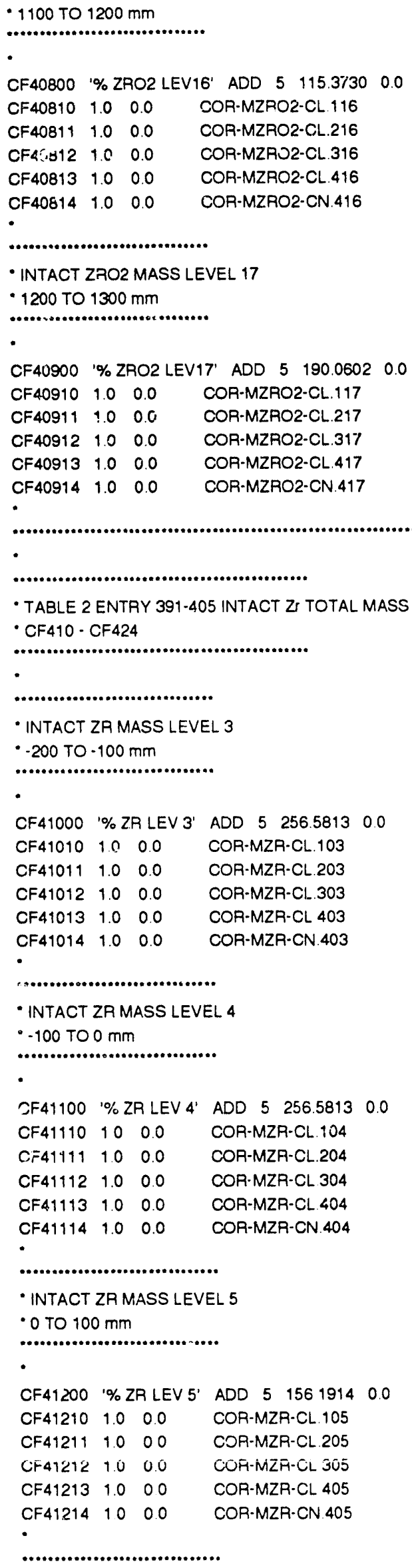




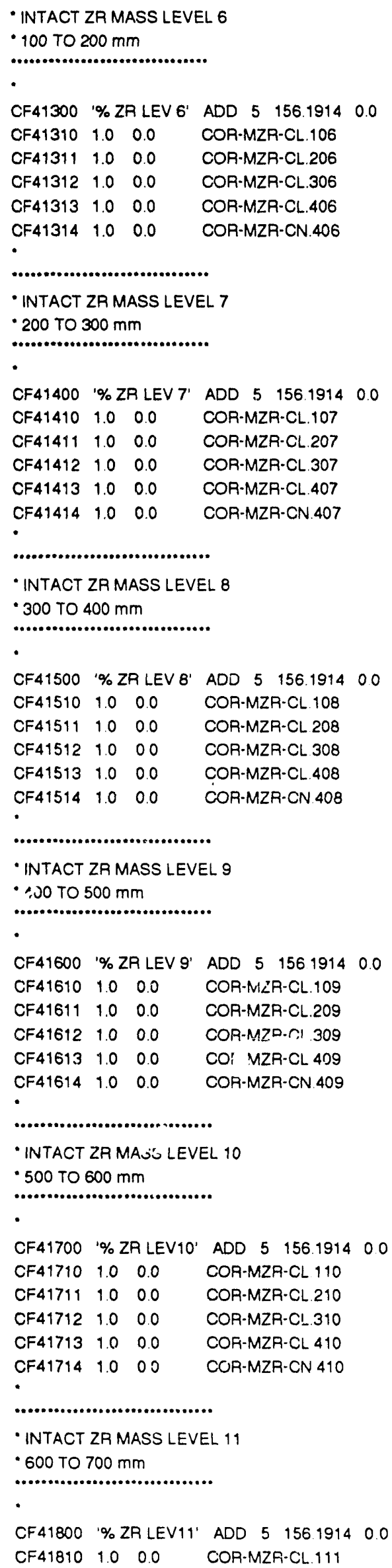




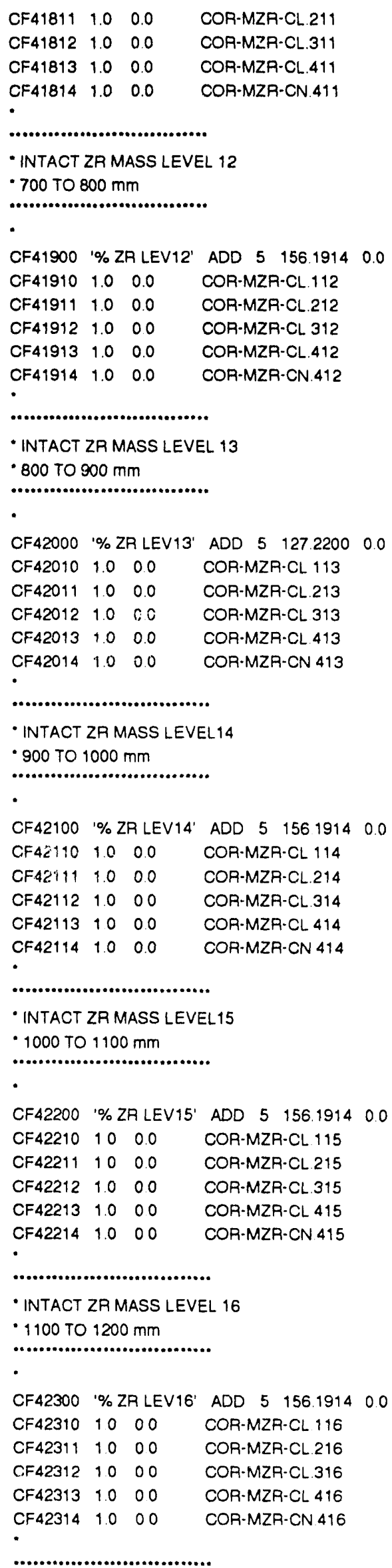




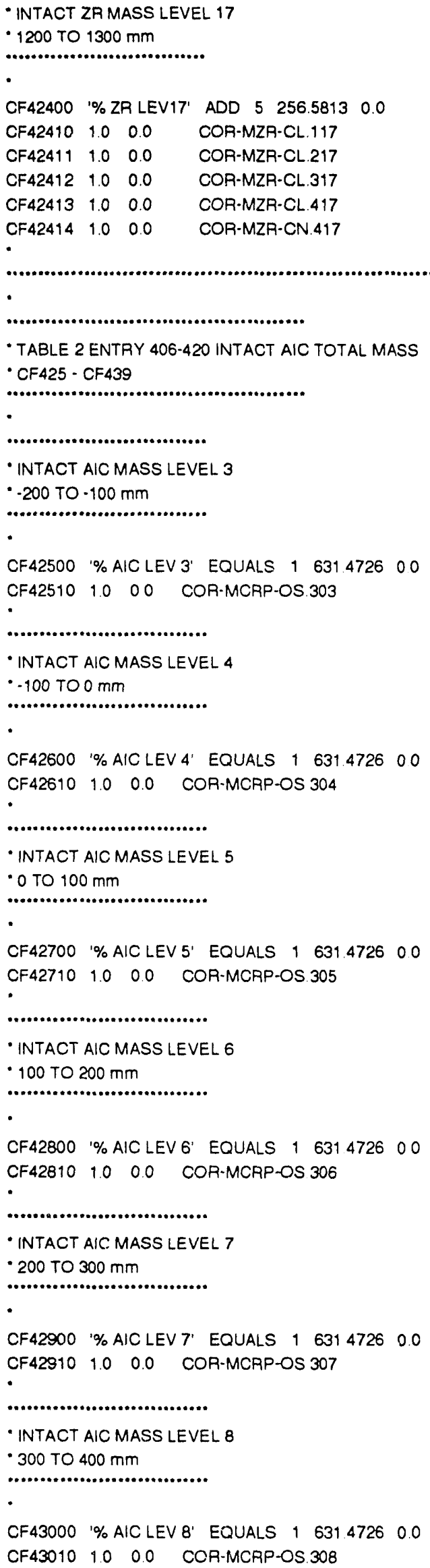


-.................................

- INTACT AIC MASS LEVEL 9

- 400 TO $500 \mathrm{~mm}$

...............................

•

CF43100 '\% AIC LEV 9' EQUALS $1 \quad 631.4726 \quad 0.0$

CF43110 $1.0 \quad 0.0 \quad$ COR-MCRP-OS 309

-

.................................

- INTACT AIC MASS LEVEL 10

- 500 TO $600 \mathrm{~mm}$

..................................

-

CF43200 '\% AIC LEV1O' EQUALS $1631.4726 \quad 0.0$ $\begin{array}{llll}\text { CF43210 } & 1.0 & 0.0 & \text { COR-MCPP-OS } 310\end{array}$

-

•................................

- INTACT AIC MASS LEVEL 11

600 TO $700 \mathrm{~mm}$

+...............................

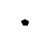

CF43300 '\% AIC LEV 11' EQUALS $1631.4726 \quad 0.0$ $\begin{array}{llll}\text { CF43310 } & 1.0 & 0.0 \quad \text { COR-MCRP-OS.311 }\end{array}$

-

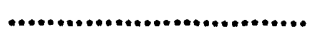

- INTACT AIC MASS LEVEL 12

- 700 TO $800 \mathrm{~mm}$

..............................

-

CF43400 '\% AIC LEV 12 ' EQUALS $16314726 \quad 0.0$ CF43410 $10 \quad 00$ COR-MCRP-OS 312

-

[..................................

- INTACT AIC MASS LEVEl 13

- 800 TO $900 \mathrm{~mm}$

...............................

-

CF43500 '\% AICLEV 13' EQUALS $1631.4726 \quad 0.0$

CF43510 $1.0 \quad 0.0$ COR-MCRP.OS 313

-

...............................

- INTACT AIC MASS LEVEL14

- 900 TO $1000 \mathrm{~mm}$

...............................

-

CF43600 '\% AIC LEV 14' EQUALS $163^{4} 4726 \quad 0.0$ CF43610 $1.0 \quad 00 \quad$ COR-MCRP-OS 314

-

- INTACT AIC MASS LEVEL15

- 1000 TO $1100 \mathrm{~mm}$

................................

-

CF43700 '\% AIC LEV 15' EQUALS $1631.4726 \quad 00$ $\begin{array}{llll}\text { CF43710 } & 1.0 & 0.0 \quad \text { COR-MCRP-OS } 315\end{array}$

-

...................................

- INTACT AIC MASS LEVEl 16

- 1100 TO $1200 \mathrm{~mm}$

-..................................

-

CF43800 '\% AIC LEV 16' EQUALS $16314726 \quad 00$

$\begin{array}{llll}\text { CF43810 } & 1.0 & 0.0 & \text { COR-MCRP-OS.316 }\end{array}$

-

- INTACT AIC MASS LEVEL 17 


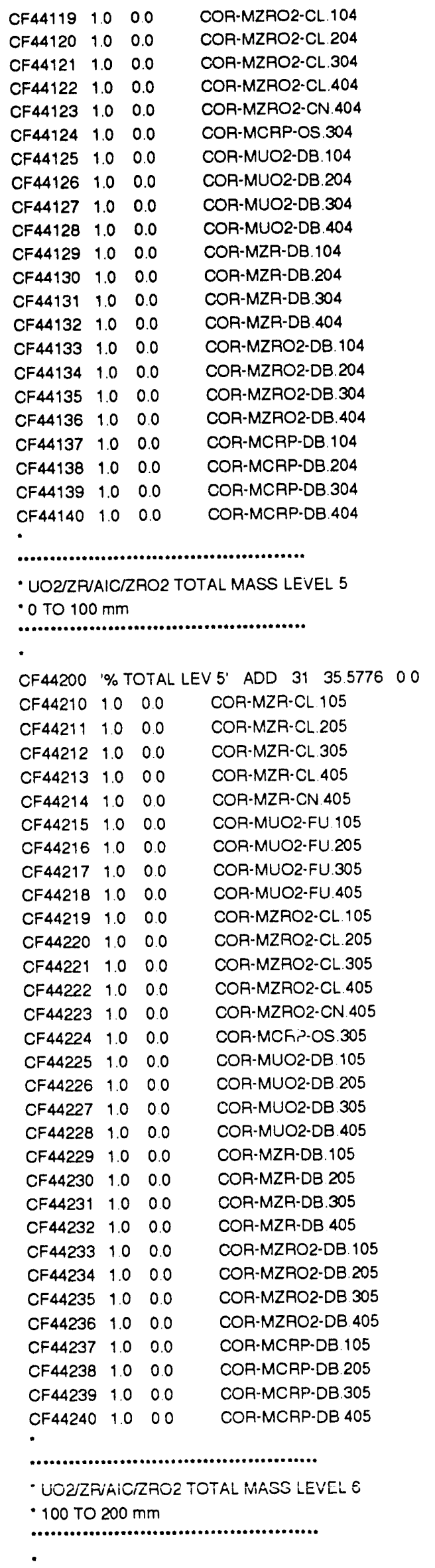

COR-MZRO2-CL.104 COR-MZRO2-CL.204 A.MZRO2-CL 304 COR-MZRO2-DB 304 COR-MZRO2-DB.404 COR-MCRP-DB.104 $\begin{array}{llll}\text { CF44139 } & 1.0 & 0.0 & \text { COR-MCRP-DB.304 } \\ \text { CF44140 } & 1.0 & 0.0 & \text { COR-MCRP-DB.404 }\end{array}$

- vorzzavaicizroz total mass level 5 - 0 to $100 \mathrm{~mm}$ 


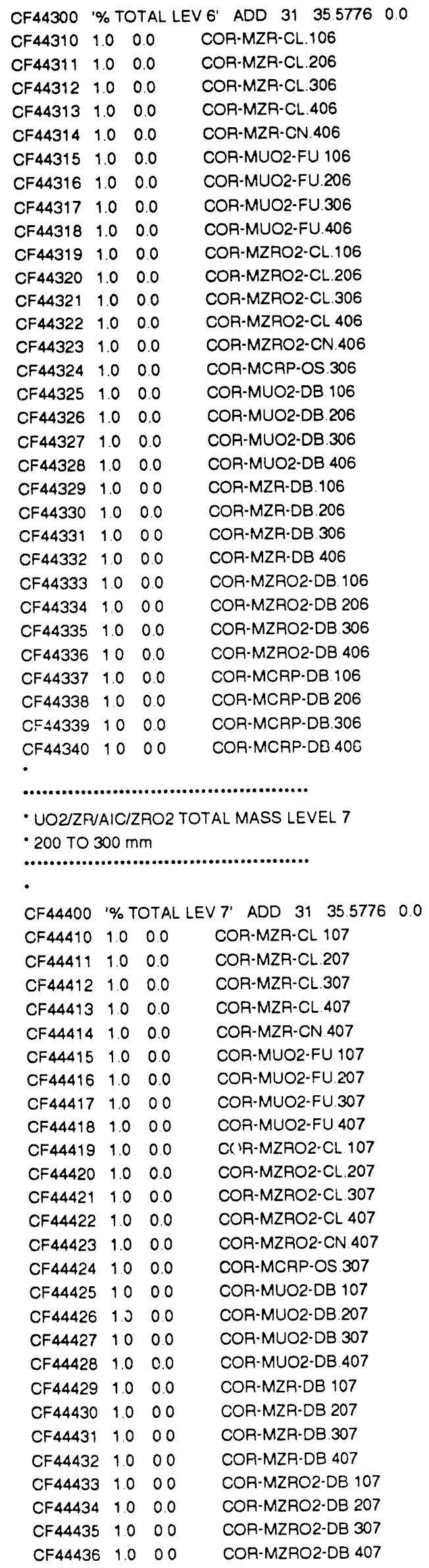




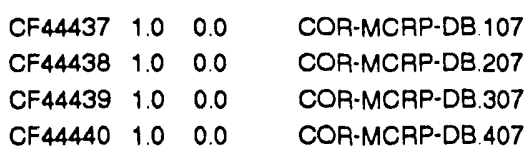




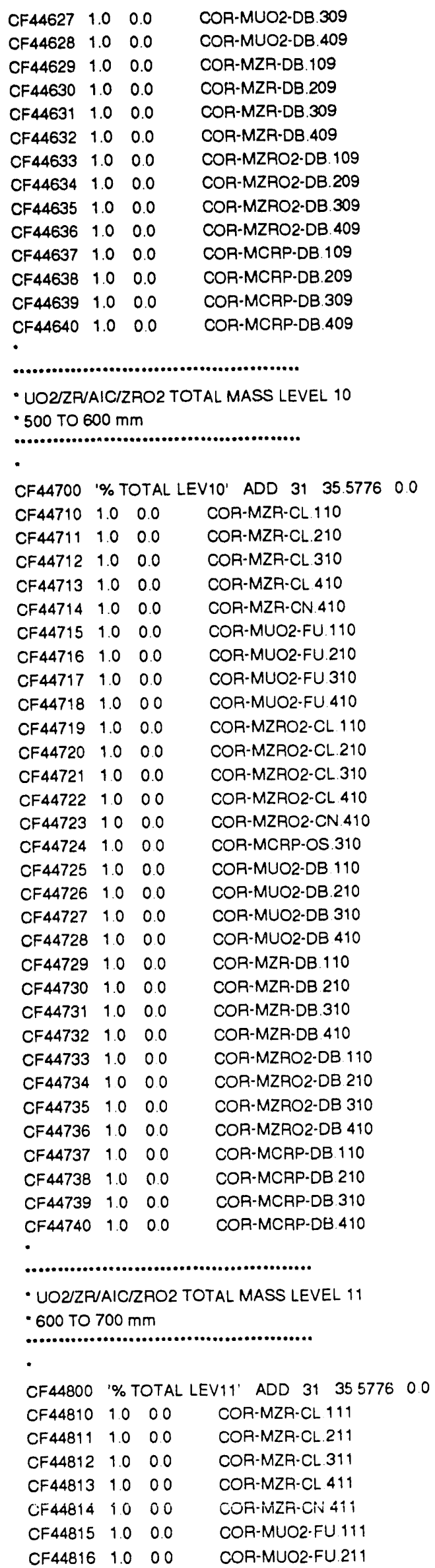




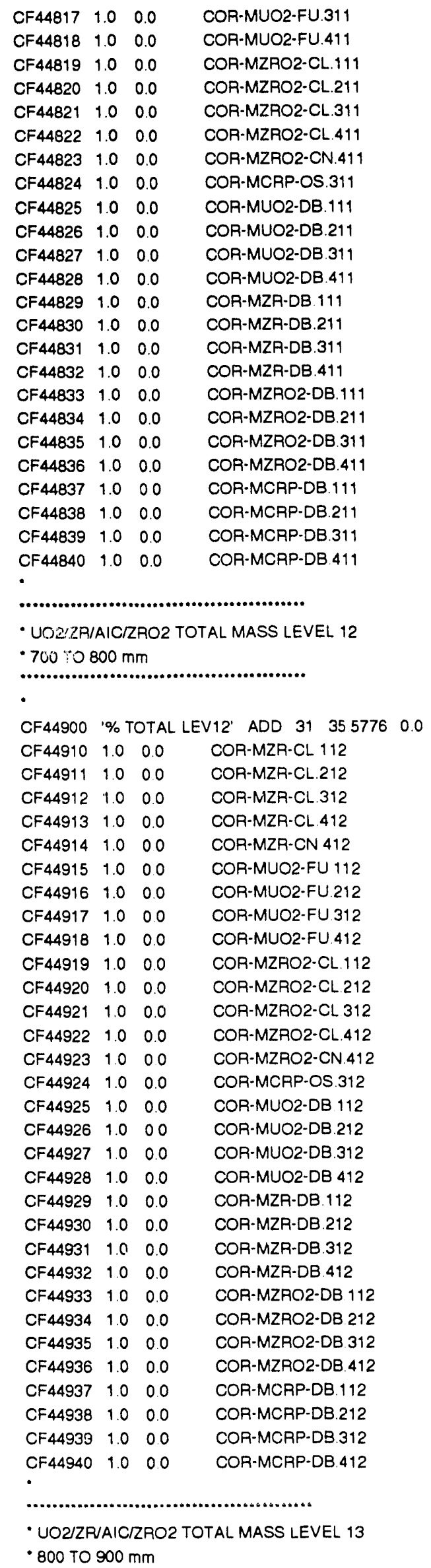

- UOZIZR/AIC/ZRO2 TOTAL MASS LEVEL 12

- $70070800 \mathrm{~mm}$

.

CF44900 '\% TOTAL LEV12' ADD $31 \quad 355776 \quad 0.0$

CF44910 $1.0 \quad 0.0$

COR-MZR-CL 112

COR-MZR-CL.212

CF44911 $1.0 \quad 0.0$

CF44912 $1.0 \quad 0.0$

CF44913 $1.0 \quad 0.0$ COR-MZR-CL.312 COR-MZR-CL 412 COR-MZR-CN 412

CF44914 $1.0 \quad 00$

CF44915 $1.0 \quad 00$

$\begin{array}{lll}\text { CF44916 } & 1.0 \quad 0.0\end{array}$

CF44917 $1.0 \quad 0.0$

CF44918 $1.0 \quad 0.0$

$\begin{array}{lll}\text { CF44919 } 1.0 \quad 0.0 & 0.0\end{array}$

CF44920 $1.0 \quad 0.0$

CF44921 $1.0 \quad 0.0$

CF44922 $1.0 \quad 0.0$

CF44923 $1.0 \quad 00$

$\begin{array}{lll}\text { CF44924 } 1.0 \quad 0.0 & 0.0\end{array}$

CF $44925 \quad 1.0 \quad 0.0$

CF44926 $1.0 \quad 00$

$\begin{array}{lll}\text { CF44927 } 1.0 \quad 0.0 & 0\end{array}$

CF $44928 \quad 1.0 \quad 0.0$

CF $44929 \quad 1.0 \quad 0.0$

$C F 44930 \quad 1.0 \quad 0.0$

$\begin{array}{lll}\text { CF44931 } & 1.0 & 0.0\end{array}$

$C F 44932 \quad 1.0 \quad 0.0$

CF $44933 \quad 1.0 \quad 0.0$

CF $44934 \quad 1.0 \quad 0.0$

CF44935 $1.0 \quad 0.0$

$\begin{array}{lll}C F 44936 & 1.0 & 0.0\end{array}$

CF44937 $1.0 \quad 0.0$

$C F 44938 \quad 1.0 \quad 0.0$

CF44939 $1.0 \quad 0.0$

CF44940 $1.0 \quad 0.0$

COR-MUO2-FU 112

COR-MUO2-FU.212

COR-MUO2-FU 312

COR-MUO2-FU 412

COR-MZRO2-CL. 112

COR-MZRO2-CL 212

COR-MZRO2-CL 312

COR-MZRO2-CL.412

COR-MZRO2-CN 412

COR-MCRP-OS.312

COR-MUO2-DB 112

COR-MUO2-DB.212

COR-MUO2-DB.312

COR-MUO2-DB 412

COR-MZR-DB. 112

COR-MZR-DB.212

COR-MZR-DB.312

COR-MZR-DB 412

COR-MZRO2-DB 112

COR-MZRO2-DB.212

COR-MZRO2-DB. 312

COR-MZRO2-DB.412

COR-MCRP-DB.112

COR-MCRP-DB.212

COR-MCRP-DB.312

COR-MCRP-DB.412

-

- UO2/ZRIAIC/ZRO2 TOTAL MASS LEVEL 13

- 800 TO $900 \mathrm{~mm}$ 


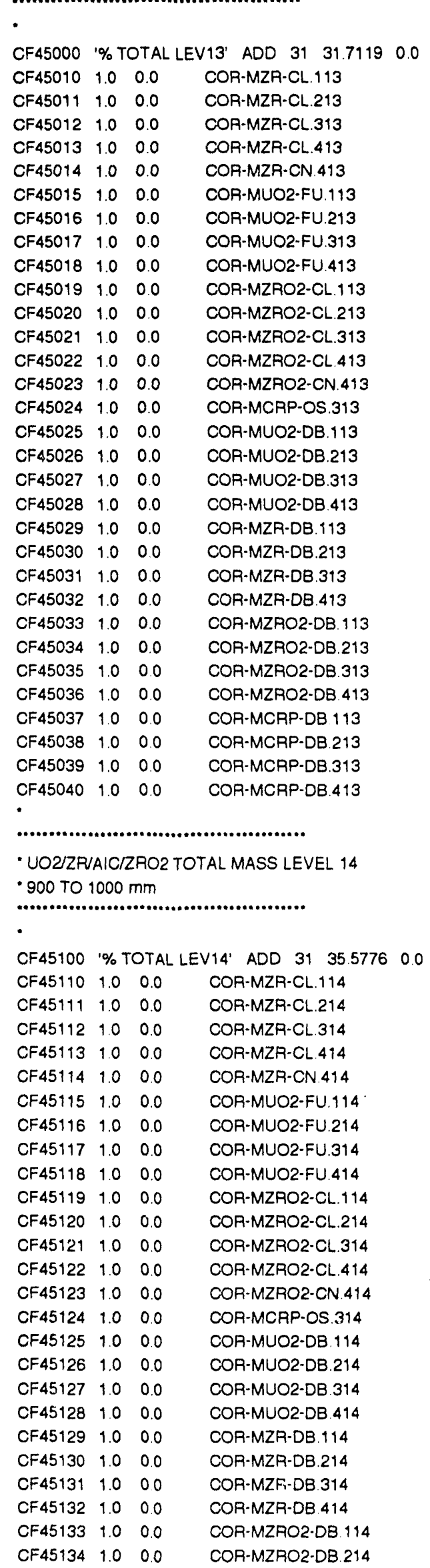




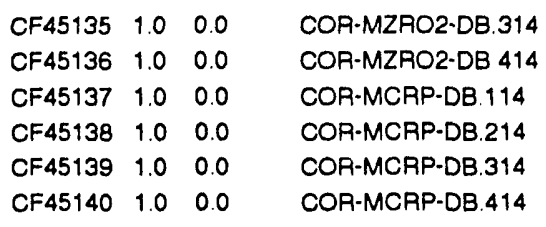




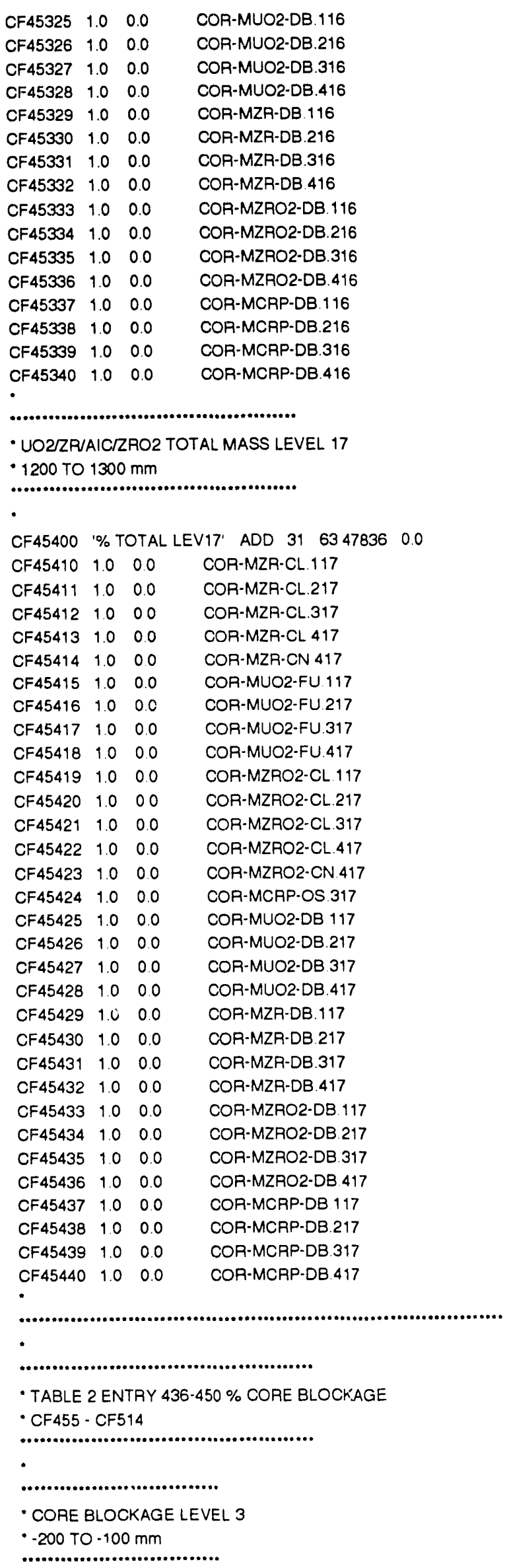

- CORE BLOCKAGE LEVEL 3

- 200 TO $-100 \mathrm{~mm}$ 


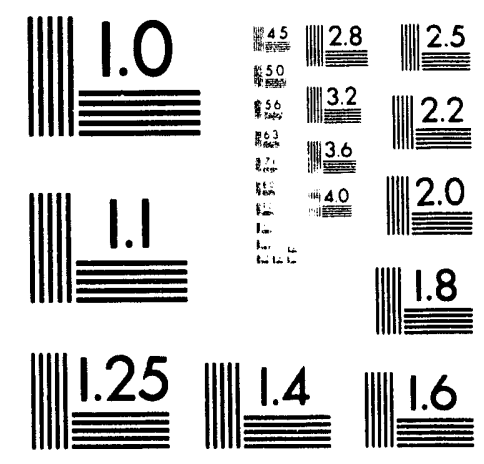



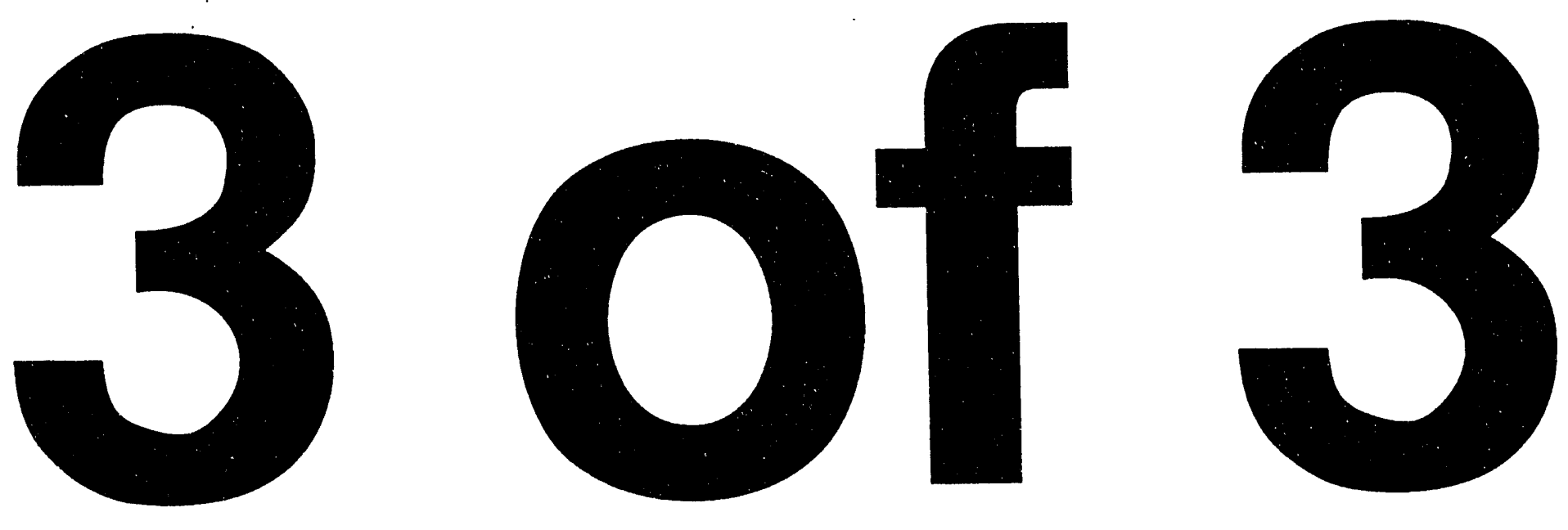


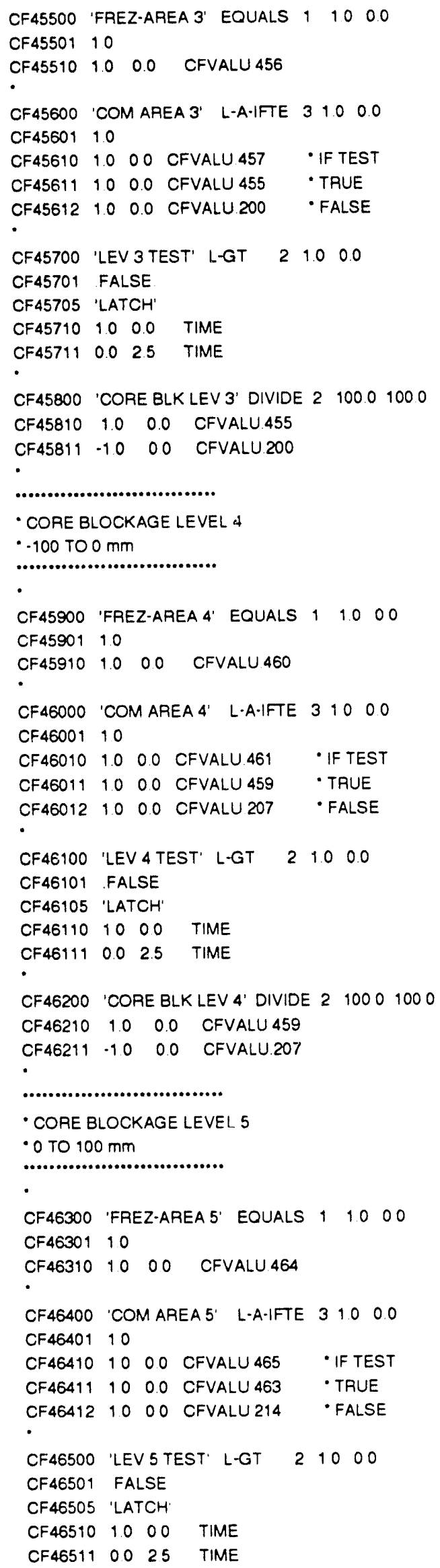




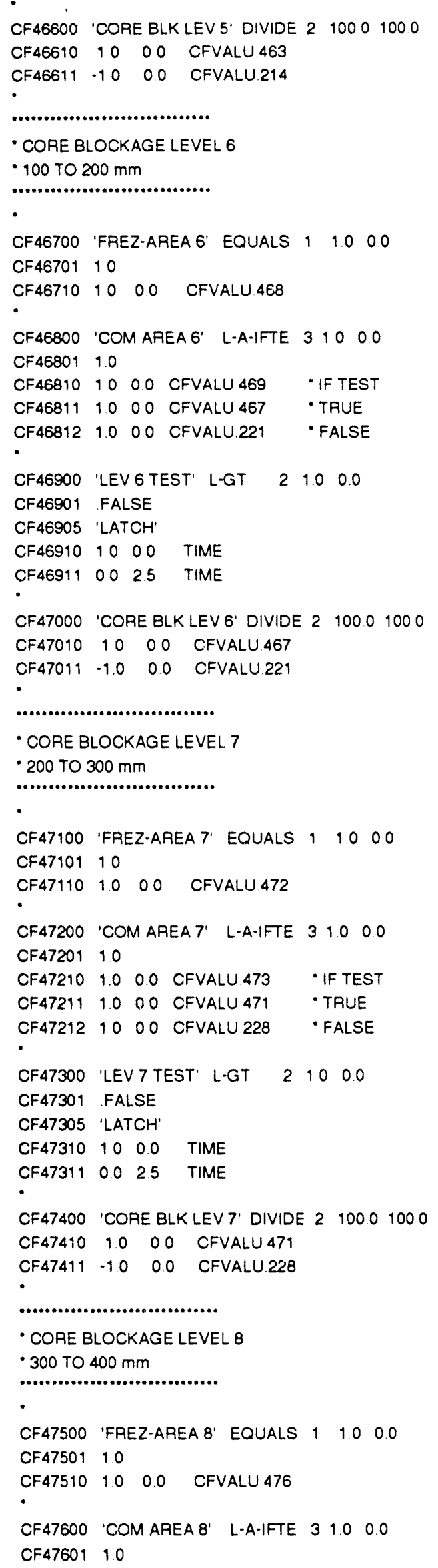$$
\text { CF47400 'CORE BLKLEV 7' DIVIDE } 2 \quad 10001000
$$ 


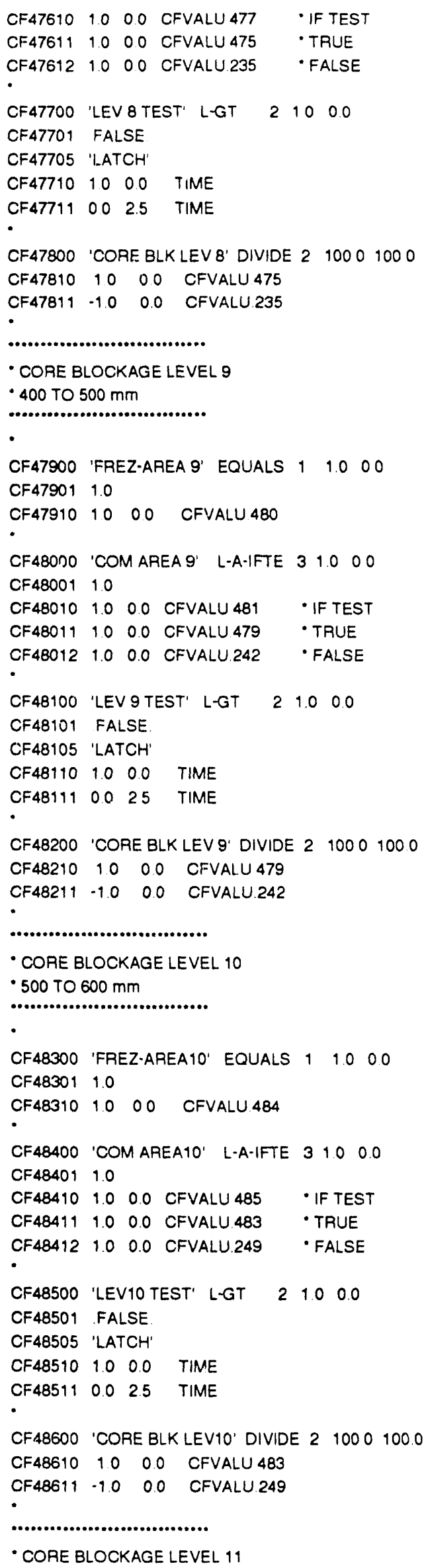




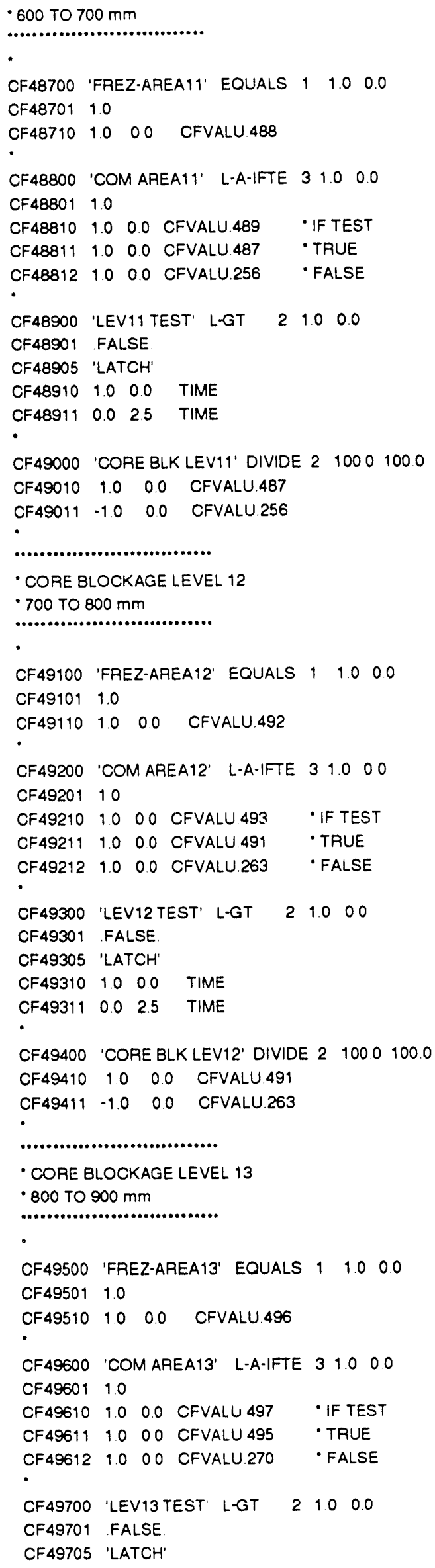




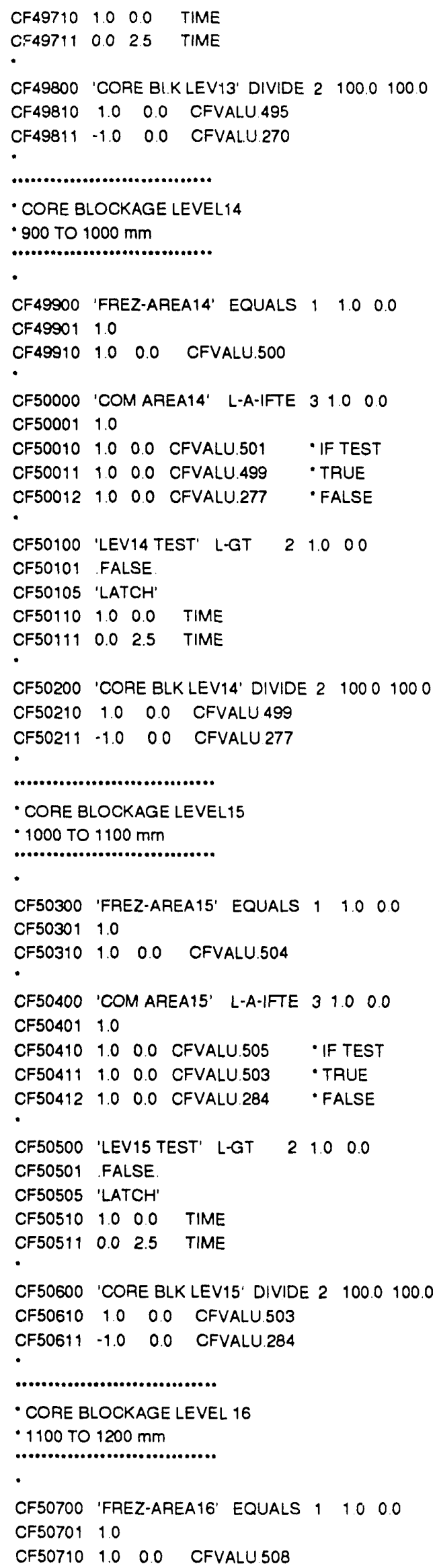




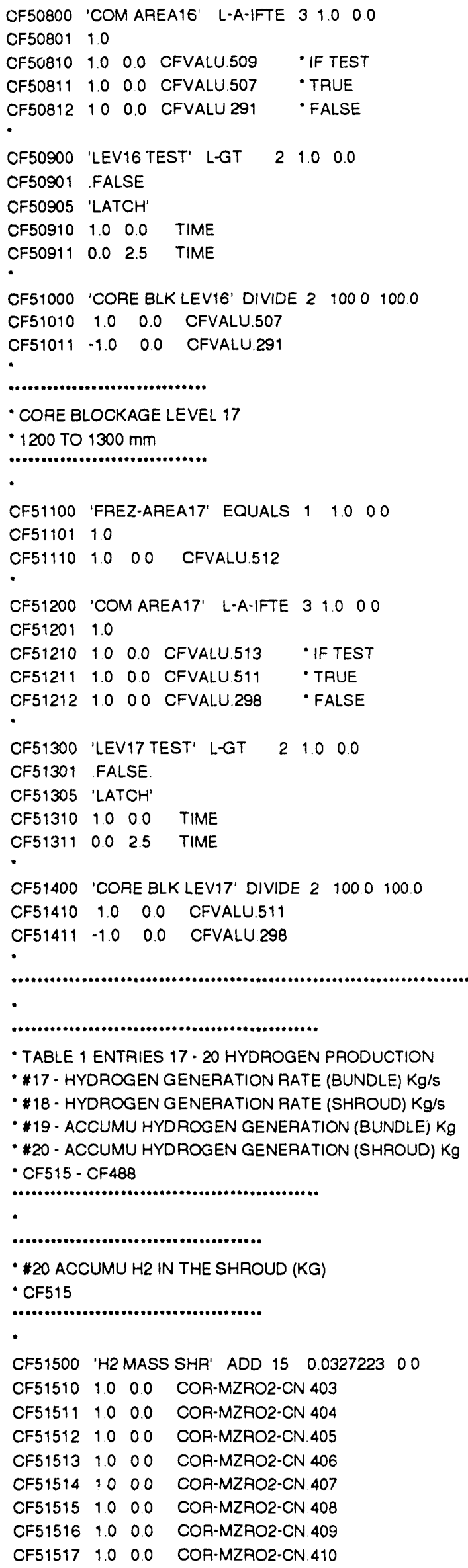




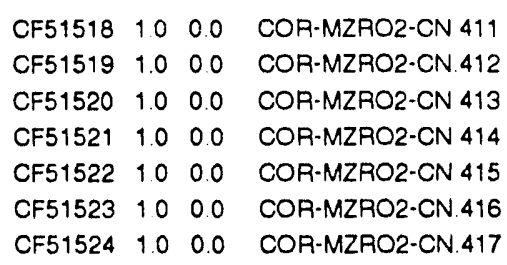

- 18 H2 GENERATION IN THE SHROUD (KG/S)

- \#19 ACCUMU H2 IN THE BUNDLE (KG)

- CF517

........................................

CF51700 'H2 MASS BUN' ADD $2 \quad 100.0$

CF51710 $1.0 \quad 0.0 \quad$ FL-I-MFLOW 4.240

CF51711 1 -1.0 0.0 CFVALU.515

-

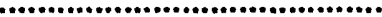

* 17 H2 GENERATION IN THE BUNDLE (KG/S)

- CF518

(..........................................

CF51800 'H2 RATE BUN' ADD $2 \quad 1.0 \quad 0.0$

CF51810 $1.0 \quad 0.0 \quad$ FL-MFLOW 4240

CF51811 $-1.0 \quad 0.0 \quad$ CFVALU 516

.........................................

- TABLE 1 ENTRY 3 SYSTEM PRESSURE (MPA)

- CF519

-

CF51900 'SYSTEM PRESS' EQUALS $111.0 \quad 0.0$

CF51910 $1.0 \mathrm{E}-6 \quad 0.0 \quad$ CVH-P.220

-

..........................................

- TABLE 1 ENTRY 4 STEAM INLET FLOW (KG/S)

- CF520

.........................................

CF52000 'STEAM INLET FL' TAB-FUN $1 \quad 1.0 \quad 0.0$ CF52003 030

CF52010 $1.0 \quad 0.0 \quad$ TIME

-

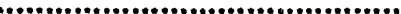

- TABLE 1 ENTRY 5 ARGON INLET FLOW (KG/S)

- CF521

-

CF52100 'ARGON INLET FL' TAB-FUN $1 \quad 1.0 \quad 0.0$

CF52103 010

$\begin{array}{llll}\text { CF52110 } & 1.0 & 0.0 & \text { TIME }\end{array}$

.........................................

- TABLE 1 ENTRY 6 WATER INLET FLOW (KG/S)

- CF522 


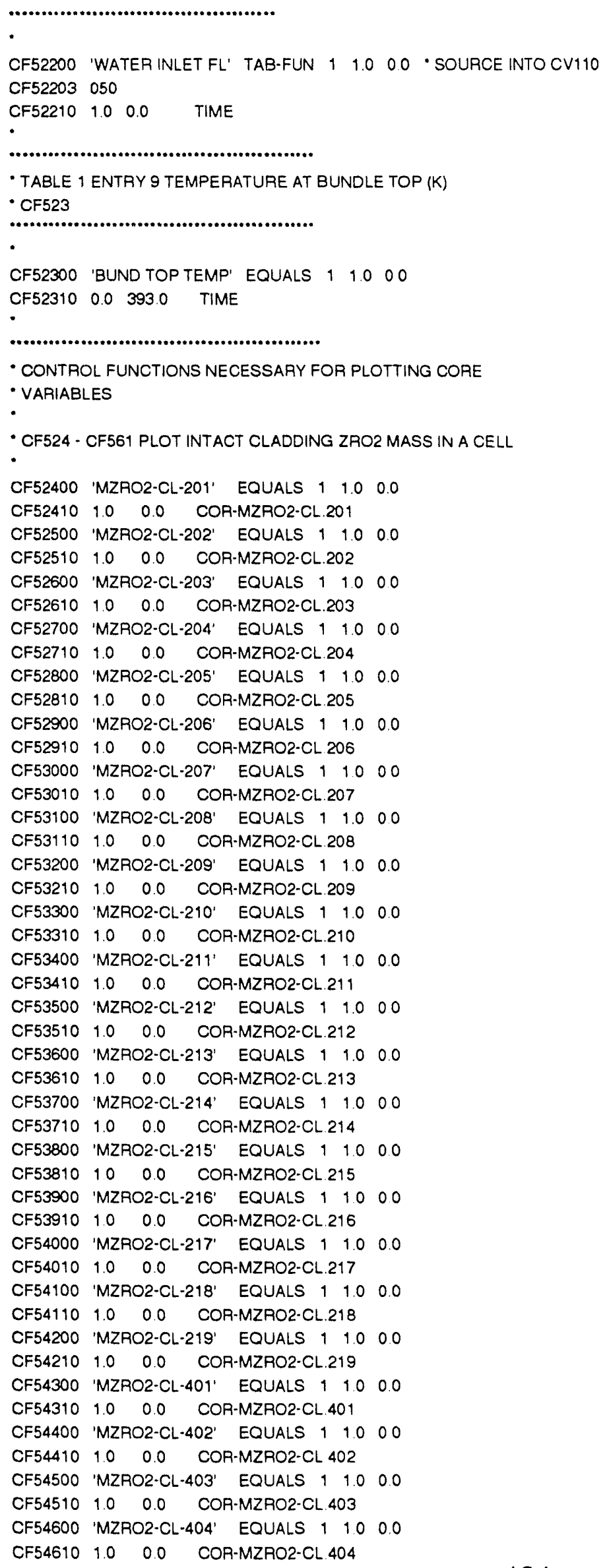


CF54700 'MZRO2-CL-405' EQUALS $110 \quad 00$ CF54710 $1.0 \quad 00 \quad$ COR-MZROĆC.CL 405

CF54800 'MZRO2-CL-406' EQUALS 11000 CF54810 $1.0 \quad 0.0 \quad$ COR-MZRO2-CL.406

CF54900 'MZRO2-CL-407' EQUALS $111.0 \quad 0.0$

CF54910 $10 \quad 00 \quad$ COR-MZRO2-CL 407

CF55000 'MZRO2-CL-408' EQUALS $1 \quad 1000$

CF55010 $1.0 \quad 0.0 \quad$ COR-MZRO2-CL 408

CF55100 'MZRO2-CL-409' EQUALS 111000

CF55110 10 OO COR-MZRO2-CL 409

CF55200 'MZRO2-CL-410' EQUALS 111.00 .0

CF55210 1.0 0.0 COR-MZRO2-CL 410

CF55300 'MZRO2-CL-411' EQUALS $110 \quad 00$

CF55310 10 OO O COR-MZRO2-CL 411

CF55400 'MZRO2-CL-412' EQUALS $1110 \quad 0.0$

CF55410 $1.0 \quad 00$ COR-MZRO2-CL.412

CF55500 'MZRO2-CL-413' EQUALS 1100.0

CF55510 $1.0 \quad 0.0 \quad$ COR-MZRO2-CL.413

CF55600 'MZRO2-CL-414' EQUALS 11.00 .0

CF55610 $1.0 \quad 0.0 \quad$ COR-MZRO2-CL 414

CF55700 'MZRO2-CL-415' EQUALS $1 \quad 1.0 \quad 0.0$

CF55710 $1.0 \quad 0.0 \quad$ COR-MZRO2-CL.415

CF55800 'MZRO2-CL-416' EQUALS 111000

CF55810 $1.0 \quad 0.0 \quad$ COR-MZRO2-CL.416

CF55900 'MZRO2-CL-417' EQUALS $111.0 \quad 00$

CF55910 $1.0 \quad 0.0 \quad$ COR-MZRO2-CL 417

CF56000 'MZRO2-CL-418' EQUALS 11.000

CF56010 $1.0 \quad 0.0 \quad$ COR-MZAO2-CL 418

CF56100 'MZRO2-CL-499' EQUALS 1100.0

CF56110 $110 \quad 0.0 \quad$ COR-MZRO2-CL 419

-

- CF562 - CF580 PLOT INTACT OTHER STRUCTURE CONTROL

- poIson MASS IN A CÉLL

CF56200 'MCRP-OS-301' EQUALS 11.000

CF56210 $1.0 \quad 00 \quad$ COR-MCAP-OS 301

CF56300 'MCRP-OS-302' EQUALS 1100.0

CF56310 $1.0 \quad 0.0 \quad$ COP-MCRP-OS 302

CF56400 'MCRP-OS-303' EQUALS 111000

CF56410 $1.0 \quad 0.0 \quad$ COR-MCRP.OS 303

CF56500 'MCRP-OS-304' EQUALS 11.000

CF56510 $10 \quad 00$ COR-MCRP-OS 304

CF56600 'MCRP.OS-305' EQUALS $1 \quad 1.0 \quad 0.0$

CF56610 $1.0 \quad 0.0 \quad$ COR-MCRP-OS 305

CF56700 'MCRP-OS-306' EQUALS $1 \quad 1.0 \quad 0.0$

CF56710 $1.0 \quad 00$ COR-MCRP-OS 306

CF56800 'MCAP-OS-307' EQUALS $110 \quad 00$

CF56810 $1.0 \quad 0.0$ COR-MCRP.OS 307

CF56900 'MCRP-OS-308' EQUALS $1110 \quad 0.0$

CF56910 $1.0 \quad 0.0 \quad$ COR-MCRP-OS 308

CF57000 'MCRP-OS-309' EQUALS $111.0 \quad 0.0$

CF57010 $1.0 \quad 0.0 \quad$ COR-MCRP-OS 309

CF57100 'NCRP-OS-310' EQUALS $111.0 \quad 0.0$

CF57110 $1.0 \quad 0.0 \quad$ COR-MCRP-OS 310

CF57200 'MCRP-OS-311' EQUALS 11.000

CF57210 $10 \quad 0.0 \quad$ COR-MCRP-OS.311

CF57300 'MCRP-OS-312' EQUALS 111000

CF57310 $1.0 \quad 0.0 \quad$ COR-MCRP-OS.312

CF57400 'MCRP-OS-313' EQUALS $1110 \quad 0.0$

CF57410 $1.0 \quad 0.0 \quad$ COR-MCRP-OS 313

CF57500 'MCRP-OS-314' EQUALS 11.000

CF57510 $1.0 \quad 0.0 \quad$ COR-MCRP-OS 314

CF57600 'MCRP-OS-315' EQUALS 111000

$\begin{array}{llll}\text { CF57610 } & 10 & 0.0 & \text { COR-MCRP-OS } 315\end{array}$

CF57700 'MCRP-OS-316' EQUALS 111.000

$\begin{array}{llll}\text { CF57710 } & 1.0 & 0.0 & \text { COR-MCRP-OS.316 }\end{array}$ 


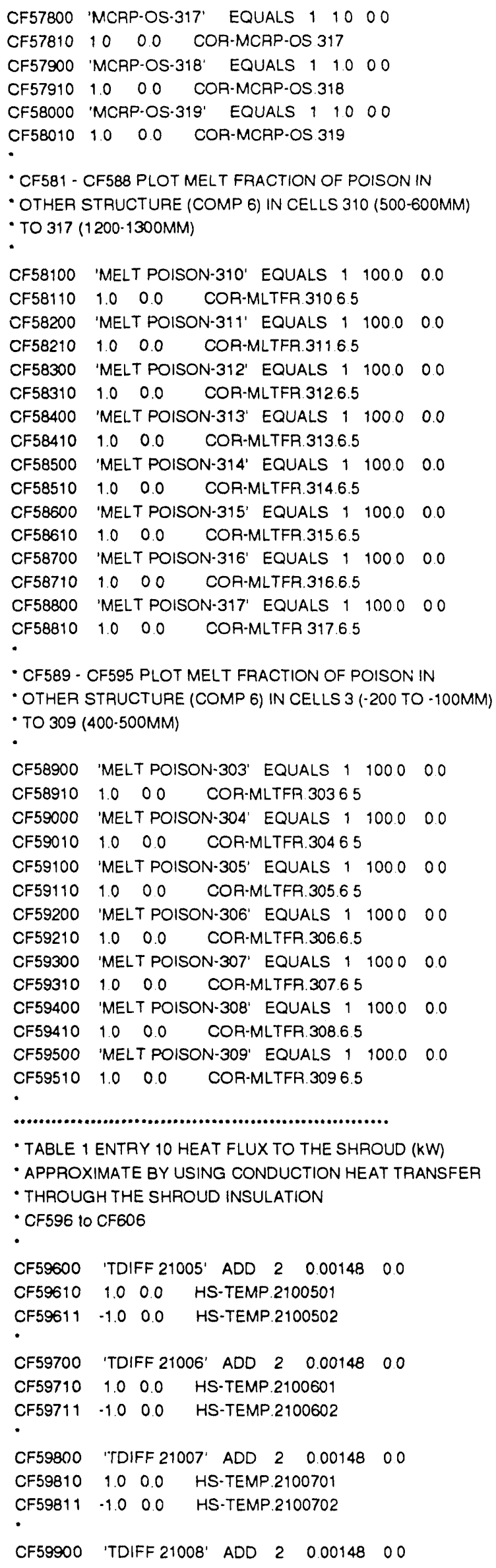




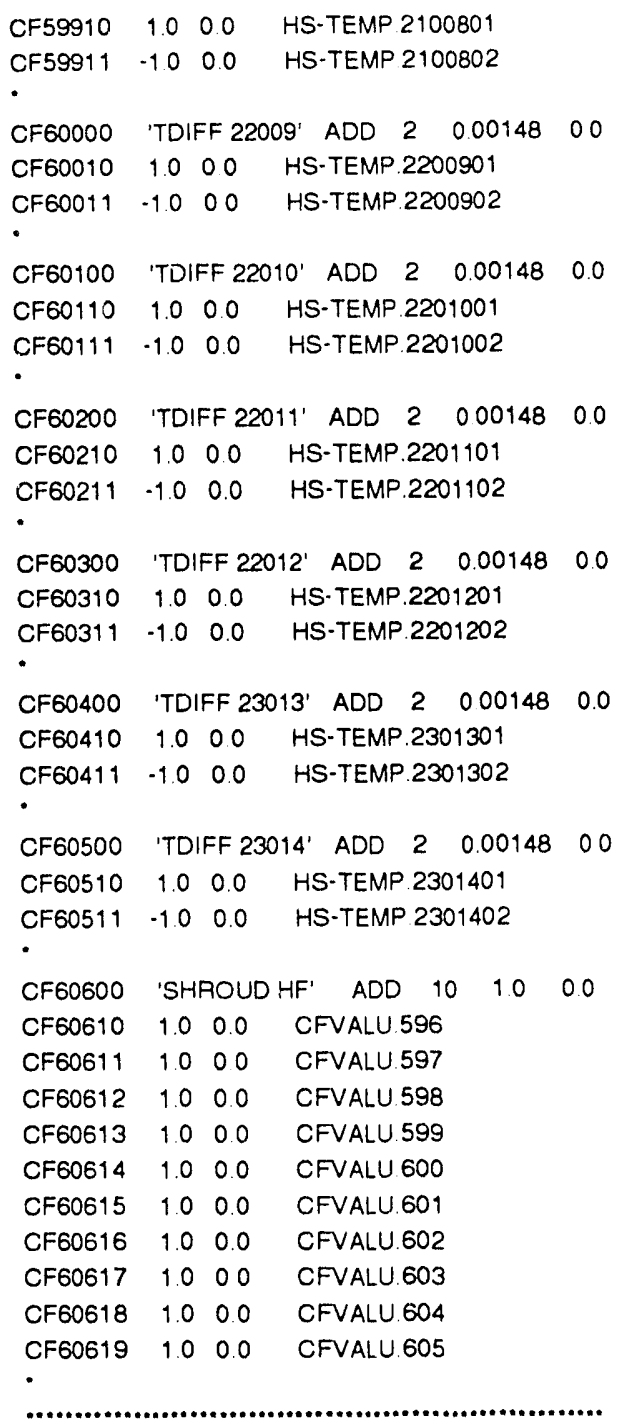

- TABLE 1 eNTRY 11 HeAT FLUX INTO FLUID (KW)

- APPROXIMATE BY USING COR-QCNV VARIABLE

- CF607 to CF606

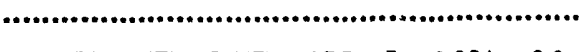

$\begin{array}{llllll}\text {-CF60700 'FLUID HF' ADD } 5 & 0.001 & 0.0\end{array}$

-CF60710 $1.0 \quad 00$ COR.QCNV.110

$\begin{array}{llll}\text { CFF60711 } & 1.0 & 0.0 & \text { COR-QCNV } 210\end{array}$

-CF60712 $1.0 \quad 0.0 \quad$ COR-QCNV.220

-CF60713 $1.0 \quad 0.0 \quad$ COR-QCNV.230

-CF60714 $1.0 \cap J$ COR.QCVN.240

- TABLE 1 ENTRY 12 HEAT STORED IN BUNDLE (kW')

- APPROXIMATE BY TAKING DERIVATIVE OF COR-ENERGY-TOT

- CF608

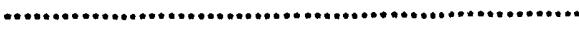

$\begin{array}{lllll}-C F 60800 & \text { 'FLUID HF' DER-F } 2 & 0.001 & 0.0\end{array}$

-CF60810 $1.0 \quad 0.0$ COR-ENERGY-TOT

$\begin{array}{llll}\text { •CF60811 } & 1.0 & 0.0 & \text { TIME }\end{array}$

- table 1 entry 15 POWER generation by OXIDATION

- THIS ENTRY INCLUDES ENERGY GENERATED BY THE BUNDLE

- AND THE SHROUD AS THE CORE PACKAGE PRESENTLY DOES 


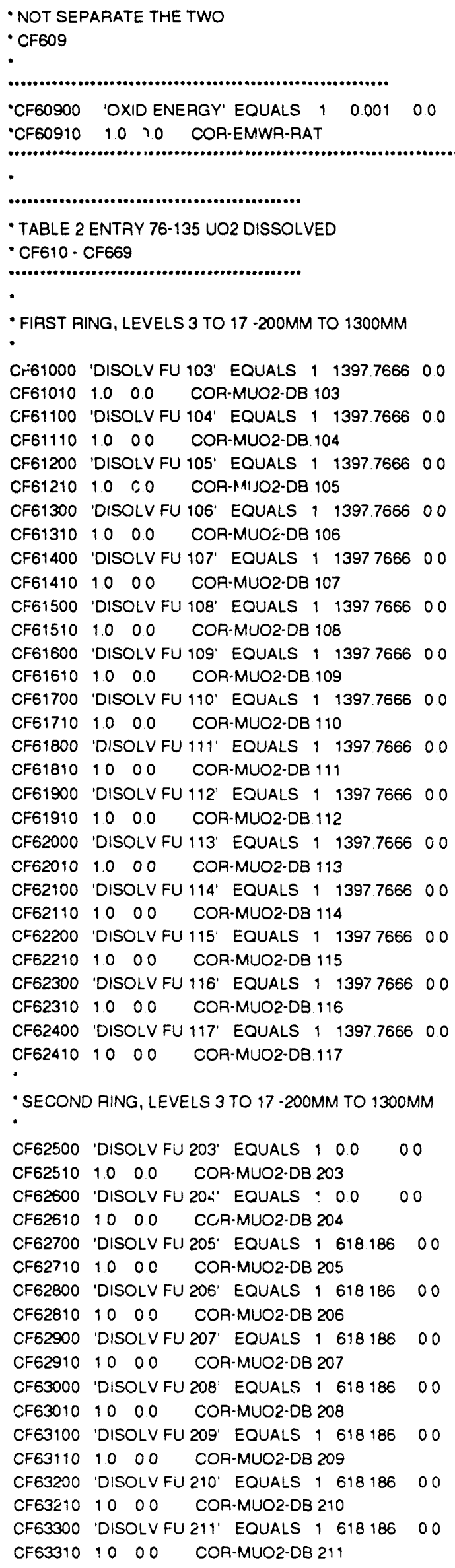




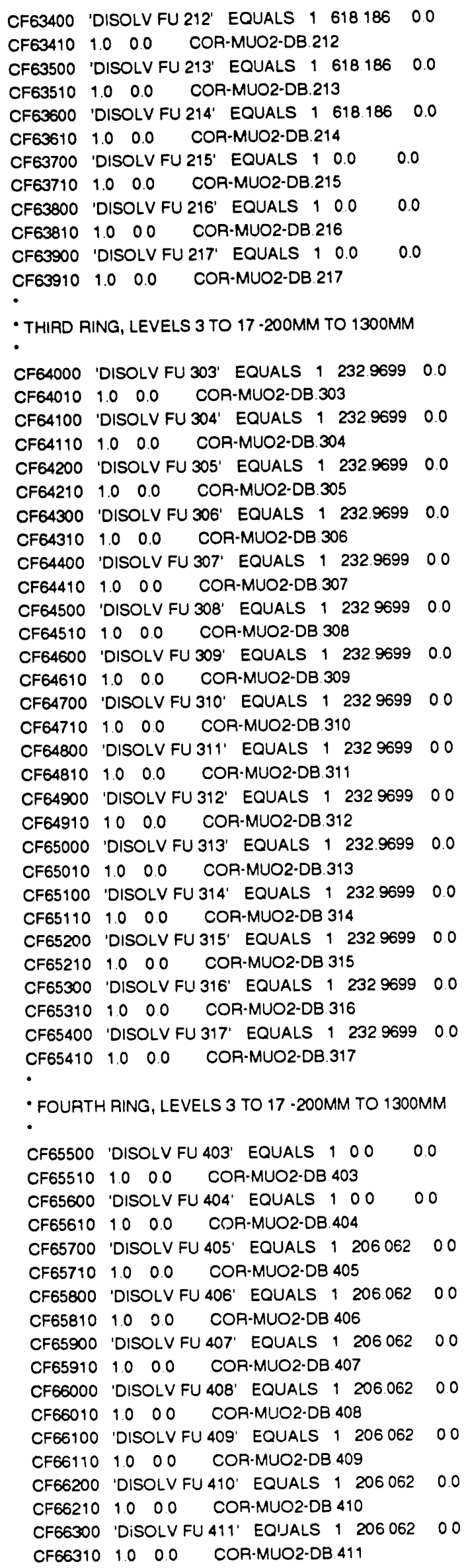




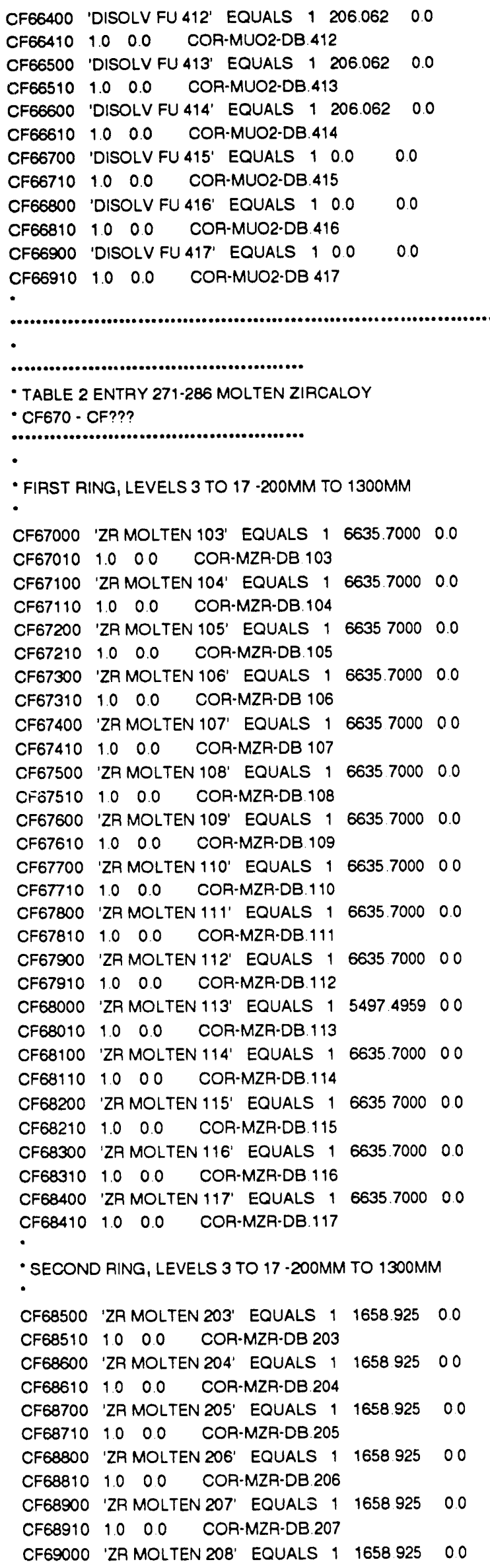




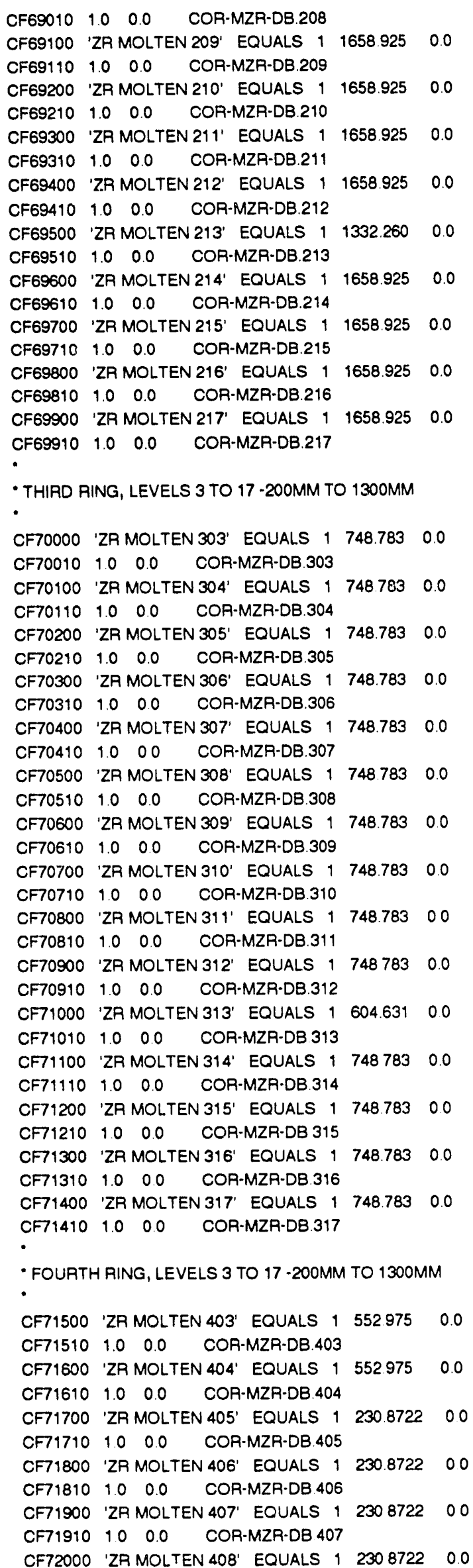$$
\text { CF71500 'ZR MOLTEN 403' EQUALS } 15529750.0
$$ 


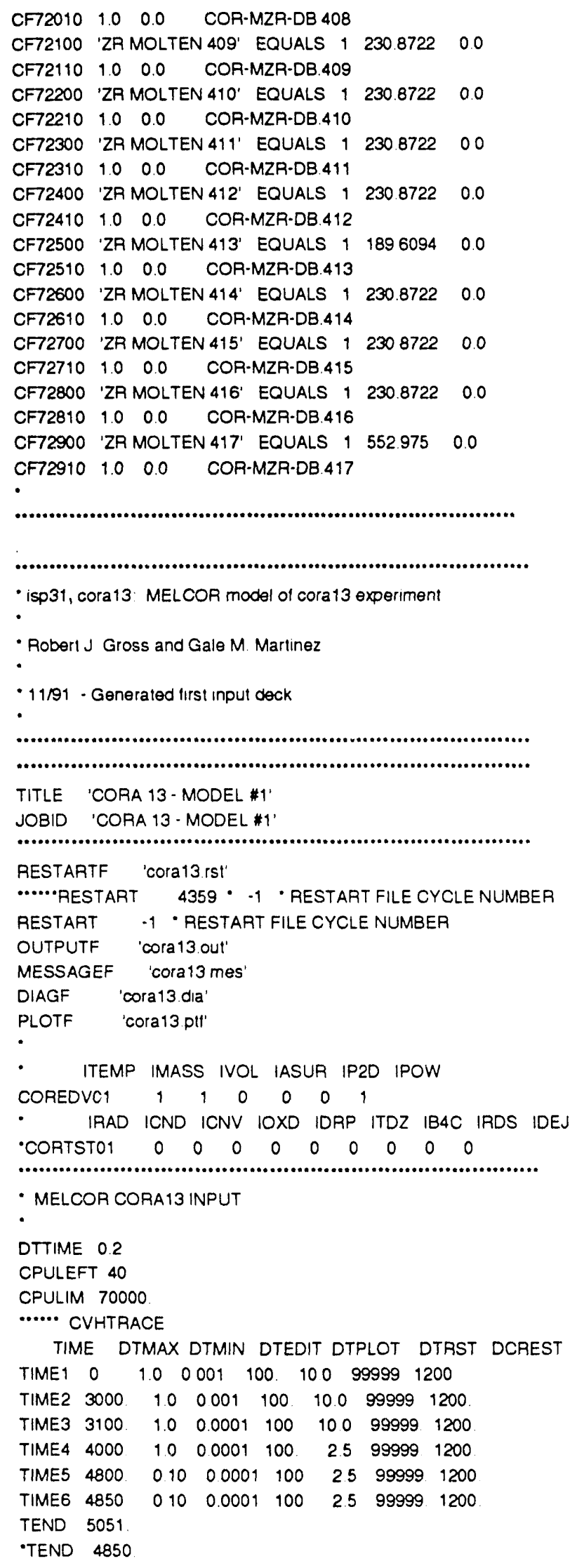




\section{Appendix B: Electrical Heater Subroutines}

MELCOR does not have an internal model for electrical heater rods and the associated electrical circuits. MELCOR 1.8.2 does have a standard interface which will allow the user to supply FORTRAN routines to model the specific electrical features of a test facility and return the power generated when supplied with the time and temperature distribution. This FORTRAN code can be loaded with MELCOR using the MELCOR link utility "MULINKMEL" and will replace dummy routines in the default MELCOR source code library.

The code used for the CORA 13 experiment is shown below. There are five subroutines.

1. ELHEAT - This is the only routine called from MELCOR. Given the time and current temperature distribution in the COR materials, it must return the current power distribution. The specific nodalization used in the MELCOR model (19 axial levels and 4 radial rings) is assumed in the code. Additional details are contained in the comments in the code.

2. ELVOLT - This routine returns the electrical voltage, current, and power from the defined boundary conditions for this experiment, given the time and ring number.

3. ELREST - This routine defines the electrical resistance, given the material and the temperature for a rod section.

4. ELCONS - This routine contains the geometrical information concerning the electrical rod configuration.

5. ELOUTF - This routine controls the separate output file generated by these routines. If a calculation is being restarted, the file is positioned to the correct point for extension. The output file can be listed or read by another code to generate plotted information. 


\begin{tabular}{|c|c|c|}
\hline *DECK & $\begin{array}{l}\text { ELHEAT } \\
\text { SUBROUT INE ELHEAT (NCOMP, NLEVEL, NRING, TEMP, POWER) }\end{array}$ & $\begin{array}{l}\text { ELHEAT. } 1 \\
\text { ELHEAT. } 2 \\
\text { ELHEAT. } 3\end{array}$ \\
\hline \multicolumn{3}{|c|}{ 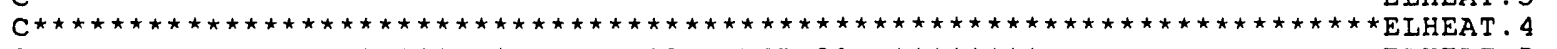 } \\
\hline $\begin{array}{l}\text { C } \\
\text { C }\end{array}$ & 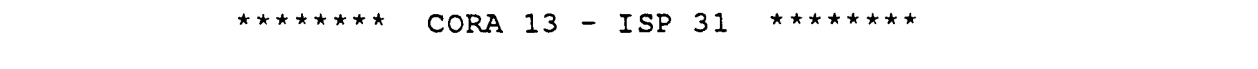 & $\begin{array}{l}\text { ELHEAT. } 5 \\
\text { ELHEAT. } 6\end{array}$ \\
\hline $\begin{array}{l}\mathrm{C} \\
\mathrm{C}\end{array}$ & $\begin{array}{l}\text { This is a special routine for MELCOR to treat electrical heater } \\
\text { rods for CORA } 13 \text { test (ISP } 31 \text { ). Specific COR zoning is assumed. }\end{array}$ & $\begin{array}{l}\text { ELHEAT. } 7 \\
\text { ELHEAT. } 8\end{array}$ \\
\hline $\begin{array}{l}\mathrm{C} \\
\mathrm{C} \\
\mathrm{C}\end{array}$ & $\begin{array}{l}\text { The CoR model has } 19 \text { levels and } 4 \text { rings. Rings } 2 \text { and } 4 \text { have } \\
\text { electrical rods. }\end{array}$ & $\begin{array}{l}\text { ELHEAT. } 9 \\
\text { ELHEAT. } 10 \\
\text { ELHEAT. } 11\end{array}$ \\
\hline C & For input time and temperature, return power in each rod section. & $\begin{array}{l}\text { ELHEAT. } 11 \\
\text { ELHEAT. } 12\end{array}$ \\
\hline C & 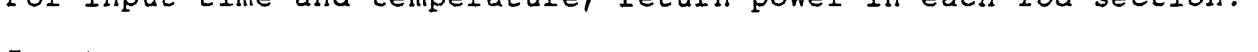 & ELHEAT.13 \\
\hline C & Inputs: & ELHEAT. 14 \\
\hline C & & HEAT. 15 \\
\hline C & NCOMP = number of components - this calcuation only uses one of & T. 16 \\
\hline C & values, KCOMP, to insert power. NCOMP is for dimensions & HEAT. 17 \\
\hline C & of arrays. & HEAT. 18 \\
\hline C & & HEAT. 19 \\
\hline $\begin{array}{l}\mathrm{C} \\
\mathrm{C}\end{array}$ & NLEVEL = number of MELCOR levels in COR - NOTE: The EL package & T. 20 \\
\hline C & $\begin{array}{l}\text { for CORA will have one more level than COR package for } \\
\text { CU section of rods which are not in the MEICOR COR }\end{array}$ & $\begin{array}{l}\text { HEAT. } 21 \\
\text { HEAT. } 22\end{array}$ \\
\hline C & nodalization. Extra level is at top. & AT. 23 \\
\hline c & & T. 24 \\
\hline C & NRING = number of MELCOR rings (must be 4 for this package) & EAT. 25 \\
\hline $\mathrm{C}$ & & EAT. 26 \\
\hline $\begin{array}{l}\mathrm{C} \\
\mathrm{C}\end{array}$ & TEMP = array of temperatures - dimension (NCOMP, NLEVEL, NRING) & EAT. 27 \\
\hline C & Outputs: & $\begin{array}{l}\text { ELHEAT. } 28 \\
\text { ELHEAT. } 29\end{array}$ \\
\hline $\mathrm{C}$ & & ELHEAT. 30 \\
\hline C & POWER = array of powers - dimension (NLEVEL, NRING) & HEAT. 31 \\
\hline & (rings 1 \& 3 will always be zero) & HEAT. 32 \\
\hline $\mathrm{C}$ & & $1 \mathrm{~T} .33$ \\
\hline C & & IEAT. 34 \\
\hline $\begin{array}{l}\mathrm{C} \\
\mathrm{C}\end{array}$ & Inputs from common block & HEAT. 35 \\
\hline $\mathrm{C}$ & TIME $=$ time (s) & $\begin{array}{l}\text { EAT. } 36 \\
\text { EAT. } 37\end{array}$ \\
\hline $\mathrm{C}$ & & HEAT. 38 \\
\hline C & $D T=t i m e$ step & САT. 39 \\
\hline $\mathrm{C}$ & & HEAT. 40 \\
\hline $\mathrm{C}$ & NCYCLE = cycle number & HEAT. 41 \\
\hline C & & AT. 42 \\
\hline C & Reference - CORA 13 specification Report & AT. 43 \\
\hline & & AT. 44 \\
\hline & 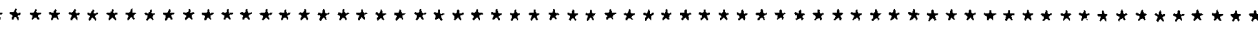 & AT. 45 \\
\hline C & & EAT. 46 \\
\hline C & This routine replaces a dummy routine in standard MEICOR pack & AT. 47 \\
\hline C & Routine is replaced at link time with normal melcor maintenance & HEAT. 48 \\
\hline $\begin{array}{l}\mathrm{C} \\
\mathrm{C}\end{array}$ & utility mulinkmel. This is the only entry into EL package. & ELHEAT. 49 \\
\hline $\begin{array}{l}\mathrm{C} \\
\mathrm{C}\end{array}$ & This package generates its own output file "corael out" separate & \\
\hline C & This package generates its own output file "corael.out" separate & HEAT. 51 \\
\hline C & from normal melcor output. The file serves for both printed and & AT. 52 \\
\hline C & graphics output. The file is automatically extended during a & ELHEAT. 53 \\
\hline C & & HEAT. 54 \\
\hline C & & AT. 55 \\
\hline C & The call to this package is activated by setting the third & QAT. 56 \\
\hline $\begin{array}{l}\mathrm{C} \\
\mathrm{c}\end{array}$ & parameter on COR input record COR00002. & AT.5 \\
\hline C & Data for specific CORA test is hard coded in following routines. & ELHEAT. 58 \\
\hline $\mathrm{C}$ & Data for specific CORA test is hard coded in following routines. & $\begin{array}{l}\text { ELHEAT. } 59 \\
\text { ELHEAT. } 60\end{array}$ \\
\hline C & S. I. Thompson \& R. J. Gross & ELHEAT. 61 \\
\hline C & Thermal/Hydraulic Analysis Department, 6418 & ELHEAT. 62 \\
\hline C & Sandia National Iaboratory & ELHEAT .63 \\
\hline C & Albuquerque, New Mexico USA 87185-5800 & AT. 64 \\
\hline $\mathrm{C}$ & & AT. 65 \\
\hline & 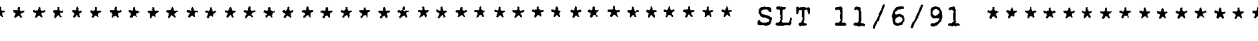 & HEAT. 66 \\
\hline C & & ELHEAT .67 \\
\hline & & ELHEAT. 68 \\
\hline & DIMENSION TEMP (NCOMP, NLEVEL, NRING), POWER (NLEVEI, NRING) & $9 T .69$ \\
\hline & component number for electrical part & ELHEAT. 70 \\
\hline & component number for electrical part of rod & E $\lrcorner H E A T .71$ \\
\hline
\end{tabular}


PARAMETER $(K C O M P=1)$

ELHEAT. 72

ELHEAT. 73

ELHEAT .74

ELHEAT 75

ELHEAT .76

ELHEAT .77

ELHEAT .78

ELHEAT .79

ELHEAT .80

ELHEAT .81

ELHEAT .82

ELHEAT. 83

ELHEAT . 84

ELHEAT .85

ELHEAT .86

ELHEAT .87

ELHEAT .88

ELHEAT. 89

ELHEAT .90

ELHEAT. 91

ELHEAT .92

ELHEAT .93

ELHEAT. 94

ELHEAT. 95

ELHEAT .96

ELHEAT .97

ELHEAT .98

ELHEAT. 99

ELHEAT .100

ELHEAT .101

ELHEAT .102

ELHEAT .103

ELHEAT . 104

ELHEAT .105

ELHEAT .106

ELHEAT .107

ELHEAT .108

ELHEAT. 109

ELHEAT .110

ELHEAT. 111

ELHEAT. 112

ELHEAT .113

ELHEAT .114

ELHEAT . 115

ELHEAT. 116

ELHEAT .117

ELHEAT. 118

ELHEAT .119

ELHEAT .120

ELHEAT .121

ELHEAT .122

ELHEAT .123

ELHEAT .124

ELHEAT .125

ELHEAT . 126

ELHEAT .127

ELHEAT. 128

ELHEAT .129

ELHEAT .130

ELHEAT . 131

ELHEAT .132

EIHEAT. 133

ELHEAT. 134

ELHEAT. 135

ELHEAT. 136

ELHEAT. 137

ELHEAT .138

ELHEAT .139

ELHEAT 140

ELHEAT .141

ELHEAT .142

ELHEAT .143

ELHEAT .144 


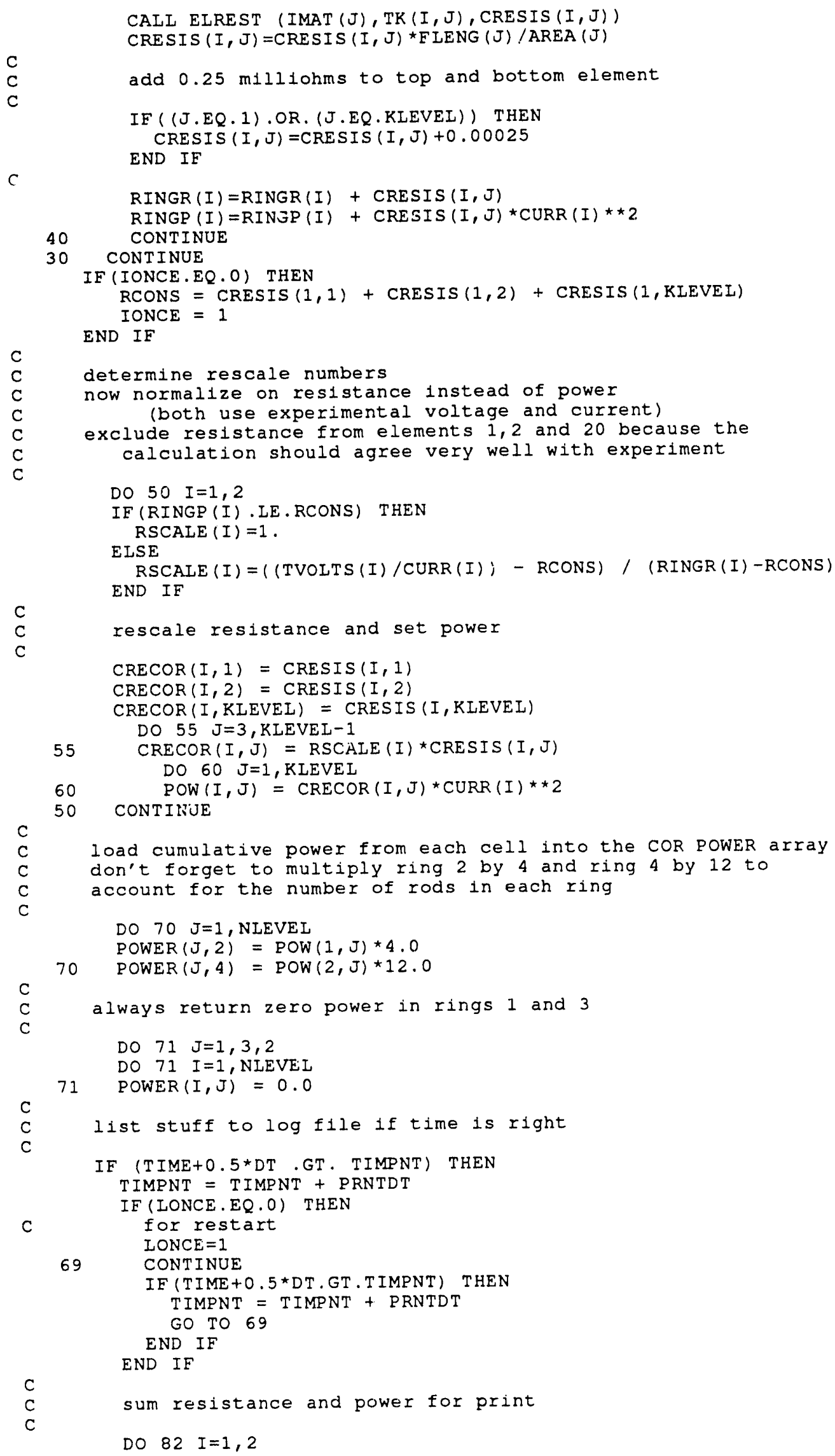

ELHEAT .145

ELHEAT .146

ELHEAT .147

ELHEAT .148

EIHEAT .149

ELHEAT .150

ELHEAT .151

ELHEAT .152

ELHEAT .153

ELHEAT .154

EIHEAT .155

ELHEAT .156

ELHEAT .157

ELHEAT .158

ELHEAT .159

ELHEAT .160

ELHEAT .161

ELHEAT. 162

ELHEAT .163

ELHEAT .164

ELHEAT .165

ELHEAT .166

ELHEAT .167

ELHEAT .168

ELHEAT. 169

ELHEAT .170

ELHEAT .171

ELHEAT .172

ELHEAT. 173

ELHEAT .174

ELHEAT .175

ELHEAT .176

EIHEAT .177

ELHEAT .178

ELHEAT .179

ELHEAT .180

ELHEAT .181

ELHEAT .182

ELHEAT .183

ELHEAT .184

ELHEAT .185

ELHEAT .186

ELHEAT .187

ELHEAT .188

ELHEAT .189

ELHEAT. 190

EIHEAT .191

ELHEAT .192

ELHEAT .193

ELHEAT .194

ELHEAT .195

ELHEAT .196

ELHEAT .197

ELHEAT .198

ELHEAT .199

ELHEAT .200

ELHEAT .201

ELHEAT .202

ELHEAT .203

ELHEAT .204

ELHEAT .205

EIHEAT .206

ELHEAT .207

ELHEAT .208

ELHEAT .209

ELHEAT .210

ELHEAT . 211

ELHEAT .212

ELHEAT .213

ELHEAT . 214

ELHEAT . 215

ELHEAT .216

ELHEAT .217 
$\operatorname{RINGRC}(I)=0$.

ELHEAT. 218

$\operatorname{RINGP}(I)=0$.

DO $81 \mathrm{~J}=1$, KLEVEL

$\operatorname{RINGRC}(I)=\operatorname{RINGRC}(I)+\operatorname{CRECOR}(I, J)$ 81 RINGP $(I)$

C

WRITE (IPU, 79) TIME, (I, TVOLTS (I), CURR (I), TRESIS (I), RINGR (I), RINGRC (I), RSCALE (I), I=1,2)

79 FORMAT(' $88 \%$ \% , /,' TIME=', IPEI3.5, /,

' ring voltage current resist_data resist_cal re',

'sist corr rescale (rod)'

$, 1,1 \mathrm{X}, \mathrm{I} 1,6 \mathrm{E} 12.4,1$,

$1 X, I 1,6 E 12.4)$

C

WRITE (IPU, 78) 1, RINGP (1), 4. *RINGP (1),

2 , RINGP (2), 12. *RINGP (2), 4 . *RINGP (1)+12 * RINGP (2)

78 FORMAT(' ring power/rod power/ring total power'

$\mathrm{C}$

\& $\quad, /, 1 \mathrm{X}, \mathrm{I} 1,1 \mathrm{P}, 2 \mathrm{E} 12.4, /, 1 \mathrm{X}, \mathrm{I} 1,3 \mathrm{E} 12.4)$

FORMAT(' level mat temp, resist, power', $14 \mathrm{x}$,

$\&$ 'temp, resist, power', /,

\& $18 \mathrm{X}$,'ring 1',27X,'ring 2 (per rod)') DO $88 \mathrm{~J}=\mathrm{KLEVEL}, 1,-1$ WRITE (IPU, 84) J, IMAT (J), (TK(I,J), $\operatorname{CRECOR}(I, J), \operatorname{POW}(I, J), I=1,2)$

88 CONTINUE

C

END IF

$\mathrm{C}$

RETURN

$\mathrm{C}$

C

800 STOP ' $800 E L H E A T '$

END
ELHEAT. 219

ELHEAT .220

ELHEAT .221

ELHEAT .222

ELHEAT .223

ELHEAT .224

ELHEAT .225

ELHEAT .226

ELHEAT .227

ELHEAT .228

ELHEAT .229

ELHEAT .230

ELHEAT . 231

ELHEAT .232

ELHEAT .233

ELHEAT . 234

ELHEAT .235

ELHEAT .236

ELHEAT .237

ELHEAT .238

ELHEAT . 239

ELHEAT .240

ELHEAT .241

ELHEAT .242

ELHEAT .243

ELHEAT .244

ELHEAT .245

ELHEAT .246

ELHEAT .247

ELHEAT .248

ELHEAT .249

ELHEAT .250

ELHEAT .251

ELHEAT .252

ELHEAT .253

ELHEAT. 254 


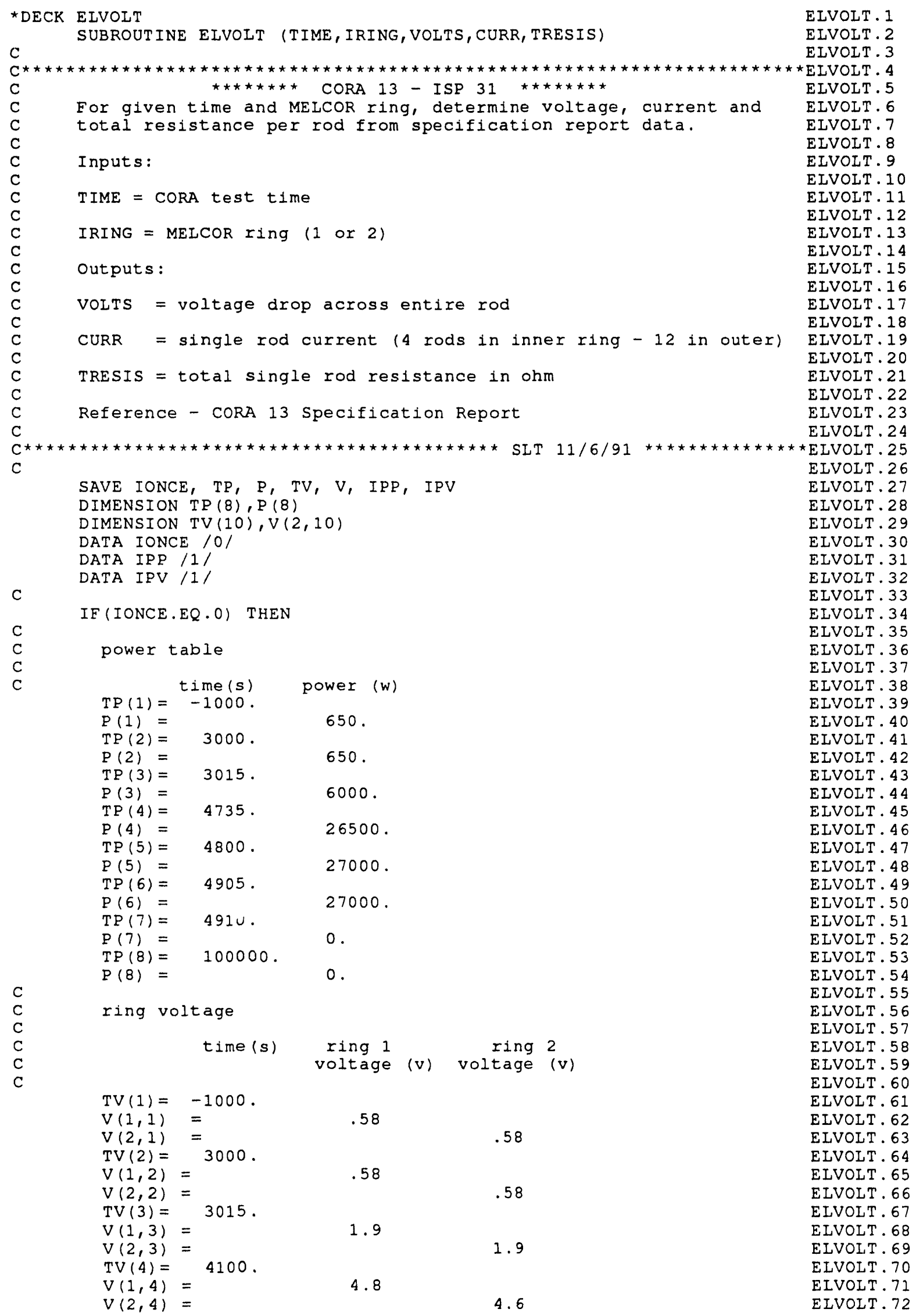




\begin{tabular}{|c|c|c|c|}
\hline $\begin{array}{l}\operatorname{TV}(5)= \\
V(1,5)\end{array}$ & $=4300$. & 5.7 & \\
\hline$V(2,5)$ & $=$ & & 5.5 \\
\hline $\begin{array}{l}\operatorname{TV}(6)= \\
V(1,6)\end{array}$ & $=4400$. & 5.9 & \\
\hline $\mathrm{V}(2,6)$ & $=$ & & 5.8 \\
\hline $\operatorname{TV}(7)=$ & $=4735$. & & \\
\hline $\begin{array}{l}V(1,7) \\
V(2,7)\end{array}$ & $\begin{array}{l}= \\
=\end{array}$ & 6.8 & 6.8 \\
\hline $\operatorname{TV}(B)=$ & 4905 . & & \\
\hline$v(1,8)$ & $=$ & 6.8 & \\
\hline$v(2,8)$ & $=$ & & 6.8 \\
\hline $\begin{array}{l}\operatorname{TV}(9)= \\
V(1,9)\end{array}$ & $=4910$. & 0.2 & \\
\hline$v(2,9)$ & $=$ & . & 0.2 \\
\hline $\operatorname{TV}(10)=$ & $=10000$. & & \\
\hline$V(1,10)$ & $=$ & 0.2 & \\
\hline $\begin{array}{l}V(2,10) \\
I O N C E=1\end{array}$ & $=$ & & 0.2 \\
\hline
\end{tabular}

\section{C}

C
C
C
C
C

10 CONTINUE

IF (TIME.GT.TP (IPP+1)) THEN

I $P P=I P P+1$

GO TO 10

END IF

11 CONTINUE

IF (TIME.IT.TP (IPP)) THEN

I P P $=$ IPP -1

GO TO 11

END IF

20 CONTINUE

IF (TIME.GT.TV (IPV+1)) THEN

$I P V=I P V+1$

GO TO 20

END IF

21 CONTINUE

IF (TIME.IT.TV (IPV)) THEN

$I P V=I P V-1$

GO TO 21

END IF

C determine power in each rod

power in each rod is the same

$R O D P=(P(I P P+1)$ * $(T I M E-T P(I P P))+P(I P P)$ * TP $(I P P+1)-T I M E)) /$

$\&$

$(16 . *(\mathrm{TP}(\mathrm{IPP}+1)-\mathrm{TP}(\mathrm{IPP})))$

$I R=\operatorname{MAX}(1, \operatorname{MIN}(2, I R I N G))$

VOLTS $=(V(I R, I P V+1)$ * $(T I M E-T V(I P V))+V(I R, I P V)$ * TV $(I P V+1)-T I M E)) /$

$\&$ $(T V(I P V+1)-T V(I P V))$

CURR=RODP /VOLTS

TRESIS $=$ RODP $/ \operatorname{MAX}(1 . E-20, C U R R \star \star 2)$

RETURN

END
ELVOLT. 73

ELVOLT. 74

ELVOIT 75

ELVOLT. 76

ELVOLT . 77

ELVOIT .78

ELVOLT. 79

ELVOLT.80

ELVOIT. 81

ELVOLT .82

ELVOLT. 83

ELVOLT .84

ELVOLT .85

ELVOLT. 86

ELVOLT. 87

EIVOLT. 88

ELVOLT .89

EIVOIT. 90

ELVOLT . 91

ELVOIT .92

ELVOIT .93

ELVOIT .94

ELVOLT .95

ELVOLT .96

ELVOLT. 97

ELVOIT. 98

EIVOLT. 99

ELVOLT. 100

ELVOIT. 101

ELVOLT. 102

ELVOLT .103

ELVOIT. 104

ELVOLT. 105

ELVOIT . 106

ELVOLT .107

ELVOLT. 108

ELVOIT. 109

ELVOLT. 110

ELVOLT. 111

ELVOLT. 112

EIVOIT. 113

ELVOLT .114

ELVOLT. 115

ELVOIT. 116

ELVOLT.117

ELVOIT. 118

ELVOIT.119

ELVOLT .120

ELVOIT. 121

ELVOLT. 122

ELVOLT. 123

ELVOLT. 124

ELVOIT. 125

ELVOLT. 126

ELVOLT. 127

ELVOLT. 128

ELVOLT. 129

ELVOIT. 130

ELVOLT.131 


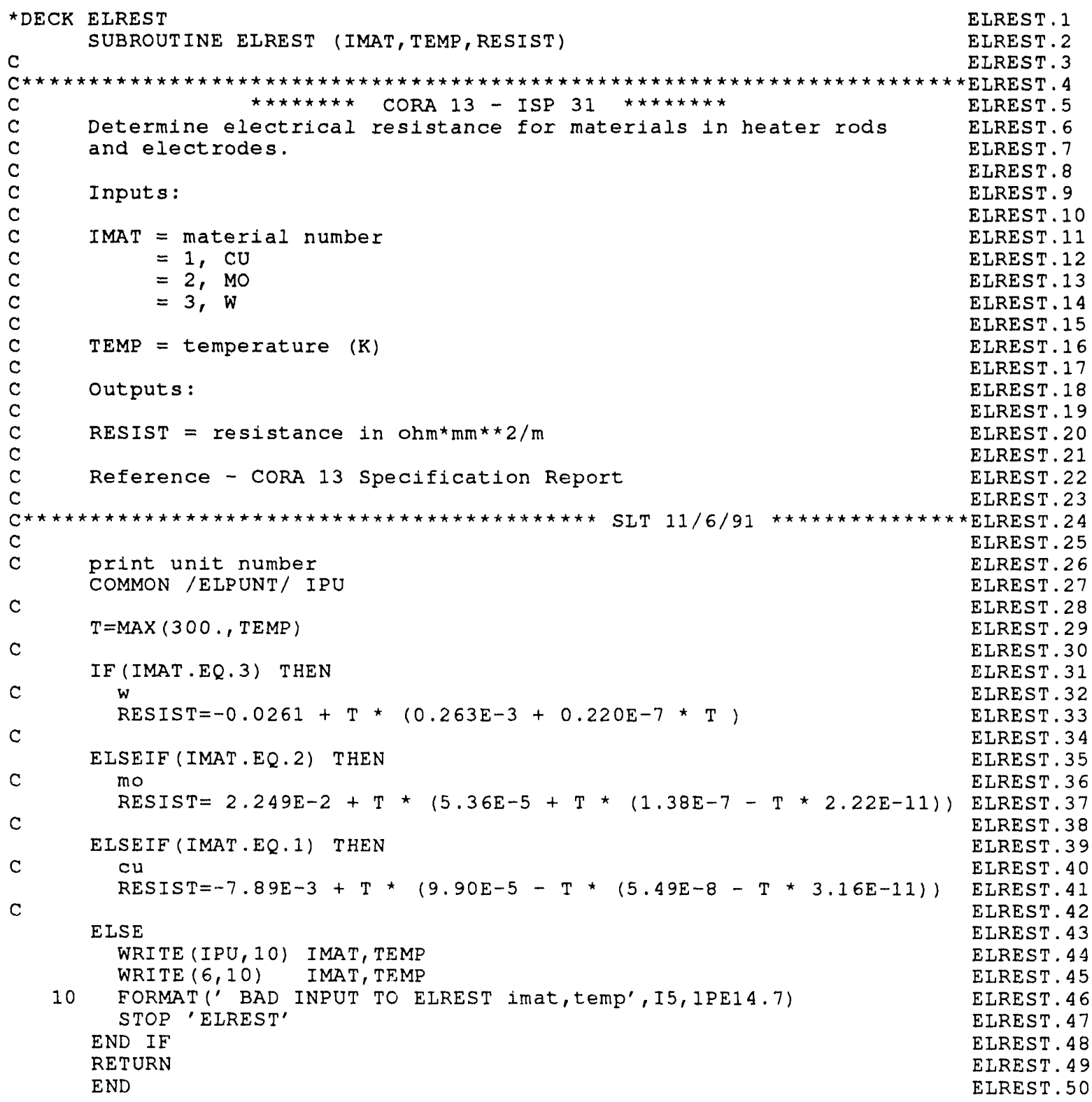




\begin{tabular}{|c|c|c|}
\hline * DECK & $\begin{array}{l}\text { ELCONS } \\
\text { SUBROUTINE ELCONS (KLEVEL, FLENG, AREA, IMAT, TIMPNT, PRNTDT, TCON) }\end{array}$ & $\begin{array}{l}\text { ELCONS. } 1 \\
\text { ELCONS. } 2 \\
\text { ELCONS. } 3\end{array}$ \\
\hline \multicolumn{3}{|c|}{ 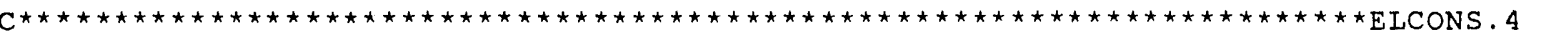 } \\
\hline C & 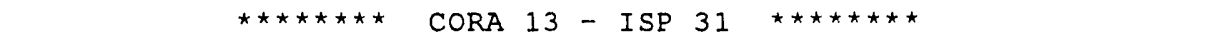 & ELCONS. 5 \\
\hline C & Set rod materials \& geometry for each ring and level. Data must & EICONS. 6 \\
\hline C & agree with MELCOR COR input. & ELCONS. 7 \\
\hline C & & ELCONS. 8 \\
\hline C & Reference - CORA 13 Specification Report & EICONS. 9 \\
\hline $\mathrm{C}$ & & ELCONS. 10 \\
\hline C & Inputs: & ELCONS. 11 \\
\hline C & & ELCONS. 12 \\
\hline C & KLEVEL = number of axial levels & ELCONS. 13 \\
\hline C & & ELCONS. 14 \\
\hline C & Outputs: & ELCONS. 15 \\
\hline C & & ELCONS. 16 \\
\hline C & FLENG = array of axial seguments lengths in meters & ELCONS. 17 \\
\hline $\mathrm{C}$ & & ELCONS. 18 \\
\hline $\begin{array}{l}\mathrm{C} \\
\mathrm{C}\end{array}$ & $\mathrm{AREA}=$ array of cross-sectional areas in $\mathrm{mm} 2$ & $\begin{array}{l}\text { ELCONS. } 19 \\
\text { ELCONS. } 20\end{array}$ \\
\hline C & $=$ array of material numbers for each section & ELCONS. 21 \\
\hline & copper is 1 & ELCONS. 22 \\
\hline C & n.olybcienum is 2 & ELCONS .23 \\
\hline C & tungsten is 3 & ELCONS. 24 \\
\hline C & & ELCONS. 25 \\
\hline $\begin{array}{l}\mathrm{C} \\
\mathrm{C}\end{array}$ & TIMPNT = print frequency for this package & ELCONS. 26 \\
\hline $\begin{array}{l}\mathrm{C} \\
\mathrm{C}\end{array}$ & TCON = three element temperature array for & ELCONS. 27 \\
\hline $\mathrm{c}$ & bottom two nodes (in quench bucket) and & $\begin{array}{l}\text { ELCONS. } 28 \\
\text { ELCONS } 29\end{array}$ \\
\hline C & top node (top shroud - element 3 ). These are & ELCONS. 30 \\
\hline C & used to determine resistance and are assumed & ELCONS. 31 \\
\hline C & constant during the calculation. & ELCONS. 32 \\
\hline C & & ELCONS. 33 \\
\hline$C^{\star \star \star \star \star \star ~}$ & 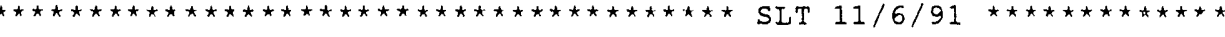 & * ELCONS. 3 \\
\hline C & & ELCONS .35 \\
\hline & SAVE & ELCONS. 36 \\
\hline & PARAMETER $(P I E=3.1415926)$ & ELCONS. $3^{\circ}$ \\
\hline & PARAMETER (ILEVEL $=20)$ & ELCONS. 3 \\
\hline $\mathrm{C}$ & & ELCONS . 3 \\
\hline C & following are melcor common blocks (system independent) & ELCONS. 40 \\
\hline 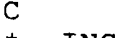 & & ELCONS. 41 \\
\hline *- INC & ELUDE MXXTIM & ELCONS. 42 \\
\hline $\mathrm{C}$ & TIME COMMON BLOCK & ELCONS. 43 \\
\hline C & TIME $=$ PROBLEM TIME & ELCONS. 44 \\
\hline C & $\mathrm{DT}=\mathrm{TIMESTEP}$ & ELCONS. 45 \\
\hline C & $C P U=C P U$ TIME & ELCONS. 46 \\
\hline C & NCYCLE = CYCLE NUMBER & ELCONS. 4 \\
\hline C & NDTPAK = PACKAGE CONTROIING TIMESTEP & ELCONS. 48 \\
\hline & COMMON /MXXTIM/ TIME, DT, CPU, NCYCLE & ELCONS. 49 \\
\hline & COMMON /MXXTPK/ NDTPAK & ELCONS. 5 \\
\hline & CHARACTER $* 3$ NDTPAK & ELCONS. 5 \\
\hline C & & ELCONS. 5 \\
\hline *- & & ELCONS. 5 \\
\hline C & rod materials \& geometry for each ring and level & ELCONS. 5 \\
\hline C & length in $M$ area in $\mathrm{mm} 2$ material number & ELCONS. 5 \\
\hline & DIMENSION FLENG (KLEVEL), AREA (KLEVEL), IMAT (KLEVEL), TCON (3) & ELCONS .5 \\
\hline C & & ELCONS. 5 \\
\hline C & print unit number & ELCONS. 5 \\
\hline C & & ELCONS. 5 \\
\hline & COMMON /EIPUNT/ IPU & ELCONS. 6 \\
\hline & DATA IONCE /O/ & ELCONS. 61 \\
\hline C & & ELCONS. 6 \\
\hline C & set print frequency for output (in seconds) & ELCONS. 6 \\
\hline C & & ELCONS. 6 \\
\hline & PRNTDT $=2.5$ & ELCONS. 6 \\
\hline & TIMPNT $=$ PRNTDT & ELCONS. 6 \\
\hline C & & ELCONS .67 \\
\hline $\begin{array}{l}\mathrm{C} \\
\mathrm{C}\end{array}$ & temperatures for bottom (2) levels and top level & ELCONS. 68 \\
\hline C & $\operatorname{TCON}(1)=313$ & $\begin{array}{l}\text { ELCONS. } 69 \\
\text { ELCONS. } 70\end{array}$ \\
\hline & $\begin{array}{l}\operatorname{TCON}(1)=313 \\
\operatorname{TCON}(2)=313\end{array}$ & $\begin{array}{l}\text { ELCONS. } 7 \\
\text { ELCONS. } 7\end{array}$ \\
\hline & $\operatorname{TCON}(3)=393$ & ELCONS. 7 \\
\hline
\end{tabular}




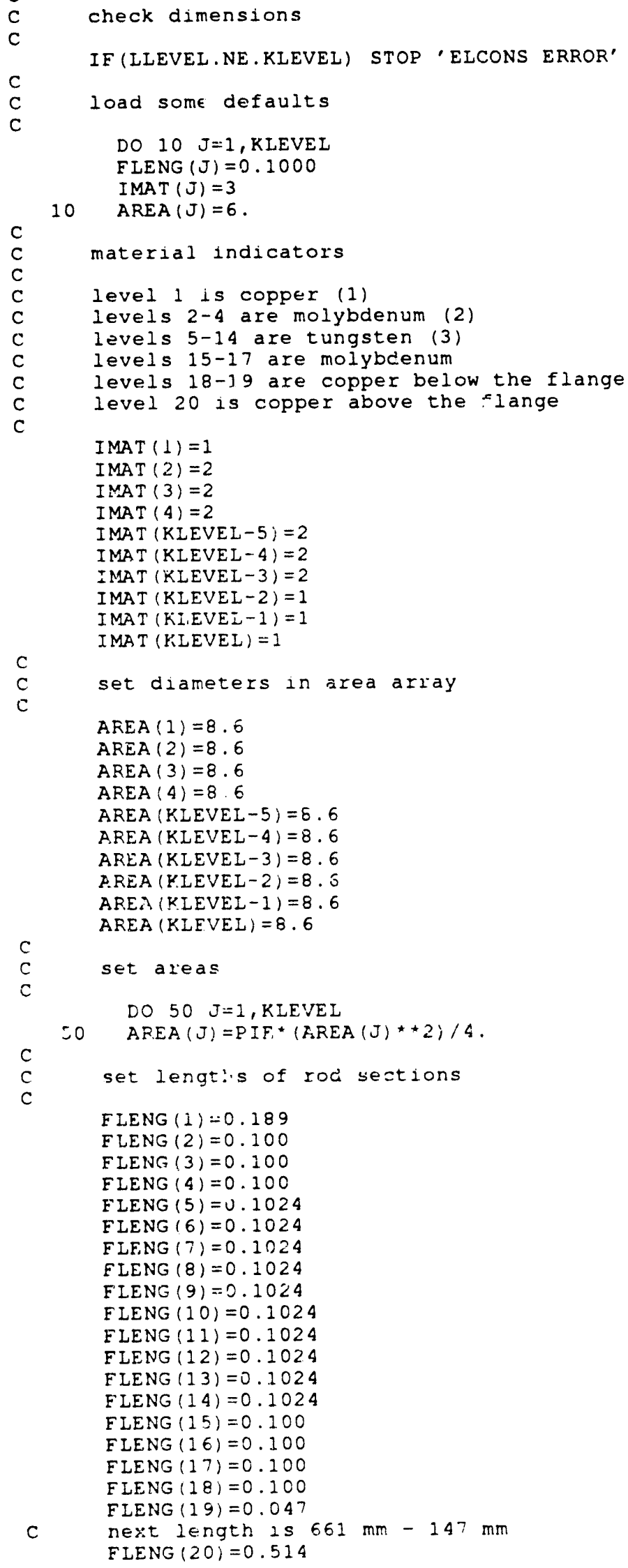

ELCONS. 73

ELCONS. 74

ELCONS. 7 j

ELCONS. 76

ELCONS. 77

ELCONS. 78

ELCONS 79

ELCONS .80

EICONS. 81

ELCONS. 82

ELCONS. 83

ELCONS. 84

ELCONS. 85

ELCONS. 86

ELCONS .87

ELCONS .88

ELCONS .89

EICONS. 90

ELCONS. 91

ELCONS .92

EICONS. 93

ELCONS .94

ELCONS .95

ELCONS . 96

ELCONS. 97

ELCONS. 98

ELCONS .99

ELCONS. 100

ELCONS. 101

ELCONS. 102

ELCONS. 103

EICONS. 104

ELCONS. 105

ELCONS. 106

ELCONS .107

ELCONS. 108

ELCONS. 109

ELCONS. 110

ELCONS.111

ELCONS. 112

ELCONS. 113

ELCONS.114

ELCONS. 115

ELCONS . 116

ELCONS. 117

ELCONS. 118

ELCONS. 119

ELCONS. 120

ELCONS. 121

ELCONS. 122

ELCONS. 123

EICONS .124

ELCONS 125

ELCONS. 126

ELCONS. 127

EICONS. 128

ELCONS.129

ELCONS .130

EICONS.131

ELCONS. 132

ELCONS. 133

ELCONS. 134

ELCONS .135

ELCONS. 136

ELCONS. 137

ELCONS. 138

ELCONS. 139

EICONS. 140

EICONS.141

ELCONS. 142

ELCONS. 143

ELCONS. 144

EICONS. 145 


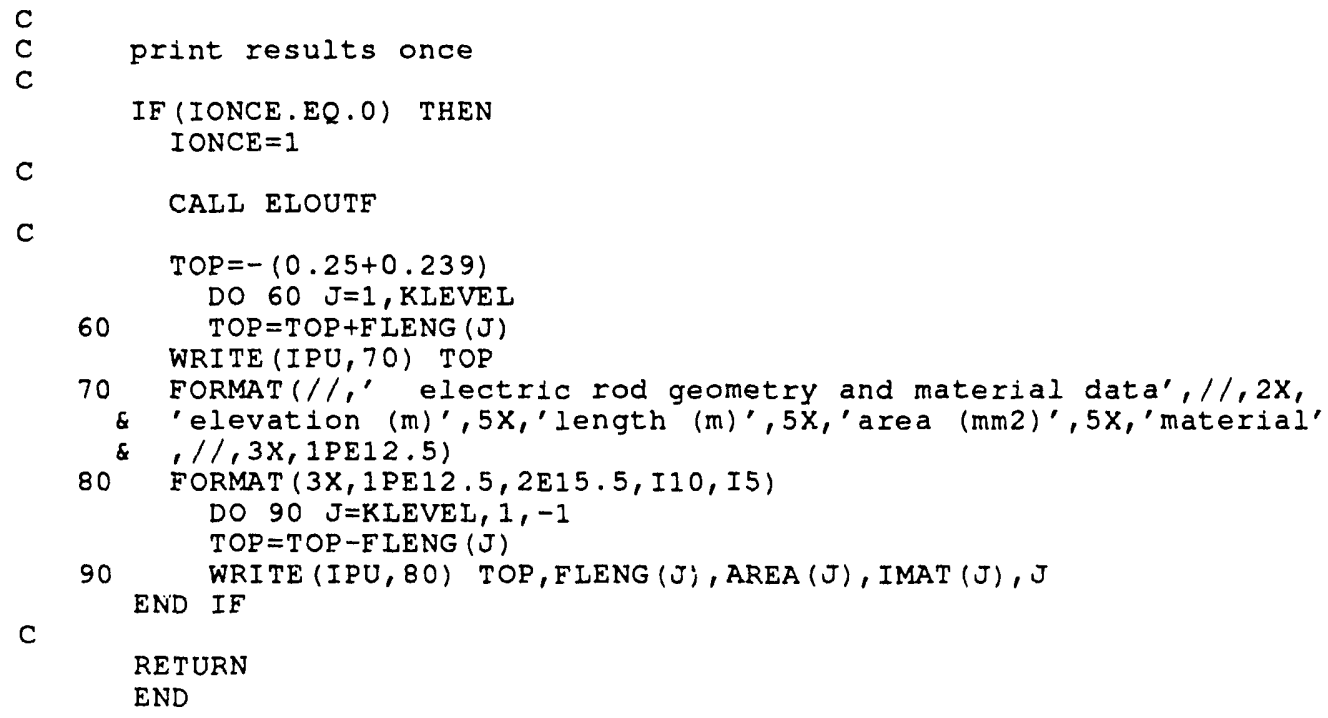

ELCONS. 146 ELCONS. 147 ELCONS.148 ELCONS. 149 ELCONS.150 ELCONS.151 EICONS. 152 EICONS .153 EICONS.154 EICONS. 155 EICONS. 156 ELCONS 157 EICONS. 158 EICONS. 159 ELCONS. 160 EICONS.161 ELCONS. 162 ELCONS. 163 EICONS. 164 ELCONS. 165 ELCONS. 166 ELCONS. 167 EICONS. 168 


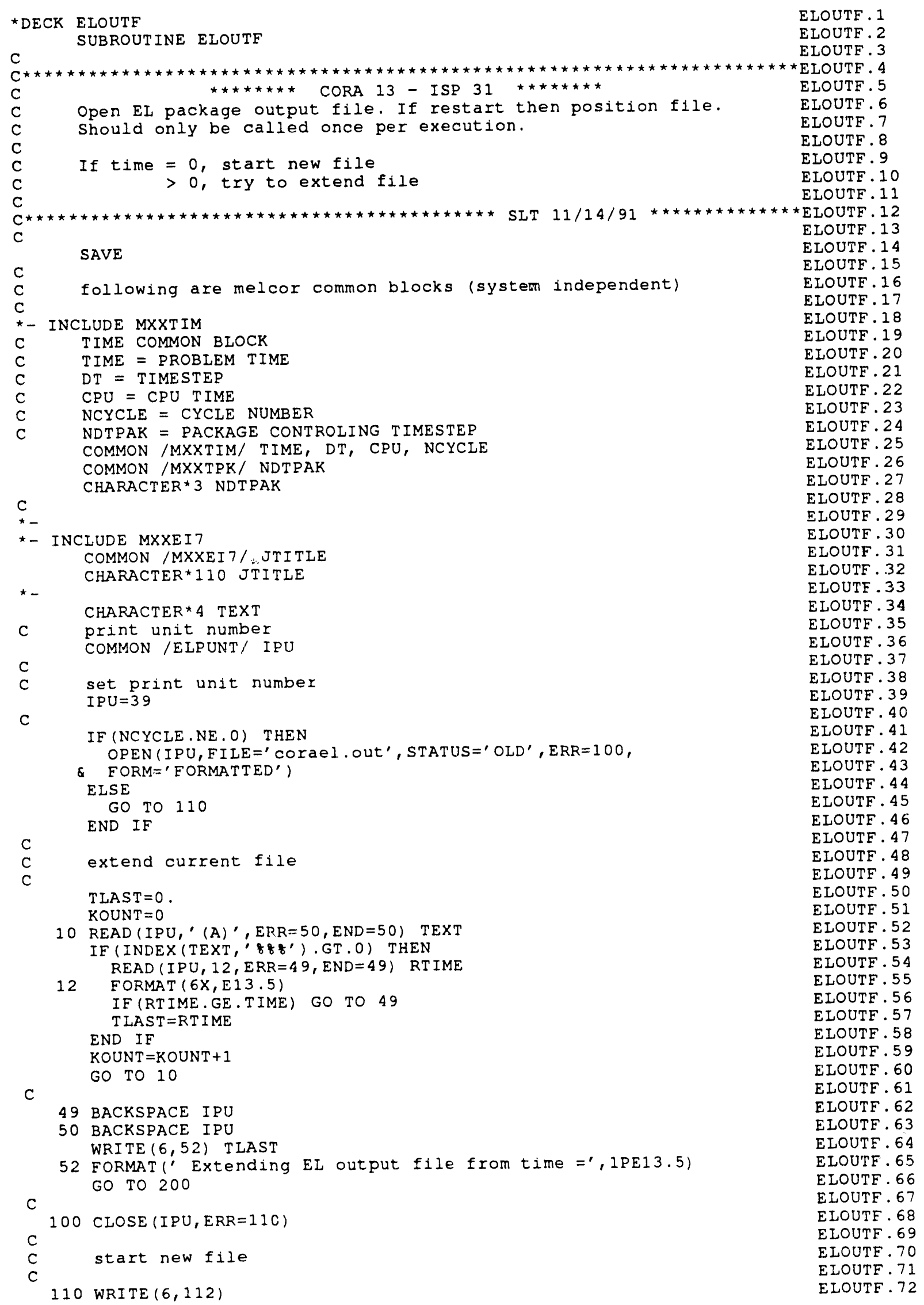


112 FORMAT(' Generating new EL output file')

ELOUTF. 73

ELOUTF. 74

ELOUTF. 75

ELOUTF. 76

ELOUTF. 77

C

\& FORM='FORMATTED')

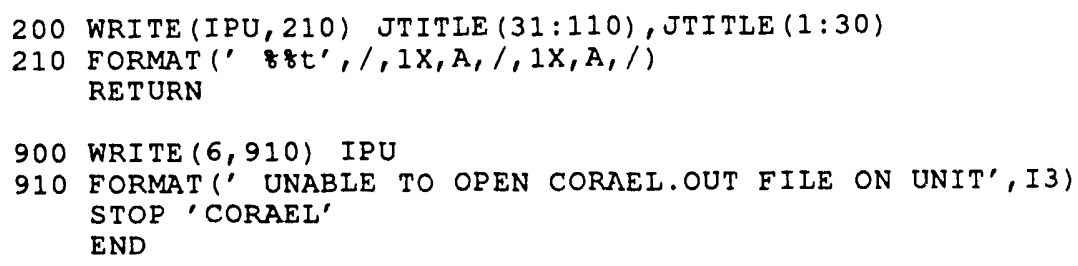




\section{External Distribution:}

U.S. Nuclear Regulatory Commission (16)

Attn: S. Acharya, NLS-372

Y. S. Chen, NLN-344

M. A. Cunningham, NLS-372

F. Eltawila, NLN-344

R. B. Foulds, NLN-344

C. G. Tinkler, NLN-344

L. E. Lancaster, NLS-372

R. O. Meyer, NLS-007

J. A. Mitchell, NLS-314

C. P. Ryder, NLS-372

L. Soffer, NLS-324

B. Sheron, NLS-007

J. A. Murphy, NLS-007

L. M. Shotkin, NLN-353

N. Lauben, NLN-353

R. Landry, NLN-344

Washington, DC 20555

S. Y. Chen

Argonne National Laboratory

9700 South Cass Avenue

Argonne, IL 60439

Battelle Columbus Laboratories (3)

Attn: P. Cybulskis

M. Carmel

R. S. Denning

505 King Avenue

Columbus, $\mathrm{OH} 43201$

Brookhaven National Laboratory (2)

Attn: I. K. Madni

T. Pratt

Building 130

32 Lewis

Upton, NY 11973 
Idaho National Engineering Laboratory (5)

Attn: A. Brown

R. J. Dallman

D. W. Golden

S. E. Reed

G. W. Johnsen

EG\&G Idaho

P. O. Box 1625

Idaho Falls, ID 83404

D. Jones

El International

P. O. Box 50736

Idaho Falls, ID 83405

Electric Power Research Institute (3)

Attn: E. Fuller

R. N. Oehlberg

B. R. Sehgal

P. O. Box 10412

Palo Alto, CA 94303

Los Alamos National Laboratory (2)

Attn: B. E. Boyack, K-551

D. R. Liles, K-553

P. O. Box 1663

Los Alamos, NM 87545

Oak Ridge National Laboratory (11)

Attn: S. R. Greene, MS-8057

R. H. Morris, MS-8057

S. E. Fisher, MS-8057

R. Sanders, MS-8057

T. L. Heatherly, MS-8057

S. A. Hodge, MS- 8057

C. R. Hyman, MS-8057

E. W. Patton, MS- 8057

D. B. Simpson, MS-8057

R. P. Taleyarkhan, MS-8057

M. L. Tobias, MS- 8088

P. O. Box 2009

Oak Ridge, TN 37831-8057 
Andrzej Drozd

Nuclear Regulatory Commission

OWFN, MS 8E1

11555 Rockville Pike

Rockville, MD 20852

W. P. Barthold

Barthold \& Associates

132 Seven Oaks Drive

Knoxville, TN 37922

Science Applications Intl. Corp. (4)

Attn: E. Dombrowski

M. T. Leonard

K. C. Wagner

K. A. Williams

2109 Air Park Road, SE

Albuquerque, NM 87106

Savannah River Laboratory (2)

Attn: J. K. Norkus

L. A. Wooten

Westinghouse Savannah River Co.

Bldg. 773-41A

Aiken, SC 29808-0001

Westinghouse Hanford Company (2)

Attn: D. Ogden

O. Wang

P. O. Box 1970

Richland, WA 99352

General Electric Company (4)

Knolls Atomic Power Laboratory

Attn: D. F. McMullan

G. H. Epstein

E. Mennard

Joe Alfeo

Building F3, Room 8

P. O. Box 1072

Schenectady, NY 12301-1072 
Bettis Atomic Power Laboratory (4)

Attn: Mark Riley

Mark Lucot

Vincent Baiamonte

Jim Lucas

P. O. Box 79

West Mifflin, PA 15122

Mohsen Khatib-Rahbar

Energy Research Inc.

P. O. Box 2034

Rockville, MD 20852

V. K. Dhir

2445 22nd Street

Santa Monica, CA 90403

R. Viskanta

Purdue University

Heat Transfer Laboratory

School of Mechanical Engineering

West Lafayette, IN 47907

Dr. Jim Gieseke

Battelle Memorial Institute

505 King Avenue

Columbus, Ohio 43201

M. A. Kenton

Gabor, Kenton \& Associates

770 Pasquinelli Drive

Suite 426

Westmont, IL 60559

University of California (2)

Attn: W. H. Amarasooriya

$T$. Theofanous

ERC-CRSS

Santa Barbara, CA 93106 


\section{F. E. Haskin}

University of New Mexico

Department of Chemical and Nuclear Engineering

Albuquerque, NM 87131

J. C. Lee

University of Michigan

Department of Nuclear Engineering

Cooley Building, North Campus

College of Engineering

Ann Arbor, MI 48109-2104

University of Wisconsin (2)

Department of Nuclear Engineering

Attn: M. L. Corradini

G. A. Moses

Engineering Research Building

1500 Johnson Drive

Madison, WI 53706

Ramu K. Sundaram

Manager, LOCA Analysis Group

Nuclear Engineering

Yankee Atomic Electric Company

580 Main Street

Bolton, MA 01740

CEGA

Attn: John Bolin

Roseanne Harrington

P. O. Box 85608

San Diego, CA 92186-9784

M. Plys

Fauske \& Associates

16W070 West 83rd Street

Burr Ridge, IL 60521 
Nick Trikouros

GPU Nuclear Corporation

One Upper Pond Road

Parsippany, NJ 07054

B. Raychaudhuri

Nebraska Public Power District

PRA \& Engineering Review Group

P. O. Box 499

Columbus, NE 68601

Frank Elia

Stone \& Webster Engineering Corp.

245 Summer Street

Boston, MA 02210

Samir S. Girgis

Atomic Energy of Canada Limited

CANDU Operations

Sheridan Park Research Community

Mississagua, Ontario

CANADA L5K1B2

Paul J. Fehrenback

Chalk River Nuclear Laboratories

Fuel Engineering Branch, RSR Division

Chalk River, Ontario

CANADA KOJ1JO

Andrej Mitro

Institute of Radioecology and Applied Nuclear Techniques

Garbiarska 2

P. O. Box A-41

04061 Košice

CZECHOSLOVAKIA

Shih-Kuei Cheng

Atomic Energy Council, Nuclear Safety

67, Lane 144, Keelung Road Sec. 4

Taipei, Taiwan

REPUBLIC OF CHINA 
Lainsu Kao, Associate Scientist

Atomic Energy Council

Institute of Nuclear Energy Research

P. O. Box 303

Lung-Tan, 32500

Taiwan

REPUBLIC OF CHINA

Technical Research Centre of Finland (3)

Nuclear Engineering Laboratory

Attn: Lasse Mattila

Ilona Lindholm

Esko Pekkarinen

P. O. Box 208 (Tekniikantie 4)

SF-002151 Espoo

FINLAND

Jorma V. Sandberg

Finnish Center Radiation \& Nucl. Safety

Dept. of Nuclear Safety

P. O. Box 268

SF-00101 Helsinki

FINLAND

Akihide Hidaka

Safety Research Department

Reactor Accident Studies and Modelling Branch

DRS/SEMAR

Cadarache Nuclear Center

13108 Saint-Paul-Lez-Durance Cedex

FRANCE

Dr. Lothar Wolf

Battelle Institute EV

AM Romerhof 35

D-6000

Frankfurt/Main 90

GERMANY 
Gesellschaft für Reaktorsicherheit (2)

Attn: Ulrich Erven

Walter Erdmann

Schwertnergasse 1

D-5000 Koln 1

GERMANY

Kernforschungzentrum, Karlsruhe (2)

Attn: P. Hofmann

Werner Scholtyssek

P. O. Box 3640

D-7500 Karlsruhe 1

GERMANY

György Gyenes

Central Research Institute for Physics

Institute for Atomic Energy Research

H-1525 Budapest, P. O. Box 49

HUNGARY

Joint Research Center

Commission of the European Communities

Attn: Alan Jones

lain Shepherd

Safety Technology Institute

21020 Ispra (Va)

ITALY

Giovanni Saponaro

ENEA

National Committee for R\&D of Nuclear Energy

Via Vitaliano Brancati, 48

00144 Rome

ITALY

Kunihisa Soda

Japan Atomic Energy Research Institute

Tokai-mura, Naka-gun, Ibaraki-ken

319-11, JAPAN 
Dr. Susumi Suguri, Director General

Japan Institute of Nuclear Safety

Fujita Kankou Toranoman Bldg. 7F

3-17-1, Toranoman

Minato-Ku, Tokyo, 105

JAPAN

Korea Atomic Energy Research Inst. (3)

Attn: Kun-Joong Yoo

Song-Won Cho

Dong-Ha Kim

P. O. Box 7, Daeduk Danji

Daejon

SOUTH KOREA 305-353

Netherlands Energy Research Foundation (2)

Attn: Karel J. Brinkmann

E. J. Velema

P. O. Box 1

1755 ZG Petten

THE NETHERLANDS

Dr. Valery F. Strizhov

Russian Academy of Science

Institute of Nuclear Safety

Moscow, G. Gulsky, 52

113191, RUSSIA

Universidad Politecnica de Madrid (2)

Attn: Augustin Alonzo Santos

Francisco Martin

E.T.S. Ingenieros Industriales

Jose Butierrez Abascal, 2

28006 Madrid

SPAIN 
Juan Bagues

Consejo de Seguridad Nuclear

Justo Dorado, 11

28040, Madrid

SPAIN

Oddbjörn Sandervåg

Statens Kärnkraftinspektion

Swedish Nuclear Power Inspectorate

Box 2710610252 Stockholm

SWEDEN

L. Hammar, Director

Division of Research

Swedish Nuclear Power Inspectorate

Statens Kärnkraftinspektion

Sehlstedtsgatan 11

Box 27106

S-102-50 Stockholm

SWEDEN

Swiss Federal Nuclear Safety Inspectorate (4)

Attn: S. Chakraborty

Sang Lung Chan

U. Schmocker

H. P. Isaak

$\mathrm{CH}-5232$ Villigen-HSK

SWITZERLAND

United Kingdom Atomic Energy Agency (3)

Winfrith Technology Center

Attn: T. Haste

S. R. Kinnersley

S. W. Sweet

Winfrith, Dorchester, Dorset

UNITED KINGDOM, DTS 8DH 
United Kingdom Atomic Energy Authority (2)

Safety \& Reliability Directorate

Attn: M. I. Roberison

C. Wheatley

Wigui aw Lane, Culcheth, Warrington

Cheshire, WA3 4NE

UNITED KINGDOM 
Internal Distribution:

6400 N. R. Ortiz

6412 A. L. Camp

6412 S. E. Dingman

6413 F. T. Harper

6414 J. E. Kelly

$6415 \mathrm{~K}$. D. Bergeron

6418 S. L. Thompson (10)

6418 E. A. Boucherson

6418 R. K. Cole

6418 A. A. Elsbernd

6418 R. J. Gross (10)

6418 L. N. Kmetyk

6418 G. M. Martinez

6418 R. C. Smith

6418 D. S. Stuart

6418 R. M. Summers

6418 T. J. Tautges

$6429 \mathrm{~K}$. E. Washington

7141 Technical Library (5)

7151 Technical Publications

7613-2 Document Processing for DOE/OSTI (10)

8523-2 Central Technical Files 

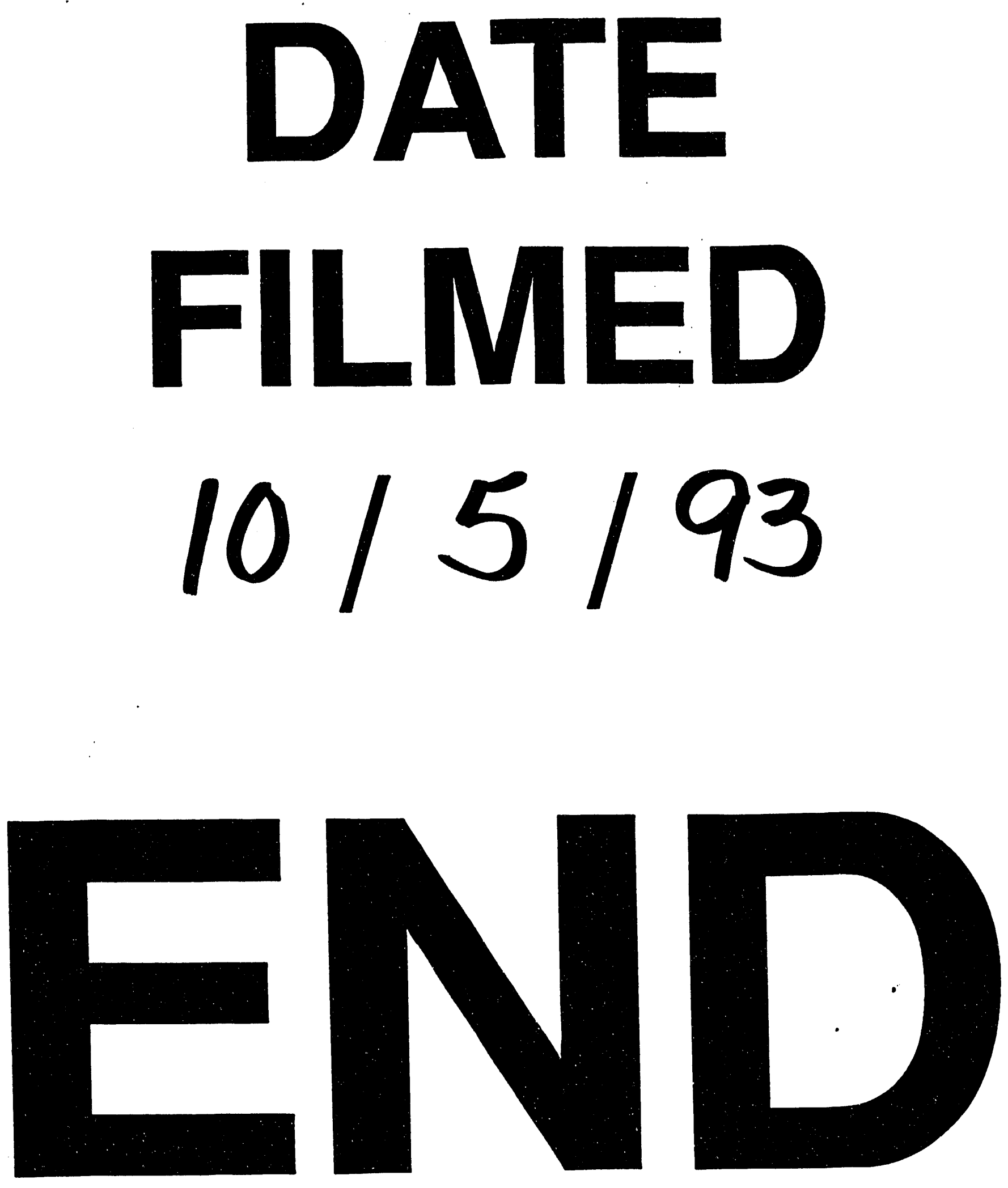
